\title{
ABA-deficiency and molecular mechanisms involved in the dehydration response and ripening of citrus fruit
}

Dissertation submitted in partial fulfilment of the requirements for obtaining the degree of International Doctor (Ph. D.) in Biotechnology

By

Francisco Romero Gascón

Supervisors

María Teresa Lafuente Rodríguez

María Jesús Rodrigo Esteve 


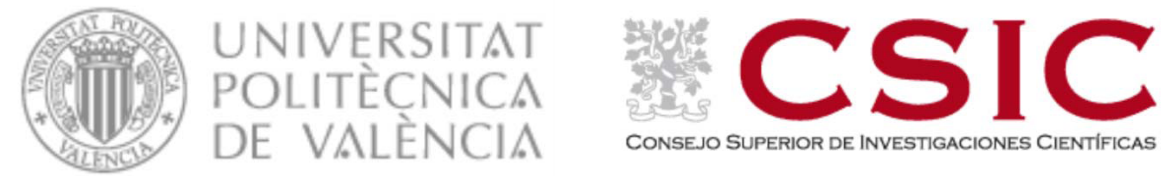

Las Dras. María Teresa Lafuente Rodríguez, Investigador Científico del Consejo Superior de Investigaciones Científicas (CSIC) con destino en el Instituto de Agroquímica y Tecnología de los Alimentos (IATA), y Dạ María Jesús Rodrigo Esteve, Científico Titular del citado Instituto:

\section{CERTIFICAN:}

Que D. Francisco Romero Gascón, Licenciado en Biología por la Universidad de Valencia y Postgraduado en Biología Molecular Celular y Genética por la misma Universidad, ha realizado bajo nuestra dirección el trabajo que, con el título 'ABAdeficiency and molecular mechanisms involved in the dehydration response and ripening of citrus fruit', presenta para optar al grado de Doctor Internacional en Biotecnología por la Universidad Politécnica de Valencia.

Y para que así conste a los efectos oportunos, firman el presente certificado en Paterna, a de del 2012. 

El Doctor D. José Gadea Vacas, Profesor Titular de la Universidad Politécnica:

\section{CERTIFICA:}

Que D. Francisco Romero Gascón, Licenciado en Biología por la Universidad de Valencia y Postgraduado en Biología Molecular Celular y Genética por la misma Universidad, ha realizado bajo su tutela el trabajo que, con el título 'ABA-deficiency and molecular mechanisms involved in the dehydration response and ripening of citrus fruit', presenta para optar al grado de Doctor Internacional en Biotecnología por la Universidad Politécnica de Valencia.

Y para que así conste a los efectos oportunos, firman el presente certificado en Paterna, a de del 2012.

Dr. José Gadea Vacas 



\section{ACKNOWLEDGEMENTS}

First, I would like to thank my supervisors, Dr. Ma Teresa Lafuente and Dr. Ma Jesús Rodrigo, their scientific guidance to develop this work and for giving me the opportunity to begin my scientific career in a great environment. For believing in me from the beginning, for always respecting my point of view, for your confidence and your endless patience, thank you so much.

Thanks to my Tutor at the UPV, Dr. José Gadea, for his guidance with the paper work, and for his bioinformatics assistance. I also thank to Dr. Javier Forment and Dr. Ma Ángeles Martínez-Godoy the microarray development in the framework of the Citrus Functional Genomic Project (CFGP). I would like to thank Dr. Luis Navarro for allowing us the use of the Citrus Germoplasm Bank (IVIAMoncada). I also thank to Paco Rico his help with the printing work and with the assembly of the manuscript.

Very special thanks to Dr. Luis González-Candelas, for his help, unconditional guidance and support at any time I have need it; because I will never find smoking times more productive than ours. I am also grateful to Dr. Lorenzo Zacarías, Dr. José F. Marcos and Dr. Fernando Alférez for their useful discussions and comments. I would like to point out my appreciation to the advice and guidance of Dr. Ana R. Ballester in bioinformatics analyses.

My acknowledgement to our Technicians, Mạ Dolores Arocas, Ma José Pascual, Amparo Beneyto and Ana Izquierdo, and to the other colleagues that have been roled at any time in the Postharvest Group. 
Thanks to my lab mates from the beginning of this History. My most sincere gratitude to Lourdes, Berta, Beatriz, Ana Rose, Pili, Meritxell, Monica and Eleonora for their help and support at scientific and personal level. We have shared unique moments inside and outside of these walls that I will not forget. Because these years would have not been the same without all of you, thanks a lot.

Finally, I thank to the project AGL2006-09496/ALI from Ministerio de Ciencia e Innovación that has supported my FPI fellowship. This work has been also supported by the Ministerio de Ciencia y Tecnología (Research Grants AGL2009-11969 and AGL2009-11558) and by the Generalitat Valenciana (Grant PROMETEO/2010/010). 


\section{AGRADECIMIENTOS}

Estos años habrían sido aún más duros sin el apoyo y los ánimos de mi familia y amigos:

A mis amigos. Porque aún cuando no entendíais nada de lo que os contaba, os esforzabais en aguantar mis charlas y desahogos sobre Navelate, Pinalate, los chips y el peel pitting... Gracias.

A Amparo. Porque para mí el Sistema no funciona; sólo tus besos, vida mía.

A mi madre, a mi hermano y a toda mi familia. La felicidad es más si se comparte. Así me siento yo con vuestros logros y así me habéis demostrado sentiros vosotros con los míos propios. Por haber sabido, además, compartir mis problemas y hacer que menguaran al ser oídos, gracias.

A mi padre. ...más orgulloso estoy yo de ti. 



\section{ABSTRACT}

The aim of this work has been to unravel the influence of the phytohormone $A B A$ in the molecular mechanisms underlying the postharvest dehydration response and the development and ripening of citrus fruit, taking advantage of the spontaneous fruit-specific ABA-deficient 'Pinalate' mutant, which is more prone to dehydration and to develop non-chilling peel pitting (NCPP) than its wild-type 'Navelate' orange. Results of the comparative transcriptomic analysis between fruit of both cultivars stored under moderate water stress (70-75\% RH, 12 으) favouring the occurrence of NCPP highlighted the ability of parental fruit to induce early molecular responses, including both ABAdependent and independent genes, aimed to reduce water loss and their detrimental effects. ABA application to mutant fruit increased hormone levels and modulated relevant transcriptomic changes related to protein ubiquitination, although did not substantially modify either dehydration rate or NCPP incidence. Additionally, the ABA perception system components in Citrus were identified and their regulation under developmental and stressful conditions increasing $A B A$ in reproductive and vegetative tissues of both cultivars was investigated. Six PYR/PYL/RCAR ABA receptors, five PP2CA negative regulators, and two subclass III SnRK2 downstream protein kinases showed conserved motifs for protein folding, interaction and functionality. Minor differences in the regulation of the $A B A$ receptors and the CsSnRK2s were found, whereas CSPP2CAs levels were lower in the mutant fruit. In addition, ABA receptors and CsSnRK2s gene expression patterns depended on the tissue, the stress severity and the source of the ABA signal from a developmental or stressful stimulus, whilst CSPP2CAs displayed a consistent pattern. Overall results suggest that the ABA-deficient mutant fruit may sense $A B A$ although the hormone signal could be impaired because reduced 
CsPP2CAs levels causing altered water stress response and higher NCPP susceptibility. 


\section{RESUMEN}

El objetivo de este trabajo ha sido estudiar la influencia de la hormona ácido abscísico (ABA) en los mecanismos moleculares implicados en la respuesta a la deshidratación y en la maduración de los frutos cítricos, haciendo uso de un mutante espontáneo de la naranja 'Navelate', Ilamado 'Pinalate', que presenta una deficiencia en ABA específica de fruto y es propenso a la deshidratación y a desarrollar 'colapso de la corteza' (NCPP, del inglés Non-Chilling Peel Pitting). Los resultados del análisis transcriptómico comparativo entre los frutos de ambas variedades almacenados en condiciones de estrés hídrico moderado (70-75\% HR y 12 으), que favorecen el desarrollo de NCPP, reveló la capacidad de los frutos del parental para inducir respuestas moleculares tempranas, incluyendo genes dependientes e independientes de $A B A$, dirigidas a reducir la pérdida de agua y los efectos adversos de este estrés. La aplicación de ABA a los frutos del mutante incrementó los niveles de la hormona y moduló cambios transcriptómicos relevantes relacionados con la ubiquitinación de proteínas, aunque no modificó sustancialmente ni la tasa de deshidratación ni la incidencia del NCPP. De forma complementaria, se han identificado los componentes del sistema de percepción del $A B A$ en Citrus y se ha investigado su regulación durante el desarrollo del fruto y bajo condiciones de estrés hídrico en frutos y hojas de ambas variedades, situaciones que causan aumento en ABA. Seis receptores de ABA (PYR/PYL/RCAR), cinco reguladores negativos (PP2CA) y dos proteínas quinasas (SnRK2) mostraron motivos conservados para el plegamiento, la interacción y la funcionalidad proteica. El análisis transcripcional apenas mostró diferencias entre 'Navelate' y 'Pinalate' en la regulación de los receptores de ABA y las CsSnRK2s, mientras que los niveles de CSPP2CAs se mantuvieron más bajos en los frutos deficientes en ABA. Además, los patrones de expresión de los receptores de ABA y las CsSnRK2s dependieron del tejido, la severidad del estrés y el estímulo inductor de la 
acumulación de ABA (la maduración del fruto o el estrés hídrico), mientras que las CSPP2CAs mostraron un mismo patrón de respuesta independientemente del proceso y el tejido analizado. Los resultados globales sugieren que los frutos de 'Pinalate' deficientes en ABA pueden percibir el ABA, aunque la transducción de la señal hormonal pueda estar alterada debido a los niveles reducidos de las CSPP2CAs causando, consecuentemente, una respuesta deficiente al estrés hídrico y una mayor susceptibilidad al NCPP. 


\section{RESUM}

L'objectiu d'aquest treball ha sigut estudiar la influència de l'hormona àcid abscísic ( $A B A$ ) en els mecanismes moleculars implicats en la resposta a la deshidratació i la maduració dels fruits cítrics, fent ús d'un mutant espontani de la taronja 'Navelate', anomenat 'Pinalate', que presenta una deficiència en ABA específica de fruit i és propens a la deshidratació i a desenvolupar 'ratat' (NCPP, de I'anglès Non-Chilling Peel Pitting). Els resultats de l'anàlisi transcriptomic comparatiu entre els fruits d'ambdós varietats emmagatzemats en condicions d'estrès hídric moderat (70-75\% HR i 12 C), que afavoreixen el desenvolupament de NCPP, revelaren la capacitat dels fruits del parental per a induir respostes moleculars primerenques, incloent gens dependents $i$ independents d'ABA, dirigides a reduir la pèrdua d'aigua i els efectes adversos de l'estrès. L'aplicació d'ABA als fruits del mutant incrementà els nivells de l'hormona i va modular canvis transcriptomics rellevants relacionats amb la ubiquitinació de proteïnes, encara que no va modificar substancialment ni la taxa de deshidratació ni la incidència del NCPP. De manera complementària, s'han identificat els components del sistema de percepció del ABA en Citrus i s'ha investigat la seua regulació durant el desenvolupament del fruit i sota condicions d'estrès hídric en fruits i fulles d'ambdós varietats, situacions que causen l'augment en ABA. Sis receptors d'ABA (PYR/PYL/RCAR), cinc reguladors negatius (PP2CA) i dos proteïnes quinases (SnRK2) mostraren motius conservats per al plegament, la interacció i la funcionalitat proteica. L'anàlisi transcripcional no va mostrar diferències entre 'Navelate' i 'Pinalate' en la regulació dels receptors d'ABA i les CsSnRK2s, mentre que els nivells de CSPP2CAs es van mantenir més baixos en els fruits deficients en ABA. A més, els patrons d'expressió dels receptors d'ABA i les CsSnRK2s van dependre del teixit, la severitat de l'estrès i l'estímul inductor de l'acumulació d'ABA (la maduració del fruits o l'estrès hídric), mentre que les CsPP2CAs 
mostraren un mateix patró de resposta independentment del procés i del teixit analitzat. Els resultats globals suggereixen que els fruits de 'Pinalate' deficients en $A B A$ poden percebre l'ABA, encara que la transducció del senyal hormonal puga estar alterada debut als reduïts nivells de les CSPP2CAs causant, conseqüentment, una resposta deficient a l'estrès hídric i una major susceptibilitat al NCPP. 
TABLE OF CONTENTS

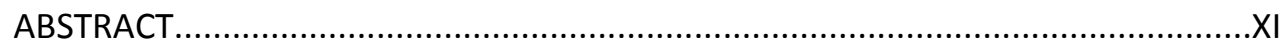

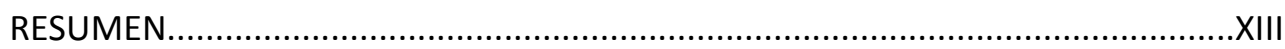

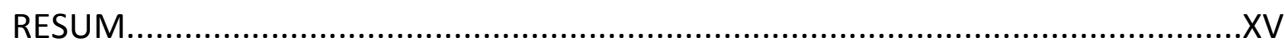

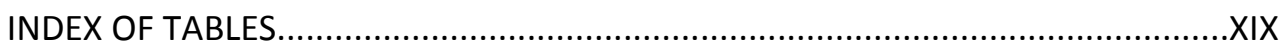

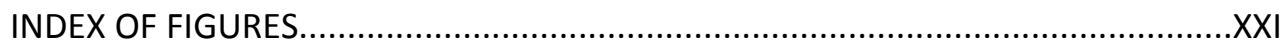

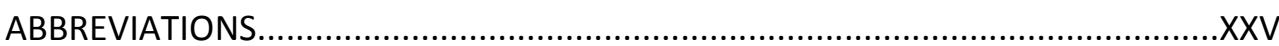

1. INTRODUCTION.................................................................................

1.1. THE HORMONE ABSCISIC ACID: PHYSIOLOGICAL ROLES.............................

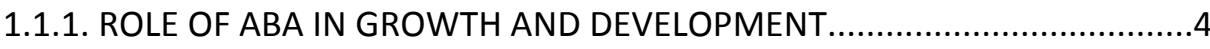

1.1.2. DUAL ROLE OF ABA UNDER STRESS CONDITIONS.................................

1.1.2.1. ABIOTIC STRESS..............................................................

1.1.2.2. BIOTIC STRESSES ......................................................11

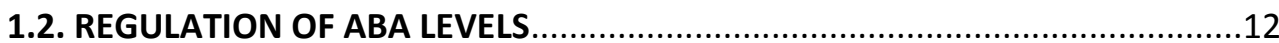

1.3. PHYSIOLOGICAL EFFECTS OF THE ABA DEFICIENCY ................................17

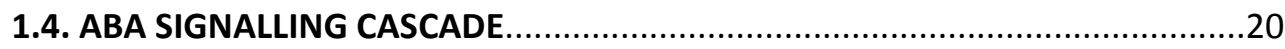

1.4.1. HORMONE PERCEPTION: ABA RECEPTORS.......................................21

1.4.1.1. FCA: Flowering time control protein.......................................21

1.4.1.2. CHLH: Magnesium-protoporphyrin IX chelatase.......................22

1.4.1.3. GCPR: G-protein-coupled receptors.....................................23

1.4.1.4. PYR/PYL/RCAR proteins: cytosolic receptors...........................24

1.4.2. CLADE-A PROTEIN PHOSPHATASES 2C: NEGATIVE REGULATORS..........27

1.4.3. PROTEIN KINASES INVOLVED IN THE ABA SIGNALLING CASCADE..........30

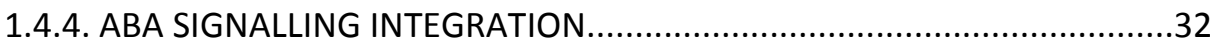

XVII 
3. RESULTS .41

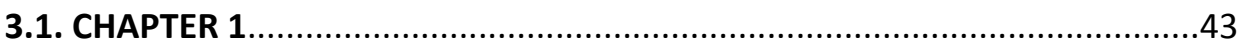
Unravelling molecular responses to moderate dehydration in harvested fruit of sweet orange (Citrus sinensis L. Osbeck) using a fruit-specific ABAdeficient mutant

3.2. CHAPTER 2

The Citrus ABA-signalosome: Identification and transcriptional regulation during sweet orange fruit ripening and leaf dehydration

3.3. CHAPTER 3

Differential expression of the Citrus sinensis ABA perception system genes in postharvest fruit dehydration

4. GENERAL DISCUSSION. .169

5. CONCLUSIONS

6. REFERENCES .193

XVIII 


\section{INDEX OF TABLES}

\section{Introduction}

Table 1. Transcriptional profiling of $P Y R / P Y L / R C A R$ ABA receptors upon $A B A$ treatment and stress conditions that increase endogenous $A B A$ levels in seedlings and leaves of Arabidopsis.....

Table 2. Transcriptional profiling of PP2CAs upon $A B A$ treatment and stress conditions that increase endogenous $A B A$ levels in seedlings and leaves of Arabidopsis

\section{Results Chapter 1}

Table 1. Selected genes and primers used for qRT-PCR analysis in the flavedo of 'Navelate', 'Pinalate' and ABA-treated 'Pinalate' fruits stored at 12 ○ $\mathrm{C}$ and 70$75 \% \mathrm{RH}$ for up to six weeks. .55

Table 2. Functional categorization of differentially expressed genes in the flavedo of 'Navelate', 'Pinalate' and ABA-treated 'Pinalate' fruits stored at $12 \stackrel{\circ}{\circ} \mathrm{C}$ and $70-75 \% \mathrm{RH}$ for 1 and 3 weeks respect to $\mathrm{FH}$ fruits. .62

Table 3. Genes belonging to the most specific and relevant biological processes differentially represented in the flavedo of 'Navelate', 'Pinalate' and ABAtreated 'Pinalate' fruits stored at $12 \stackrel{\circ}{\circ} \mathrm{C}$ and $70-75 \% \mathrm{RH}$.

\section{Supplementary material Chapter 1}

Table S1. Representative set of ABA-regulated genes whose expression did not significantly (SAM, FDR < 0.01) change in 'Pinalate' fruits after ABA treatment respect to $\mathrm{FH}$ 'Pinalate' fruits.

\section{Results Chapter 2}

Table 1. Comparison of $P Y R / P Y L / R C A R$, clade-A $P P 2 C$ s and subclass III SnRK2s genes between Arabidopsis thaliana and Citrus sinensis. .97 


\section{Supplementary material Chapter 2}

Table S1. Colour evolution of 'Navelate' and 'Pinalate' fruits during ripening.....127

Table S2. Primers designed for gene expression analysis by quantitative RTPCR..

Table S3. Similarity matrix between Citrus and Arabidopsis PYR/PYL/RCAR proteins based on deduced amino acid and sequences alignment. 128

Table S4. Similarity matrix between Citrus and Arabidopsis clade-A PP2C proteins based on deduced amino acid and sequences alignment

Table S5. Similarity matrix between Citrus and Arabidopsis subclass III SnRK2 proteins based on deduced amino acid and sequences alignment. 130

Table S6. Absolute gene expression analysis by qRT-PCR of the ABA-signalosome components in 'Navelate' and 'Pinalate' varieties during fruit ripening and leaf dehydration 130

\section{Results Chapter 3}

Table 1. Primers designed for gene expression analysis of the ABA-signalling core components by quantitative RT-PCR

Table 2. Absolute gene expression analysis by qRT-PCR of the ABA-signalosome components, ABA content and percentage of weight loss in 'Navelate', 'Pinalate' and ABA-treated 'Pinalate' fruit during moderate water stress conditions. 150 


\section{INDEX OF FIGURES}

\section{Introduction}

Figure 1. Roles of abscisic acid in plant development and survival 4

Figure 2. Non-chilling peel pitting symptoms in Citrus cultivars .11

Figure 3. Differential phenotype and susceptibility to non-chilling peel pitting of 'Navelate' and 'Pinalate' fruit. .20

Figure 4. Model for the ABA-dependent PYR/PYL/RCAR-mediated inhibition of PP2CA activity and the consequent release of the SnRK2 for allowing the downstream ABA signalling. .34

\section{Results Chapter 1}

Figure 1. Non-chilling peel pitting index (A), percentage of fruit weight loss per surface area (B) and ABA content in the flavedo (C) of 'Navelate' (squares) and 'Pinalate' (circles) fruits treated (white) or not (black) with ABA and stored for up to 6 weeks at 12 ㅇ $\mathrm{C}$ and $70-75 \% \mathrm{RH}$.

Figure 2. Venn diagrams showing differentially expressed genes (SAM analysis, FDR $<0.01$ ) in the flavedo of 'Navelate', 'Pinalate' and ABA-treated 'Pinalate' fruits stored at $12{ }^{\circ} \mathrm{C}$ and $70-75 \% \mathrm{RH}$ for $1(\mathrm{~A})$ and 3 (B) weeks

Figure 3. (A) Principal Component (PCA) and (B) Hierarchical Cluster Analysis (HCA) of flavedo large-scale transcriptional profiles of 'Navelate' $(\mathrm{N})$, 'Pinalate' $(P)$ and ABA-treated 'Pinalate' $(P+A B A)$ fruits stored for one (1W) and three weeks ( $3 \mathrm{~W}$ ) at $12{ }^{\circ} \mathrm{C}$ and $70-75 \% \mathrm{RH}$ respect to $\mathrm{FH}$ fruits. Colours in PCA for each condition are consistent with those in HCA..... 60

Figure 4. Real time qRT-PCR expression analysis for candidate genes selected from microarrays analysis. Relative transcript abundance for selected genes belonging to 'Water deprivation' (A), 'Di-, tri-valent inorganic cation transport' (B), 'Carbohydrate biosynthesis' (C) and 'Protein ubiquitination' (D) biological processes differentially regulated in 'Navelate' (squares) and 'Pinalate' (circles) fruits treated (white) or not (black) with ABA and stored for up to 6 weeks at 12 ㅇ $\mathrm{C}$ and $70-75 \% \mathrm{RH}$ .65 


\section{Supplementary material Chapter 1}

Figure S1. Non-chilling peel pitting index (A) and percentage of fruit weight loss per surface area (B) of 'Navelate' (squares) fruits treated (white) or not (black) with $\mathrm{ABA}$ and stored for up to 6 weeks at $12{ }^{\circ} \mathrm{C}$ and $70-75 \% \mathrm{RH}$. 84

Figure S2. Percentage of decay in 'Navelate' (white), 'Pinalate' (grey) and ABAtreated 'Pinalate' (black) fruits stored at $12 \stackrel{\circ}{\circ} \mathrm{C}$ and $70-75 \% \mathrm{RH}$

\section{Results Chapter 2}

Figure 1. Phylogenetic trees containing $C$. sinensis and $A$. thaliana PYR/PYL/RCAR ABA receptors (A), PP2CAs (B) and SnRK2s protein kinases (C).

Figure 2. ABA content in the flavedo of 'Navelate' (black) and 'Pinalate' (white) fruit during development and ripening (Immature Green, IG; Mature Green I, MI; Mature Green II, MII; Breaker, Bk; Coloured, C; Full Coloured, FC). 102

Figure 3. Relative gene expression analysis by qRT-PCR of Citrus PYR/PYL/RCAR ABA receptors (A), clade-A PP2Cs (B) and subclass III SnRK2s (C) in 'Navelate' (black) and 'Pinalate' (white) fruits during fruit development and ripening. Expression values were referred to MI 'Navelate' fruits. 104

Figure 4. Effect of water stress on weight loss and ABA content in 'Navelate' and 'Pinalate' detached leaves. Changes in control samples are represented as black bars and in water-stressed leaves as white bars 107

Figure 5. Relative gene expression analysis of Citrus PYR/PYL/RCAR ABA receptors in control (black) and water-stressed (white) leaves. 108

Figure 6. Relative gene expression analysis by qRT-PCR of Citrus clade-A PP2Cs in control (black) and water-stressed (white) 'Navelate' and 'Pinalate' leaves...109

Figure 7. Relative gene expression analysis by qRT-PCR of Citrus subclass III SnRK2s in control (black) and water-stressed (white) leaves

\section{Supplementary material Chapter 2}

Figure S1. Multiple sequence alignment of the Arabidopsis thaliana and Citrus sinensis ABA signalling core components. (A) START-like domain of the ABAreceptors. (B) PP2C-like domain of the clade-A PP2Cs proteins. (C) Subclass III SnRK2s full protein sequences. Predicted secondary structures of AtPYR1 (A), 
AtABI1 (B) and AtSnRK2.6 $(\mathrm{C})$ are reported below the corresponding alignment.

Figure S2. Predicted tertiary structure model of the ABA-signalosome components of Citrus by using the Arabidopsis available crystallographic structure of homologous proteins as templates in I-Tasser program (left). Overlay of the predicted structure with the corresponding Arabidopsis homologous (right). (AD) PYR/PYL/RCAR ABA-receptors. (E) PP2CA. (F) SnRK2 135

Figure S3. Gene expression analysis by RT-qPCR of Citrus HVA22E (upper panel) and $A L D H$ (lower panel) in 'Navelate' (black) and 'Pinalate' (white) fruits during development and ripening stages. Expression values are relative to transcript levels obtained in MI 'Navelate' fruits. .136

\section{Results Chapter 3}

Figure 1. Relative gene expression analysis of Citrus $P Y R / P Y L / R C A R$ ABA receptors in 'Navelate' (squares) and 'Pinalate' (circle) fruit, treated (white) or not (black) with $A B A$ and stored under conditions causing moderate water-stress (70-75\% $\mathrm{RH}$ and $12 \circ \mathrm{\circ}$ ). Expression values are relative to transcript levels obtained in $\mathrm{FH}$ 'Navelate' fruit.

Figure 2. Relative gene expression analysis of Citrus PP2CA negative regulators in 'Navelate' (squares) and 'Pinalate' (circle) fruit, treated (white) or not (black) with $\mathrm{ABA}$ and stored under conditions causing moderate water-stress (70-75\% $\mathrm{RH}$ and $12 \mathrm{\circ}$ ). Expression values are relative to transcript levels obtained in $\mathrm{FH}$ 'Navelate' fruit. 152

Figure 3. Relative gene expression analysis of Citrus SnRK2 downstream protein kinases in 'Navelate' (squares) and 'Pinalate' (circle) fruit, treated (white) or not (black) with $A B A$ and stored under conditions causing moderate waterstress (70-75\% RH and $12 \stackrel{\circ}{\circ})$. Expression values are relative to transcript levels obtained in FH 'Navelate' fruit.

.154

Figure 4. Non-chilling peel pitting incidence in 'Navelate' (squares) and 'Pinalate' (circle) fruit, treated (white) or not (black) with ABA, stored for up to 6 weeks

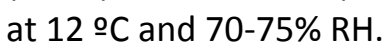
156

Figure 5. $A B A$ signalling integration model in dehydrated citrus fruit and influence of ABA-deficiency. .160 



\section{ABBREVIATIONS}

ABA: Abscisic acid

ABAR: ABA-receptor

ABF: ABA binding factor

ABRE: ABA responsive elements

ANOVA: Analysis of variance

AREBF: ABA-responsive element binding factor

Bk: Breaker

BR: Brassinosteroids

C: Coloured

CDPK: $\mathrm{Ca}^{2+}$-dependent protein kinases

CFGP: Citrus Functional Genomic Project

CHLH: $\mathrm{H}$ subunit of the magnesium-protoporphyrin IX chelatase

DPA: Dihydrophaseic acid

FC: Full coloured

FCA: Flowering time control protein

FDR: False discovery rate

FH: Freshly harvested

FW: Fresh weight

GA: Gibberellins

GCPR: G-protein-coupled receptor

GGPP: Geranylgeranyl pyrophosphate

GO: Gene ontology

HCA: Hierarchical cluster analysis

IAA: Indol-acetic acid / Auxin

IG: Immature green

IPP: Isopentenyl pyrophosphate

JA: Jasmonic acid

LEA: Late-embryogenesis-abundant

MAPK: Mitogen-activated protein kinases

MEP: 2C-methyl-D-erythritol-4-phosphate

MI: Mature green I

MII: Mature green II 
MoCo: Molybdenum cofactor

NCED: Nine-cis-epoxycarotenoid dioxygenase

NCPP: Non-chilling peel pitting

PA: Phaseic acid

PCA: Principal component analysis

PP: Protein phosphatase

PP2CA: Clade A protein phosphatase 2C

PYL: PYR-like

PYR: Pyrabactin Resistance

RCAR: Regulatory components of ABA receptors

REST: Relative expression software tool

RH: Relative humidity

ROS: Reactive oxygen species

RPK1: Receptor protein kinase 1

RT-qPCR: Reverse transcription quantitative polymerase chain reaction

SA: Salicylic acid

SAM: Significant analysis of microarrays

SnRK: Sucrose non-fermenting 1-related protein kinase

ZEP: zeaxanthin epoxidase 
1. INTRODUCTION 



\subsection{THE HORMONE ABSCISIC ACID: PHYSIOLOGICAL ROLES}

The hormone abscisic acid (ABA) was discovered by two independent groups when trying to isolate endogenous plant regulators (Ohkuma et al., 1963; Cornforth et al., 1965). Ohkuma et al. (1963) were looking for compounds promoting leaf abscission in cotton plants and, therefore, they named the identified compound as Abscissin II. On the other hand, the aim of Cornforth et al. (1965) was to isolate biological compounds responsible for bud dormancy. Their search resulted in the identification of a compound present in sycamore leaves able to inhibit wheat embryo germination, which was named Dormin. Later analyses revealed that abscissin II and dormin was the same chemical compound, an isoprenoid-derived molecule, which was renamed as ABA (Cracker and Abeles, 1969; Addicott and Lyon, 1969). Although ABA was firstly identified in plants, several researches provided evidences for its presence in algae and fungi, which suggested that the origin of this hormone was prior to the division of the kingdoms (Nambara and Marion-Poll, 2005).

The phytohormone $A B A$ is involved in the regulation of growth and development in plants but also plays important roles as endogenous messenger in biotic and abiotic stress responses (Fig. 1). Thus, ABA is a key regulator of fundamental developmental processes such as seed dormancy and germination, senescence, leaf and fruit abscission, and fruit ripening. Moreover, it plays a dominant role in the regulation of stomatal movements and enhancing drought tolerance in response to the osmotic stresses that result from water deprivation, salinity or freezing. These developmental and stress signals result in changes in ABA levels, followed by relevant changes in gene expression and adaptive physiological responses. 


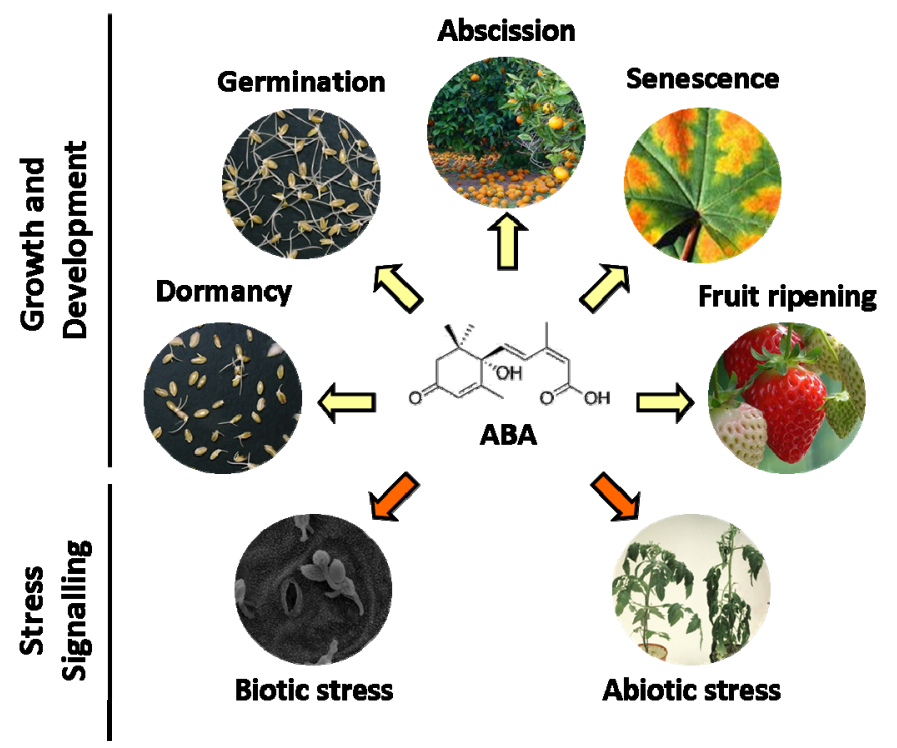

Figure 1. Schematic roles of abscisic acid (ABA), which controls a broad variety of crucial activities related to plant growth, development and survival.

\subsubsection{ROLE OF ABA IN PLANT GROWTH AND DEVELOPMENT}

The hormone $A B A$ is required in plants to control and fine-tune growth and developmental processes under non-stressful conditions. Studies carried out in Arabidopsis demonstrated that $\mathrm{ABA}$ regulates germination and is crucial for seed development, and its effect depends on the tissue and concentration (Finkelstein et al., 2002). Thus, the hormone prevents seed abortion and promotes embryo growth in early embryogenesis (Frey et al., 2004; Kim et al., 2012), whereas it induces seed dormancy and promotes seed desiccation tolerance at the late stages of this process (Karssen et al., 1983). Other reports have also suggested a key function for ABA during seed development, inhibiting precocious germination and the induction of primary dormancy (Nambara et al., 2010). Seed dormancy and germination are complex processes controlled by a large number of genes. Despite of the crucial role of ABA (Finkelstein et al., 2002), the involvement of other plant regulators in these processes has been also 
described (Kucera et al., 2005). Whereas ABA is a positive regulator of dormancy induction and a negative regulator of germination (Karssen et al., 1983), gibberellins (GA) release dormancy, promotes germination and counteract $A B A$ effects (Debeaujon and Koornneef, 2000). Similarly, ethylene and brassinosteroids (BR) promote seed germination and also counteract $A B A$ inhibitory effects (Kepczynski and Kepczynska, 1997).

The involvement of $A B A$ in the regulation of abscission has been broadly accepted (Roberts et al., 2002). It has been suggested that ABA stimulates abscission in leaves, seeds and flowers through ethylene-associated senescence in particular tissues (Cracker and Abeles, 1969; Aneja et al., 1999; Roberts et al., 2002; Trivellini et al., 2011). In agreement, Gómez-Cadenas et al. (1996; 2002) pointed out the key role of ethylene as activator of leaf abscission in waterstressed citrus trees, and suggested that $A B A$ was the primary stress signal responsible for the increase in ethylene. Work performed in citrus fruit further revealed a crosstalk between $A B A$ and ethylene for triggering fruit abscission (Gómez-Cadenas et al., 2000; Agustí et al., 2008). Results obtained in mature sweet cherry, which are very prone to abscission, suggested, however, that the $A B A$ increase observed at late stages of fruit ripening was more likely related to senescence than to the abscission process itself (Blanusa et al., 2006). In contrast, Botton et al. (2011) showed that, besides the senescence-driven abscission of ripe apple fruits, the physiological drop occurring during early stages of fruit development was regulated by a sugar-ABA crosstalk.

Among physiological roles of $A B A$, it is also relevant the involvement of this hormone in the ripening of both climacteric and non-climacteric fruits. Auxins (IAA), GA, cytokinins and ethylene have been also involved at various stages of fruit development and maturation (Nitsch, 1970), although the role of ethylene in this process merits a special mention. The relationship existing between $A B A$ and 
ethylene in the development and ripening of climacteric fruits, such as nectarine and tomato, is well known (Ziliotto et al., 2008; Zhang et al., 2009b) since several reports suggested that the $A B A$ accumulation just before the peak of ethylene production triggers ethylene biosynthesis responsible for climacteric fruit ripening (Zhang et al., 2001; Zhang et al., 2009a; Bastías et al., 2011). The role of ABA in non-climacteric fruit is less clear in spite of several reports have correlated the increase in $A B A$ levels during fruit ripening with the increase in sugars content and the decrease in organic acids or fruit colouration, which are classical traits occurring during fruit maturation (Giribaldi et al., 2010; Chai et al., 2011; Ren et al., 2011; Gambetta et al., 2011; Li et al., 2012b).

The involvement of $A B A$ in the ripening process of citrus, a nonclimacteric fruit, has been also studied (Lafuente et al., 1997; Alférez and Zacarías, 1999; Rodrigo et al., 2003; Rodrigo et al., 2006). Within the context of the crosstalk between $A B A$ and ethylene, it has been suggested that ethylene would regulate the initiation of citrus fruit degreening, whereas $A B A$ controls the rate of the process (Alférez and Zacarías, 1999). In agreement, Rodrigo et al. (2003) showed that ABA deficiency did not modify the initiation of chlorophyll loss, although the rate of degreening was lower in an ABA-deficient citrus mutant fruit. Recent comparative transcriptomic analysis between wild-type orange and this ABA-deficient mutant fruit has revealed that a high number of biological processes were equally modulated in both cultivars during fruit ripening, but also have highlighted a set of ABA-dependent biological responses that were downregulated in the ABA-deficient fruit (Romero et al., 2010). Together, these findings have highlighted a relevant role of $A B A$ in the process of fruit ripening in Citrus. 


\subsubsection{DUAL ROLE OF ABA UNDER STRESS CONDITIONS}

Plants have evolved a wide range of mechanisms to cope with biotic and abiotic stresses. Hormone signalling pathways, such as those regulated by $A B A$, salicylic acid (SA), jasmonic acid (JA) and ethylene, play key roles in the crosstalk between biotic and abiotic stress signalling (Fujita et al., 2006). Focusing on ABA, it is well known that changes in this hormone levels can modulate the closure of stomata and hence water loss in response to abiotic stress conditions. The stomatal closure not only leads to water conservation but also serves as a defence mechanism in preventing pathogen invasions, thereby acting as a scaffold for crosstalk between biotic and abiotic stress responses involving $A B A$ action (Lee and Luan, 2012). Within this context, Fujita et al. (2006) suggested an antagonistic interaction between ABA-mediated abiotic stress signalling and disease resistance. This relationship may simply suggest that plants have developed strategies to avoid simultaneously producing proteins that are involved in abiotic stress and disease resistance responses.

\subsubsection{ABIOTIC STRESSES.}

Drought and high salinity stresses may provoke a strong increase of $A B A$ levels in the plant, resulting in major changes in gene expression and physiological adaptive responses (Zhu, 2002). Other abiotic stresses such as cold and freeze partially share downstream signalling components involved in this stress response (Shinozaki and Yamaguchi-Shinozaki, 2000; Seki et al., 2002; Yamaguchi-Shinozaki and Shinozaki, 2006). In salt stress, ABA contributes to the Salt Overly Sensitive (SOS) pathway, in which ion homeostasis is regulated through $\mathrm{Ca}^{2+}$ signal and membrane-bound proton transporters (Halfter et al., 2000; Liu et al., 2000), increasing the levels of second messengers ( $\mathrm{Ca}^{2+}$ and $1,4,5-$ inositol triphosphate) and producing reactive oxygen species (ROS) that amplify 
the stress signal (Pei et al., 1997; Pei et al., 2000). In contrast, molecular response to cold stress mainly involves $A B A$-independent signals, activating chaperone proteins, detoxification enzymes, and enzymes for osmoprotectants synthesis (Yamaguchi-Shinozaki and Shinozaki, 2006).

Within the context of the present work, water stress is one of the most important abiotic factors affecting plant growth, development and survival. Water stress causes removal of water from the cytoplasm to the extracellular space, causing a reduction in the cytosolic and vacuolar volumes. This provokes an altered ROS homeostasis and, consequently, the production of toxic substances and signal transduction molecules (Miller et al., 2010). On the other hand, water stress causes the accumulation of sugars, poly-alcohols, amino acids and amines, which function as osmolytes, antioxidants, scavengers and/or signalling molecules that help plants to tolerate dehydration stress (Bray, 1993; Ingram and Bartels, 1996; Bray et al., 2000; Bartels and Sunkar, 2005; Seki et al., 2007). In addition, water stress promotes the accumulation of $A B A$ through the induction of $A B A$ biosynthetic genes, such as ZEP (zeaxanthin epoxidase) and NCED (Nine-cisepoxycarotenoid dioxygenase). In turn, $A B A$ stimulates the expression of $A B A$ signalling genes, such as protein phosphatases (PPs) and bZIP transcription factors, which amplify the stress signal. Most of the mechanisms involved in drought tolerance are based on osmotic adjustment and protection of cellular structures from the effects of dehydration (Yamaguchi-Shinozaki and Shinozaki, 2006; Seki et al., 2007; Shinozaki and Yamaguchi-Shinozaki, 2007). ABA play a key role in the prevention of detrimental effects caused by dehydration since it regulates the synthesis of dehydrins and other LEA proteins, which are known to act as chaperons protecting proteins and membranes under this stress conditions (Ingram and Bartels, 1996; Verslues and Bray, 2006). In addition, ABA modulates ion-chelating proteins and/or transporters that trigger ions 
sequestration/mobilization into the vacuole, playing an important role in retaining water inside the cell (Zhu, 2002; Geiger et al., 2009).

Although the tight relationship between $A B A$ and dehydration is well established, it is noteworthy that ABA-independent pathways may also operate in response to water stress (Riera et al., 2005; Wilkinson and Davies, 2010). In addition, many water-stress responsive genes are specifically regulated by $A B A$ (Bartels and Sunkar, 2005), whereas others are commonly modulated by ABA and JA (Nemhauser et al., 2006; Huang et al., 2008). IAA, cytokinin, ethylene, BR and $\mathrm{GA}$ also modulate the expression of a wide number of common drought-related genes, which suggests a complex interplay among different signalling pathways during water stress response (Huang et al., 2008).

Stomatal closure is one of the most important physiological responses to prevent water loss through transpiration. In a very simplified view, stomata movements are regulated by transport events. Stomatal opening is driven by hyperpolarization of the guard cell membrane, which is caused by $\mathrm{H}^{+}$-ATPasedependent proton efflux. This activates $\mathrm{K}^{+}$-inward-rectifying channels (Lebaudy et al., 2007) and induces solute influx followed by water uptake, which turns turgid the guard cells and opens the stoma. Under water stress, ABA content increases and anion channels are activated, throwing anions out of the cell and starting depolarization of the membrane (Geiger et al., 2009; Geiger et al., 2011). In turn, ABA inhibits the activity of the proton pump ATPase and the $\mathrm{K}^{+}$-inward-rectifying channels to prevent from hyperpolarization (Merlot et al., 2007; Sato et al., 2009). Membrane depolarization also leads to activation of the $\mathrm{K}^{+}$-outward-rectifying channel to throw out $\mathrm{K}^{+}$(Lebaudy et al., 2007), contributing to decrease the osmotic pressure. This decrease leads to a reduction of turgor potential, closing the pore and decreasing evapotranspiration rate (Israelsson et al., 2006; Kim et al., 2010; Hubbard et al., 2012). 
The regulation of stomatal movements also involves JA, BR, SA, ethylene, $I A A$, and cytokinin signalling. $A B A, J A, B R$ and $S A$ have been described as positive regulators of stomatal closure, whereas IAA and cytokinins are positive regulators of stomatal opening. Thus, interaction of cytokinin or IAA with ABA inhibits the ABA-mediated stomatal closure, while interaction between $A B A$ and $S A$, JA or BR positively regulates this process (Dodd, 2003; Acharya and Assmann, 2009).

$A B A$ can also modulate root growth promoting primary root elongation in order to counteract water balance when the stress persists, (Sharp, 2002; Sharp et al., 2004). Complementary, $A B A$ has been implicated in inhibiting the development of lateral roots under water stress conditions, which might represent an adaptive response from the plant by restricting root horizontal proliferation and benefiting primary root growth, having this way, better chances to search for new and deeper water resources (De Smet et al., 2003; Xiong et al., 2006).

Dehydration is one of the most important stresses affecting agricultural crop productivity and quality. Specifically, water loss during postharvest handling and storage reduces external quality and hence commercial value of fresh fruit. However, the study of the molecular mechanisms underlying fruit dehydration has been limited to a few sets of genes involved in secondary metabolism and ABA signalling and biosynthesis (Schwartz et al., 1997; Burbidge et al., 1999; Alférez et al., 2008; Bonghi et al., 2012; Loyola et al., 2012). In order to get an overview of the biological processes playing a role in the fruit stress tolerance, transcriptomic research has been performed in grapes. These studies indicated that molecular responses were differently regulated by dehydration occurring before or after harvesting the fruit and also by the level of stress severity (Rizzini et al., 2009; Deluc et al., 2009; Zamboni et al., 2010; Bonghi et al., 2012). 
Within the context of Citrus fruit and the detrimental effects caused by dehydration, it is interesting to note that many citrus cultivars are prone to develop peel depressions affecting both the inner (albedo) and the outer part (flavedo) of the peel, which becomes bronze and necrotic as the disorder progresses (Alférez et al., 2005; Lafuente and Zacarías, 2006; Alférez et al., 2010). This physiological disorder, known as non-chilling peel pitting (NCPP) (Fig. 2), rind breakdown, or rind staining (Agustí et al., 2001; Lafuente and Sala, 2002), occurs at temperatures higher than those causing chilling injury, and is enhanced by dehydration in both attached and detached citrus fruits (Alférez et al., 2003; Alférez and Burns, 2004; Lafuente and Zacarías, 2006).
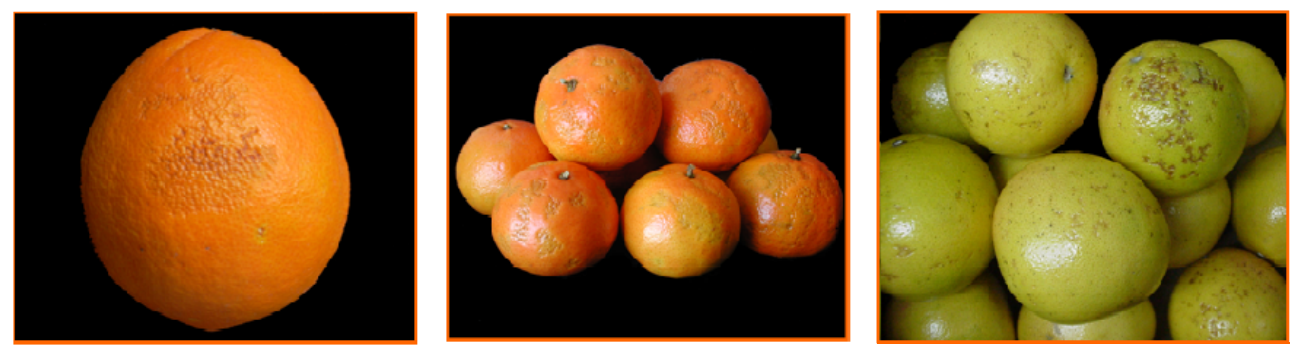

Figure 2. Non-chilling peel pitting damage in several Citrus cultivars. From the left, 'Navelina' orange, 'Clemenules' mandarin, and 'Marsh' grapefruit.

\subsubsection{BIOTIC STRESS.}

Stoma is a natural opening in the plant and has been recognized as a major point of entry to internal tissues for plant pathogenic bacteria (Melotto et al., 2008; Lee and Luan, 2012). In agreement, stomatal closure has been reported to be part of the early-stage plant innate immune response to restrict microbe invasion. Moreover, the ABA signalling pathway in guard cells has been connected with the rapid stomatal closure upon bacterial perception (Kaliff et al., 2007; Zeng et al., 2010). Melotto et al. (2006) showed that pathogen-associated molecular 
pattern (PAMP), which is recognized by plants and triggers plant innate immunity, induces stomatal closure. ABA-biosynthetic (aba3-1) and insensitive (ost1-2) mutants failed to induce PAMP-mediated stomatal closure, which suggested that this process required an active ABA signal transduction (Melotto et al., 2006). Therefore, it was proposed that ABA plays a relevant role in pre-invasive defence against bacteria and has a positive effect on disease resistance.

In addition to its action in stomatal closure, ABA affects pathogen responses by interacting with other hormones that have been classically associated with plant defence mechanisms (Alvarez et al., 1998). ABA is connected to the SA, JA and ethylene signalling pathways. Thus, it has been reported that $A B A$ suppress both the SA-dependent disease resistance (Yasuda et al., 2008) and the JA- and ethylene-dependent induction of defence-related genes (Anderson et al., 2004). Therefore, in late-stage response, ABA exerts both the resistance suppression and the promotion of the susceptibility to microbe infection.

Overall, the role of $A B A$ in biotic stress is not straightforward owing to its multifaceted function depending on the different tissues, developmental stages of the plant, and the kind of pathogen (Mauch-Mani and Mauch, 2005; de TorresZabala et al., 2007; Ton et al., 2009). Under controversial evidences pointing to either the repression or the promotion of disease resistance by ABA, Ton et al. (2009) proposed an integrative model in which ABA played a stimulatory role in plant defence during early stages of pathogen invasion and a mostly suppressive influence at later colonization stages.

\subsection{REGULATION OF ABA LEVELS}

The endogenous ABA content, which ranges from nanomolar to micromolar values depending on the tissue and the environmental conditions, is 
determined by the balance among biosynthesis, catabolism, release from inactive conjugates, and transport rates.

The ABA biosynthesis starts in plastids with the production of C5isopentenyl pyrophosphate (IPP) from glyceraldehyde-3-phosphate and pyruvate, through the 2C-methyl-D-erythritol-4-phosphate (MEP) pathway. IPP is converted to a C20 product named geranylgeranyl pyrophosphate (GGPP), which leads to the synthesis of the carotene phytoene $(\mathrm{C} 40)$ by condensation of two molecules of GGPP. Desaturation and isomerisation convert phytoene in lycopene, which subsequently goes through cyclization and hydroxylation to yield $\beta, \beta$-carotene and finally the xanthophyll zeaxanthin. Zeaxanthin is converted to antheraxanthin and later to violaxanthin by the same enzyme, zeaxanthin epoxidase (ZEP or ABA1). Then, trans-violaxanthin is transformed into trans-neoxanthin by a neoxanthin synthase (ABA4). Two putative isomerases might transform transviolaxanthin and trans-neoxanthin into the nine-cis isomers although they have not been yet characterized. These nine-cis-isomers are cleaved by the NCED enzymes into a C15 product named xanthoxin and a C25 apocarotenoid metabolite. Then xanthoxin is translocated to the cytoplasm and reduced to abscisic aldehyde by the ABA2 reductase. Finally, this aldehyde is oxidized to convert its functional group in a carboxylic acid. This step is catalyzed by the aldehyde oxidase (AAO3), which requires a molybdenum cofactor (MoCo or $A B A 3$ ) for its functionality (reviewed in Nambara and Marion-Poll, 2005; Wasilewska et al., 2008; Rodríguez-Concepción, 2010; Farré et al., 2010; Ruiz-Sola and Rodríguez-Concepción, 2012).

The up-regulation of several $A B A$ biosynthetic genes is a common response to all ABA-mediated stress and developmental signals. In these responses, the induction of the NCED genes has been largely considered as the first committed step of the ABA biosynthesis. In Arabidopsis, Tan et al. (2003) 
reported that this gene family is composed of nine members and that only five of them (AtNCED2, AtNCED3, AtNCED5, AtNCED6 and AtNCED9) were targeted to plastids and likely involved in ABA production, showing a complex pattern of localized expression. Thus, AtNCED2 and AtNCED3 accounted for the total NCED activity in lateral roots, whereas AtNCED2, AtNCED3, AtNCED5 and AtNCED6 were expressed in flowers. AtNCED5 and AtNCED6 transcripts prevailed in anthers and pollen, respectively, whereas AtNCED3 was the most stress-induced gene in leaves (Tan et al., 2003). In addition, all these genes, except AtNCED2, were expressed in seeds (Tan et al., 2003), although only AtNCED6 and AtNCED9 were required for the $A B A$ synthesis that controlled seed dormancy and germination (Lefebvre et al., 2006; Martínez-Andújar et al., 2011). Recently, Frey et al. (2012) showed the involvement of AtNCED5 in the induction of seed dormancy, plant growth and water stress tolerance.

These genes have been also studied in a high number of both climacteric and non-climacteric fruits. Studies performed in tomato, avocado, peach and persimmon indicated that NCED genes expression was induced as ripening progressed, showing a maximum before the ethylene production (Chernys and Zeevaart, 2000; Leng et al., 2009; Zhang et al., 2009a; Sun et al., 2012b). In nonclimacteric fruits such as strawberry, watermelon, sweet cherry and grape, NCED genes were mainly induced in response to water stress and $A B A$ application, and transcripts accumulation paralleled $A B A$ increase during fruit ripening (Zhang et al., 2009a; Ren et al., 2010; Ji et al., 2012; Li et al., 2012b). In citrus fruit, the expression of the NCED gene family has been also characterized. Rodrigo et al. (2006) showed that CSNCED1 and CSNCED2 displayed different expression patterns in response to leaf dehydration and during fruit ripening of sweet orange. Complementary, Agustí et al. (2007) indicated that CCNCED3 (named CSNCED1 in sweet orange) and CCNCED5 (homolog to CSNCED2) genes were 
preferentially induced in leaves and ripening fruits of Clemenules mandarin, respectively. In agreement, Kato et al. (2006) showed that CitNCED2 (CSNCED2) and CitNCED3 (CSNCED1) displayed a complex expression pattern that was not conserved among varieties and tissues.

Together with $A B A$ biosynthesis, $A B A$ levels are regulated by the catabolism of the active form of $A B A$. Thus, stress-induced rises in $A B A$ also regulate gene expression of the ABA 8'-hydroxylase, a cytochrome P450 monooxygenase that catalyze the transformation of $A B A$ in 8'-hydroxy $A B A$ (Cutler and Krochko, 1999), which is spontaneously isomerized to phaseic acid (PA) (Krochko et al., 1998). PA is further reduced to dihydrophaseic acid (DPA), by a soluble reductase (Gillard and Walton, 1976).

Another mechanism for reducing the pool of active $A B A$ into the cell after a stress stimulus consists in the conjugation of $A B A$ with a glucosyl ester (ABA-GE) group and its recruitment into the vacuole. When $A B A$ is required after a stress or developmental signal, this storage of ABA-GE is hydrolyzed by $\beta$-glucosidases localized in the endoplasmic reticulum, contributing to the increase in the concentration of active ABA in the cell (Lee et al., 2006). This mechanism has been proposed as an alternative, complementary to the induction of $A B A$ biosynthetic genes, by which plants would rapidly adjust the ABA levels in order to quickly respond to changing environmental conditions (Lee et al., 2006).

Previous studies suggested that $A B A$ was produced in the roots and transported from there to the aerial part of the plant (Wilkinson and Davies, 2002). Complementary, it has been suggested that JA is needed for ABA increase in citrus roots under drought stress conditions since initial burst of JA could lead to the induction of ABA-biosynthetic genes (de Ollas et al., 2012). In contrast, works in Arabidopsis plants indicated that vascular tissues localized in the shoot were major tissues providing dehydration-induced ABA pools (Endo et al., 2008; 
Ikegami et al., 2009). Despite ABA is synthesized and metabolized in these tissues, it is well known that it acts in stomatal responses of distant guard cells. Therefore, plants need intercellular transport of the hormone. In last years, two plasma membrane-type $A B C$ transporters with ability to bind and transport $A B A$ have been described in Arabidopsis (Kang et al., 2010; Kuromori et al., 2010). The AtABCG25 exporter was a plasma membrane-localized protein mainly expressed in vascular tissues. Loss-of-function mutants presented hypersensitivity to $A B A$ in germination and seedling establishment, and overexpressing plants presented a slower rate of water loss by transpiration. Therefore, it seems that AtABCG25 transported ABA from the vascular tissue to foliar cells (Kuromori et al., 2010). In the case of the AtABCG40 transporter, it has been described that this protein was able to bind $A B A$, was localized in the plasma membrane, and had ability to transport $A B A$ into foliar cells across the lipid bilayer. Consequently, Kang et al. (2010) suggested that AtABCG40 function was to import ABA into de cell. More recently, Kanno et al. (2012) have reported that a nitrate transporter had ability to bind and transport ABA from vascular tissues. Knockout mutants of this ABAimporting transporter (A/T1) displayed low sensitivity to applied ABA during Arabidopsis seed germination, whereas overexpression of AlT1 resulted in ABA hypersensitivity. These findings indicated that ABA transport is complex and could present redundancy among their components.

The high number of key points for regulating availability of active $A B A$ into the cell, together with the newly discovered soluble intracellular ABA receptors (explained in Section 1.4), suggest a modular network by which ABA levels, and hence signal transduction, might be rapidly regulated into the cell to elicit a timely response. 


\subsection{PHYSIOLOGICAL EFFECTS OF THE ABA DEFICIENCY}

Plant hormone mutants have been used extensively to elucidate biosynthetic pathways and to define the involvement of hormones in physiological processes. Focusing on $A B A$, natural and induced knockout mutants of biosynthetic genes have been characterized (Armstrong et al., 1995; Schwartz et al., 1997; Xiong et al., 2001; Seo et al., 2004; González-Guzman et al., 2004; Barrero et al., 2006; North et al., 2007; Fan et al., 2009; Frey et al., 2012).

The mutation of the ZEP/ABA1 enzyme of the ABA biosynthetic pathway caused ABA-deficient mutants that displayed, even under well-watered conditions, wilty phenotypes and reduced size of the leaves, inflorescences and flowers (Barrero et al., 2005). Physiological characterization of the Arabidopsis aao3 mutant showed an ABA-deficient phenotype, osmotolerance in germination and wilty leaves (Seo et al., 2004; González-Guzman et al., 2004; Barrero et al., 2006). In addition, Seo et al. (2004) demonstrated that these mutants (AAO1AAO4) displayed reduced or not affected dormancy because a partial redundancy among genes. Similarly, aba3 mutant plants, which lack the MoCo required for AAO activity, showed ABA-deficiency and increased transpiration rate, as well as impaired cold-gene regulation (Xiong et al., 2001). Moreover, it has been reported that aba3 mutants failed increasing JA levels, even when NCED genes were overexpressed in this genetic background (Fan et al., 2009), and that the levels of SA increased whilst biomass and relative leaf water content decreased in these mutants (Asensi-Fabado and Munné-Bosch, 2011).

The redundancy existing among the NCED gene family members has been confirmed by combining different knockout nced genes (Frey et al., 2012). The most severe phenotype among these mutations (nced3/nced5) showed reduced seed dormancy and vegetative growth, together with increased water loss and decreased ABA levels under normal and stress conditions (Frey et al., 2012). 
Similar approaches have been developed in horticultural crops. NCED gene was silenced by RNAi in strawberry fruit reducing ABA levels, which impaired response of ABA-downstream signalling genes and showed uncoloured phenotype that was rescued by exogenous treatment with the hormone (Jia et al., 2011). By using the same strategy Sun et al. (2012a) reduced NCED activity, which led to down regulation of major genes encoding cell wall catabolic enzymes in tomato. It has been also demonstrated that ABA-deficiency in sitiens tomato mutant fruit (Tal and Nevo, 1973; Taylor and Tarr, 1984) led to increased cuticle permeability, which was correlated with disease resistance (Curvers et al., 2010). On the other hand, it has been demonstrated that ABA-deficiency in the double mutant notabilis/flacca tomato (Tal and Nevo, 1973; Taylor and Tarr, 1984) strongly correlates with reduced cell size, plant growth, leaf surface area, drought-induced wilting and ABA-related gene expression (Nitsch et al., 2012). In agreement, the mutation of the ZEP gene in tomato fruits (named high pigmentation 3, hp3) caused ABA-deficiency and the enlargement of the plastid compartment size probably by increasing plastid division, which enabled a higher storage capacity of carotenoids pigments (Galpaz et al., 2008).

Because of the complexity of obtaining artificially-generated mutants in woody plants, the access to spontaneous hormone mutants is of particular scientific interest. In citrus, a spontaneous fruit-specific ABA-deficient mutant from the 'Navelate' orange (Citrus sinensis L. Osbeck), named 'Pinalate' (Fig. 3), was biochemically characterized (Rodrigo et al., 2003). 'Pinalate' orange presented distinctive yellow-coloured fruit because a partial blockage at the $\zeta$ carotene desaturase step of the carotenoid biosynthetic pathway, which caused the accumulation of uncoloured carotenes, the decrease of xanthophylls content and a fruit-specific ABA-deficiency (Rodrigo et al., 2003). Physiological comparative approaches indicated that $A B A$ deficiency in the mutant might be 
responsible for the higher transpiration rate (Alférez et al., 2005) and higher sucrose content (Holland et al., 2005) as compared to its parental. Furthermore, 'Pinalate' fruit displayed higher susceptibility to develop NCPP at 12 으 at high relative humidity (85-90\% RH) than 'Navelate' (Alférez et al., 2005). In this regard, it was also demonstrated that the enzymes superoxide dismutase and catalase might be involved in the lower susceptibility of parental fruit to develop NCPP (Sala et al., 2005) and that the enzymes phenylalanine ammonia-lyase and glucanase may be good biochemical markers of NCPP (Sala et al., 2005; SanchezBallesta et al., 2008). In addition, during natural ripening, the rate of fruit degreening was lower in 'Pinalate' as compared to its wild-type cultivar (Alférez and Zacarías, 1999; Rodrigo et al., 2003). High throughput transcriptional analysis during fruit ripening revealed a number of common biological processes between both cultivars, but also ABA-dependent processes lacking in the mutant (Romero et al., 2010). Therefore, the fruit-specific ABA-deficient 'Pinalate' orange offered an exceptional experimental system to investigate the involvement of endogenous $A B A$ in the water stress response of citrus fruit, as well as its relationship with the development of NCPP. Moreover, the comparative analysis of parental and mutant fruit would help to understand the role of endogenous $A B A$ in the regulation of the hormone-perception system components during citrus fruit ripening and dehydration. 


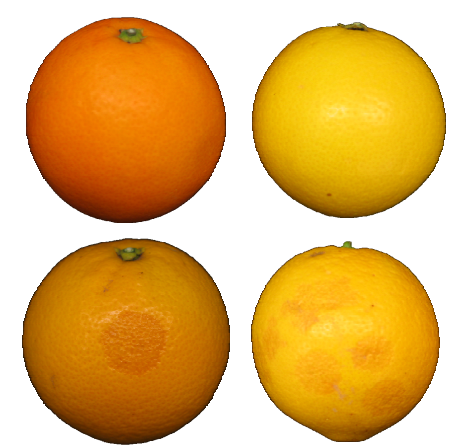

Figure 3. Differential phenotype and susceptibility of 'Navelate' (left) and its fruit-specific ABAdeficient mutant 'Pinalate' (right) fruit to NCPP. Upper fruits were freshly harvested (FH) and lower fruits were stored for 3 weeks at $12{ }^{\circ} \mathrm{C}$ and $70-75 \% \mathrm{RH}$.

\subsection{ABA SIGNALLING CASCADE}

The ABA signalling pathway has been largely investigated, and a number of ABA-responsive genes and interacting proteins have been identified (Bartels and Sunkar, 2005; Shinozaki and Yamaguchi-Shinozaki, 2007). However, how ABA is perceived has been controversial and no consensus was achieved until 2009, when a family of cytosolic proteins was identified as ABA receptors by using different approaches (Park et al., 2009; Ma et al., 2009; Santiago et al., 2009b; Nishimura et al., 2010). These proteins have the ability to perceive the hormone and to start the signal transduction. Signal follows downstream in the pathway through the ABA-dependent receptor-mediated inhibition of the negative regulators, which allows the release of positive effectors and, subsequently, the switch on/off of transcription factors and proteins that modulate transcriptional and/or physiological responses (Fig. 4). Thus, through physicochemical properties of the signalling components and reversible phosphorilation processes, the $A B A$ signalling cascade can be summarized in four simple steps that go from the hormone perception to gene expression (Klingler et al., 2010; Weiner et al., 2010; Joshi-Saha et al., 2011). 


\subsubsection{HORMONE PERCEPTION: ABA RECEPTORS}

To understand a hormone signalling pathway it is critical to know how the hormone is perceived and how its signal is transduced. In the case of ABA, several evidences support that multiple $A B A$ receptors perceive the hormone signal outside and inside the cells, being this perception tissue- and developmental stage-specific (Finkelstein et al., 2002) and dependent on the physiological process and on the stress imposed (Szostkiewicz et al., 2010). Following a brief description of the different $A B A$ receptors identified up to now is provided.

\subsubsection{FCA: Flowering time control protein}

The first putative ABA receptor identified in Arabidopsis thaliana was FCA (Flowering time control protein) (Razem et al., 2006). FCA is a nuclear RNA-binding protein previously characterized as a flowering time regulator (Macknight et al., 1997). Razem et al. (2006) proposed a signalling pathway in which FCA bound with high affinity and in a stereoespecific binding manner to (+)$A B A$, hence inhibiting the association of FCA with FY (Flowering locus $Y$ ). The inhibition of the complex composed of FCA-FY by ABA enhanced the accumulation of the floral repressor FLC (Flowering locus C), which consequently delayed the flowering process. However, FCA loss-of-function mutants did not show the expected phenotypes in any of the common ABA-regulated physiological responses related to germination, stomatal regulation or primary root development. Therefore, subsequent works questioned the role of FCA as an ABA receptor (Risk et al., 2008) and, finally, authors had to retract on the model proposed (Razem et al., 2008). 


\subsubsection{CHLH: Magnesium-protoporphyrin IX chelatase}

In a new attempt to found ABA-binding proteins, Zhang et al. (2002) identified a second putative ABA receptor isolated from broad bean leaves by an affinity chromatography. Analysis of this protein (named ABA Receptor, $A B A R$ ) revealed a high homology degree to the $H$ subunit of the magnesiumprotoporphyrin IX chelatase (CHLH) of Arabidopsis thaliana, which contained a chloroplast signal peptide in its sequence that localized this protein in this organelle (Shen et al., 2006). In addition to its role producing Mg-protoporphyrinIX, CHLH/ABAR had been also previously described as a key element in the plastidto-nucleus signalling (Mochizuki et al., 2001). The CHLH/ABAR binding to ABA was confirmed and its function was explored by using RNAi and overexpressing transgenic lines (Shen et al., 2006). ABA-insensitive phenotypes in seed germination, post-germination growth and $A B A$-induced stomatal closure were found in the knockout mutants, whereas overexpressing CHLH/ABAR plants showed opposite phenotypes and hypersensitivity to the hormone (Shen et al., 2006). Moreover, they found that downstream ABA-related signalling genes were differently regulated in these mutants. Within this context, Shang et al. (2010) proposed a model for the ABA signal transduction: $C H L H / A B A R$ bound to $A B A$ recruit WRKY proteins, negative regulators of the pathway, hence releasing the ABA-dependent transcription factors from a constitutive blockage and allowing the expression of ABA-responsive genes. Nevertheless, the role of this protein as $A B A$ receptor has been also controversial since native protein lacked $A B A$ binding ability in barley, and knockout mutants in this plant displayed wild-type phenotypes in the post-germination and stomatal closure responses (Müller and Hansson, 2009). Further support for the involvement of this protein in the ABA perception arrived from studies performed in fruits of agronomic interest. Thus, $C H L H / A B A R$ transcript accumulation negatively correlated with the increment of 
$A B A$ along ripening of sweet cherry, and the hormone treatment significantly decreased the expression of this gene (Ren et al., 2011). Moreover, CHLH/ABAR gene was silenced by RNAi in strawberry fruit (Jia et al., 2011), and the resulting mutant displayed altered $A B A$, sugars and antocyanins content, as well as impaired regulation of ABA-responsive genes during fruit maturation. Moreover, ABA treatment did not rescue the uncoloured phenotype of this mutant. Together, these results suggested a role for $\mathrm{CHLH} / \mathrm{ABAR}$ in the regulation of the $A B A$ signal but also reinforced the idea of the involvement of $A B A$ in the ripening of non-climacteric fruits.

\subsubsection{GCPR: G-protein-coupled receptors}

A third group of proteins that merits mention as potential $A B A$ receptors is the family of G-protein-coupled receptors (GCPRs). The GPCRs are proteins anchored to plasma membrane through a seven-transmembrane domain that interacts with the intracellular heterotrimeric $G$ protein complexes. It has been shown that the ligand binding to the GCPR triggers the conversion of the inactive G-heterotrimeric complex G $\alpha-G D P / G \beta \gamma$ to an active form in which the GDP of the G $\alpha$-subunit has been changed by the energetic GTP in a classical signalling cascade. Then, G $\alpha-G T P$ and/or the dimeric G $\beta Y$ subunit can transduce the signal to downstream effectors (McCudden et al., 2005). Liu et al. (2007) reported that a GCPR (GCR2) interacts with the Ga subunit GPA1 to mediate well known ABA responses in Arabidopsis. In addition, ABA binding to GCR2 led to the dissociation of the GCR2-GPA1 complex. Overexpressing mutants displayed ABA hypersensitivity and those showing loss-of-function presented ABA-insensitive phenotypes in all the hormone responses. These results suggested GCR2 as a positive regulator in the ABA signalling. Nevertheless, several groups found opposite results to those reported by Liu et al. (2007), which ought to question 
the functionality of this protein as a new ABA receptor (Gao et al., 2007; Guo et al., 2008; Risk et al., 2009). Thereafter, two new GCPR proteins (GTG1 and GTG2) were predicted by in silico analysis as potential ABA receptors (Pandey et al., 2009). Although double knockout mutant showed ABA-insensitive phenotypes in germination, growth, stomatal closure and expression of ABA-responsive genes, GTG1 and GTG2 showed a very low affinity to ABA in binding assays. Nevertheless, both GTG1 and GTG2 bound to GPA1, which was thought as a negative regulator of the GTGs activity in this new model of ABA signalling (Pandey et al., 2009).

Therefore, even taking into account this high controversy, all these findings conduced to highlight the relevance of the negative regulation loops for the fine-tuning of the ABA signalling pathway. This is in agreement with the signal transduction models proposed for other phytohormones such as IAA, GA and ethylene, in which the blockage or degradation of constitutive repressors allows a rapid and specific physiological response (Dharmasiri et al., 2005; Ueguchi-Tanaka et al., 2005; Kepinski and Leyser, 2005).

\subsubsection{PYR/PYL/RCAR proteins: cytosolic receptors}

Recent breakthrough studies have revealed the existence of soluble cytosolic proteins with ability to bind $A B A$. This last group of $A B A$ receptors is composed of the PYR/PYL/RCAR proteins, which have been independently identified by different research groups in Arabidopsis (Park et al., 2009; Ma et al., 2009; Santiago et al., 2009b; Nishimura et al., 2010). By one hand, Park et al. (2009) identified PYR1 through a chemical genetic strategy in which a new synthetic ABA agonist, called pyrabactin, was used. Therefore, this family was named PYR/PYL (Pyrabactin Resistance and PYR1-Like). In an alternative approach, Santiago et al. (2009b) identified PYL5, PYL6 and PYL8 proteins in a yeast twohybrid screen in which HAB1 protein phosphatase $2 \mathrm{C}$ (PP2C) was used as bait. 
Similarly, Ma et al. (2009) identified PYL9/RCAR1 and PYL8/RCAR3 by using the same strategy but a different protein phosphatase $(A B I 2)$ as bait. This group named this family as regulatory components of ABA receptors (RCAR). Independently, Nishimura et al. (2010) performed an in vivo strategy and indentified nine PYR/PYL/RCAR proteins as major ABI1-interactors.

In Arabidopsis, the PYR/PYL/RCAR family is composed of 14 members of small proteins that belong to a superfamily of soluble ligand-binding proteins defined as START/BetV I superfamily (Klingler et al., 2010). Binding assays determined that these proteins directly interact with ABA (Ma et al., 2009; Miyazono et al., 2009; Santiago et al., 2009b; Szostkiewicz et al., 2010), although they displayed different affinities to the hormone according to their oligomeric state (Dupeux et al., 2011b) and stereospecificity (Santiago et al., 2009b). Thus, it was demonstrated that monomeric receptors showed higher affinity to bind $A B A$ than those with a dimeric structure, and that the same PYR/PYL/RCAR binds with different affinity to plus or minus stereoisomer of $A B A$. Moreover, biochemical analyses revealed that PYR/PYL/RCAR proteins directly bind clade A PP2Cs (Park et al., 2009; Ma et al., 2009; Santiago et al., 2009b; Nishimura et al., 2010), which are well known negative regulators of the pathway (Rodríguez et al., 1998a; Gosti et al., 1999; Merlot et al., 2001; Saez et al., 2004).

Beside this, genetic evidence also supported the role of PYR/PYL/RCAR proteins as positive regulators of the pathway. Park et al. (2009) demonstrated that loss-of-function mutants (pyr1/py/1/py/4 and pyr1/py/1/py/2/py/4) showed insensitive phenotypes to $A B A$ in germination and root growth, and impaired $A B A-$ induced stomatal closure and expression of ABA-responsive genes. In addition, overexpression of PYL5 (Santiago et al., 2009b) and PYL9 (Ma et al., 2009) displayed hypersensitivity to the hormone in similar responses. 
Together, biochemical and genetic analyses demonstrated that these PYR/PYL/RCARs were ABA intracellular receptors able to control different aspects of $A B A$ signalling and physiology. In spite of their role as positive regulators of the ABA signal, expression analysis performed in seedlings and plants of Arabidopsis revealed that most of the $P Y R / P Y L / R C A R$ genes were down-regulated by both ABA treatment and stress-induced ABA levels (Table 1) (Szostkiewicz et al., 2010).

Table 1. Transcriptional profiling of PYR/PYL/RCAR ABA receptors upon ABA treatment and stress conditions that increase endogenous ABA levels in seedlings and leaves of Arabidopsis. The numbers are the ratio of expression levels between treated and control samples.

\begin{tabular}{|c|c|c|c|c|c|c|c|c|c|c|}
\hline \multirow[b]{2}{*}{ Treatment } & \multicolumn{10}{|c|}{ RCAR / PYR gene } \\
\hline & $\begin{array}{c}\text { RCAR11 / } \\
\text { PYR1 }\end{array}$ & $\begin{array}{c}\text { RCAR12 / } \\
\text { PYL1 }\end{array}$ & $\begin{array}{c}\text { RCAR14 / } \\
\text { PYL2 }\end{array}$ & $\begin{array}{c}\text { RCAR13 / } \\
\text { PYL3 }\end{array}$ & $\begin{array}{c}\text { RCAR10/ } \\
\text { PYL4 }\end{array}$ & $\begin{array}{c}\text { RCAR8 / } \\
\text { PYL5 }\end{array}$ & $\begin{array}{c}\text { RCAR9/ } \\
\text { PYL6 }\end{array}$ & $\begin{array}{c}\text { RCAR2 / } \\
\text { PYL7 }\end{array}$ & $\begin{array}{c}\text { RCAR3 / } \\
\text { PYL8 }\end{array}$ & $\begin{array}{c}\text { RCAR1 / } \\
\text { PYL9 }\end{array}$ \\
\hline$A B A^{a}$ & 0.37 & 0.41 & 1.03 & 1.57 & 0.04 & 0.18 & 0.14 & 1.29 & 0.48 & 1.66 \\
\hline Drought $^{b}$ & 1.30 & 0.91 & 0.44 & 1.60 & 0.19 & 7.72 & 1.64 & 0.94 & 0.29 & 0.87 \\
\hline Osmotic $^{c}$ & 0.45 & 0.40 & 0.32 & 1.57 & 0.09 & 0.51 & 0.33 & 0.99 & 0.47 & 0.87 \\
\hline Salt ${ }^{d}$ & 0.59 & 0.65 & 0.53 & 1.43 & 0.13 & 0.38 & 0.17 & 1.30 & 0.43 & 1.06 \\
\hline
\end{tabular}

Based on Genevestigator database and adapted from Szostkiewicz et al., 2010. Orange and green shading indicates significant $(P<0.01)$ up and down regulation, respectively. ${ }^{\mathrm{a}}$ Seedling treated with $10 \mathrm{mM}$ ABA. ${ }^{\mathrm{b}}$ Dehydrated leaves for 7 days. ${ }^{c}$ Plants treated with $300 \mathrm{mM}$ Mannitol. ${ }^{d}$ Plants treated with $150 \mathrm{mM} \mathrm{NaCl}$.

Recent breakthroughs on the ABA-response signalling mechanisms have been particularly relevant to agriculture since they have provided a deeper insight into the molecular events involved in stress tolerance and developmental processes. Thus, the discovery of the PYR/PYL/RCAR ABA receptors encouraged new researches aimed to improve drought hardiness in horticultural and crop plants (Chai et al., 2011; Sun et al., 2011; Kim et al., 2012; Li et al., 2012a). In rice, 13 putative orthologues to $P Y R / P Y L / R C A R$ genes were identified, and plants overexpressing OSRCAR5 showed hypersensitivity to $A B A$ during seed germination and growth (Kim et al., 2012). In tomato, eight genes homologues to the PYR/PYL/RCAR family were transcriptionally analyzed during fruit development and ripening, and also in vegetative tissue in response to stress (Sun et al., 2011). 
Such investigation demonstrated that genes were both regulated under stress and during non-stressful conditions, giving support to the role of this hormone in fruit developmental processes. In non-climacteric fruit such as strawberry, the involvement of these receptors in fruit ripening process was also undertaken. Thus, Chai et al. (2011) showed that silencing PYR1 gene delayed strawberry fruit ripening, altered $A B A$ content and sensitivity, and reduced the transcript levels of a set of ABA-responsive genes. In grape, three PYR/PYL/RCAR genes have been isolated (Li et al., 2012a), although only one of them showed the ability to bind $A B A$ and to inhibit the phosphatase activity of $A B I 1$. Further studies revealed that grape $A B A$ signalling cascade consists of at least seven $A B A$ receptors showing organ and stress specificity (Boneh et al., 2012b).

Overall, limited information is available about the involvement of the ABA perception system in the developmental or stress responses in horticultural and crop plants and, up to now, there is no report analyzing the expression of this set of genes as a whole in non-climacteric fruits.

\subsubsection{CLADE-A PROTEIN PHOSPHATASES 2C (PP2CA): NEGATIVE REGULATORS}

The reversible phosphorilation of proteins is a fundamental mechanism to modulate cellular processes. Protein phosphatases provide modulations of phosphoregulation by reversing the action of protein kinases. PPs have been grouped in two major classes based on their substrate specificity: protein tyrosine phosphatases and serine/threonine phosphatases. This last group has been divided in two subcategories (PP1 and PP2) based on enzymological criteria. In addition, PP2s have been further distinguished by their metal requirements. PP2C-type protein phosphatases, which are the largest family of PP2s, are composed of monomeric enzymes whose activity depends on $\mathrm{Mg}^{2+}$ or $\mathrm{Mn}^{2+}$ 
(Rodríguez, 1998). The 76 members of this family identified in Arabidopsis fall into 10 clades (A-J) (Schweighofer et al., 2004). Among them, at least six of the nine members of the clade $A$ (PP2CAs) have been involved in the regulation of the ABA signal transduction.

The first evidence of the role of PP2CAs in the ABA signalling pathway arrived from loss-of-function abi1 and abi2 mutants (Rodríguez et al., 1998a; Gosti et al., 1999; Merlot et al., 2001), whose phenotype provoked to name this subfamily as ABA insensitive. The other members of the PP2CAs were clustered in three further subfamilies. $H A B 1$ and $H A B 2$ were identified by homology to $A B I$ proteins, and their null mutants displayed hypersensitivity to ABA (Rodríguez et al., 1998b). In a genetic screening searching for mutants with enhanced ABA response in germination and post-germination, $A H G 1$ and $A H G 3$ were identified and named hypersensitive to germination (Nishimura et al., 2004; Yoshida et al., 2006b; Nishimura et al., 2007). Finally, a family of three members (HAl1, HAI2 and $H A I 3)$ showing a highly ABA-induced response was described (Leonhardt et al., 2004).

Genetic evidence was crucial to elucidate the role of these proteins as negative regulators of the $A B A$ signalling pathway. Loss-of-function mutants from $A B I 1, H A B 1$ and $A H G 3$, revealed hypersensitive phenotypes to the hormone in germination, growth, stomatal closure and expression of ABA-responsive genes (Saez et al., 2004; Leonhardt et al., 2004; Saez et al., 2006; Kuhn et al., 2006; Yoshida et al., 2006b). The hypersensitive mutant ahg1-1, displayed a strong phenotype in germination and post-germination growth but no evident responses in adult plants. In contrast, 35S:AHG3 and 35S:HAB1 overexpressing lines showed $A B A$ insensitivity in seed germination and growth, as well as increased transpiration rates in adult plants (Saez et al., 2004; Kuhn et al., 2006), mainly due to reduced stomatal closure (Kuhn et al., 2006). In agreement with this, and 
contrary to findings mentioned above for PYR/PYL/RCAR ABA receptors, public Arabidopsis databases and results from several works (Nishimura et al., 2007; Rubio et al., 2009; Szostkiewicz et al., 2010) indicated that these negative regulators of the $A B A$ signal cascade are highly induced in response to $A B A$ application and/or environmental stresses increasing endogenous ABA levels (Table 2). Additionally, it was found overlapping functions among the members of several PP2CA subfamilies. For instance, double mutant ahg1-1/ahg3-1 exhibited a stronger phenotype than the single mutant lines in germination and postgermination growth, although functional differences in germination efficiency or seed dormancy were already observed when analyzing the singles mutants (Nishimura et al., 2007).

Table 2. Transcriptional profiling of PP2CAs upon ABA treatment and stress conditions that increase endogenous ABA levels in seedlings and leaves of Arabidopsis. The numbers are the ratio of expression levels between treated and control samples.

\begin{tabular}{cccccccccc}
\hline & \multicolumn{7}{c}{ PP2CA gene } \\
\cline { 2 - 10 } Treatment & $A B / 1$ & ABI2 & HAB1 & HAB2 & AHG1 & AHG3 & HAl1 & HAI2 & HAI3 \\
\hline ABA $^{\mathrm{a}}$ & 12.82 & 59.67 & 7.72 & 3.34 & 1.26 & 9.65 & 11.66 & 10.61 & 10.67 \\
Drought $^{\mathrm{b}}$ & 1.83 & 12.56 & 16.00 & 4.24 & 74.91 & 8.74 & 15.93 & 15.40 & 10.59 \\
Osmotic $^{\mathrm{c}}$ & 9.99 & 14.18 & 7.52 & 2.58 & 15.52 & 8.44 & 11.40 & 8.59 & 9.43 \\
Salt $^{\mathrm{d}}$ & 5.57 & 6.19 & 3.16 & 1.69 & 5.27 & 5.56 & 10.99 & 9.96 & 8.02 \\
\hline
\end{tabular}

Based on Genevestigator database and adapted from Szostkiewicz et al., 2010. Orange shading indicates

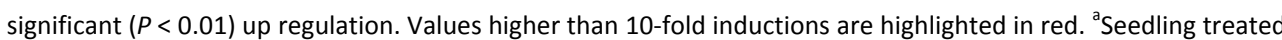

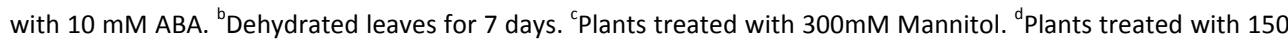
$\mathrm{mM} \mathrm{NaCl}$.

Because of the relevance of $A B A$ regulating the dehydration response, the elucidation of the ABA signalling cascade can be used to improve benefits in commercial agriculture. Seiler et al. (2011) found that development of barley grain under drought was ABA-controlled through PYL/PP2CA-mediated activation of the ABI5 transcription factor. Sun et al. (2011) performed a transcriptional 
study in which the relationship between $A B A$ and the $P P 2 C A$ s gene-regulation was highlighted in different organs, developmental stages and in response to water stress. Studies performed in grape identified six putative PP2CAs and revealed that their expressions in leaves and roots were highly regulated by abiotic ABAincreasing stresses such as high salt concentration, cold and drought (Boneh et al., 2012a; Boneh et al., 2012b), and that sugar and exogenous ABA regulated these and other $A B A$-signalling genes during ripening of this non-climacteric fruit (Gambetta et al., 2011). Therefore, recent works in crops of agronomic value attempt to find potential targets for biotechnological research.

\subsubsection{PROTEIN KINASES INVOLVED IN THE ABA SIGNALLING CASCADE}

Protein kinases are a wide family of proteins whose cellular function is to phosphorilate other proteins, or even auto-phosphorilate themselves, to turn on their functionality. Among the high number of families sharing this function, a group of calcium-independent protein kinases (SnRK2s) merits a special mention as important factors in the ABA signalling (Yoshida et al., 2002; Fujii et al., 2007; Fujii and Zhu, 2009; Fujita et al., 2009) since their interactions with the negative regulators PP2CAs have been reported (Umezawa et al., 2009; Vlad et al., 2009; Hirayama and Umezawa, 2010). Several protein kinases from other families have been also involved in ABA signalling, such as the receptor-like kinase 1 (RPK1) (Osakabe et al., 2005), the mitogen-activated protein kinases (MAPK) (Jammes et al., 2009), and a number of $\mathrm{Ca}^{2+}$-dependent protein kinases (CDPK) (Choi et al., 2000; Mori et al., 2006; Zou et al., 2010). Because of the high number of reports describing the integration of the ABA signal through the PYR/PYL/RCAR receptors and the downstream complex composed of the PP2CAs and the SnRK2s, this section will be focused on the SnRK2 family. 
Sucrose non-fermenting 1-related protein kinases family (SnRKs) in Arabidopsis is composed of 38 proteins divided in three groups (SnRK1, SnRK2 and SnRK3) accordingly to their sequence similarity and functional domains (Hrabak et al., 2003). The group of SnRK2 is composed of 10 plant-specific proteins, which present a characteristic D-rich C-terminal domain that is essential for transducing the ABA signal (Yoshida et al., 2006a). Among them, three proteins classified into the subclass III, named SnRK2.2, SnRK2.3 and SnRK2.6, are strongly activated by ABA in Arabidopsis. The structure and functionality of this subclass of SnRK2s is conserved in rice (Kobayashi et al., 2004), and their corresponding orthologues have been classified into the same subfamily on the basis of results obtained from in silico analyses of tomato and grape (Sun et al., 2011; Boneh et al., 2012a).

The first subclass III SnRK2 protein identified was described as a guard cell-specific kinase implicated in the ABA-induced stomatal closure in Vicia faba ( $\mathrm{Li}$ et al., 2000). By genetic screen looking for proteins that displayed a reduced ability to close stomata in response to drought stress, the orthologue found in Arabidopsis was named open stomata 1 (OST1/SnRK2.6/SRK2E) (Mustilli et al., 2002). The ost1 null mutants showed high insensitivity to ABA-mediated stomatal closure (Yoshida et al., 2002; Mustilli et al., 2002). The analysis of the OST1/SnRK2.6-related kinases, SnRK2.2 and SnRK2.3, revealed that all members of this subclass played relevant roles in mediating $A B A$ signalling during seed dormancy, germination and growth, as well as regulating gene expression in response to ABA (Fujii et al., 2007). It is interesting to note that SnRK2.2 and SnRK2.3 single mutants did not display a clear ABA response phenotypes, whereas the double mutant snrk2.2/snrk2.3 showed a strong ABA-insensitive phenotype in the processes mentioned above, which suggested a marked redundancy between these genes (Fujii et al., 2007). The analysis of the triple mutant snrk2.2/snrk2.3/snrk2.6 revealed extreme insensitive phenotypes to all ABA- 
mediated responses, which led to classify SnRK2.2/SnRK2.3/SnRK2.6 proteins as central positive regulators in ABA signalling (Fujii and Zhu, 2009; Fujita et al., 2009). Therefore, these results suggested that these proteins had redundant functions and that subclass III SnRK2-mediated protein phosphorylation is absolutely essential for ABA signalling (Fujii and Zhu, 2009; Fujita et al., 2009).

Functionality of the subclass III SnRK2s has been confirmed in crops of agronomic interest such as rice (Kobayashi et al., 2004) and maize (Li et al., 2009), but not in fruits. Nevertheless, several reports have already analyzed the expression pattern of these genes in tomato fruits (Sun et al., 2011) and in grape (Boneh et al., 2012a). Results obtained in tomato fruit showed that SnRK2s were transiently induced by exogenous ABA and highly expressed at the most immature stages, concomitantly with lowest endogenous ABA levels (Sun et al., 2011). However, water stress-induced ABA content in tomato leaves had little effect on the transcript levels of these genes. In agreement, water stress slightly changed gene expression of the subclass III SnRK2s in grape leaves (Boneh et al., 2012a).

\subsubsection{ABA SIGNALLING INTEGRATION}

The ABA signalling pathway has been considered a very complex network since it involves numerous proteins (Bartels and Sunkar, 2005; Shinozaki and Yamaguchi-Shinozaki, 2007). The identification of the core elements of the pathway, PYR/PYL/RCAR-PP2CA-SnRK2 (also named ABA-signalosome), has simplified the integration of these components in a signal transduction mainly regulated by a negative feedback loop (Umezawa et al., 2009; Vlad et al., 2009; Fujii and Zhu, 2009). This breakthrough was possible due to the elucidation of the crystallographic structures of each component and of the putative complexes formed in absence/presence of the hormone (Melcher et al., 2009; Santiago et al., 2009a; Weiner et al., 2010; Dupeux et al., 2011a). 
The PYR/PYL/RCAR protein structures consist of a central seven-stranded $\beta$-sheet flanked by two $\alpha$-helixes highly conserved among species (Ma et al., 2009; Santiago et al., 2009b; Chai et al., 2011; Sun et al., 2011; Kim et al., 2012). This $\beta$ sheet produces a cavity that contains a ligand-binding pocket that closes after ABA binding through conformational changes of two conserved $\beta$-loops that serve as gate and latch (Park et al., 2009; Ma et al., 2009; Melcher et al., 2009; Santiago et al., 2012). Comparison of the catalytic core of the different Arabidopsis PP2CAs with that of their orthologues in other plant species, indicated that critical activesite residues are highly conserved (Rodríguez, 1998; Schweighofer et al., 2004; Xue et al., 2008; Sun et al., 2011; Boneh et al., 2012a). Structural protein analyses further demonstrated that PP2CAs shared a similar folding pattern formed by a central sandwich of two $\beta$-sheets enclosed by two $\alpha$-helices at each side of the catalytic site, which contains $3 \mathrm{Mn}^{2+}$ or $\mathrm{Mg}^{2+}$ ions (Melcher et al., 2009; Miyazono et al., 2009; Yin et al., 2009; Dupeux et al., 2011a). Subclass III SnRK2s contains a kinase catalytic domain at the $\mathrm{N}$-terminus with a well-conserved activation loop, and the C-termini rich in aspartic residues (Belin et al., 2006; Yoshida et al., 2006a). Moreover, it has been demonstrated that phosphorylation of conserved serine residues in the activation loop play a crucial role in SnRK2s function (Belin et al., 2006; Boudsocq et al., 2007).

In Arabidopsis, it has been shown that, in the absence of ABA, PP2CAs constitutively interact with subclass III SnRK2s through the D-rich C-terminal domain (Yoshida et al., 2006a; Umezawa et al., 2009; Fujii and Zhu, 2009) inactivating them by dephosphorylation of serine residues located in the activation loop (Umezawa et al., 2009; Vlad et al., 2009; Fujii and Zhu, 2009). Moreover, it has been demonstrated that $A B A$ binding to the receptors is enhanced when PYR/PYL/RCAR proteins are bound to their negative regulators PP2CAs (Park et al., 2009; Ma et al., 2009; Melcher et al., 2009; Dupeux et al., 
2011a; Santiago et al., 2012). After ABA binding, the receptor locks in a closed structure that inhibits the PP2CA active site (Melcher et al., 2009; Santiago et al., 2009b). Therefore, ABA-induced PYR/PYL/RCAR-mediated inhibition of PP2CAs releases SnRK2s from their constitutive blockage, allowing its activation by phosphorylation (Mustilli et al., 2002; Umezawa et al., 2009; Vlad et al., 2009; Fujii and Zhu, 2009) and the ABA signal transduction downstream in the pathway (Fig. 4). Thus, SnRK2s positively regulate $A B A$ response by phosphorylation and activation of $A B F / A R E B$ bZIP transcription factors that bind to $A B A$ responsive elements (ABRE) (Kobayashi et al., 2005; Fujita et al., 2009; Yoshida et al., 2010). It is also noticing that SnRK2s have been involved in the phosphorylation of different proteins, such as SLAC1 and KAT1 ion channels and NADPH oxidases in guard cells, associated with the control of ABA-induced stomata closure (Geiger et al., 2009; Sirichandra et al., 2009).
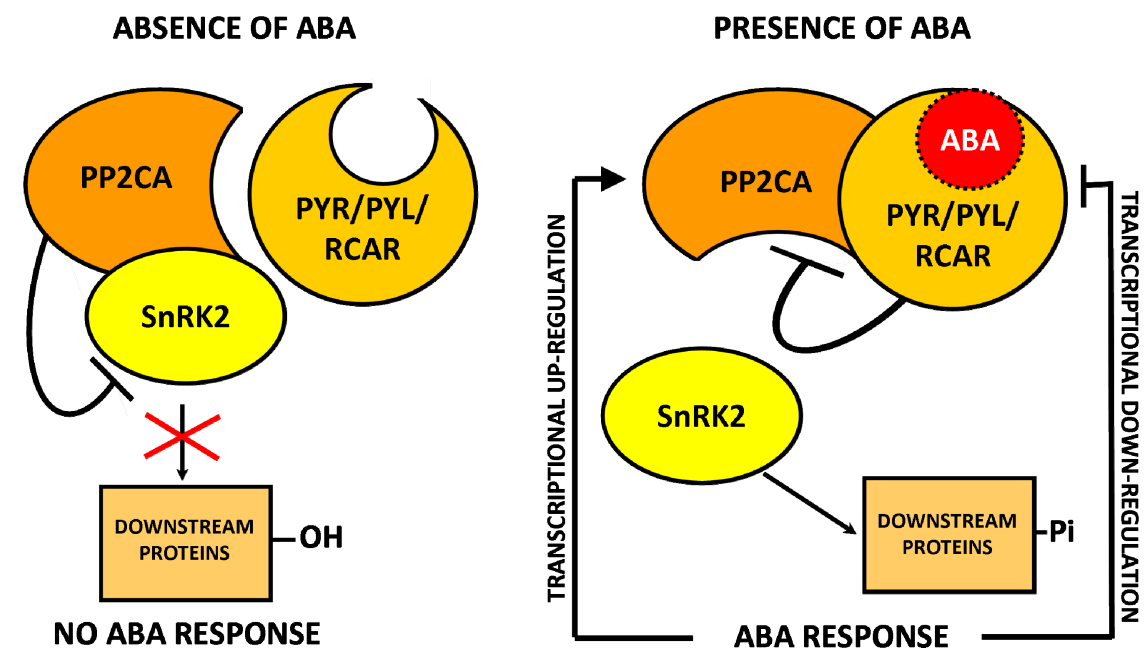

Figure 4. Integration of the ABA signalling cascade. Model for ABA-dependent PYR/PYL/RCARmediated inhibition of PP2CA activity and the consequent release of the SnRK2 for allowing the downstream ABA signalling. Adapted from Park et al. 2009. Details of the model are explained in the text. 
In addition to these new structural insights, transcriptional profiling of the several components of the ABA-signalosome fits with the negative-feedback regulatory mechanism previously described by Merlot et al. (2001) for PP2CAs transcripts regulation. Thus, it was proposed that exogenous $A B A$ or stressinduced rises in the hormone levels would induce the initial ABA-mediated PYR/PYL/RCAR inactivation of PP2CAs. This inactivation would turn on ABAresponsive genes and be later attenuated by the combination of both the ABAinduced down-regulation of PYR/PYL/RCARs expression and the up-regulation of the PP2CAs, which would restore the initial conditions. Therefore, the dual response of PP2CAs to ABA (regulated negatively by the input $A B A$ and positively by the ABA signalling output) provides a dynamic and precise mechanism to adjust the adaptive response of plants to the strength and duration of the stress (Figure 4) (Vlad et al., 2009; Santiago et al., 2009b). 

2. OBJECTIVES 

The main objective of this $\mathrm{PhD}$ dissertation has been to characterize the involvement of $\mathrm{ABA}$ in the molecular mechanisms underlying the dehydration response and in the development and ripening of citrus fruit, taking the advantage of a fruit-specific ABA-deficient mutant, named 'Pinalate', from the wild type cultivar 'Navelate'.

This main purpose can be divided in the following partial objectives:

1. To characterize the molecular mechanisms involved in the response of harvested citrus fruits to dehydration and the potential role of $A B A$ in this process, as well as elucidating the possible relationship between these two components (dehydration and $\mathrm{ABA}$ ) and the development of peel damage during fruit storage at non-chilling temperature.

2. To identify the ABA perception system components in Citrus and to obtain a deeper insight into the transcriptional modulation of these elements under developmental and water stressful conditions increasing $A B A$ in reproductive and vegetative tissues. 

3. RESULTS 



\subsection{CHAPTER 1}

Unravelling molecular responses to moderate dehydration in harvested fruit of sweet orange (Citrus sinensis L. Osbeck) using a fruit-specific ABA-deficient mutant

Journal of Experimental Botany (2012) 63, 2753-2767

Paco Romero, María J. Rodrigo, Fernando Alférez, Ana-Rosa Ballester, Luis González-Candelas, Lorenzo Zacarías and María T. Lafuente* 



\section{ABSTRACT}

Water stress affects many agronomic traits that may be regulated by the phytohormone abscisic acid (ABA). Within these traits, loss of fruit quality becomes important in many citrus cultivars that develop peel damage in response to dehydration. To study peel dehydration transcriptional responsiveness in harvested citrus fruit and the putative role of $A B A$ in this process, we have performed a comparative large-scale transcriptional analysis of water-stressed fruits of the wild-type 'Navelate' orange (Citrus sinesis L. Osbeck) and its spontaneous ABA-deficient mutant 'Pinalate', which is more prone to dehydration and to develop peel damage. Major changes in gene expression occurring in the wild-type line were impaired in mutant fruit. Gene ontology analysis revealed the ability of 'Navelate' fruits to induce the 'response to water deprivation' and 'di-, tri-valent inorganic cation transport' biological processes, as well as the repression of the 'carbohydrate biosynthesis' process in the mutant. Exogenous ABA triggered relevant transcriptional changes and repressed the 'protein ubiquitination' process although it could not fully rescue the physiological behaviour of the mutant. Overall, results indicate that dehydration responsiveness requires $A B A-d e p e n d e n t$ and independent signals, and highlight that the ability of citrus fruits to trigger molecular responses against dehydration is an important factor in reducing their susceptibility to develop peel damage. 


\section{INTRODUCTION}

Plant growth, crop agricultural productivity and quality are adversely affected by both biotic and abiotic stress factors. The effect of water stress on physiological and molecular responses of model plants has been largely described (Bray et al., 2000; Bartels and Sunkar, 2005; Seki et al., 2007). However, in spite of the relevance of this environmental factor on fruit quality, knowledge of these mechanisms in fruits is limited. Nevertheless, transcriptomic studies conducted in grapes indicate that genes, gene categories, and regulatory elements are differently affected by dehydration occurring before or after harvesting the fruit and also by the stress severity (Grimplet et al., 2007; Rizzini et al., 2009; Deluc et al., 2009; Zamboni et al., 2010).

Studies conducted in plants show that water stress causes removal of water from cytoplasm to extracellular space causing a reduction in the cytosolic and vacuolar volumes and an alteration of reactive oxygen species homeostasis, which originates accumulation of toxic substances but also the production of signal transduction molecules (Miller et al., 2010). Accumulation of sugars, polyalcohols, amino acids, amines and $A B A$ in response to water stress have been demonstrated in the model plant Arabidopsis thaliana and in a number of important horticultural crops (Bartels and Sunkar, 2005; Seki et al., 2007). Since these metabolites function as osmolytes, antioxidants, scavengers and/or signalling molecules that can help plants to tolerate abiotic stresses, changes in their homeostasis are thought to be associated with the maintenance of structure and function of cellular component networks. Therefore, the metabolic pathways of these compounds have been largely investigated (Seki et al., 2007) although regulatory networks and cross-talk between their components need further investigation (Yamaguchi-Shinozaki and Shinozaki, 2006; Shinozaki and Yamaguchi-Shinozaki, 2007). Deregulation of these water stress metabolites 
and/or responsive genes can be finally manifested as cellular damaged tissues (Alférez et al., 2008). Moreover, mechanisms occurring in grape berries dehydrated after harvest (Grimplet et al., 2007; Zamboni et al., 2010) or in berries from water-stressed vines (Deluc et al., 2009) indicated that dehydration may have a profound effect on the expression of genes associated with the biosynthesis of relevant compounds that ultimately impact fruit quality. Functional characterization of the stress-induced genes also highlights the relevance of the secondary metabolism, which may be affected by the rate and intensity of dehydration (Rizzini et al., 2009). Furthermore, it should be also considered the relevance of fruit surface properties in the dehydration of detached fruits.

The tight relationship between $A B A$ and dehydration is well known (Bartels and Sunkar, 2005; Shinozaki and Yamaguchi-Shinozaki, 2007), although

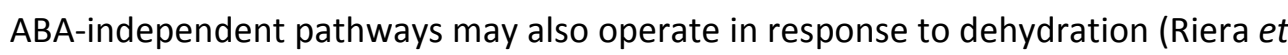
al., 2005). Plant hormone mutants have been extensively used to elucidate signal transduction pathways and to define the involvement of hormones in physiological processes. Focusing on $A B A$, natural and induced knockout and overexpressing mutants of biosynthetic and signalling transduction genes in Arabidopsis (Armstrong et al., 1995; Koornneef et al., 2004) and other plant species (Pena-Cortes et al., 1989; Groot and Karssen, 1992; Schwartz et al., 1997; Burbidge et al., 1999) have been characterized. However, the availability of artificially generated mutants is very uncommon in woody plants. Therefore, the access to spontaneous fruit hormone mutants is of particular scientific interest. A spontaneous fruit-specific ABA-deficient mutant from the wild-type 'Navelate' orange (Citrus sinensis L. Osbeck), named 'Pinalate', has been described (Rodrigo et al., 2003). 'Pinalate' orange presents distinctive yellow-coloured fruit because of a partial blockage of the carotenoid biosynthetic pathway, causing a fruit- 
specific ABA-deficiency. Moreover, harvested 'Pinalate' fruit shows higher dehydration and much higher susceptibility than its parental to develop peel depressions, which in advanced stages become bronze and necrotic (Alférez et al., 2005; Sala et al., 2005). This physiological disorder, known as 'non-chilling peel pitting' (NCPP), 'rind breakdown' or 'rind staining' (Agustí et al., 2001; Lafuente and Sala, 2002), occurs in many citrus cultivars at temperatures above $11 \stackrel{\circ}{ } \mathrm{C}$, with water stress being an important causal factor in both attached and detached fruits (Alférez et al., 2003; Lafuente and Zacarías, 2006). Therefore, because of its higher susceptibility to develop NCPP and to dehydration, and its fruit-specific ABA deficiency, 'Pinalate' fruit is a valuable experimental system to understand the involvement of $A B A$ in the molecular mechanisms underlying the response of citrus fruits to water stress causing eventually peel damage.

In the last decade, 'omics' tools have been widely used to characterize regulatory networks involved in plant abiotic stress responses (Urano et al., 2010). Numerous transcriptomic studies have been conducted to analyze model and crop plants transcriptome under various stress conditions, and have identified thousands of stress-responsive genes (Vij and Tyagi, 2007). Genome-wide studies have been also carried out in fruits with the aim of characterizing ripening or their responses to several stresses or hormone treatments (Maul et al., 2008; Ziliotto et al., 2008; Liu et al., 2009) but information on changes occurring in the transcriptome of water-stressed fruits is limited to grapes (Grimplet et al., 2007; Rizzini et al., 2009; Deluc et al., 2009). Over the past years, the Spanish Citrus Functional Genomic Project (CFGP) has generated useful tools for citrus transcriptomic research. Citrus cDNA microarrays have been developed in this Consortium (Forment et al., 2005; Martínez-Godoy et al., 2008), and the latest generation contains 21081 (20K) putative citrus unigenes, which offers a good representation of the citrus genome. In the framework of the CFGP, important 
insights in citrus biology have been already achieved (Cercós et al., 2006; Gandía et al., 2007; Agustí et al., 2008; Alós et al., 2008; Huerta et al., 2008; Brumós et al., 2009; Ballester et al., 2011). Global changes in gene expression in response to drought have been characterized in citrus seedlings (Gimeno et al., 2009). However, in spite of the relevance of dehydration in fruit quality, a large-scale transcriptomic profile of citrus fruit in response to this stress has not been conducted so far.

With the aim of characterizing molecular mechanisms involved in the response of harvested citrus fruits to dehydration and the potential role of $A B A$ in this process, as well as to elucidate the possible relationship existing between these two components and the occurrence of NCPP, a large-scale transcriptional analysis in the flavedo of 'Navelate' and its mutant 'Pinalate' oranges has been conducted by using the CFGP 20K microarray. To that end, fruits from both cultivars were stored at a temperature and $\mathrm{RH}$ causing moderate water stress and the appearance of peel damage. In addition, transcriptomic changes occurring in 'Pinalate' fruit treated with ABA were examined. 


\section{MATERIALS AND METHODS}

\section{Plant material and $A B A$ treatment}

Full mature fruits of 'Navelate' (Citrus sinensis L. Osbeck) orange and its spontaneous ABA-deficient mutant 'Pinalate' were randomly harvested from adult trees grown in experimental orchards under normal cultural practices at 'The Spanish Citrus Germoplasm Bank' at Instituto Valenciano de Investigaciones Agrarias (Moncada, Valencia, Spain). After harvest, fruits without any damage or visual defects were immediately delivered to the laboratory. To test whether application of $A B A$ modified the postharvest response of 'Pinalate' fruit to dehydration, fruits from both cultivars were divided into two groups. The first group was treated with ABA (Sigma-Aldrich, St. Louis, MO, USA) by dipping the fruits for $1 \mathrm{~min}$ in an aqueous solution of $1 \mathrm{mM}$ ABA containing $0.7 \%$ ethanol to dissolve the hormone, while fruits of the second group were just treated with water containing $0.7 \%$ ethanol by following the same procedure. Fruits were dried at room temperature and then stored in the dark at $12{ }^{\circ} \mathrm{C}$ and $70-75 \% \mathrm{RH}$ for up to 6 weeks. The ABA treatment was repeated every 2 weeks to ensure high ABA levels during fruit storage. Likewise, 'Pinalate' and 'Navelate' control fruits were dipped into $0.7 \%$ ethanol at these times. Periodically, flavedo (outer coloured part of the peel) samples were collected from the total surface of fruits, frozen and homogenized in liquid nitrogen, and kept at -80 o $\mathrm{C}$ for later analysis. Three biological replicates, each consisting of 5 fruits, were collected at each sampling period.

\section{Peel damage incidence and water loss measurement}

A visual rating scale from 0 (no peel damage) to 4 (severe damage), based on surface necrosis and intensity of peel browning, was used to evaluate the incidence of NCPP in fruits stored at 12 ㅇ $\mathrm{C}$ and $70-75 \% \mathrm{RH}$. The average NCPP 
index was calculated by summing the products of the number of fruits in each category by the value assigned to each category in the rating scale, and then dividing the resulting sum by the total number of fruits evaluated. In citrus fruit, water is lost mainly through the peel surface. Therefore the cumulative percentage of fruit weight loss occurring during storage was expressed per $\mathrm{cm}^{2}$ of fruit surface area. Fruit surface was estimated by using the Turrel's tables after measuring the diameter and height of the fruits (Turrel, 1946). Results are the means of 3 replicates of 10 fruits each \pm SE.

\section{RNA isolation, cDNA labelling and microarray hybridization}

Total RNA was extracted from frozen flavedo samples by a modified method of the previously described by Rodrigo et al. (2004), as reported by Ballester et al. (2006). Total RNA was treated with Ribonuclease-free DNase (Ambion/Applied Biosystems, Austin, TX, USA) following the manufacturer's instructions for removing possible genomic DNA contaminations. Thereafter, the amount of RNA was measured by spectrophotometric analysis (Nanodrop, Thermo Fisher Scientific, Madrid, Spain) and its quality was verified by agarose gel electrophoresis and ethidium-bromide staining. cDNA synthesis and purification, dye coupling, and labelled-cDNA purification were accomplished according to the method described by Forment et al. (2005). cDNA samples were Cy5-labelled and co-hybridized with a Cy3-labelled cDNA reference pool from a mixture containing equal amounts of RNA from all experimental samples assayed. The use of this reference sample has been widely used in Citrus transcriptomic research since it represents a powerful tool for reducing the number of hybridizations to make all the possible pairwise comparisons between samples (Agustí et al., 2008). Microarray hybridization and slide washes were performed by a modified method of that proposed by Forment et al. (2005) as described by Ballester et al. (2011). 
The cDNA microarrays used were developed in the framework of the CFGP (http://bioinfo.ibmcp.upv.es/genomics/cfgpDB/), and contained 21081 putative unigenes (20K) isolated from 52 cDNA libraries of citrus generated from a wide range of varieties, developmental and fruit ripening stages, and from different tissues subjected to biotic and abiotic stress conditions (Martínez-Godoy et al., 2008).

\section{Microarray data acquisition and analysis}

Hybridized microarrays were scanned by using a GenePix 4000A scanner (Axon Instruments, Sunnyvale, CA, USA) equipped with GenePix Pro 6.0 image acquisition software (Axon Instruments), following manufacturer's instructions to adjust the channels intensity ratio to 1.0 and the percentage of saturated spots close to $1 \%$. Non-homogeneous and aberrant spots were discarded. Only spots with a background-subtracted intensity greater than 2-fold the mean of background intensity were used for normalization and further analysis. In order to compensate labelling differences among samples and other non-biological sources of variability, results were normalized by using Print-Tip-Lowess method, included in the Acuity 4.0 software (Axon Instruments), by using background subtracted median values and an intensity-based Lowess function within and among microarrays. Thereafter, differentially expressed genes for all possible pairwise comparisons were determined by applying the Significant Analysis of Microarrays (SAM) program (Tusher et al., 2001) from the TM4 Microarray Software Suite (Saeed et al., 2003). Genes that satisfied a statistical threshold (False Discovery Rate) lower than 0.01 were identified as differentially expressed genes. FatiGO+ (Babelomics, http://bioinfo.cipf.es/), developed by Al-Shahrour et al. (2004), was used to identify biological processes significantly under- or overrepresented in a particular set of differentially expressed genes relative to a 
reference group containing all genes present in the microarrays having an Arabidopsis homologous. Gene ontology analysis for induced and repressed genes was independently performed applying a Fisher two tailed test with a $p$-value lower than 0.05 . In this analysis, the specificity of the biological process increases with the GO level from 3 to 9. Multivariate analyses as Principal Component (PCA) and Hierarchical Cluster Analysis (HCA) (ANOVA test, Benjamini-Hochberg FDR < 0.05) were performed by using the MultiExperiment Viewer (MeV) tool of TM4 Microarray Software Suite (Saeed et al., 2003).

\section{qRT-PCR expression analysis}

Reverse transcription followed by quantitative polymerase chain reaction analysis (qRT-PCR) was performed to validate microarray results and to examine the time-course expression pattern of selected genes along fruit storage by using a LightCycler 480 Instrument (Roche Diagnostics, Mannheim, Germany) equipped with LightCycler SW 1.5 software. A two-step qRT-PCR assay was designed as suggested by Udvardi et al. (2008). cDNAs were synthesized from all analyzed samples by using $400 \mathrm{U}$ of SuperScript III RT (Invitrogen, Paisley, United Kingdom) in presence of $0.5 \mu \mathrm{g}$ of Oligo(dT) 20-mer (Invitrogen) and $10 \mathrm{U}$ of Ribonuclease Inhibitor (Invitrogen) according to manufacturer's instructions. Gene-specific primers were designed using DNAMAN 4.03 software (Lynnon BioSoft, Quebec, Canada). Both synthesized CDNA and the primer pairs were thereafter incubated with LightCycler 480 SYBR Green I Master (Roche Diagnostics) at 95 ㅇ C for $10 \mathrm{~min}$

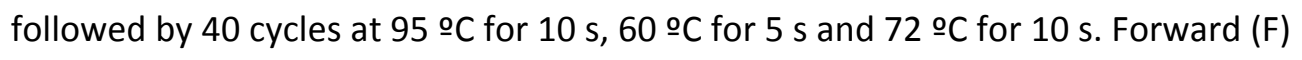
and reverse $(R)$ sequences for specific primers and correlation coefficients $\left(r^{2}\right)$ between the $\log _{2}$-transformed expression values as measured by microarray and RT-PCR analyses for each gene are shown in Table 1. To rule out non-specific amplified products, melting curve analysis were performed and the reaction 
products were sequenced. To transform fluorescent intensity measurements into relative mRNA levels, a 2-fold dilution series of a mixture containing an equal amount of each cDNA sample was used and standard curves were constructed for all studied genes. Reference genes CSACT (F 5'-TTAACCCCAAGGCCAACAGA-3'; R 5'-TCCCTCATAGATTGGTACAGTATGAGA-3'), CsEF1 $\alpha$ (F 5'-ATTGACAAGCGTGTGATT GAGC-3'; R 5'-TCCACAAGGCAATATCAATGGTA-3'), CsGAPDH (F 5'-CGTCCCTCTGCA AGATGACTCT-3'; R 5'-GGAAGGTCAAGATCGGAATCAA-3') and CSTUB (F 5'-GCATCT TGAACCCGGTAC-3'; R 5'-ATCAATTCGGCGCCTTCAG-3'), whose constitutive expression along fruit storage was confirmed by using geNorm program (Vandesompele et al., 2002), were used for data normalization. Statistical analysis (Pair Wise Fixed Reallocation Randomisation Test) was carried out by using the Relative Expression Software Tool (REST, http://rest.gene-quantification.info) (Pfaffl, 2001). Each sample was analyzed in triplicate and mean ratios \pm SE were calculated.

\section{ABA analysis}

ABA analysis was performed as described by Lafuente et al. (1997). ABA was extracted from $1 \mathrm{~g}$ fresh weight (FW) frozen flavedo with $80 \%$ acetone containing $0.5 \mathrm{~g} \mathrm{~L}^{-1}$ citric acid and $100 \mathrm{mg} \mathrm{L}^{-1}$ of butylated hydroxytoluene. After centrifugation, the supernatant was diluted in 3 serial dilutions in ice-cold TBS (6.05 $\mathrm{g} \mathrm{L}^{-1}$ Tris, $8.8 \mathrm{~g} \mathrm{~L}^{-1} \mathrm{NaCl}$ and $0.2 \mathrm{mg} \mathrm{L}^{-1} \mathrm{MgCl}_{2}$ ) adjusted to $\mathrm{pH} 7.8$ with $6 \mathrm{~N} \mathrm{HCl}$. Three samples for each dilution were analyzed by an indirect ELISA method using the ABA-4'-BSA conjugate that was synthesized as previously reported by Weiler (1980) with some modifications (Norman et al., 1988). The results are the means of 3 replicate samples \pm SE. 


\section{Statistics}

A mean comparison using the Tukey's test and Statgraphics.5.1 Software (Manugistics, Inc.) was performed to determine significant differences at $p \leq 0.05$ in NCPP, fruit weight loss per surface area and ABA levels between samples of 'Navelate' and 'Pinalate' fruits, treated or not with ABA, during fruit storage at 12 oC and $70-75 \% \mathrm{RH}$.

Table 1. Selected genes and primers used for quantitative RT-PCR analysis and comparison between Citrus 20K microarray and qRT-PCR gene expression data. Multiple linear regression analysis $\left(r^{2}\right)$ was performed for each reported gene including samples from all comparisons and storage periods.

\begin{tabular}{|c|c|c|c|c|c|c|}
\hline Gene & $\begin{array}{l}\text { Citrus unigene } \\
\text { (CFGP DB) }\end{array}$ & $\begin{array}{l}\text { Most similar } \\
\text { protein }\end{array}$ & $\begin{array}{l}\text { Homolog in } \\
\text { Arabidopsis }\end{array}$ & $\begin{array}{l}\text { Forward / } \\
\text { Reverse }\end{array}$ & Sequence $5^{\prime} \rightarrow 3^{\prime}$ & $r^{2}$ \\
\hline \multirow{2}{*}{ CsCOPT2 } & \multirow{2}{*}{ aCL7045Contig1 } & \multirow{2}{*}{$\begin{array}{l}\text { Copper transporter } \\
\text { protein homolog }\end{array}$} & \multirow{2}{*}{ АТЗG46900 } & $\mathrm{F}$ & GGGGGCCGACCTGAAGAAC & \multirow{2}{*}{0.98} \\
\hline & & & & R & CGCACTAGCCGCTAGAAAAG & \\
\hline \multirow{2}{*}{ CsCOPT5 } & \multirow{2}{*}{ aCL1547Contig2 } & \multirow{2}{*}{ T1M15_50 protein } & \multirow{2}{*}{ AT5G20650 } & $\mathrm{F}$ & GGAGGACAGGCGCGTCCG & \multirow{2}{*}{0.90} \\
\hline & & & & $\mathrm{R}$ & GCCGAGAATTTCCCGACGAC & \\
\hline \multirow{2}{*}{ CsHVA22E } & \multirow{2}{*}{ aC31106H02EF_c } & \multirow{2}{*}{$\begin{array}{c}\text { Abscisic acid- } \\
\text { induced-like protein }\end{array}$} & \multirow{2}{*}{ AT5G50720 } & $\mathrm{F}$ & GCGGCATGGCTGGTTCTGC & \multirow{2}{*}{0.91} \\
\hline & & & & $\mathrm{R}$ & GCCTCGTGCTCCCCTTTCTT & \\
\hline \multirow{2}{*}{ CsIPS } & \multirow{2}{*}{ aC31301D12EF_c } & \multirow{2}{*}{$\begin{array}{l}\text { Inositol-3-phosphate } \\
\text { synthase }\end{array}$} & \multirow{2}{*}{ AT2G22240 } & $\mathrm{F}$ & GGACACAGTGCAACAAGCCA & \multirow{2}{*}{0.95} \\
\hline & & & & $\mathrm{R}$ & CCCATCCTCCAAACACAATG & \\
\hline \multirow{2}{*}{ CsMYC } & \multirow{2}{*}{ aC04028A10SK_c } & \multirow{2}{*}{$\begin{array}{l}\text { MYC transcription } \\
\text { factor }\end{array}$} & \multirow{2}{*}{ AT1G32640 } & $\mathrm{F}$ & GCCTGAGTCCGGGGAGATAT & \multirow{2}{*}{0.92} \\
\hline & & & & $\mathrm{R}$ & сCCTCTCGAAGTAGGAGATC & \\
\hline \multirow[b]{2}{*}{ CsNCED1 } & \multirow[b]{2}{*}{ aCL1933Contig1 } & \multirow{2}{*}{$\begin{array}{c}\mathrm{N} \text {-cis- } \\
\text { epoxycarotenoid } \\
\text { dioxigenase } 1\end{array}$} & \multirow[b]{2}{*}{ АT3G14440 } & $\mathrm{F}$ & CCACGATGATAGCTCATCCG & \multirow[b]{2}{*}{0.93} \\
\hline & & & & R & CCACTTGCTGGTCAGGCACC & \\
\hline \multirow{2}{*}{ CSNRAMP1 } & \multirow{2}{*}{ alC0AAA15AB01RM1_C } & \multirow{2}{*}{$\begin{array}{l}\text { Metal transporter } \\
\text { Nramp1 }\end{array}$} & AT1G80830 & $\mathrm{F}$ & GCCACTGGGCAGCCCCAG & 0.93 \\
\hline & & & A11080830 & $\mathrm{R}$ & CAGCTTGTCTTATCGGGCAC & 0.93 \\
\hline & & Metal transporter & & $\mathrm{F}$ & GGCTCTGAGCTTCTTATTGGC & \\
\hline CSNRAMP3 & aCL34/6Contig1 & Nramp3 & A12G23150 & $\mathrm{R}$ & GGACACGGCCTTTCTTACTG & 0.93 \\
\hline CsPUBg & aCL8840Contig1 & F2103.7 protein & AT3G07360 & $\mathrm{F}$ & AGCAAGAGCTGTGCGTGATG & $0.97-3$ \\
\hline & acl8840Contig1 & F2103./protein & Al3G0/360 & R & GCGAAGCATGCAAGAAACTCC & 0.97 \\
\hline & & Immediate-early & & $\mathrm{F}$ & AAGATCCGGTGACGACGACT & \\
\hline CSPUB21 & aC31304F06EF_c & $\begin{array}{l}\text { fungal elicitor } \\
\text { protein CMPG1 }\end{array}$ & AT5G37490 & $\mathrm{R}$ & GCACCCAACTTGATCCTGTGT & 0.90 \\
\hline CSRD19 & aCl96Contig1 & Cysteine proteinase & AT4G39090 & $\mathrm{F}$ & GCACGACCGTAGGTTCACTAT & 0.93 \\
\hline 年 & act & & A14005000 & $\mathrm{R}$ & GTCCGGCGGAACTCGGCC & 0.03 \\
\hline CSRD21 & aCL23Contig3 & Cysteine protease & AT1G47128 & $\mathrm{F}$ & GCCCTGAGAGCAACACTTGC & 0.90 \\
\hline & & $\mathrm{CP} 1$ & & $\mathrm{R}$ & GGGATAGTCATGTGGGCAGC & \\
\hline
\end{tabular}




\section{RESULTS}

Susceptibility of 'Navelate' and the ABA-deficient mutant 'Pinalate' fruit to nonchilling peel pitting and dehydration and influence of exogenous $A B A$

The susceptibility of fruits of the ABA-deficient mutant 'Pinalate' to NCPP was much higher than that of fruits of its parental 'Navelate' (Fig. 1A). Peel pitting was already visible by 1 week in stored 'Pinalate' fruits, while in 'Navelate' fruits the incidence of the disorder was barely detected. This difference between mutant and wild-type fruits was much more evident as storage progressed, reaching the highest difference by 3 weeks, when mutant fruits showed about a 5fold higher NCPP index than the parental fruits (Fig. 1A). By this period, the weight loss per surface area in mutant fruits was twice that of 'Navelate' fruits (Fig. 1B).

ABA level in the flavedo of FH 'Pinalate' fruits was about 5-fold lower than in 'Navelate' fruits (Fig. 1C). A rapid increase in the ABA content occurred in 'Navelate' peel by 1 week, while it remained at low levels in 'Pinalate' fruits along storage (Fig. 1C). By the end of the experiment (6 weeks), ABA content in parental fruits was about 4-fold higher than in the mutant. In this context, it is noteworthy that ABA-treated 'Pinalate' fruits had even slightly higher phytohormone levels than the wild type from the beginning of the experiment (Fig. 1C) but the treatment had little effect on reducing the susceptibility of the mutant to NCPP (Fig. 1A) or its dehydration rate (Fig. 1B). Likewise, exogenous ABA did not significantly modify the severity of NCPP or weight loss per surface area in wildtype fruits (Fig. S1) 


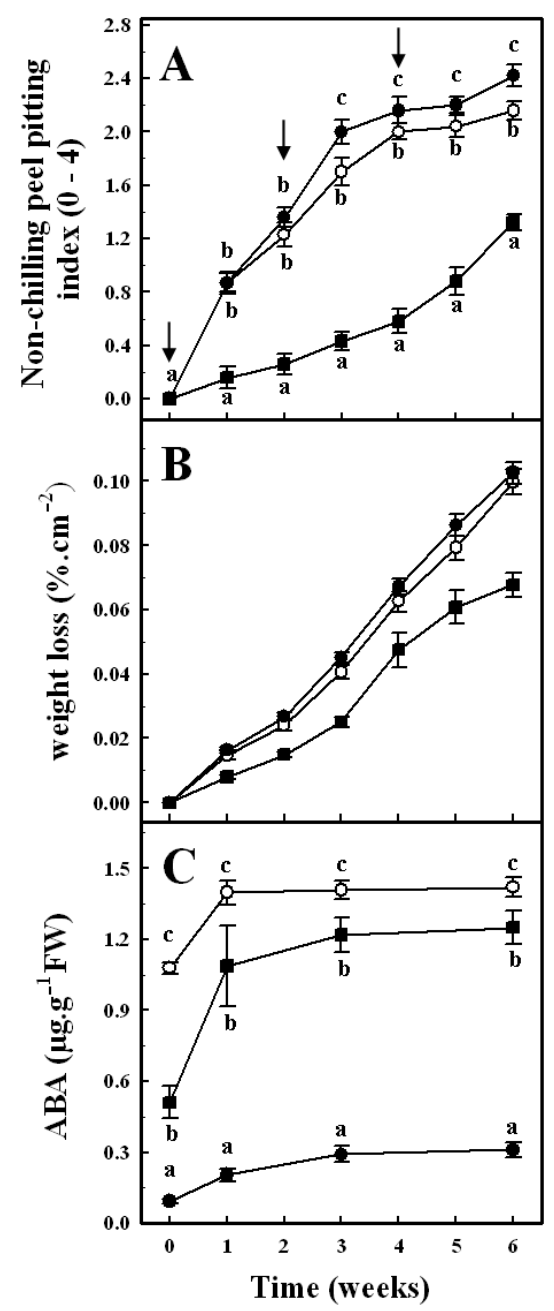

Figure 1. Non-chilling peel pitting index (A), percentage of fruit weight loss per surface area (B) and ABA content in the flavedo (C) of 'Navelate' (squares) and 'Pinalate' (circles) fruits treated (white) or not (black) with $A B A$ and stored for up to 6 weeks at $12{ }^{\circ} \mathrm{C}$ and $70-75 \% \mathrm{RH}$. The arrows indicate when ABA was applied. Results are the means of three biological replicates of 10 fruits each $\pm \mathrm{SE}$. Mean separation was performed by applying Tukey's test. Significant differences $(p \leq 0.05)$ in NCPP index and $A B A$ content between samples for the same storage period are indicated by different letters. Significant differences $(p \leq 0.05)$ in weight loss (panel $B$ ) between 'Navelate' and 'Pinalate' samples, treated or not with $A B A$, were found from the first week of storage while no statistical differences were found between control and ABA-treated 'Pinalate' fruits. 


\section{Comparative transcriptional profiling during storage conditions inducing moderate water stress}

Considering the sharply increase in ABA content in 'Navelate' oranges by 1 week, and also the marked difference in NCPP index between varieties by 3 weeks, both time-points were selected for microarray hybridizations to compare changes in transcriptional profiling of both genotypes with respect to $\mathrm{FH}$ fruits. The above mentioned results indicate that applying $A B A$ did not rescue the phenotype of the mutant. In order to determine whether increasing endogenous ABA levels in the mutant may simulate the molecular responses induced by moderate water stress in the wild-type phenotype, ABA-treated 'Pinalate' fruits were also included in the transcriptome analysis. Venn diagrams summarize the number of differentially expressed genes (SAM, FDR $<0.01$ ) in fruits stored for 1 (Fig. 2A) or 3 (Fig. 2B) weeks respect to FH fruits.

Major changes in the number of differentially expressed genes occurred by 1 week in 'Navelate' fruits (Fig. 2A) and by 3 weeks in 'Pinalate' (Fig. 2B). This effect was even more marked in the ABA-treated fruits (Fig. 2B). It is also noteworthy that repression prevailed in both cultivars along whole storage. Major inductions (1131 genes) occurred in parental fruits by 1 week, while a small set of up-regulated genes was found in both 'Pinalate' fruits treated or not with ABA (182 and 65, respectively) (Fig. 2A). Likewise, 'Navelate' showed the highest number of down-regulated genes by 1 week (1956). The expression of 322 of them also decreased in 'Pinalate', although this number was reduced (65) when ABA was applied (Fig. 2A). By 3 weeks (Fig. 2B), the number of induced (192) and repressed (269) genes in the flavedo of 'Navelate' fruits was less remarkable. By contrast, a high increment in the number of down-regulated genes was observed in 'Pinalate' (1221) and this effect was enhanced by applying ABA (2237) (Fig. 2B). 
A

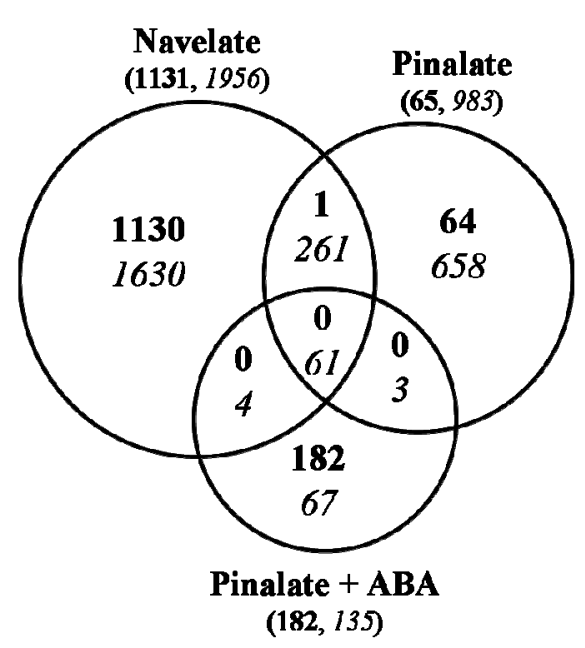

B

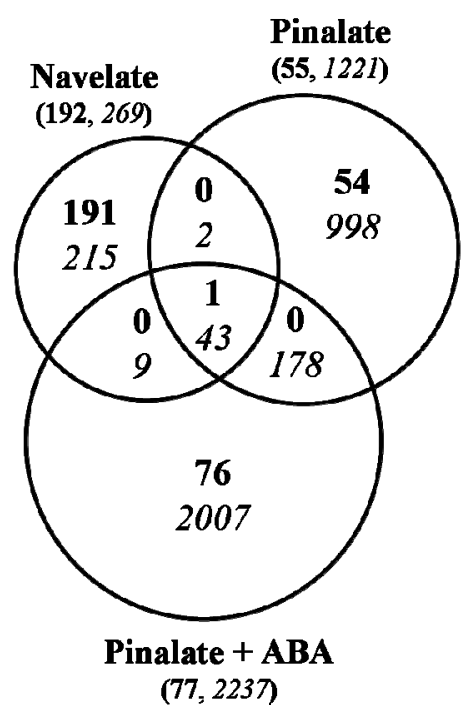

Figure 2. Venn diagrams showing differentially expressed genes (SAM analysis, FDR $<0.01$ ) in the flavedo of 'Navelate', 'Pinalate' and ABA-treated 'Pinalate' fruits stored at $12{ }^{\circ} \mathrm{C}$ and $70-75 \%$ RH for 1 (A) and 3 (B) weeks. Expression levels of up- (bold) and down-regulated (italics) genes in these fruits were compared to those of FH fruits from each variety. Numbers in brackets are the sum of all induced (bold) or repressed (italics) genes in each particular condition. The sizes of the circles are consistent with the total number of differentially expressed genes for each condition.

Principal Component (PCA) and Hierarchical Cluster Analysis (HCA) were performed to validate the repeatability of the microarray data across replications and to cluster samples according to their global gene expression profile. ANOVA test revealed that 1471 genes, from a total of 21081, showed differential expression and were used for PCA and HCA. In all conditions, the transcriptional profile of the 3 separate RNA replicate samples were tightly clustered (Fig. 3A). On the other hand, PCA revealed marked differences in gene expression patterns between $\mathrm{FH}$ and stored fruits (X axis, explaining $44 \%$ of the total variation), and also between $\mathrm{FH}$ fruits of both genotypes (variation $\mathrm{Y}$ and $\mathrm{Z}$ axes $=18.8 \%$, Fig. $3 A)$. 'Pinalate' (P) fruits stored for 1 week (1W) were distributed in the middle of 
the three axes, close to mutant fruits stored for 3 weeks (P3W). By this period, fruits of 'Navelate' (N1W) were clustered in the upper part of the $Y$ axis and far from those stored for 3 weeks (N3W). ABA-treated 'Pinalate' fruits stored for 3 weeks $(P 3 W+A)$ grouped together, far from both P3W and P1W+A fruits (Fig. 3A). HCA confirmed results obtained by PCA. 'Navelate' and 'Pinalate' FH fruits were separately clustered in an independent branch from the stored samples, which were grouped by storage period (Fig. 3B). Interestingly, P1W+A fruits clustered into an independent group.

$\mathbf{A}$

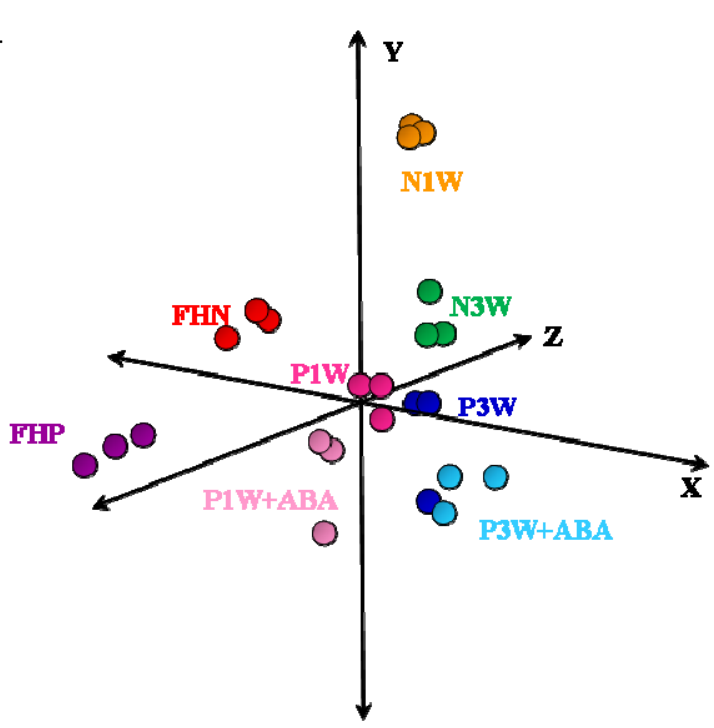

B

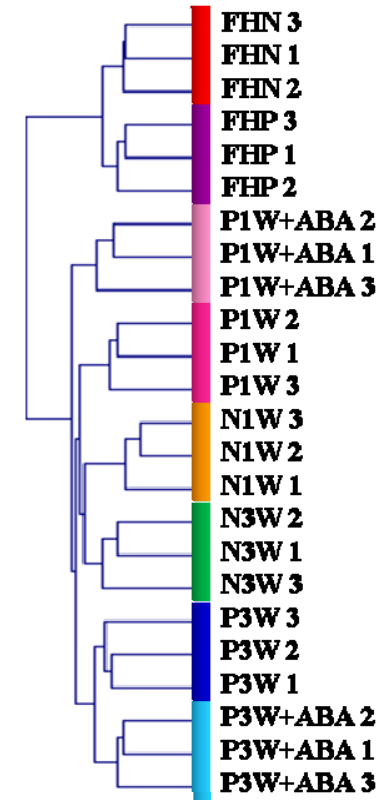

Figure 3. (A) Principal Component (PCA) and (B) Hierarchical Cluster Analysis (HCA) of flavedo largescale transcriptional profiles of 'Navelate' $(N)$, 'Pinalate' $(P)$ and ABA-treated 'Pinalate' $(P+A B A)$ fruits stored for one (1W) and three weeks (3W) at $12 \mathrm{o} C$ and $70-75 \% \mathrm{RH}$ respect to FH fruits. Colours in PCA for each condition are consistent with those in HCA. The three axes in PCA account $62.8 \%$ of the total variance among varieties and storage periods. Three biological replicates from each condition were used for both analyses. 


\section{Functional categorization of differentially expressed genes}

Gene ontology analysis identified biological processes significantly underor over-represented in the sets of differentially expressed genes selected from the SAM analysis. This analysis revealed that repressed genes in 'Navelate' fruit stored for 1 week were enriched in biological processes related to biopolymer, heterocycle and RNA metabolism, and to cellular biosynthesis with respect to $\mathrm{FH}$ fruits, while induced genes were enriched in the response to water deprivation and the di-, tri-valent inorganic cation transport processes (Table 2). However, the differentially expressed genes in 'Navelate' fruits stored for 3 weeks were not statistically grouped in any biological process. Likewise, no biological process was over-represented in either 'Pinalate' or 'Pinalate $+A B A^{\prime}$ fruits stored for 1 week. In contrast, the down-regulated genes in the mutant fruits stored for 3 weeks, treated or not with $A B A$, were statistically enriched in the same processes. Among these processes, responses to biotic and abiotic stimulus, including light, temperature, jasmonic acid, wounding and to other organism, as well as processes related to energy derivation and carbohydrate biosynthesis were identified. Interestingly, the inhibition of 'protein ubiquitination', associated with protein degradation, was the unique biological process differentially affected by the ABA treatment in mutant fruits (Table 2).

Genes belonging to the most relevant and specific biological processes (higher GO levels) are shown in Table 3. Among genes belonging to 'water deprivation' biological process, genes involved in ABA synthesis and perception (NCED1, ZEP and PP2C), ABA-responsive genes (HVA22E, Lea5 and ADH) and ABAdependent transcription factors ( $H B 7, N A C 4$ and $A B F 4$ ) were found. Furthermore, genes included in this process encoded aquaporins, vacuolar proton-pump, and other proteins playing protective roles against dehydration (Table 3). 
Table 2. Functional categorization of differentially expressed genes in the flavedo of 'Navelate', 'Pinalate' and ABA-treated 'Pinalate' fruits stored at 12 ㅇ C and 70-75\% RH for 1 and 3 weeks respect to $\mathrm{FH}$ fruits. Arrows indicate enriched biological processes (FatiGO+, $P \leq 0.05$ ) in sets of significantly (SAM analysis, FDR $<0.01$ ) induced $(\uparrow)$ or repressed $(\downarrow)$ genes into each condition.

\begin{tabular}{|c|c|c|c|c|c|}
\hline \multirow[b]{2}{*}{$\begin{array}{l}\text { GO } \\
\text { Level }\end{array}$} & \multirow[b]{2}{*}{ GO Code } & \multirow[b]{2}{*}{ Biological Process } & \multirow{2}{*}{$\frac{1 \text { week }}{\text { Navelate }}$} & \multicolumn{2}{|c|}{3 weeks } \\
\hline & & & & Pinalate & $\begin{array}{l}\text { Pinalate } \\
+ \text { ABA }\end{array}$ \\
\hline 4 & 0043283 & Biopolymer metabolic process & $\downarrow$ & & \\
\hline 4 & 0044249 & Cellular biosynthetic process & $\downarrow$ & & \\
\hline 4 & 0006091 & Generation of precursor metabolites and energy & & $\downarrow$ & $\downarrow$ \\
\hline 4 & 0046483 & Heterocycle metabolic process & $\downarrow$ & & \\
\hline 4 & 0006800 & $\begin{array}{l}\text { Oxygen and reactive oxygen species metabolic } \\
\text { process }\end{array}$ & & $\downarrow$ & $\downarrow$ \\
\hline 4 & 0048583 & Regulation of response to stimulus & & $\downarrow$ & $\downarrow$ \\
\hline 4 & 0009753 & Response to jasmonic acid stimulus & & $\downarrow$ & $\downarrow$ \\
\hline 4 & 0051707 & Response to other organism & & $\downarrow$ & $\downarrow$ \\
\hline 4 & 0009314 & Response to radiation & & $\downarrow$ & $\downarrow$ \\
\hline 4 & 0009266 & Response to temperature stimulus & & $\downarrow$ & $\downarrow$ \\
\hline 4 & 0009415 & Response to water & $\uparrow$ & & \\
\hline 4 & 0009611 & Response to wounding & & $\downarrow$ & $\downarrow$ \\
\hline 5 & 0015980 & Energy derivation by oxidation of organic compounds & & $\downarrow$ & $\downarrow$ \\
\hline 5 & 0009416 & Response to light stimulus & & $\downarrow$ & $\downarrow$ \\
\hline 5 & 0009414 & Response to water deprivation & $\uparrow$ & & \\
\hline 5 & 0016070 & RNA metabolic process & $\downarrow$ & & \\
\hline 7 & 0016051 & Carbohydrate biosynthetic process & & $\downarrow$ & $\downarrow$ \\
\hline 7 & 0015674 & Di-, tri-valent inorganic cation transport & $\uparrow$ & & \\
\hline 9 & 0016567 & Protein ubiquitination & & & $\downarrow$ \\
\hline
\end{tabular}

Within the inorganic cation transport process, iron transporters and chelators, several copper transporters and two calcium-dependent transporter proteins were identified (Table 3). It is also noteworthy to highlight that the most specific process ('carbohydrate biosynthesis') repressed in both 'Pinalate' and 'Pinalate' fruits treated with $A B A$, included not only biosynthesis-related genes but also genes related to cell-wall metabolism, a MYC transcription factor and an inositol-3-phosphate synthase (Table 3). The unique biological process affected by exogenous $A B A$ in 'Pinalate' fruits ('protein ubiquitination') included 6 genes belonging to a super-family of E3-ubiquitin ligases involved in protein degradation and with high similarity to plant U-box domain-containing proteins (PUB) of Arabidopsis (Table 3). 
Table 3. Genes differentially expressed in the indicated comparisons and belonging to the most specific and relevant biological processes. N1W > FHN, genes induced in 'Navelate' fruits stored for 1 week respect to FH fruits; P3W < FHP, genes repressed in 'Pinalate' fruits stored for 3 weeks respect to FH fruits; P3W+ABA < FHP, genes repressed in ABA-treated 'Pinalate' fruits stored for 3 weeks respect to $\mathrm{FH}$ fruits. Asterisks refer to genes chosen for multiple linear regression and qRT-PCR analysis.

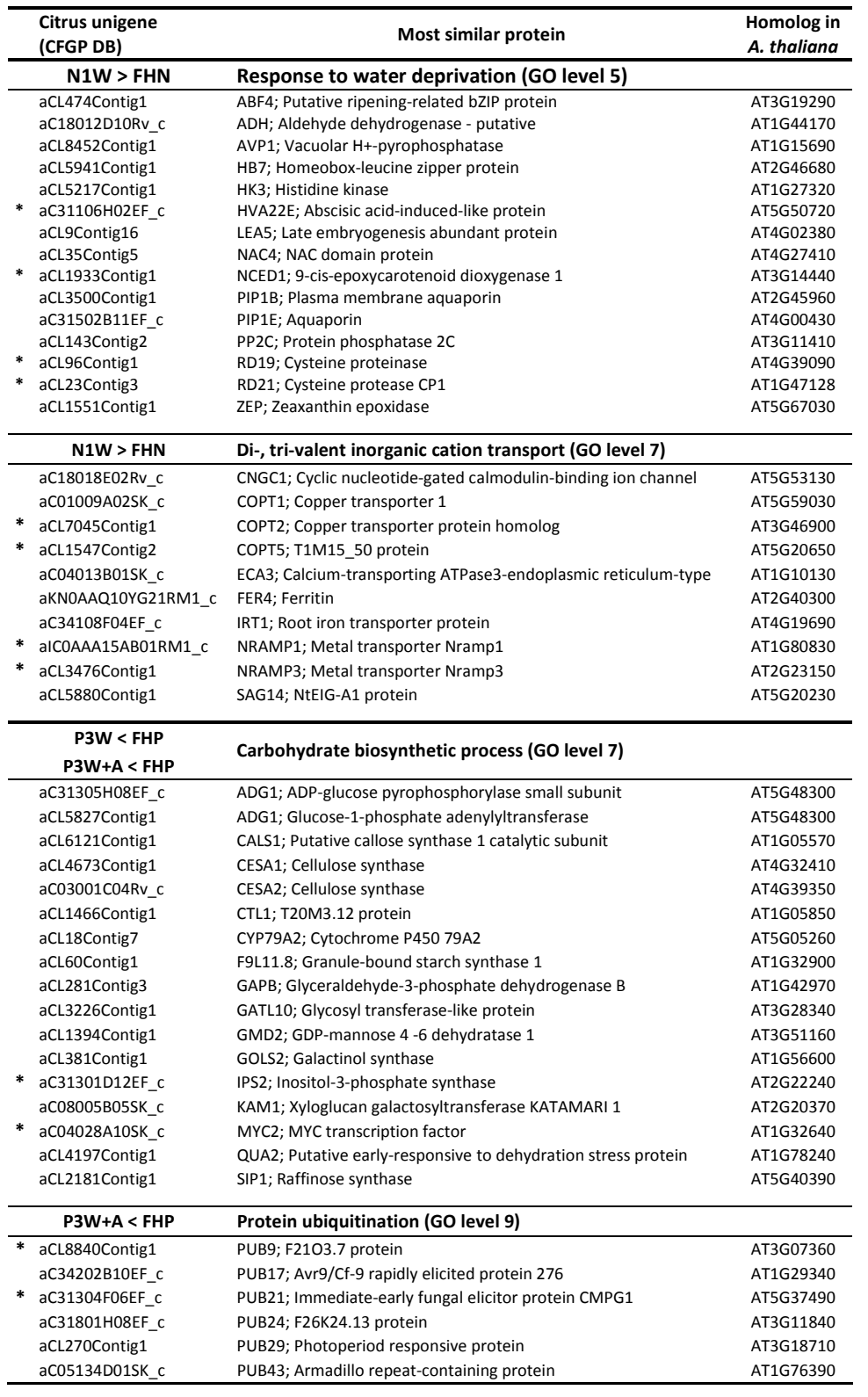




\section{Expression profiles for selected genes by qRT-PCR analysis}

Quantitative RT-PCR analysis was conducted to validate microarray gene expression data and to further characterize expression patterns of selected genes in fruits exposed to moderate water stress for up to 6 weeks. Comparison between the transcript abundance data obtained by the $20 \mathrm{~K}$ microarray and by RT-PCR analysis with gene-specific primers revealed a high correlation for all selected genes with $r^{2}$ values between 0.90 and 0.98 (Table 1). Among genes belonging to 'response to water deprivation' biological process, the genes CsRD19 and CSRD21, with homology to dehydration responsive genes of Arabidopsis (AT4G39090 and AT1G47128, respectively), the CSHVA22E, homologous to an ABA-inducible gene (AT5G50720), and the gene CSNCED1 (AT3G14440), involved in $A B A$ biosynthesis, were selected. A rapid and transient increase in relative expression levels of these genes was observed by 1 week in parental fruits. Interestingly, the relative expression level of CSNCED1 also increased in the flavedo of 'Pinalate' fruit, but such increase was much lower than that occurring in 'Navelate'. Moreover, such increases were not induced by applying ABA to the mutant (Fig. 4A). Within the 'di-, tri-valent inorganic cation transport' biological process, CSCOPT2 and CSCOPT5 genes, with homology to copper transporters of Arabidopsis (AT3G46900 and AT5G20650, respectively), and CSNRAMP1 and CsNRAMP3, homologous to iron transporter genes (AT1G80830 and AT2G23150, respectively), were selected. The expression levels of all these genes in FH mutant fruits were higher than in the parental fruits (Fig. 4B). However, a higher increase in their expression was detected in wild-type fruits exposed to moderate dehydration for 1 week than in mutant. From these genes, only the expression levels of CSCOPT5 continued increasing in response to dehydration for up to 3 weeks. Accumulation of CSNRAMP1 was, in general, higher during storage in 'Navelate' fruits. In contrast, expression levels of CSCOPT2 and CSNRAMP3 were 
higher in 'Pinalate' fruits. Interestingly, the expression pattern of these two genes in mutant fruits treated with $A B A$ was more similar to that of parental fruits than to the mutant fruits (Fig. 4B).
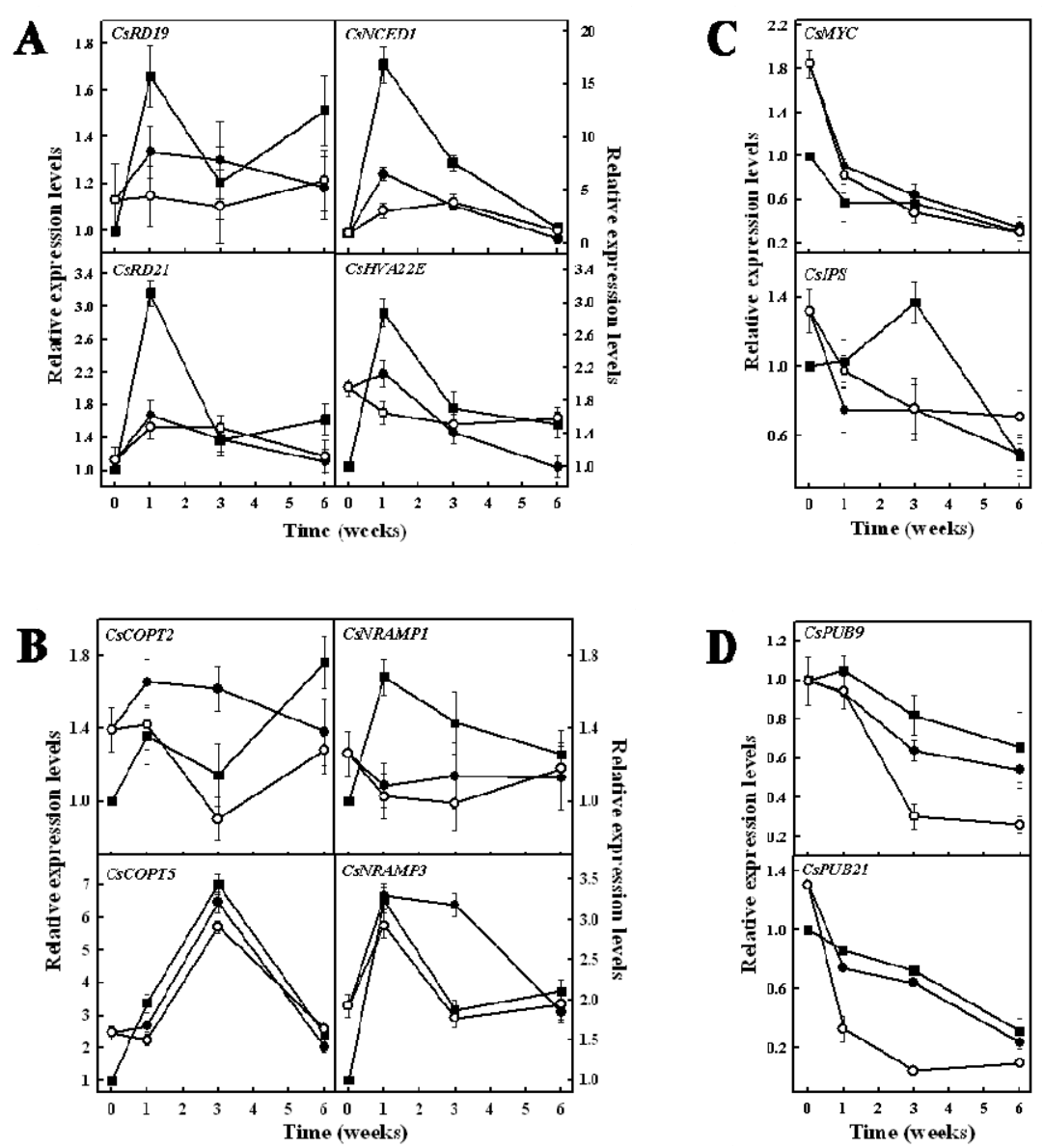

Figure 4. Real time qRT-PCR expression analysis for candidate genes selected from microarrays analysis. Relative transcript abundance for selected genes belonging to 'Water deprivation' (A), 'Di-, tri-valent inorganic cation transport' (B), 'Carbohydrate biosynthesis' (C) and 'Protein ubiquitination' (D) biological processes differentially regulated in 'Navelate' (squares) and 'Pinalate' (circles) fruits treated (white) or not (black) with $\mathrm{ABA}$ and stored for up to 6 weeks at 12 으 $\mathrm{C}$ and $70-75 \% \mathrm{RH}$. Transcript levels for all conditions were referred to $\mathrm{FH}$ 'Navelate' fruits and expressed as relative values. Data are the mean values of three biological replicates \pm SE. 
On the other hand, citrus unigenes CSIPS and CSMYC, with homology to genes encoding a inositol-3-phosphate synthase (AT2G22240) and a MYC transcription factor (AT1G32640), respectively, were selected as representative genes of the 'carbohydrate biosynthesis' biological process. Both genes were repressed in the ABA-treated and non-treated 'Pinalate' fruits, though their expression levels in FH mutant fruits were higher than in 'Navelate' fruits (Fig. 4C). Expression levels of CSMYC transcription factor also decreased in the parental, while that of CSIPS increased from 1 to 3 weeks of storage (Fig. 4C). Genes CsPUB9 and CSPUB21 encoding proteins showing homology to E3-ubiquitin-ligases of $A$. thaliana involved in ABA (AT3G07360) and pathogen (AT5G37490) responses respectively, were selected among genes of the 'protein ubiquitination' biological process (Table 3). The rate of decrease in expression levels of both genes was similar in parental and mutant fruits but applying $A B A$ had a marked effect on favouring repression (Fig. 4D). 


\section{DISCUSSION}

The working hypothesis was that the ABA-deficiency may be an important factor for the high susceptibility of 'Pinalate' fruit to dehydration and to NCPP. To test this hypothesis and to understand the molecular mechanisms underlying both processes in citrus fruit, a comparative large-scale transcriptional analysis has been performed in harvested 'Navelate', 'Pinalate' and in ABA-treated 'Pinalate' fruits stored under conditions (12 $\mathrm{o}$ and $70-75 \% \mathrm{RH}$ ) causing moderate water stress and peel damage. The higher susceptibility to NCPP (Fig. 1A) and dehydration (Fig. 1B) observed in 'Pinalate' fruit agree with previous data showing that, under the same storage conditions, fruit weight loss and the decrease in water potential of the flavedo tissue was higher in fruits of the mutant (Alférez et al., 2005).

Differential gene expression analysis (Fig. 2) further revealed the higher ability of 'Navelate' fruit to develop earlier molecular responses to postharvest dehydration. These responses might contribute to reduce detrimental effects caused by dehydration and hence to the delay in peel damage development with respect to mutant fruit, which showed evident damage by 1 week. Thus, gene ontology analysis revealed that the most specific biological processes induced only in 'Navelate' fruit by 1 week were 'response to water deprivation' and 'di-, tri-valent inorganic cation transport' (Table 2), which fit into classical plant responses to water deficit and osmotic adjustment (Shinozaki et al., 1998; Ramanjulu and Bartels, 2002). This result is also in concordance with previous findings showing that transport and abiotic stress-related genes are differentially regulated by dehydration in detached grape berries (Grimplet et al., 2007; Rizzini et al., 2009; Zamboni et al., 2010). As expected, most of the genes belonging to the 'response to water deprivation' biological process (Table 3 ) were related to $A B A$. Thus, genes involved in ABA synthesis and perception (NCED1, ZEP and 
$P P 2 C), A B A-d e p e n d e n t$ transcription factors (HB7, NAC4 and ABF4), and also genes encoding ABA-responsive proteins (HVA22E, Lea5 and $A D H$ ) were identified, which highlights that the responses of 'Navelate' oranges to dehydration are modulated, at least in part, by the phytohormone. Among ABAdependent genes belonging to this process, it is also worth mentioning those encoding proteins with homology to the plasma membrane PIP1B and PIP1E aquaporins as they play important roles adjusting osmotic potential in dehydrated plants (Shinozaki et al., 1998; Shinozaki and Yamaguchi-Shinozaki, 2007). Therefore, and considering the fact that the number of stomata per surface area in fruits of both cultivars is similar (Alférez and Zacarías, unpublished data), the above results indicate a higher ability of 'Navelate' fruits to synthesize ABA, which controls stomata closure to reduce dehydration, and also to modulate ABArelated genes important for cell homeostasis and viability and hence for the reduction of peel damage. Other genes within this process (e.g. CsRD19 and CsRD21) have not been classified as up-regulated by $A B A$ in different plant systems (Koizumi et al., 1993; Coupe et al., 2003). From the results of the present work, it cannot be ruled out that they are ABA-dependent in citrus fruits since they were not induced by dehydration in the mutant. Nevertheless, genes within other categories like CSCOPT5 and CSNRAMP3 were induced by dehydration in both 'Navelate' and the ABA-deficient 'Pinalate' fruits. In addition, the expression of these genes did not increase either in 'Pinalate' fruits after the ABA treatment. Therefore, these results in citrus fruit might support previous findings suggesting the involvement of $A B A$-independent genes in the response to dehydration in plants (Riera et al., 2005). In this context, it should be mentioned that the occurrence of alternative dehydration-responsive pathway(s) to minimize waterloss in plants under ABA deficiency has been reported (Wilkinson and Davies, 2010). Furthermore, it cannot be excluded that physico-chemical properties of the 
fruit surface may be altered in the mutant since $A B A$ may affect epicuticular wax biosynthesis in plants (Islam et al., 2009) and also cuticle permeability, development and composition in fruits (Curvers et al., 2010). Although the effect of different hormones on the synthesis or morphology of epicuticular waxes have been shown in citrus fruits (El-Otmani et al., 1986; Cajuste et al., 2010), that of $A B A$ has not been described yet. Therefore, the availability of the spontaneous 'Pinalate' ABA-deficient mutant and its high susceptibility to dehydration encourages new investigations aimed to determine how ABA deficiency impacts the cuticle wax composition.

Besides the 'response to water deprivation' process, the inorganic cation transport appears to be operating in the lower susceptibility of 'Navelate' fruit to dehydration and NCPP. The transport and/or the sequestration of ions constitute a plant strategy to prevent water loss from the cytoplasm to the extracellular matrix and the subsequent osmotic stress originated by dehydration (Shinozaki et al., 1998; Ramanjulu and Bartels, 2002). Prevention of water and osmotic stress has been mainly attributed to potassium, chloride and calcium ions. However, results obtained in the present work revealed that the 'di-, tri-valent inorganic cation transport' biological process, induced only in 'Navelate' fruit by 1 week, involved calcium (ECA3 and GNC1), iron (FER4, IRT1, NRAMP1 and NRAMP3) and copper chelators and transporters (COPT1, COPT2, COPT5 and SAG14). Copper and iron cations are trace elements and, consequently, their concentration inside the cell might barely affect cell osmotic pressure. Therefore, an attractive possibility from the present results is that these metal transporters could play a role in the tolerance of citrus fruit to dehydration by modulating ABA-responsive pathways. This would be in concordance with previous findings indicating that these ions may affect the ABA-dependent signal transduction pathway in plants (Sudo et al., 2008). Within the context of this work, it is noteworthy that iron and 
copper cations are required as cofactors of superoxide dismutases that may contribute to the lower susceptibility of 'Navelate' fruit to develop NCPP (Sala et al., 2005). It is known that an excess of metals may lead to the disruption of cellular processes and finally to cell death, and that the prevention of such harmful effects require the participation of metal-binding proteins and transporters (Puig et al., 2007). Thus, the higher increase in the expression levels of iron and copper transporters detected in the wild-type fruit (Fig. 4B), suggests that the impaired ability of the ABA-deficient mutant to regulate metal homeostasis could be relevant for its higher susceptibility to dehydration and NCPP.

Most of the differentially expressed genes were down-regulated in the mutant by 3 weeks (Fig. 2B) and grouped into numerous biological processes (Table 2), being 'carbohydrate biosynthesis' the most specific. This is in agreement with previous results showing a higher reduction in soluble sugars and starch in 'Pinalate' respect to parental fruits during development of NCPP (Holland et al., 2005), and highlights the interplay between $A B A$ and sugars in plants. This process grouped not only genes involved in the metabolism of soluble sugars and starch but also in the metabolism of cell wall polysaccharides and putative regulatory elements, such as a MYC transcription factor and a gene (CSIPS) involved in regulating the levels of inositol-3-phosphate, which constitutes a node for the crosslink among several signalling pathways (Kaur and Gupta, 2005). The CsMYC transcription factor displays a $63 \%$ of identity with the ABA-responsive AtMYC2, which triggers the slow adaptive response of Arabidopsis to dehydration (Abe et al., 2003; Bartels and Sunkar, 2005) and, therefore, the CSMYC transcript might be involved in the tolerance of citrus fruit to water stress. Nevertheless, this Citrus gene appears not to be a limiting step in this process since its expression levels continuously decreased in the ABA-deficient mutant but also in the parental fruit. 
Expression analysis showed that CSIPS transcript levels also decreased in 'Pinalate' fruit for up to 6 weeks but transiently increased in the wild-type phenotype when the highest difference in NCPP between both varieties was observed (Fig. 4C, 3 weeks). This result suggests a higher availability of the second messenger inositol3-phosphate in the wild type, which might favour putative signalling pathways involved in the protection of fruit against detrimental effects caused by water stress and NCPP, whereas these pathways might be impaired in the ABA-deficient mutant. The above results, together with the high number of down-regulated genes belonging to the 'carbohydrate biosynthesis' process in mutant fruit, and the well known protective roles of sugars against osmotic and water stresses in plants (Bartels and Sunkar, 2005; Seki et al., 2007), suggest that the repression of this biological process is relevant for the susceptibility of citrus fruit to such stresses leading to peel damage. The repression of this process was also associated with the enhancement of NCPP in 'Navelate' fruits exposed to a different stress (Establés-Ortiz et al., 2009), indicating the relevance of carbohydrate metabolism in the convergence of the mechanisms underlying NCPP.

The interpretation of results derived from the application of plant growth regulators to hormone-deficient mutants may be complex as these treatments may fail to recover the wild-type phenotypes. Different examples can be found in the literature in fruits (Sandhu et al., 2011) and also in seedlings (Mahouachi et al., 2011) in spite of the ability of seedling plants to use foliar- or roots-applied hormones and to translocate them to almost all plant parts (Mäkelä et al., 1996). Results from ABA treatment on 'Navelate' fruits suggests that endogenous levels of the phytohormone might be sufficient to trigger cellular processes coping with dehydration and further consequences related to peel damage in the wild-type orange since NCPP index and weight loss were not significantly affected by the 
ABA application (Fig. S1). Interestingly, application of ABA increased the hormone content in the flavedo of 'Pinalate' mutant fruit to levels that were always slightly higher than those of the parental, triggered changes in the expression of thousands of genes, and repressed the 'protein ubiquitination' biological process. However, it did not modify either the expression levels of a subset of ABAregulated genes (Bartels and Sunkar, 2005) (Table S1) or rescue the wild-type phenotype since exogenous ABA slightly affected the incidence of NCPP and did not modify the cumulative weight loss of mutant fruits. Therefore, these results, together with the obtained by multivariate and qRT-PCR analyses (Fig. 3 and 4), indicate that exogenous ABA modulates gene expression in 'Pinalate' fruits but it is not fully effective either redirecting the mutant transcriptome towards that of the parental fruit or recovering its phenotype. These results might be unexpected but there are several examples showing that $A B A$ did not rescue normal phenotype in ABA-deficient mutants (Busk and Pagès, 1998). In addition, plants may be less sensitive to exogenous $A B A$ under normal conditions than to the stress-induced rises in endogenous ABA (Imay et al., 1995). In agreement with these ideas, Mahouachi et al. (2011) reported that ABA treatment did not stimulate physiological responses of papaya seedlings exposed to drought, whereas treatments favouring the rise of endogenous $A B A$ levels were able to trigger physiological responses coping with dehydration. Taking together these ideas and that 'Pinalate' has reduced ABA levels during the whole period of development and ripening (Rodrigo et al., 2003), it cannot be ruled out the possibility of an altered ABA-perception system in 'Pinalate' fruit, as reported in other hormone-deficient mutants (Guo and Ecker, 2004), or some defect in the $A B A$ signalling transduction pathway that would impair its responses to the $A B A$ treatment. Therefore, it would be interesting to further investigate whether there are differences in the regulation of the ABA-signalling components, which have 
been recently characterized in Arabidopsis (Park et al., 2009; Ma et al., 2009), between mutant and wild-type fruits under water stress conditions.

In spite of the relevance of plant sensitivity for triggering hormoneresponses, Hoth et al. (2002) found that treating seedlings of the Arabidopsis ABAinsensitive mutant abi1-1 with ABA induced relevant changes in the expression of genes and processes regulated by the hormone although, as expected, it did not rescue the typical $A B A$-insensitive phenotype. The modulation of protein ubiquitination was observed by these authors after ABA treatment. Interestingly, this was the only biological process down-regulated by exogenous $A B A$ in 'Pinalate', which suggests the involvement of protein degradation in the ABAsignalling network in citrus fruits. In this context, it is also noteworthy to mention different reports associating this biological process with ABA-signalling/responses in the model plant Arabidopsis (López-Molina et al., 2003; Zhang et al., 2005; Luo et al., 2006; Ryu et al., 2010). The six Citrus genes grouped into 'protein ubiquitination' biological process encoded plant U-box (PUB) domain-containing proteins with E3-ubiquitin ligase activity. Three of them (PUB9, PUB17, PUB43) have been related to ABA (Samuel et al., 2008; Raab et al., 2009; Ni et al., 2010) and the others (PUB21, PUB24 and PUB29) to cell death signalling and plant defence responses to biotic stress (Libault et al., 2007). In concordance with that, it was found that rots developed earlier ( 3 weeks) and with higher incidence during storage in ABA-treated mutant fruits respect to non-treated mutant or parental fruits (Fig. S2). Real-time expression analysis of CSPUB9 and CSPUB21 genes further revealed an enhanced repression of transcript levels in ABA-treated 'Pinalate' fruit, which further confirm that the protein ubiquitination process may be negatively regulated by ABA treatment in mutant fruit. Therefore, these results suggest a crosslink between $A B A$ and the modulation of defence responses in 
citrus fruit through proteins involved in the ubiquitin-proteasome system machinery.

In conclusion, the comparative transcriptional analysis between 'Navelate' and its mutant 'Pinalate' fruits highlights the ability of parental fruit to develop responses to reduce water loss and other detrimental consequences caused by this stress. These responses involve the 'water deprivation' and the 'di-, tri-valent inorganic cation transport' biological processes, which include both ABAdependent and independent genes. The alteration of these responses in the mutant fruit suggests their relevance for the prevention of peel damage in citrus fruit. Likewise, repression of the 'carbohydrate biosynthesis' process occurred specifically in 'Pinalate' fruits, which showed higher susceptibility to NCPP. Overall, results suggest that the sensitivity/response to $A B A$ may be impaired in the ABA-deficient mutant fruit and reveals molecular mechanisms triggering the response to water stress in citrus fruit. 


\section{REFERENCES}

Abe H, Urao T, Ito T, Seki M, Shinozaki K, Yamaguchi-Shinozaki K. 2003. Arabidopsis AtMYC2 (bHLH) and AtMYB2 (MYB) function as transcriptional activators in abscisic acid signaling. The Plant Cell 15, 63-78.

Agustí J, Merelo P, Cercós M, Tadeo FR, Talón M. 2008. Ethylene-induced differential gene expression during abscission of citrus leaves. Journal of Experimental Botany 59, 2717-2733.

Agustí M, Almela V, Juan M, Alférez F, Tadeo FR, Zacarías L. 2001. Histological and physiological characterization of rind breakdown of 'Navelate' sweet orange. Annals of Botany 88, 415-422.

Al-Shahrour F, Díaz-Uriarte R, Dopazo J. 2004. FatiGO: a web tool for finding significant associations of Gene Ontology terms with groups of genes. Bioinformatics 20, 578-580.

Alférez F, Agustí M, Zacarías L. 2003. Postharvest rind staining in Navel oranges is aggravated by changes in storage relative humidity: effect on respiration, ethylene production and water potential. Postharvest Biology and Technology 28, 143-152.

Alférez F, Lluch Y, Burns JK. 2008. Phospholipase A2 and postharvest peel pitting in citrus fruit. Postharvest Biology and Technology 49, 69-76.

Alférez F, Sala JM, Sanchez-Ballesta MT, Mulas M, Lafuente MT, Zacarías L. 2005. A comparative study of the postharvest performance of an ABA-deficient mutant of oranges: I. Physiological and quality aspects. Postharvest Biology and Technology 37, 222-231.

Alós E, Roca M, Iglesias DJ, et al. 2008. An evaluation of the basis and consequences of a stay-green mutation in the navel negra Citrus mutant using transcriptomic and proteomic profiling and metabolite analysis. Plant Physiology 147, 1300-1315.

Armstrong F, Leung J, Grabov A, Brearley J, Giraudat J, Blatt MR. 1995. Sensitivity to abscisic acid of guard-cell $\mathrm{K}^{+}$channels is suppressed by abi1-1, a mutant Arabidopsis gene encoding a putative protein phosphatase. Proceedings of the National Academy of Sciences of the United States of America 92, 9520-9524.

Ballester AR, Lafuente MT, Forment J, Gadea J, de Vos RCH, Bovy AG, Gonzalez-Candelas L. 2011. Transcriptomic profiling of citrus fruit peel tissues reveals fundamental effects of phenylpropanoids and ethylene on induced resistance. Molecular Plant Pathology 12, 879897. 
Ballester AR, Lafuente MT, González-Candelas L. 2006. Spatial study of antioxidant enzymes, peroxidase and phenylalanine ammonia-lyase in the citrus fruit-Penicillium digitatum interaction. Postharvest Biology and Technology 39, 115-124.

Bartels D, Sunkar R. 2005. Drought and salt tolerance in plants. Critical Reviews in Plant Sciences 24, 23-58.

Bray EA, Bayley-Serres J, Weretilnyk E. 2000. Response to abiotic stresses. In: Gruissem W, Buchannan B, Jones R, eds. Biochemistry and Molecular Biology of Plants, American Society of Plant Physiologists, pp. 1158-1249.

Brumós J, Colmenero-Flores JM, Conesa A, et al. 2009. Membrane transporters and carbon metabolism implicated in chloride homeostasis differentiate salt stress responses in tolerant and sensitive Citrus rootstocks. Functional \& Integrative Genomics 9, 293-309.

Burbidge A, Grieve TM, Jackson A, Thompson A, McCarty DR, Taylor IB. 1999. Characterization of the ABA-deficient tomato mutant notabilis and its relationship with maize Vp14. Plant Journal 17, 427-431.

Busk PK, Pagès M. 1998. Regulation of abscisic acid-induced transcription. Plant Molecular Biology 37, 425-435.

Cajuste JF, González-Candelas L, Veyrat A, García-Breijo FJ, Reig-Armiñana J, Lafuente MT. 2010. Epicuticular wax content and morphology as related to ethylene and storage performance 'Navelate' orange fruit. Postharvest Biology and Technology 55, 29-35.

Cercós M, Soler G, Iglesias DJ, Gadea J, Forment J, Talón M. 2006. Global analysis of gene expression during development and ripening of citrus fruit flesh. A proposed mechanism for citric acid utilization. Plant Molecular Biology 62, 513-527.

Coupe SA, Sinclair BK, Watson LM, Heyes JA, Eason JR. 2003. Identification of dehydration-responsive cysteine proteases during post-harvest senescence of broccoli florets. Journal of Experimental Botany 54, 1045-1056.

Curvers K, Seifi H, Mouille G, et al. 2010. Abscisic acid deficiency causes changes in cuticle permeability and pectin composition that influence tomato resistance to Botrytis cinerea. Plant Physiology 154, 847-860.

Deluc L, Quilici D, Decendit A, et al. 2009. Water deficit alters differentially metabolic pathways affecting important flavor and quality traits in grape berries of Cabernet Sauvignon and Chardonnay. BMC Genomics 10, 212. 
El-Otmani M, Coggins Jr. VW, Eaks IL. 1986. Fruit age and gibberellic acid effect on epicuticularwax accumulation, respiration, and internal atmosphere of Navel orange fruit. Journal of the American Society for Horticultural Science 111, 228-232.

Establés-Ortiz B, Lafuente MT, González-Candelas L, Forment J, Gadea J. 2009. Transcriptomic analysis of ethylene-induced tolerance to non-chilling peel pitting in citrus fruit. Acta Horticulturae 839, 555-560.

Forment J, Gadea J, Huerta L, et al. 2005. Development of a citrus genome-wide EST collection and cDNA microarray as resources for genomic studies. Plant Molecular Biology 57, 375-391.

Gandía M, Conesa A, Ancillo G, et al. 2007. Transcriptional response of Citrus aurantifolia to infection by Citrus tristeza virus. Virology 367, 298-306.

Gimeno J, Gadea J, Forment J, et al. 2009. Shared and novel molecular responses of mandarin to drought. Plant Molecular Biology 70, 403-420.

Grimplet J, Deluc L, Tillett R, Wheatley M, Schlauch K, Cramer G, Cushman J. 2007. Tissue-specific mRNA expression profiling in grape berry tissues. BMC Genomics 8, 187.

Groot SPC, Karssen CM. 1992. Dormancy and germination of abscisic acid-deficient tomato seeds: Studies with the sitiens mutant. Plant Physiology 99, 952-958.

Guo H, Ecker JR. 2004. The ethylene signaling pathway: new insights. Current Opinion in Plant Biology 7, 40-49.

Holland N, Menezes HC, Lafuente MT. 2005. Carbohydrate metabolism as related to hightemperature conditioning and peel disorders occurring during storage of citrus fruit. Journal of Agricultural and Food Chemistry 53, 8790-8796.

Hoth S, Morgante M, Sanchez JP, Hanafey MK, Tingey SV, Chua NH. 2002. Genome-wide gene expression profiling in Arabidopsis thaliana reveals new targets of abscisic acid and largerly impaired gene regulation in the abi1-1 mutant. Journal of Cell Science 115, 4891 4900 .

Huerta L, Forment J, Gadea J, Fagoaga C, Peña L, Pérez-Amador MA, García-Martínez JL. 2008. Gene expression analysis in citrus reveals the role of gibberellins on photosynthesis and stress. Plant, Cell and Environment 61, 1620-1633.

Imay R, Moses MS, Bray EA. 1995. Expression of an ABA-induced gene of tomato in transgenic tobacco during periods of water deficit. Journal of Experimental Botany 46, 1077-1084. 
Islam M, Du H, Ning J, Ye H, Xiong L. 2009. Characterization of Glossy1-homologous genes in rice involved in leaf wax accumulation and drought resistance. Plant Molecular Biology 70, 443-456.

Kaur N, Gupta AK. 2005. Signal transduction pathways under abiotic stresses in plants. Current Science 88, 1771-1780.

Koizumi M, Yamaguchi-Shinozaki K, Tsuji H, Shinozaki K. 1993. Structure and expression of two genes that encode distinct drought-inducible cysteine proteinases in Arabidopsis thaliana. Gene 129, 175-182.

Koornneef M, Alonso-Blanco C, Vreugdenhil D. 2004. Naturally occurring genetic variation in Arabidopsis thaliana. Annual Review of Plant Biology 55, 141-172.

Lafuente MT, Martínez-Téllez MA, Zacarías L. 1997. Abscisic acid in the response of 'Fortune' mandarins to chilling. Effect of maturity and high-temperature conditioning. Journal of the Science of Food Agriculture 73, 494-502.

Lafuente MT, Sala JM. 2002. Abscisic acid levels and the influence of ethylene, humidity and storage temperature on the incidence of postharvest rindstaning of 'Navelina' orange (Citrus sinensis L. Osbeck) fruit. Postharvest Biology and Technology 25, 49-57.

Lafuente MT, Zacarías L. 2006. Postharvest physiological disorders in citrus fruit. Stewart Postharvest Review 1, 1-9.

Libault M, Wan J, Czechowski T, Udvardi M, Stacey G. 2007. Identification of 118 Arabidopsis transcription factor and 30 ubiquitin-ligase genes responding to chitin, a plant-defense elicitor. Molecular Plant-Microbe Interactions 20, 900-911.

Liu Q, Zhu A, Chai L, et al. 2009. Transcriptome analysis of a spontaneous mutant in sweet orange (Citrus sinensis L. Osbeck) during fruit development. Journal of Experimental Botany 60, 801-813.

López-Molina L, Mongrand S, Kinoshita N, Chua NH. 2003. AFP is a novel negative regulator of $\mathrm{ABA}$ signaling that promotes $\mathrm{ABI} 5$ protein degradation. Genes \& Development 17, 410-418.

Luo J, Shen G, Yan J, He C, Zhang H. 2006. AtCHIP functions as an E3 ubiquitin ligase of protein phosphatase $2 \mathrm{~A}$ subunits and alters plant response to abscisic acid treatment. The Plant Journal 46, 649-657.

Ma Y, Szostkiewicz I, Korte A, Moes D, Yang Y, Alexander C, Grill E. 2009. Regulators of PP2C phosphatase activity function as abscisic acid sensors. Science 324, 1064-1068. 
Mahouachi J, Argamasilla R, Gómez-Cadenas A. 2011. Influence of exogenous glycine betaine and abscisic acid on papaya in responses to water-deficit stress. Journal of Plant Growth Regulation 31, 1-10.

Mäkelä P, Peltonen-Sainio P, Jokinen K, Pehu E, Setälä H, Hinkkanen R, Somersalo S. 1996. Uptake and translocation of foliar-applied glycinebetaine in crop plants. Plant Science 121, 221-230.

Martínez-Godoy MA, Mauri N, Juarez J, Marques MC, Santiago J, Forment J, Gadea J. 2008. A genome-wide $20 \mathrm{~K}$ citrus microarray for gene expression analysis. BMC Genomics 9, 318.

Maul P, McCollum GT, Popp M, Guy CL, Porat R. 2008. Transcriptome profiling of grapefruit flavedo following exposure to low temperature and conditioning treatments uncovers principal molecular components involved in chilling tolerance and susceptibility. Plant, Cell and Environment 31, 752-768.

Miller G, Suzuki N, Ciftci-Yilmaz S, Mittler R. 2010. Reactive oxygen species homeostasis and signalling during drought and salinity stresses. Plant, Cell and Environment 33, 453467.

Ni X, Tian Z, Liu J, Song B, Li J, Shi X, Xie C. 2010. StPUB17, a novel potato UND/PUB/ARM repeat type gene, is associated with late blight resistance and $\mathrm{NaCl}$ stress. Plant Science 178, 158-169.

Norman SM, Poling SM, Maier VP. 1988. An indirect enzyme-linked immunosorbent assay for (+)-abscisic acid in Citrus, Ricinus, and Xanthium leaves. Journal of Agricultural and Food Chemistry 36, 225-231.

Park SY, Fung P, Nishimura N, et al. 2009. Abscisic acid inhibits type 2C protein phosphatases via the PYR/PYL family of START proteins. Science 324, 1068-1071.

Pena-Cortes H, Sanchez-Serrano JJ, Mertens R, Willmitzer L, Prat S. 1989. Abscisic acid is involved in the wound-induced expression of the proteinase inhibitor II gene in potato and tomato. Proceedings of the National Academy of Sciences of the United States of America 86, 9851-9855.

Pfaffl MW. 2001. A new mathematical model for relative quantification in real-time RTPCR. Nucleic Acids Research 29, e45.

Puig S, Andrés-Colás N, García-Molina A, Peñarrubia L. 2007. Copper and iron homeostasis in Arabidopsis: Responses to metal deficiencies, interactions and biotechnological applications. Plant, Cell and Environment 30, 271-290. 
Raab S, Drechsel G, Zarepour M, Hartung W, Koshiba T, Bittner F, Hoth S. 2009. Identification of a novel E3 ubiquitin ligase that is required for suppression of premature senescence in Arabidopsis. The Plant Journal 59, 39-51.

Ramanjulu S, Bartels D. 2002. Drought- and desiccation-induced modulation of gene expression in plants. Plant, Cell and Environment 25, 141-151.

Riera M, Valon C, Fenzi F, Giraudat J, Leung J. 2005. The genetics of adaptive responses to drought stress: abscisic acid-dependent and abscisic acid-independent signalling components. Physiologia Plantarum 123, 111-119.

Rizzini FM, Bonghi C, Tonutti P. 2009. Postharvest water loss induces marked changes in transcript profiling in skins of wine grape berries. Postharvest Biology and Technology 52, 247-253.

Rodrigo MJ, Marcos JF, Alférez F, Mallent MD, Zacarías L. 2003. Characterization of 'Pinalate', a novel Citrus sinensis mutant with a fruit-specific alteration that results in yellow pigmentation and decreased ABA content. Journal of Experimental Botany 54, 727 738.

Rodrigo MJ, Marcos JF, Zacarías L. 2004. Biochemical and molecular analysis of carotenoid biosynthesis in flavedo of orange (Citrus sinensis L.) during fruit development and maturation. Journal of Agricultural and Food Chemistry 52, 6724-6731.

Ryu MY, Cho SK, Kim WT. 2010. The Arabidopsis C3H2C3-type RING E3 ubiquitin ligase AtAIRP1 is a positive regulator of an abscisic acid-dependent response to drought stress. Plant Physiology 154, 1983-1997.

Saeed Al, Sharov V, White J, et al. 2003. TM4: A free, open-source system for microarray data management and analysis. BioTechniques 34, 374-378.

Sala JM, Sanchez-Ballesta MT, Alférez F, Mulas M, Zacarías L, Lafuente MT. 2005. A comparative study of the postharvest performance of an ABA-deficient mutant of oranges: II. Antioxidant enzymatic system and phenylalanine ammonia-lyase in non-chilling and chilling peel disorders of citrus fruit. Postharvest Biology and Technology 37, 232-240.

Samuel MA, Mudgil Y, Salt JN, Delmas F, Ramachandran S, Chilelli A, Goring DR. 2008. Interactions between the S-domain receptor kinases and AtPUB-ARM E3 ubiquitin ligases suggest a conserved signaling pathway in Arabidopsis. Plant Physiology 147, 2084-2095.

Sandhu AK, Gray DJ, Lu J, Gu L. 2011. Effects of exogenous abscisic acid on antioxidant capacities, anthocyanins, and flavonol contents of muscadine grape (Vitis rotundifolia) skins. Food Chemistry 126, 982-988. 
Schwartz SH, Tan BC, Gage DA, Zeevaart JAD, McCarty DR. 1997. Specific oxidative cleavage of carotenoids by VP14 of maize. Science 276, 1872-1874.

Seki M, Umezawa T, Urano K, Shinozaki K. 2007. Regulatory metabolic networks in drought stress responses. Current Opinion in Plant Biology 10, 296-302.

Shinozaki K, Yamaguchi-Shinozaki K. 2007. Gene networks involved in drought stress response and tolerance. Journal of Experimental Botany 58, 221-227.

Shinozaki K, Yamaguchi-Shinozaki K, Mizoguchi T, et al. 1998. Molecular responses to water stress in Arabidopsis thaliana. Journal of Plant Research 111, 345-351.

Sudo E, Itouga M, Yoshida-Hatanaka K, Ono Y, Sakakibara H. 2008. Gene expression and sensitivity in response to copper stress in rice leaves. Journal of Experimental Botany 59, 3465-3474.

Turrel FM. 1946 Tables of surfaces and volumes of spheres and of prolate and oblate spheroids, and spheroidal coeficients. The Regents of the University of California.

Tusher VG, Tibshirani R, Chu G. 2001. Significance analysis of microarrays applied to the ionizing radiation response. Proceedings of the National Academy of Sciences of the United States of America 98, 5116-5121.

Udvardi MK, Czechowski T, Scheible WR. 2008. Eleven golden rules of quantitative RTPCR. The Plant Cell 20, 1736-1737.

Urano K, Kurihara Y, Seki M, Shinozaki K. 2010. 'Omics' analyses of regulatory networks in plant abiotic stress responses. Current Opinion in Plant Biology 13, 132-138.

Vandesompele J, de Preter K, Pattyn F, Poppe B, Van Roy N, de Paepe A, Speleman F. 2002. Accurate normalization of real-time quantitative RT-PCR data by geometric averaging of multiple internal control genes. Genome Biology 3, research0034research0034.11.

Vij S, Tyagi AK. 2007. Emerging trends in the functional genomics of the abiotic stress response in crop plants: Review article. Plant Biotechnology Journal 5, 361-380.

Weiler EW. 1980. Radioimmunoassays for the differential and direct analysis of free and conjugated abscisic acid in plant extracts. Planta 148, 262-272.

Wilkinson S, Davies WJ. 2010. Drought, ozone, ABA and ethylene: new insights from cell to plant to community. Plant, Cell and Environment 33, 510-525. 
Yamaguchi-Shinozaki K, Shinozaki K. 2006. Transcriptional regulatory networks in cellular responses and tolerance to dehydration and cold stress. Annual Review of Plant Biology 57, 781-803.

Zamboni A, Di Carli M, Guzzo F, et al. 2010. Identification of putative stage-specific grapevine berry biomarkers and omics data integration into networks. Plant Physiology 154, 1439-1459.

Zhang X, Garreton V, Chua NH. 2005. The AIP2 E3 ligase acts as a novel negative regulator of ABA signaling by promoting ABI3 degradation. Genes \& Development 19, 1532-1543.

Ziliotto F, Begheldo M, Rasori A, Bonghi C, Tonutti P. 2008. Transcriptome profiling of ripening nectarine (Prunus persica L. Batsch) fruit treated with 1-MCP. Journal of Experimental Botany 59, 2781-2791. 
SUPPLEMENTARY MATERIAL

Table S1. Representative set of ABA-regulated genes whose expression did not significantly (SAM, FDR $<0.01$ ) change in 'Pinalate' fruits after ABA treatment respect to FH 'Pinalate' fruits.

\begin{tabular}{|c|c|c|c|c|c|c|}
\hline \multirow{3}{*}{$\begin{array}{l}\text { Citrus unigene } \\
\text { (CFGP) }\end{array}$} & \multirow{3}{*}{$\begin{array}{l}\text { Homolog in } \\
\text { A. thaliana }\end{array}$} & \multirow{3}{*}{ Most similar protein } & \multicolumn{4}{|c|}{ Fold expression values $\left(\log _{2}\right)$} \\
\hline & & & \multicolumn{2}{|c|}{1 week } & \multicolumn{2}{|c|}{3 weeks } \\
\hline & & & - ABA & $+\mathrm{ABA}$ & - ABA & $+\mathrm{ABA}$ \\
\hline aC04015B01SK_c & AT4G38900 & Putative bZIP transcription factor & -0.33 & -0.12 & -0.29 & -0.28 \\
\hline aC04028A10SK_c & AT1G32640 & MYC transcription factor & -2.64 & -2.07 & -2.92 & -3.17 \\
\hline aCL111Contig1 & AT1G77120 & Alcohol dehydrogenase & -0.28 & -0.06 & -0.02 & -0.11 \\
\hline aCL172Contig2 & AT5G25610 & RD22-like protein & 1.05 & 0.91 & 1.56 & n.d. \\
\hline aCL1923Contig1 & AT1G32640 & Transcription factor AtMYC & 0.47 & 0.61 & 0.37 & 0.72 \\
\hline aCL2272Contig1 & AT4G26080 & Protein phosphatase- $2 \mathrm{C}$ & 0.31 & 0.19 & 0.19 & 0.12 \\
\hline aCL2763Contig1 & АТЗG20310 & Ethylene-responsive transcription factor 3 & -0.07 & -0.22 & 0.27 & 0.15 \\
\hline aCL3553Contig1 & AT1G45249 & Putative ripening-related bZIP protein & -0.50 & -0.28 & -0.39 & -0.40 \\
\hline aCL4559Contig1 & AT5G52300 & Low-temperature-induced $65 \mathrm{kDa}$ protein & -0.36 & 0.25 & -0.28 & -0.10 \\
\hline aCL474Contig1 & АТЗG19290 & Putative ripening-related bZIP protein & 0.62 & 0.61 & 0.12 & 0.26 \\
\hline aCL474Contig2 & АT3G19290 & Putative ripening-related bZIP protein & 0.12 & -0.23 & 0.61 & 0.26 \\
\hline aCL5131Contig1 & АТ2G36270 & Abscisic acid insensitive 5 & n.d. & 0.58 & 0.47 & n.d. \\
\hline aCL6186Contig1 & АT3G15730 & Phospholipase $\mathrm{D}$ alpha 1 precursor & -0.17 & -0.38 & -0.60 & -0.65 \\
\hline aCL7631Contig1 & АT3G56850 & BZIP transcription factor & 0.31 & 0.03 & 0.45 & 0.24 \\
\hline alC0AAA65DA09RM1_c & AT2G26300 & G protein alpha subunit & 0.43 & 0.48 & 0.39 & 0.52 \\
\hline alC0AAA88DA08RM1_c & AT4G27410 & NAC domain-containing protein 68 & -0.06 & -0.39 & 0.25 & 0.40 \\
\hline
\end{tabular}

n.d. not detected 


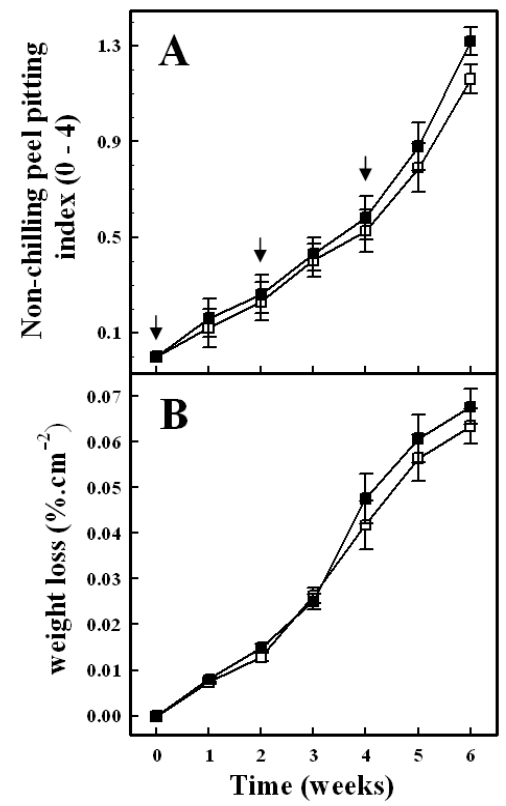

Figure S1. Non-chilling peel pitting index $(A)$ and percentage of fruit weight loss per surface area (B) of 'Navelate' (squares) fruits treated (white) or not (black) with ABA and stored for up to 6 weeks at $12{ }^{\circ} \mathrm{C}$ and $70-75 \% \mathrm{RH}$. The arrows indicate when ABA was applied. Results are the means of three biological replicates of 10 fruits each \pm SE. Mean separation was performed by applying Tukey's test. No significant differences $(p \leq 0.05)$ between samples for the same storage period were found.

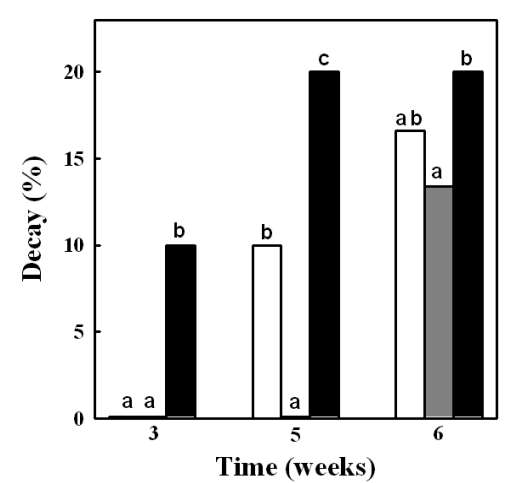

Figure S2. Percentage of decay in 'Navelate' (white), 'Pinalate' (grey) and ABA-treated 'Pinalate' (black) fruits stored at $12 \stackrel{\circ}{\circ}$ and $70-75 \% \mathrm{RH}$. Different letters for the same storage period indicate significant differences according to Tukey's test $(P$-value $\leq 0.05)$. 


\subsection{CHAPTER 2}

The Citrus ABA-signalosome: Identification and transcriptional regulation during sweet orange fruit ripening and leaf dehydration

Journal of Experimental Botany (2012) 63, 4931-4945

Paco Romero, María T. Lafuente and María J. Rodrigo* 



\section{ABSTRACT}

The abscisic acid (ABA) signalling core in plants include the cytosolic $A B A$ receptors (PYR/PYL/RCARs), the clade-A type 2C protein phosphatases (PP2CAs), and the subclass III SNF1-related protein kinases 2 (SnRK2s). The aim of this work was to identify these ABA perception system components in sweet orange and to determine the influence of endogenous $A B A$ in their transcriptional regulation during fruit development and ripening taking advantage of the comparative analysis between a wild-type and a fruit-specific ABA-deficient mutant. Transcriptional changes in the ABA-signalosome during leaf dehydration were also studied. Six PYR/PYL/RCAR, 5 PP2CA and 2 subclass III SnRK2 genes, homologous to those of Arabidopsis, were identified into the Citrus genome. The high homology degree and conserved motifs for protein folding and for functional activity suggested that these Citrus proteins are bona-fide core elements of the ABA perception in orange. Opposite expression patterns of CSPYL4 and CSPYL5 and $A B A$ accumulation were found during ripening, although there were few differences between varieties. Contrary, changes in CSPP2CAs expression during ripening paralleled those of $A B A$ content and concurred with relevant differences between wild-type and mutant fruit transcripts accumulation. CsSnRK2s expression continuously decreased with ripening and no remarkable differences were found between cultivars. Overall, dehydration had a minor effect on CSPYR/PYL/RCAR and CSSnRK2 expression in vegetative tissue, whereas CSABI1, CSAHG1 and CSAHG3 were highly induced by water stress. Global results suggest that responsiveness to $A B A$ changes during citrus fruit ripening and leaf dehydration was higher in the CSPP2CAs negative regulators than in the other ABA-signalosome components. 


\section{INTRODUCTION}

The phytohormone abscisic acid ( $A B A)$ is a critical endogenous messenger in the adaptive responses of plants to environmental stresses (Bartels and Sunkar, 2005) and also plays a role in the biotic stress responses (Ton et al., 2009). This hormone is also crucial for the regulation of a number of physiological processes under non-stressful conditions (Finkelstein et al., 2002; Gómez-Cadenas et al., 2002; Shinozaki and Yamaguchi-Shinozaki, 2007; Kim et al., 2012). The involvement of $A B A$ in the ripening of both climacteric and non-climacteric fruits has been also studied (Lafuente et al., 1997; Alférez and Zacarías, 1999; Zhang et al., 2001; Rodrigo et al., 2003; Zhang et al., 2009a; Sun et al., 2010; Bastías et al., 2011; Jia et al., 2011). In climacteric fruits, ABA accumulates just before the peak of ethylene production, triggering ethylene biosynthesis responsible for fruit ripening (Zhang et al., 2009b). The role of ABA in non-climacteric fruits is less clear although several evidences correlate the increase in $A B A$ levels during ripening with the activation of pathways related to the ripening process (Agustí et al., 2007; Giribaldi et al., 2010; Chai et al., 2011; Ren et al., 2011; Gambetta et al., 2011). These findings indicate a relevant role of $A B A$ in the process of fruit ripening. However, although the knowledge of conventional physiology and biochemistry of $A B A$ underlying fruit development has been highly improved in the last years, the regulatory mechanisms of $A B A$ action in non-climacteric fruit ripening are less known.

A number of studies have attempted to obtain a deeper insight into the cellular and molecular responses to $\mathrm{ABA}$ in plants, comprising the perception, signalling, metabolism and transport of this phytohormone (Nambara and Marion-Poll, 2005; Verslues and Zhu, 2007; Kang et al., 2010; Kuromori et al., 2010; Antoni et al., 2011). Natural or induced plant mutants of ABA-biosynthetic and signalling genes have been extensively used to elucidate the involvement of

88 
ABA in several physiological processes (Karssen et al., 1983; Peña-Cortés et al., 1989; Groot and Karssen, 1992; Armstrong et al., 1995; Schwartz et al., 1997; Galpaz et al., 2008; Sun et al., 2012). However, less information is available about the effects of this plant regulator on non-climacteric fruit performance and physiology (Rodrigo et al., 2006; Zhang et al., 2009a; Giribaldi et al., 2010; Jia et al., 2011; Chai et al., 2011).

In woody plants, artificially generated mutants are less affordable but spontaneous mutants are more broadly found (Koornneef et al., 2004). A spontaneous fruit-specific ABA-deficient mutant from the 'Navelate' orange (Citrus sinensis L. Osbeck), named 'Pinalate', has been biochemically characterized (Rodrigo et al., 2003). 'Pinalate' orange presents distinctive yellow-coloured fruit because a partial blockage of the carotenoid biosynthetic pathway causing, consequently, a fruit-specific ABA-deficiency. During natural ripening, the onset of fruit degreening is delayed in 'Pinalate' as compared to its wild-type cultivar (Rodrigo et al., 2003). Moreover, the sensitivity to ABA and the molecular responses to fruit dehydration during postharvest storage have been shown to be impaired in this mutant, which suggested that $A B A$ perception system may fail sensing the phytohormone (Romero et al., 2012). Therefore, the fruit-specific ABA-deficient 'Pinalate' orange offers an exceptional experimental system to investigate the role of endogenous $A B A$ in the regulation of the hormoneperception system components during citrus fruit ripening.

Several evidences support that multiple $A B A$ receptors perceive the $A B A$ signal outside and inside the cells, being this perception tissue-specific (Finkelstein et al., 2002). The PYR/PYL/RCAR soluble proteins (Park et al., 2009; Ma et al., 2009), belonging to the START protein superfamily (Klingler et al., 2010), and the downstream complex composed of PP2CA and SnRK2 proteins (Umezawa et al., 2009; Vlad et al., 2009; Hirayama and Umezawa, 2010) have been shown to 
regulate the well-known ABA-responses in the model plant Arabidopsis thaliana. Thus, the $A B A$ signalling core is composed by the cytoplasm ABA receptors (PYR/PYL/RCAR), the clade A protein phosphatases type 2C (PP2CAs) as negative regulators (Gosti et al., 1999; Merlot et al., 2001), and a number of protein kinases, including the subclass III of the SNF1-related kinases family 2 (SnRK2), as positive regulators of the pathway (Yoshida et al., 2002). The PYR/PYL/RCAR proteins contain a ligand-binding pocket into a cavity that closes after ABA binding through conformational changes of two conserved $\beta$-loops that serve as gate and latch. ABA binding to the receptors is enhanced when PYR/PYL/RCAR proteins are bound to their negative regulator PP2CAs (Park et al., 2009; Ma et al., 2009; Melcher et al., 2009). This new conformation locks the receptor in a closed structure and inhibits the PP2CA active site (Melcher et al., 2009; Santiago et al., 2009a). Consequently, SnRK2 is released and can phosphorylate downstream proteins or transcription factors that trigger the expression of ABA-responsive genes (Umezawa et al., 2010). Some investigations have been conducted on ABA signalling core components at transcriptional and functional levels. In general, concomitant with ABA rises, positive effectors (PYR/PYL/RCAR and SnRKs) were transcriptionally repressed whereas negative regulators (PP2CAs) increased, modulating together downstream signalling and, consequently, physiological $A B A$ responses in model and crop plants (Huai et al., 2008; Park et al., 2009; Umezawa et al., 2009; Santiago et al., 2009b; Nishimura et al., 2010; Szostkiewicz et al., 2010; Sun et al., 2011). Currently, limited information is available in nonclimacteric fruit (Jia et al., 2011; Chai et al., 2011; Li et al., 2012) and there is no report analyzing the expression of this set of genes as a whole.

In this study, 13 genes belonging to the PYR/PYL/RCAR, PP2CA and SnRK2 families have been identified in sweet orange. In order to get a deeper insight into the modulation of the ABA signalling components during fruit development and 
ripening of this non-climacteric fruit, as well as the relationship existing between these components and the changes in the endogenous $A B A$ accumulation during these processes, the expression of the ABA-signalosome components has been investigated in 'Navelate' orange and its ABA-deficient mutant 'Pinalate' fruits during different developmental stages. Moreover, expression analysis of the ABA signalling core elements was performed in detached leaves from both cultivars subjected to dehydration. This has allowed a comparative analysis between fruit and vegetative tissue, providing further insights into the role of the different ABAsignalosome genes, and has helped to decipher whether the key genes in this system are common or tissue specific. 


\section{MATERIALS AND METHODS}

\section{Plant material and colour measurement}

Fruits of 'Navelate' (Citrus sinensis L. Osbeck) orange and its spontaneous ABA-deficient mutant 'Pinalate' were randomly harvested at 6 different ripening stages from adult trees grown at 'The Spanish Citrus Germoplasm Bank' at the Instituto Valenciano de Investigaciones Agrarias (Moncada, Valencia, Spain), and immediately delivered to the laboratory. The trees were the same age, grown in the same experimental orchard and subjected to the same standard cultural practices. The six sampling periods were chosen attending to previous reports describing colour evolution in citrus fruit during ripening (Rodrigo et al., 2004) and were defined as: Immature Green, IG; Mature Green I, MI; Mature Green II, MII; Breaker, Bk; Coloured, C; and Full Coloured, FC. Thus, fruits of both cultivars were hand harvested the same day and their colour was measured (Table S1) using a Minolta CR-330 on three locations around the equatorial plane of the fruit and expressed as the $a / b$ Hunter ratio (Stewart and Wheaton, 1972), which is classically used for colour measurement in citrus fruit. This ratio is negative for green fruit and positive for orange fruit, while zero value corresponds to yellow fruit at the midpoint of colour break period. Flavedo (outer coloured part of the peel) tissue samples were collected from the total surface of fruits, frozen and homogenized to a fine powder in liquid nitrogen, and kept at $-80 \stackrel{\circ}{\circ}$ for later analysis. Three biological replicates of 5 fruits each were collected at each sampling period.

In addition, water stress experiments in vegetative tissue were carried out in detached mature leaves. To that end, leaves were collected, weighed, and allowed to dehydrate in storage chambers under continuous light at 22 o $\mathrm{C}$. Control non-stressed leaves were kept in the chambers at 90\% RH with petioles in distilled water whereas stressed leaves were dehydrated by placing them on filter 
paper at $50-55 \% \mathrm{RH}$. The weight of the leaves was monitored periodically and tissue was collected after 0.5, 1, 3, 6 and $24 \mathrm{~h}$. Three biological replicates of four leaves were used for each time period. Leaves were frozen in liquid nitrogen, ground to a fine powder, and stored at $-80 \cong \mathrm{C}$ until analysis.

\section{RNA isolation and qRT-PCR analysis}

Total RNA was extracted from frozen flavedo and leaf samples by a modified method of that previously described by Rodrigo et al (2004) and Ballester et al (2006), as reported in Romero et al. (2012). Total RNA was treated with Ribonuclease-free DNase (Applied Biosystems) following the manufacturer's instructions. Thereafter, the amount of RNA was measured by spectrophotometric analysis and its quality was verified by agarose gel electrophoresis and ethidium-bromide staining. Reverse transcription followed by quantitative polymerase chain reaction analysis (qRT-PCR) was performed as described previously by Romero et al. (2012) to examine time-course gene expression patterns along fruit ripening and leaf dehydration. Briefly, a two-step qRT-PCR assay was designed as suggested by Udvardi et al. (2008). The cDNAs from all biological replicates were synthesized from $2 \mu \mathrm{g}$ of total RNA by using SuperScript III RT (Invitrogen) in presence of Oligo(dT) 20-mer (Invitrogen) and Ribonuclease Inhibitor (Invitrogen) according to manufacturer's instructions. Gene-specific primers were designed using DNAMAN 4.03 software (Lynnon BioSoft) and incubated, in a LightCycler 480 Instrument (Roche Diagnostics), with the cDNA samples and LightCycler 480 SYBR Green I Master (Roche Diagnostics) at

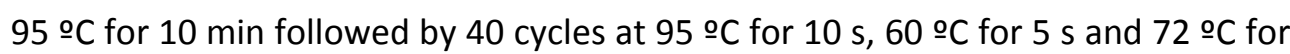
$10 \mathrm{~s}$. Forward (F) and reverse ( $R$ ) sequences for specific primers and the amplicon size for each gene are shown in Table S2. The occurrence of non-specific amplified products was ruled out after performing a melting curve analysis and sequencing 
the reaction products. Fluorescent intensity measurements were transformed into relative mRNA levels by using standard curves constructed for all studied genes. Reference genes CSACT, CSGAPDH and CSTUB (Table S2), whose constitutive expression along fruit ripening was confirmed by using geNorm program (Vandesompele et al., 2002), were used for data normalization. Statistical analysis (Pair Wise Fixed Reallocation Randomisation Test) was carried out by $\Delta \Delta C$ t method using the Relative Expression Software Tool (REST, http://rest.gene-quantification.info) (Pfaffl, 2001). Validation experiments were performed previously to ensure that the efficiency of target and housekeeping genes were relatively equivalent. Relative expression levels for all flavedo samples were referred to that obtained in MI 'Navelate' fruits and those of vegetative samples were relative to that found in FH 'Navelate' leaves. In addition, in order to compare absolute gene expression values, amplicons of each gene were cloned in pGEMT vector (Promega) and used to generate standard curves by serial dilutions. Data were then normalized by using the housekeeping genes previously mentioned. Three biological samples for each sampling period, tissue and variety were analyzed in duplicate and mean ratios were calculated.

\section{Statistical design}

Results are the means of three replicate samples \pm SE. A mean comparison using the Tukey's test was performed to determine if means values were significantly different $(P \leq 0.05)$.

\section{ABA analysis}

The ABA was extracted from $1 \mathrm{~g}$ fresh weight (FW) frozen flavedo and leaves with $80 \%$ acetone containing $0.5 \mathrm{~g} \mathrm{I}^{-1}$ citric acid and $100 \mathrm{mg} \mathrm{I}^{-1}$ of butylated hydroxytoluene as previously described by Lafuente et al. (1997). After 
centrifugation the supernatant was diluted in 3 serial dilutions in ice-cold TBS (6.05 $\mathrm{g}_{\text {Tris I }}{ }^{-1}, 8.8 \mathrm{~g} \mathrm{l}^{-1} \mathrm{NaCl}$ and $0.2 \mathrm{mg} \mathrm{l}^{-1} \mathrm{MgCl}_{2}$ at $\mathrm{pH} 7.8$ ) and 3 samples for each dilution were analyzed by the indirect ELISA reported by Walker-Simmons (1987). The ABA-BSA-(4, conjugate) was synthesized as previously reported by Weiler (1980) with some modifications (Norman et al., 1988). The results are the means of 3 biological replicates of 5 fruit each \pm SE.

\section{Sequence analyses, alignment and phylogenetics}

Sequence similarity comparisons between Arabidopsis thaliana and Citrus sinensis proteins were performed by BLASTP in the Phytozome v7.0 database (www.phytozome.org; www.citrusgenomedb.org). Search for amino acids sequences of Arabidopsis PYR/PYL/RCAR, PP2CA and SnRK2 proteins were carried out using the National Centre for Biotechnology Information (NCBI). Motive prediction was performed using whole protein sequences as input into the PSIPRED secondary structure prediction server. Tertiary structure of CSPYR1, CSPYL2, CSPYL5, CSPYL8, CSABI1 and CsSnRK2.6 proteins were modelled by using ITasser program (Roy et al., 2010), in which their corresponding Arabidopsis homologous crystallographic structures from PDB database (3K90, 3KL1, 3QRZ, $3 \cup Q H, 3 U J K$ and $3 U D B$, respectively) were used as templates. Multiple sequence alignments of PYR/PYL/RCAR, PP2CA and SnRK2 proteins were performed by using the default settings of the CLUSTALX 2.0 software and manually edited in GENEDOC (http://www.nrbsc.org/gfx/genedoc/). Based on these alignments, phylogenetic trees were constructed according to the neighbour-joining method using the PhyloWidget program. The reliability of the trees was established by conducting a 1000 bootstrap re-sampling. 


\section{RESULTS}

\section{The PYR/PYL/RCAR family in Citrus sinensis}

Genes encoding ABA receptors of Arabidopsis thaliana were used as query to identify the orthologous proteins from Citrus sinensis. In the orange genome, only 6 proteins with homology to the 14 Arabidopsis PYR/PYL/RCAR proteins were found (Table 1). The genes AtPYR1 and AtPYL1 shared homology to the same orange locus (orange1.1g046151m) and showed a 74 and $73 \%$ of identity, respectively, in 175 amino acid residues, which correspond to the $84 \%$ of the protein length. Likewise, AtPYL2 and AtPYL3 shared homology to the orange $1.1 \mathrm{~g} 046697 \mathrm{~m}$ locus and showed a 72 and $66 \%$ of identity, covering the 90 and $93 \%$ of the protein stretch, respectively. On the other hand, AtPYL4 and AtPYL6 were homologous to the protein encoded by the Citrus gene orange $1.1 \mathrm{~g} 026007 \mathrm{~m}$ and showed a 78 and $62 \%$ identity, respectively. The orange1.1g038201m locus was the most similar to the AtPYL5, AtPYL11, AtPYL12 and AtPYL13 genes and displayed a 70, 62, 62 and 56\% identity at the protein level, respectively. Genes AtPYL8 and AtPYL10 showed homology to orange 1.1 g028067m (75 and 74\% identity in 183 and 158 amino acid residues, respectively) and AtPYL7 and AtPYL9 to orange1.1g043944m (79 and 86\% identity, respectively). Attending to their highest identity with Arabidopsis proteins, Citrus genes were named CSPYR1, CSPYL2, CSPYL4, CSPYL5, CSPYL8 and CSPYL9, respectively (Table 1 ). The analysis of the genomic structure of all Citrus PYR/PYL/RCAR genes revealed that only CSPYL8 and CSPYL9 genes showed predicted introns. This is in concordance with the fact that only Arabidopsis AtPYL7, AtPYL8, AtPYL9 and AtPYL10 contained putative intron regions. The intron number of CSPYL8 and CSPYL9 was also coincident with the Arabidopsis homologous genes (Table 1 ). 
Table 1. Comparison of $P Y R / P Y L / R C A R$, clade-A PP2CS and subclass III SnRK2s genes between Arabidopsis thaliana and Citrus sinensis

\begin{tabular}{|c|c|c|c|c|c|c|c|c|c|c|}
\hline \multicolumn{4}{|c|}{ Arabidopsis thaliana } & \multicolumn{7}{|c|}{ Citrus sinensis } \\
\hline \multirow[b]{2}{*}{ Gene } & \multirow[b]{2}{*}{ Code } & \multirow[b]{2}{*}{ Introns } & \multirow[b]{2}{*}{$\begin{array}{l}\text { Amino } \\
\text { acids }\end{array}$} & \multirow[b]{2}{*}{$\begin{array}{l}\text { Citrus } \\
\text { gene }\end{array}$} & \multirow[b]{2}{*}{ Genome code } & \multirow[b]{2}{*}{ Introns } & \multirow[b]{2}{*}{$\begin{array}{l}\text { Amino } \\
\text { acids }\end{array}$} & \multicolumn{3}{|c|}{ Comparison with A. thaliana } \\
\hline & & & & & & & & $\begin{array}{c}\text { Most } \\
\text { similar }\end{array}$ & Identity & $\begin{array}{l}\text { match / } \\
\text { aligned }\end{array}$ \\
\hline AtPYR1 & AT4G17870 & 0 & 191 & CSPYR1 & orange1.1g046151m & 0 & 209 & PYR1 & $74.0 \%$ & $130 / 175$ \\
\hline AtPYL1 & AT5G46790 & 0 & 221 & & orange1.1g046151m & & & & & \\
\hline AtPYL2 & AT2G26040 & 0 & 190 & CsPYL2 & orange1.1g046697m & 0 & 187 & PYL2 & $72.0 \%$ & $121 / 168$ \\
\hline AtPYL3 & AT1G73000 & 0 & 209 & & orange1.1g046697m & & & & & \\
\hline AtPYL4 & AT2G38310 & 0 & 207 & CsPYL4 & orange $1.1 \mathrm{~g} 026007 \mathrm{~m}$ & 0 & 245 & PYL4 & $78.0 \%$ & $136 / 174$ \\
\hline AtPYL5 & AT5G05440 & 0 & 203 & CsPYL5 & orange1.1g038201m & 0 & 201 & PYL5 & $70.0 \%$ & $111 / 158$ \\
\hline AtPYL6 & AT2G40330 & 0 & 215 & & orange1.1g026007m & & & & & \\
\hline AtPYL7 & AT4G01026 & 2 & 211 & & orange1.1g043944m & & & & & \\
\hline AtPYL8 & AT5G53160 & 2 & 188 & CSPYL8 & orange1.1g028067m & 2 & 214 & PYL8 & $75.0 \%$ & $137 / 183$ \\
\hline AtPYL9 & AT1G01360 & 2 & 187 & CSPYLO & orange1.1g043944m & 2 & 186 & PYL9 & $86.0 \%$ & $143 / 167$ \\
\hline AtPYL10 & AT4G27920 & 2 & 183 & & orange1.1g028067m & & & & & \\
\hline AtPYL11 & AT5G45860 & 0 & 161 & & orange1.1g038201m & & & & & \\
\hline AtPYL12 & AT5G45870 & 0 & 159 & & orange $1.1 \mathrm{~g} 038201 \mathrm{~m}$ & & & & & \\
\hline AtPYL13 & AT4G18620 & 0 & 164 & & orange $1.1 \mathrm{~g} 038201 \mathrm{~m}$ & & & & & \\
\hline AtABI1 & AT4G26080 & 3 & 434 & CsABI1 & orange1.1g008880m & 4 & 550 & ABI1 & $68.0 \%$ & 227 / 391 \\
\hline$A t A B I 2$ & AT5G57050 & 3 & 383 & & orange1.1g008880m & & & & & \\
\hline AtAHG1 & AT5G51760 & 3 & 416 & CSAHG1 & orange1.1g013591m & 3 & 440 & AHG1 & $40.0 \%$ & $170 / 424$ \\
\hline AtAHG3 & АТЗG11410 & 3 & 399 & CSAHG3 & orange1.1g015135m & 2 & 412 & AHG3 & $66.0 \%$ & $258 / 390$ \\
\hline AtHAB1 & AT1G72770 & 4 & 406 & CsHAB1 & orange1.1g009083m & 4 & 544 & HAB1 & $57.0 \%$ & $206 / 362$ \\
\hline AtHAB2 & AT1G17550 & 3 & 511 & & orange1.1g009083m & & & & & \\
\hline AtHAl1 & AT5G59220 & 3 & 413 & & orange $1.1 \mathrm{~g} 036852 \mathrm{~m}$ & & & & & \\
\hline AtHAI2 & AT1G07430 & 2 & 442 & & orange1.1g036852m & & & & & \\
\hline AtHAl3 & AT2G29380 & 2 & 362 & CsHAI3 & orange1.1g036852m & 3 & 408 & HAl3 & $64.0 \%$ & $223 / 348$ \\
\hline AtSnRK2.2 & AT3G50500 & 8 & 369 & CsSnRK2.2 & orange1.1g017860m & 8 & 365 & SnRK2.2 & $82.0 \%$ & $297 / 362$ \\
\hline AtSnRK2.3 & AT5G66880 & 8 & 361 & & orange1.1g017936m & & & & & \\
\hline AtSnRK2.6 & AT4G33950 & 9 & 362 & CsSnRK2.6 & orange1.1g017936m & 8 & 363 & SnRK2.6 & $88.9 \%$ & $317 / 352$ \\
\hline
\end{tabular}

In order to assess the conservation degree of the ABA receptors in Citrus, amino acid sequences were aligned and the START-like domain was compared. Sequences were, in general, highly conserved between proteins of both species (Fig. S1A). The latch and gate loops of Citrus proteins were identical to those described in Arabidopsis and the functional sites for ABA-binding and PP2Cs interaction were also perfectly conserved in all Citrus proteins. No important differences between Citrus ABA-binding regions and those of the Arabidopsis were found, with the exception of an insert of 17 amino acids inside the ABAbinding region 2 of CSPYL8 protein. Furthermore, the alignment of the predicted secondary structure of AtPYR1 with the Citrus sequences showed that most of the 
elements described in this protein matched with the highly conserved regions of the Citrus homologous. High similarity in the number and location of $\alpha$-helices and strands conforming $\beta$-sheets was also found between all Citrus PYR/PYL/RCAR proteins and their Arabidopsis homologous (data not shown). In addition, predicted tertiary structure of CSPYR1, CSPYL2, CsPYL5 and CsPYL8 showed that 2 helical segments and 7 strands forming a $\beta$-sheet conformed a cavity for ligand binding highly similar to that found in their respective Arabidopsis homologous (Fig. S2A-D). Phylogenetic analysis further showed that the Citrus ABA receptors were distributed along the three main subfamilies proposed by Ma et al. (2009) in Arabidopsis, and 2 representative Citrus proteins were included in each subfamily (Fig. 1A): CsPYL8 and CsPYL9 belong to subfamily I, CsPYL4 and CsPYL5 to subfamily II, and CSPYR1 and CSPYL2 to subfamily III. In addition, similarity matrix of deduced amino acid sequences confirmed that proteins clustered into the same subfamily shared the highest percentage of similarity among Citrus proteins (Table S3).

\section{Family of clade-A PP2C proteins in Citrus sinensis}

In the Citrus sinensis genome 5 proteins were identified with significant homology to the 9 members of the clade-A PP2C family of Arabidopsis (Table 1). The Citrus gene orange1.1g008880m was the most similar to both components of the ABA-insensitive (ABI) subfamily PP2Cs, AtABI1 and AtABI2. Nevertheless, since AtABI1 showed higher identity (68\%) than AtABI2 (58\%) to the Citrus protein, the gene was named $C S A B I 1$. The members of the ABA-hypersensitive germination (AHG) subfamily, AtAHG1 and AtAHG3, showed homology (40 and 66\% identity, respectively) to different loci of the Citrus genome, which were named CSAHG1 (orange1.1g013591m) and CSAHG3 (orange1.1g015135m), respectively. Both components of the Arabidopsis homologous to $A B I$ subfamily, also named 
hypersensitive to $A B A,(A t H A B 1$ and $A t H A B 2)$ shared homology to the same Citrus locus (orange1.1g009083m) and showed very similar percentage of identity (57 and 55\%, respectively); therefore the Citrus gene was named CsHAB1.

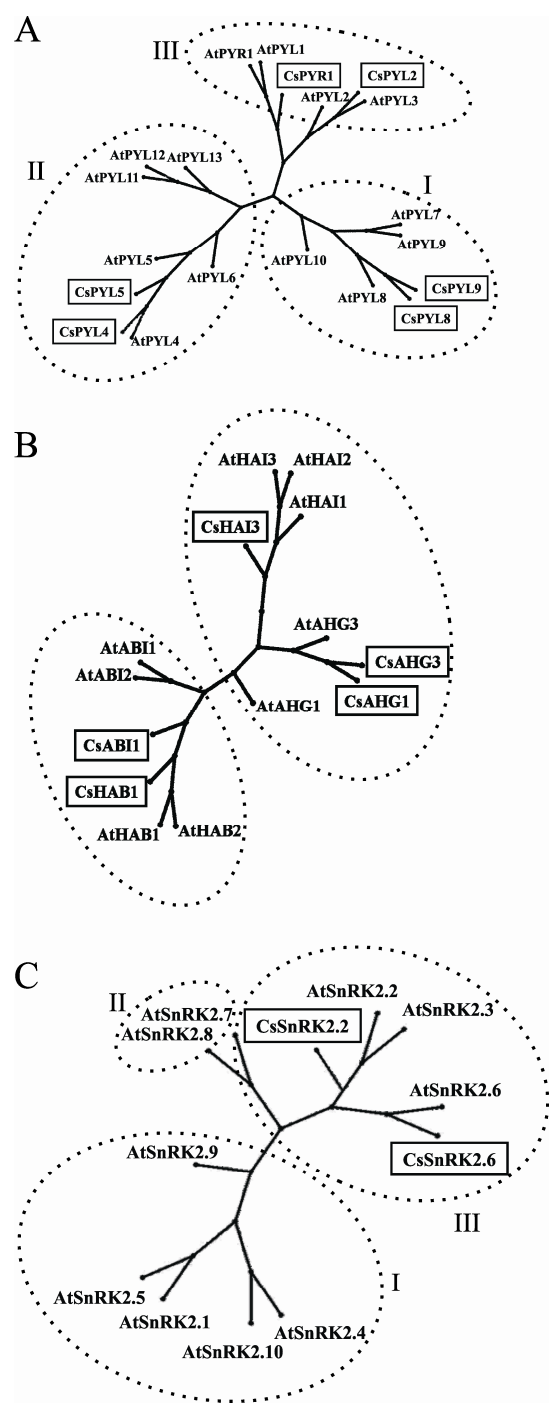

Figure 1. Unrooted phylogenetic trees containing Citrus sinensis and Arabidopsis thaliana PYR/PYL/RCAR ABA receptors (A), clade-A PP2CS (B) and SnRK2s protein kinases (C) obtained by using the neighbour-joining method in PhyloWidget software and based on the protein sequence alignments. The full name for each protein is detailed in Table 1. 
Likewise, the 3 members of the Arabidopsis highly ABA-induced (HAl) PP2CA subfamily (AtHAI1, AtHAI2 and AtHAI3) shared homology to the same locus of Citrus sinensis and displayed a 62, 57 and 64\% of identity, respectively, to the protein encoded by orange1.1g036852m, which consequently was named CsHAI3.

It is interesting to note that all genes of the clade-A PP2C from both Arabidopsis and Citrus contained introns although the intron number for most of the genes was different between species (Table 1). Concerning to the protein alignments, the PP2C-like domain was highly conserved through all proteins sequences although the length of all Citrus PP2CAs proteins was longer than the Arabidopsis homologous (Fig. S1B). Metal binding sites described in Arabidopsis were also identified in Citrus proteins and phosphatase activity regulatory sequences were identical for all proteins analyzed. The predicted secondary structure of AtABI1 matched with the most conserved regions of the alignment. Secondary structures were also predicted for the Citrus clade-A PP2Cs and similar sizes and location of the different motifs were observed when compared each protein with its Arabidopsis homologous (data not shown). Predicted tertiary structure of CSABI1 was performed by using the crystallographic structure of AtABI1 as template, and revealed a high similarity degree in protein folding between species (Fig. S2E). In addition, the phylogenetic tree performed with Arabidopsis and Citrus PP2CAs showed that Citrus proteins fitted into the two groups described by Schweighofer et al. (2004) for these Arabidopsis proteins (Fig. 1B). Accordingly, the highest percentages of similarity among Citrus proteins sequences were found between CsABI1 and CsHAB1, and among CsAHG1, CsAHG3 and CsHAI3 proteins (Table S4). Furthermore, representative genes of each group were identified and, as expected, each Citrus protein was clustered nearby to its corresponding Arabidopsis homologous. 


\section{The ABA-related subclass III SnRK2 proteins in Citrus}

Among sucrose non-fermenting related protein kinases 2 (SnRK2s) of Arabidopsis, the proteins belonging to the subclass III, SnRK2.2, SnRK2.3 and SnRK2.6, have been related to ABA signalling. A BLAST search in Citrus sinensis genome revealed that 2 different loci (orange1.1g017860m and orange1.1g017936m) shared homology with these ABA-related SnRK2s (Table 1). The protein encoded by the gene orange $1.1 \mathrm{~g} 017936 \mathrm{~m}$ showed its highest identity (90\%) to AtSnRK2.6, whereas orange1.1g017860m protein showed $82 \%$ of identity to AtSnRK2.2. Therefore, these Citrus genes were named CsSnRK2.6 and CsSnRK2.2, respectively. Gene structure analysis revealed that the number of introns in CSSnRK2.6 and CSSnRK2.2 genes was very similar to that found in their Arabidopsis homologous. Amino acid alignment of the Arabidopsis subclass III SnRK2s and their corresponding Citrus homologous showed a highly conserved kinase domain between both species (Fig. S1C). Furthermore, ATP binding and the activation loop regions as well as the ATP binding and the proton acceptor active sites were identical. By contrast, osmotic stress and ABA-responsive domains were less conserved, even among Arabidopsis proteins. The secondary structure predicted for AtSnRK2.6 showed that $\alpha$-helices and $\beta$-strands matched with the most conserved regions in the protein alignment (Fig. S1C). Additionally, the secondary structure predicted for CsSnRK2.2 revealed a high consensus in the number and location of the putative functional motifs when compared with its respective homologous (data not shown). Likewise, tertiary structure of CsSnRK2.6 was predicted by using crystallographic structure of AtSnRK2.6 as template, and protein folding was highly conserved between species (Fig. S2F). Phylogenetic analysis further revealed that Arabidopsis ABA-related SnRK2s proteins (AtSnRK2.2, AtSnRK2.3 and AtSnRK2.6) grouped in an independent branch (subclass III) to the other proteins belonging to this family, and the Citrus 
homologous (CsSnRK2.6 and CsSnRK2.2) were also clustered into this group (Fig. 1C). It should be also mentioned that these Citrus proteins displayed a high percentage ( $82 \%)$ of similarity when their sequences were compared (Table S5).

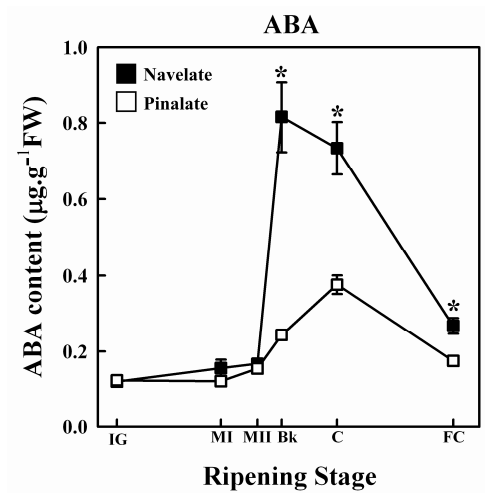

Figure 2. ABA content in the flavedo of 'Navelate' (black) and 'Pinalate' (white) fruit during development and ripening (Immature Green, IG; Mature Green I, MI; Mature Green II, MII; Breaker Bk; Coloured, C; Full Coloured, FC). Results are the means of three biological replicates of 5 fruits each \pm SE. Significant differences $(p \leq 0.05)$ in ABA content between 'Navelate' and 'Pinalate' flavedo samples for the same maturity stage are indicated by an asterisk.

\section{Transcriptional regulation of PYR/PYL/RCAR, PP2CA and subclass III SnRK2 genes} during orange fruit development and ripening: influence of endogenous $A B A$ levels.

In order to investigate the regulation of the $A B A$ signalling core during citrus fruit development and ripening, and its relationship with endogenous $A B A$ levels, the expression analysis of the 6 Citrus $P Y R / P Y L / R C A R, 5$ clade-A PP2C and 2 SnRK2 genes was carried out together with the ABA measurement in the flavedo of fruits of 'Navelate' and its ABA-deficient mutant 'Pinalate'.

Six ripening stages were selected covering from IG to FC fruits. As expected, no difference in ABA content between 'Navelate' and the 'Pinalate' mutant was found while the fruits remained green (IG, MI and MII stages) while the differences between parental and mutant fruit increased thereafter with fruit 
ripening (Fig. 2). The flavedo of parental fruits reached the highest $A B A$ levels at Bk stage and the ABA content in the mutant was more than 3-fold lower. The ABA levels in 'Pinalate' fruit peaked at the $C$ stage but the concentration was half of that reached in the parental fruits at the same ripening stage. In the flavedo of FC fruits from both varieties an important decrease in ABA content was observed, but levels in the parental fruit remained higher than in the mutant (Fig. 2).

In spite of the differential ABA accumulation in 'Navelate' and 'Pinalate' flavedo during ripening, only minor differences were observed in the expression pattern of most of the PYR/PYL/RCAR genes between both cultivars (Fig. $3 \mathrm{~A}$ ) and only remarkable differences were observed in the expression profile of CSPYR1. In parental fruit, CSPYR1 transcript levels fluctuated during ripening, reaching a maximum at $\mathrm{MII}$ and a minimum at Bk and $\mathrm{C}$ stages, and increased again at FC stage to levels similar to IG. In the mutant fruit, the maximum expression levels of the CSPYR1 were found at the IG and FC stages, reaching levels almost 2-fold higher than in 'Navelate'. Nevertheless, the CSPYR1 transcript level and profile of mutant fruit was similar to that of the parental at intermediate ripening fruit stages ( $\mathrm{MI}, \mathrm{MII}, \mathrm{Bk}$ and $\mathrm{C}$ ) and showed a minimum at $\mathrm{C}$ stage (Fig. $3 \mathrm{~A}$ ). The evolution of CSPYL4 and CSPYL5 transcripts was similar to that described above since the expression of both genes peaked at MII stage in 'Navelate' and 'Pinalate' fruit, decreased dramatically to minimum levels at Bk and C stages, respectively, and then increased again to higher levels at FC stage. It should be mentioned that the repression of $C S P Y L 4$ at Bk was 2-fold higher in the ABA-deficient mutant. 

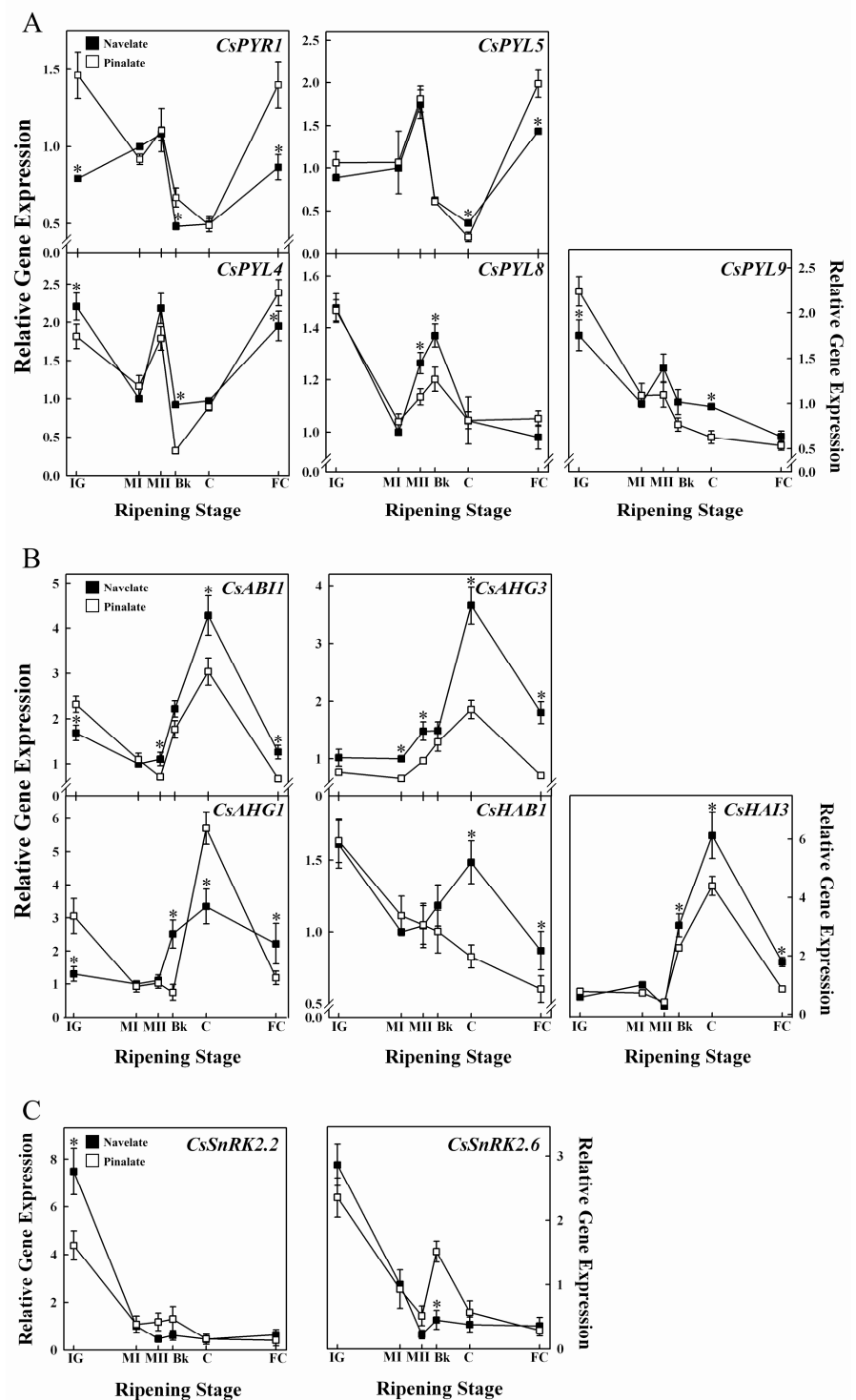

Figure 3. Relative gene expression analysis by qRT-PCR of Citrus PYR/PYL/RCAR ABA receptors (A), clade-A PP2Cs (B) and subclass III SnRK2s (C) in 'Navelate' (black) and 'Pinalate' (white) fruits during fruit development and ripening (Immature Green, IG; Mature Green I, MI; Mature Green II, MII; Breaker, Bk; Coloured, C; Full Coloured, FC). Expression values are relative to transcript levels obtained in MI 'Navelate' fruits. Values are mean ratios \pm SE from three biological samples for each sampling period and variety analyzed in duplicate. Significant differences $(P \leq 0.05)$ in gene expression between 'Navelate' and 'Pinalate' flavedo samples for the same maturity stage are indicated by an asterisk. 
Overall, in spite of the differences observed between varieties, CSPYR1, CSPYL4 and CSPYL5 genes showed a consistent pattern in which the minimum transcript levels were coincident with the highest ABA levels. On the other hand, CSPYL8 and CSPYL9 genes displayed the maximum expression at the IG stage. A transient increase in the CSPYL8 expression levels occurred at the Bk stage, which was higher in 'Navelate' fruit, and accumulation of CSPYL8 and CSPYL9 decreased to reach minimum levels at FC stage (Fig 3A). Moreover, absolute gene expression analysis further revealed similar levels of CSPYL4 and CSPYL5 transcripts, whereas the most expressed gene during fruit development and ripening was CSPYL9. It is also interesting that expression of CSPYR1 and CSPYL8 genes remained at very low levels and CSPYL2 was not detected in any of the fruit samples analyzed (Table S6).

The analysis of the Citrus clade-A PP2C genes revealed a differential regulation between both varieties. Although CSABI1, CSAHG3 and CSHAI3 transcripts accumulation followed a similar pattern peaking at $C$ stage in both 'Navelate' and 'Pinalate' fruit, the relative expression levels reached by the parental fruit were higher than those reached by the ABA-deficient mutant (Fig. 3B). Interestingly, CSAHG1 showed a similar expression profile to that described above for Citrus PP2CAs genes, but the transcript levels at the $\mathrm{C}$ stage were 2 -fold higher in 'Pinalate' than in 'Navelate'. On the other hand, CsHAB1 was the only PP2CA gene whose expression decreased continuously in 'Pinalate' during fruit ripening while in 'Navelate' displayed a transient increase at C stage. In general, the highest expression levels of the Citrus PP2CA genes were observed at the $C$ stage (Fig. 3B and Table S6), concurring with higher levels of ABA in both varieties. Interestingly, CSHAB1 showed the highest transcript accumulation in both varieties at the beginning of the experiment, followed by CSAHG3 and CSHAI3. However, only in 'Navelate fruit, transcript levels of CSAHG3 at C stage almost 
doubled that of CsHAB1 and CsHAI3, and showed more than 14-fold accumulation than the other genes of this family (Table S6).

Transcriptional analysis of Citrus SnRK2s revealed similar expression patterns between CsSnRK2.2 and CsSnRK2.6 genes, although the CsSnRK2.6 transcript accumulation was at least 8-fold higher than that of CsSnRK2.2 (Table S6).The highest transcript levels were found at the IG stage in fruits of both cultivars and decreased thereafter as ripening progressed (Fig. 3C). Differences between cultivars in CsSnRK2.2 transcript accumulation were found at the IG stage, in which parental fruit showed 2-fold higher levels than the mutant. In contrast, similar relative transcript levels were found in CsSnRK2.6 at this stage, although gene expression peaked at Bk stage in 'Pinalate' fruit but not in 'Navelate' (Fig. 3C). It should be mentioned that the expression level of these genes bottomed out in both varieties at MII stage, which was concomitant with the inductions in several $P Y R / P Y L / R C A R$ genes.

\section{Water stress-induced changes in ABA content and transcriptional regulation of}

\section{ABA-signalosome components in leaves}

The evolution of ABA content and weight loss in 'Pinalate' and 'Navelate' leaves during the course of a water stress experiment was very similar for both genotypes. The ABA content increased about 20 -fold in response to water stress by $24 \mathrm{~h}$ (Fig. 4), whereas a minor increase was observed in detached control leaves of both genotypes. Significant differences in ABA content between dehydrated and control leaves were observed after $6 \mathrm{~h}$. Differences in weight loss between control and dehydrated leaves were observed from the beginning of the experiment $(0.5 \mathrm{~h})$. Therefore, the rise in weight loss preceded that of $A B A$ and significant increases in $A B A$ in response to dehydration only occurred when the leaves reached a $10 \%$ of weight loss (Fig. 4). 


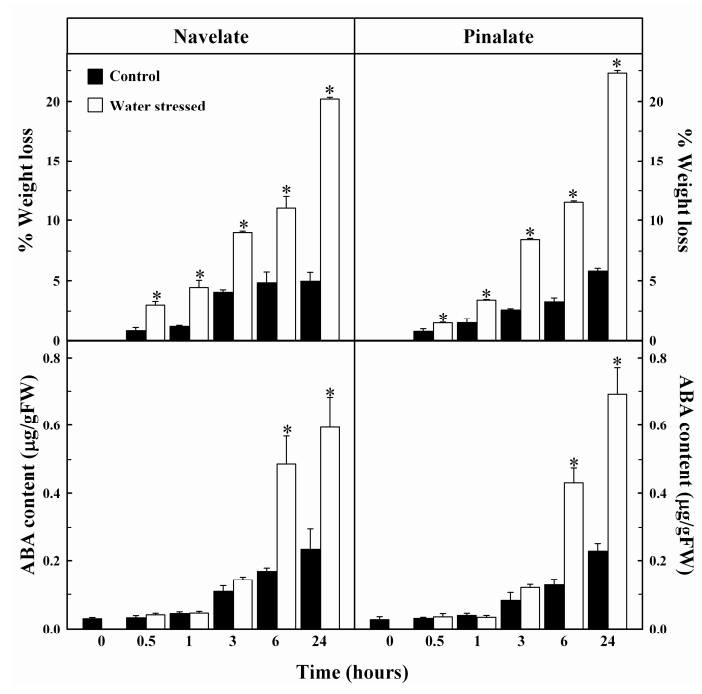

Figure 4. Effect of water stress on weight loss and ABA content in 'Navelate' and 'Pinalate' detached leaves. Changes in control samples are represented as black bars and in water-stressed leaves as white bars. Results are the means of three biological replicates of 4 leaves each \pm SE. Significant differences $(P \leq 0.05)$ in weight loss and ABA content between samples for the same analyzed period are indicated by an asterisk.

The accumulation of CSPYR1 increased in both 'Pinalate' and 'Navelate' leaves after detachment but no significant differences were found between control and water-stressed leaves until the end of the experiment (24 h) (Fig. 5). The most important increase occurred by $6 \mathrm{~h}$ and a 3 - and a 5 -fold increases were found in 'Navelate' and 'Pinalate' leaves, respectively. Thereafter, the expression level remained almost constant in the control leaves but significantly decreased in water-stressed 'Pinalate' and 'Navelate' samples (Fig. 5). Contrary to that found in flavedo samples, CSPYL2 expression was detected in leaves and results showed that this gene was down-regulated by water stress. 


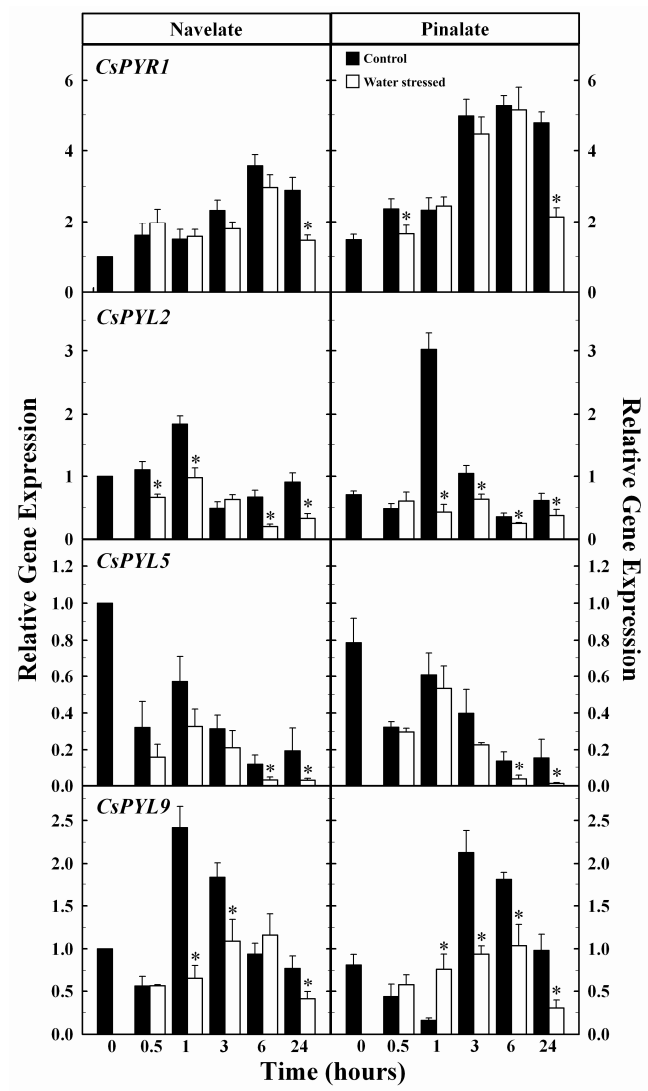

Figure 5. Relative gene expression analysis by qRT-PCR of Citrus $P Y R / P Y L / R C A R$ ABA receptors in control (black) and water-stressed (white) 'Navelate' and 'Pinalate' leaves. Results are the means of three biological replicates of 4 leaves each \pm SE. Significant differences $(P \leq 0.05)$ in gene expression between samples for the same analyzed period are indicated by an asterisk.

The CSPYL5 relative gene expression decreased rapidly $(0.5 \mathrm{~h})$ after leaf detachment and significant differences between control and water-stressed leaves were only found by 6 and $24 \mathrm{~h}$. On the other hand, CSPYL9 gene expression sharply increased and reached a maximum by 1 and $3 \mathrm{~h}$ in control 'Navelate' and 'Pinalate' leaves, respectively. The transcripts level of this gene was, in general, lower in water-stressed leaves and changes were less relevant. Moreover, CSPYL4 and CSPYL8 transcripts were not detected in fresh, detached or water-stressed 
'Pinalate' and 'Navelate' leaves. Interestingly, absolute expression showed that CSPYL2 and CSPYL9 were the most highly expressed genes in leaves, whereas CSPYR1 and CSPYL5 transcript accumulation remained at very low levels during the whole experiment (Table S6).

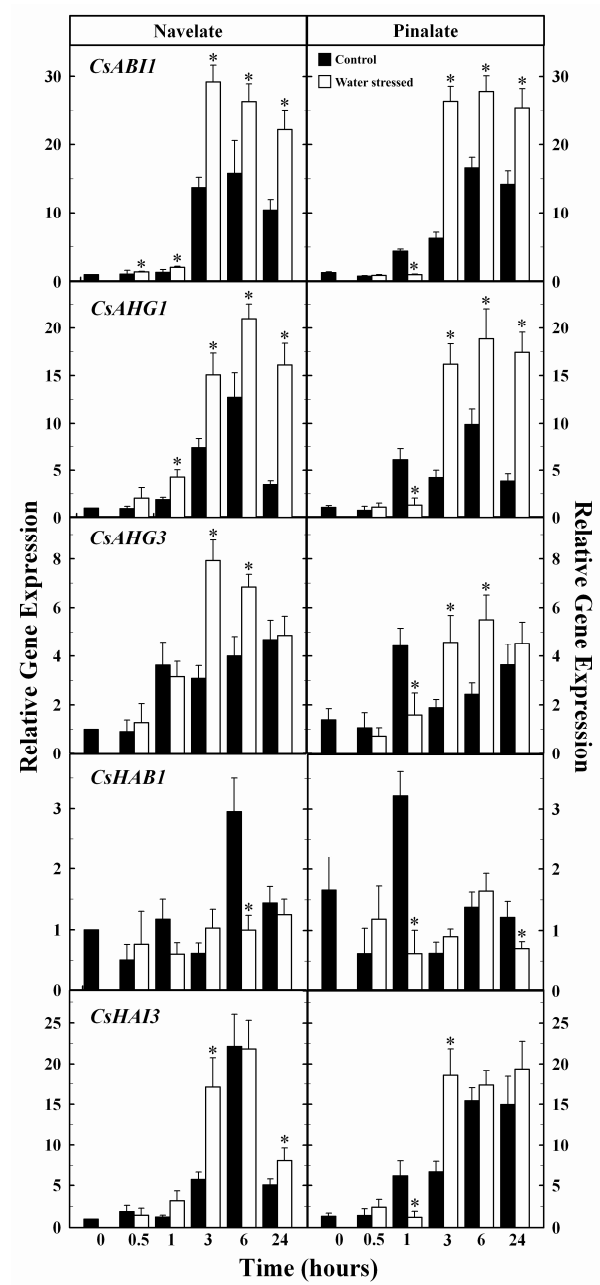

Figure 6. Relative gene expression analysis by qRT-PCR of Citrus clade-A PP2Cs in control (black) and water-stressed (white) 'Navelate' and 'Pinalate' leaves. Results are the means of three biological replicates of 4 leaves each \pm SE. Significant differences $(P \leq 0.05)$ in gene expression between samples for the same analyzed period are indicated by an asterisk. 
The expression of the CsPP2CAs genes increased after detachment in both control and stressed 'Navelate' and 'Pinalate' leaves but such increases were, in general, substantially higher in the water-stressed leaves (Fig. 6) As shown in Fig. 6 , dehydration had an important impact up-regulating the expression of both CSABI1 and CSAHG1 genes, which reached maximum levels by $3 \mathrm{~h}$ in waterstressed leaves. The effect of dehydration on CSAHG3 gene expression was also evident and important differences between control and stressed leaves were found by 3 and $6 \mathrm{~h}$ after detachment. Contrary, dehydration had little effect on CsHAB1 and CsHAI3 transcript levels. Absolute gene expression analysis revealed that CSHAB1 was the most expressed CSPP2CA in FH leaves followed by CSAHG3, CSHAI3 and CSABI1. In contrast, the most expressed genes during dehydration of 'Navelate' and 'Pinalate' leaves were CSAHG3, CsHAI3 and CSABI1 (Table S6). As occurred in fruit, CSAHG1 transcript accumulation remained at much lower levels in both varieties.

The CsSnRK2.2 gene showed a different gene expression profile in dehydrated and control leaves (Fig. 7). Transcript level of this gene transiently peaked by $0.5 \mathrm{~h}$ in 'Navelate' and 'Pinalate' water-stressed leaves, whereas the expression continuously increased from 0 to $3 \mathrm{~h}$ in the control leaves. Interestingly, CsSnRK2.2 expression was similar in control and stressed 'Navelate' and 'Pinalate' leaves by $6 \mathrm{~h}$ but transcript accumulation was higher in leaves of the mutant at the end of the experiment. The CsSnRK2.6 expression pattern barely differed between control and dehydrated leaves and was very similar in 'Navelate' and 'Pinalate'. The transcript levels of this gene continuously increased after detachment and reached a maximum by $3 \mathrm{~h}$ in 'Pinalate' and by $6 \mathrm{~h}$ in 'Navelate' leaves. It is also interesting to note that absolute gene expression of CsSnRK2.6 was substantially higher than that of CsSnRK2.2 gene along the whole experiment in both varieties (Table S6). 


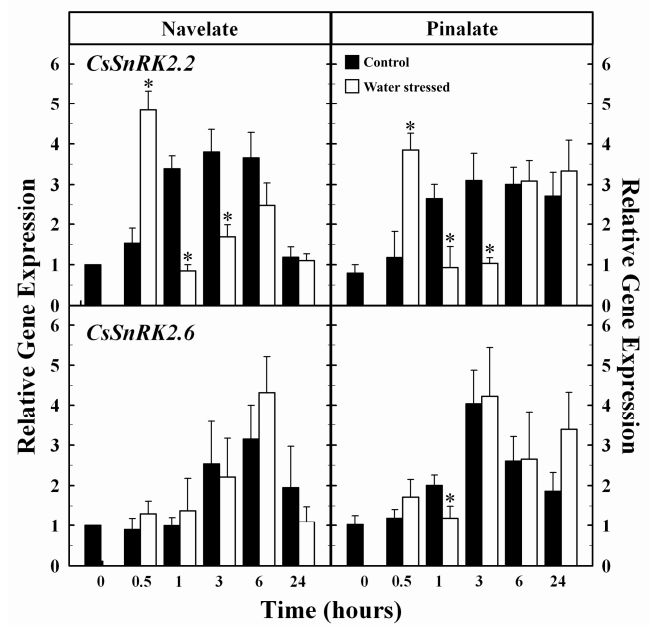

Figure 7. Relative gene expression analysis by qRT-PCR of Citrus subclass III SnRK2s in control (black) and water-stressed (white) 'Navelate' and 'Pinalate' leaves. Results are the means of three biological replicates of 4 leaves each \pm SE. Significant differences $(P \leq 0.05)$ in gene expression between samples for the same analyzed period are indicated by an asterisk. 


\section{DISCUSSION}

The homologous genes of the ABA-signalosome have been identified in this work for the first time in the Citrus genome in order to explore the relationship existing between the regulation of these components and the changes in the endogenous $A B A$ levels occurring in citrus fruit during natural fruit ripening and in dehydrated leaves. A comparative transcriptional analysis of these genes has been performed between 'Navelate' orange fruit and its spontaneous fruit-specific ABA-deficient mutant 'Pinalate'. In this context, it is noteworthy that the link between $A B A$ and the ripening process has been reported in nonclimacteric fruits like strawberry (Chai et al., 2011), grapevine (Giribaldi et al., 2010), sweet cherry (Ren et al., 2011) and citrus (Lafuente et al., 1997; Alférez and Zacarías, 1999; Rodrigo et al., 2003; Gambetta et al., 2011), although the molecular mechanism of how ABA regulates this process has not been fully established.

In silico analysis of sweet orange (Citrus sinensis) genome database has revealed that proteins belonging to the ABA-signalosome were less represented in Citrus as compared to Arabidopsis. Only 6 PYR/PYL/RCAR, 5 PP2CA and 2 subclass III SnRK2 genes were found in Citrus (Table 1) while in Arabidopsis it is composed by 14 PYR/PYL/RCAR ABA receptors, 9 clade-A PP2Cs and several protein kinases, including 3 of the subclass III SnRK2 (Merlot et al., 2001; Yoshida et al., 2002; Yoshida et al., 2006a; Park et al., 2009; Ma et al., 2009). This is in concordance with the lower number of $P Y R / P Y L / R C A R$ and PP2CA genes recently identified in tomato (Sun et al., 2011) and in strawberry (Chai et al., 2011). High percentages of identity were observed between Citrus proteins and their homologous in Arabidopsis, as well as similar protein length and genetic structures (Table 1 and Table S3-S5). Interestingly, the consensus motifs for functional protein folding, such as gate and latch regions in PYR/PYL/RCARs (Melcher et al., 2009) (Fig. S1A 
and Fig. S2), and for phosphatase activity in PP2CAs (Weiner et al., 2010) (sequences underlined in Fig. S1B) were identified in Citrus. D-rich C-terminal domain II, which has been shown to be essential for ABA signal transduction (Yoshida et al., 2006a), was also fully conserved in Citrus SnRK2s proteins (number 4 in Fig. S1C). Phylogenetic analysis revealed that Citrus PYR/PYL/RCAR were clustered together with their homologous accordingly with the distribution proposed by Ma et al. (2009), in which Arabidopsis ABA receptors were divided in three main subfamilies. In fact, two representative genes of each group were identified in the Citrus genome (Fig. 1A). The Citrus clade-A PP2Cs were clustered close to their respective homologous (Fig. 1B) and arranged in two separated branches as previously described by Schweighofer et al. (2004) in the phylogenetic analysis of Arabidopsis PP2Cs. Furthermore the two Citrus kinases, CsSnRK2.2 and CsSnRK2.6, were classified into the subclass III of AtSnRK2s (Fig. 1C), whose components have been related to ABA signalling (Fujii and Zhu, 2009). Therefore, the sweet orange proteins encoded by CSPYR/PYL/RCAR, CSPP2CA and CsSnRK2 genes identified in this work might function as the core elements of the $A B A$ perception and signalling pathway.

The comparative transcriptional analysis between wild-type 'Navelate' fruit and its ABA-deficient mutant 'Pinalate' revealed that no important differences in most of the CSPYR/PYL/RCAR expression profiles, although transcript level of CSPYR1 in IG and FC fruits was different between genotypes. This result suggests that the expression of this gene family might be developmentally regulated in Citrus and that changes in ABA content found in 'Pinalate' fruit during ripening may be sufficient for regulating CSPYR/PYL/RCAR gene expression. Indeed, the expression profiles of CSPYR1, CSPYL4 and CSPYL5 suggest the involvement of $A B A$ in their regulation since the lowest transcript levels of these genes were concomitant with the highest ABA levels in 'Navelate' 
and 'Pinalate' fruits, whereas their expressions peaked before the ABA rise (Fig. 2 and Fig. 3A). This result is in agreement with that found in sweet cherry showing the concomitant down-regulation of the plastid $A B A$ receptor magnesium chelatase $(\mathrm{CHLH})$ and the increment in endogenous $\mathrm{ABA}$ during fruit ripening (Ren et al., 2011). Overall, these results suggest that the reduction in ABA receptors gene expression may be concomitant with the rise in $A B A$ during non-climacteric fruit ripening. In this context, it should be pointed out that gene expression of PYR/PYL/RCARs is differentially affected by ABA-treatment in seedlings of Arabidopsis (Santiago et al., 2009b; Szostkiewicz et al., 2010), and that the accumulation of $P Y R / P Y L / R C A R$ transcripts may also parallel the increase in $A B A$ during ripening of strawberry and tomato fruits (Chai et al., 2011; Sun et al., 2011). In this work, 3 different expression patterns were observed among PYR/PYL/RCARs: A first set of genes (CSPYR1, CSPYL4 and CSPYL5) showed their minimum transcript levels when the highest $A B A$ content was detected in the flavedo of 'Navelate' and 'Pinalate' fruits. Although their expression patterns were similar, transcript accumulation of CSPYR1 was much lower than that of CSPYL4 and CSPYL5 genes, which showed similar values (Table S6). Secondly, CSPYL8 transcript level peaked when ABA rose during fruit ripening and, finally, CSPYL9 continuously decreased as ripening progressed, although it slightly increased before the increment in ABA in both varieties (Fig. 3A). Interestingly, genes whose changes in expression did not mirror ABA accumulation during ripening (CSPYL8 and CSPYL9) were clustered into the subfamily I (Fig. 1A). In this context, it is interesting to note that tomato genes belonging to this subfamily (SIPYL1, SIPYL2 and SIPYL3) have been related to ABA changes during fruit development and ripening (Sun et al., 2011), and functional activity for AtPYL8 and AtPYL9 proteins has been demonstrated by Ma et al (2009) in vegetative tissues. It is noteworthy, however, that ABA-binding region of CSPYL8 showed an insert of 17 amino acids, 
which is not present either in Arabidopsis or in tomato sequences and might affect the ability of this protein to bind the hormone (Fig. S1A). In addition, CSPYL8 transcript levels were much lower than that of $C S P Y L 9$, which showed the highest transcript accumulation among CSPYR/PYL/RCAR genes (Table S6). It is also interesting that the expression of $C S P Y L 2$ gene was not detected in fruits of both cultivars during ripening, which suggests that the expression of some $A B A$ receptors could be tissue-specific in Citrus. In agreement, some tomato genes such as SIPYL5, belonging to the same subfamily that CSPYL2 (subfamily III, Fig. $1 \mathrm{~A})$, were almost undetectable during fruit ripening (Sun et al., 2011). Therefore, gene expression levels pointed out the relevance of CSPYL4, CSPYL5 and CSPYL9 genes in the $A B A$ perception during fruit development and ripening.

Clade-A PP2Cs function as negative regulators of the ABA signalling pathway and their expressions are highly induced by $\mathrm{ABA}$ in plants (Merlot et al., 2001; Saez et al., 2004; Yoshida et al., 2006b; Xue et al., 2008; Li et al., 2009). Within this context, a transcriptional negative feedback regulatory mechanism has been proposed for modulating the ABA responses (Merlot et al., 2001; Melcher et al., 2009; Vlad et al., 2009; Santiago et al., 2009b; Weiner et al., 2010). Thus, the

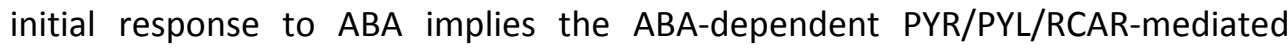
inactivation of PP2CAs, which allows the release of SnRKs and hence the phosphorylation of ABA-dependent transcription factors or other proteins. This ABA signal is later attenuated by the up-regulation of PP2CA and the downregulation of $P Y R / P Y L / R C A R$ genes in an ABA-dependent manner. Thus, the resetting of the $A B A$ transduction pathway offers a dynamic mechanism to modulate the ABA response (Santiago et al., 2009b). The expression pattern of the CSPP2CAs analyzed in this work mostly paralleled the ABA accumulation in 'Navelate' and 'Pinalate' fruit during ripening (Fig. 2 and Fig.3B) and, interestingly, the CSPP2CAs up-regulation was also concomitant with the down-regulation of 
the CSPYL4 and CSPYL5 genes (Fig. 3A). Therefore, these results suggest that a transcriptional negative feedback regulatory mechanism might be modulating the ABA responses during Citrus fruit ripening. In tomato, however, only SIPP2C1 and SIPP2C5 transcripts peaked with the increment in ABA occurring during fruit ripening, while any of the SIPYR/PYL/RCAR genes analyzed were negatively related to the accumulation of those SIPP2CS (Sun et al., 2011). Therefore, it would be interesting to further investigate the functionality of these proteins through protein-protein interactions, which would help to unravel the involvement of these subfamilies in ABA perception in Citrus.

The availability of the fruit-specific ABA-deficient mutant 'Pinalate' has allowed analyzing the relationship between the expression of the CSPP2CAs and the endogenous $A B A$ accumulation along Citrus fruit ripening. Gene expression levels of CSABI1, CSAHG3 and CSHAI3 peaked at C stage in both 'Navelate' and 'Pinalate' fruit but transcript accumulation was always higher in parental fruit. Likewise, CsHAB1 transcript levels peaked in 'Navelate' at C stage, although continuously decreased in the ABA-deficient mutant fruit (Fig. 3B). These results, together with the fact that gene expression of CSAHG3 and CsHAI3 increased from 3 to 10 -fold (Fig. 3B and Table S6), suggest an important effect of ABA content on the CSPP2CA gene expression. In agreement with this idea and with the lower differences found between cultivars in the CSPYR/PYL/RCAR transcriptional levels, Szostkiewicz et al. (2010) reported that PP2CAs were more responsive to ABA compared to ABA receptors and suggested a higher sensitivity of these negative regulators to ABA changes. Unexpectedly, although CSAHG1 showed an expression pattern similar to the other CsPP2CAs, the transcript level at $C$ stage was two-fold higher in the ABA-deficient mutant whereas the ABA content in 'Navelate' doubled that of 'Pinalate' (Fig. 2 and Fig. 3B). The increased expression of this negative regulator supports previous molecular data suggesting the 
impaired response of this mutant to $A B A$ treatments and dehydration (Romero et al., 2012). Moreover, the expression of well-known ABA-dependent genes is also strongly reduced in the mutant fruit during ripening (Fig. S3), which further supports the idea of a reduced sensitivity of 'Pinalate' fruit to ABA.

It is well known that the release of SnRK2s by PP2CAs after ABA binding to PYR/PYL/RCARs allows these positive effectors to phosphorylate downstream transcription factors and proteins involved in the ABA response (Umezawa et al., 2009; Vlad et al., 2009; Hirayama and Umezawa, 2010). Results obtained in the present work revealed that both CSSnRK2.2 and CSSnRK2.6 genes reached their highest transcript levels at the most immature stages, when the minimum $A B A$ content was detected in both cultivars (Fig. 2 and Fig. 3C), although transcript accumulation of CSSnRK2.6 gene was much higher than that of CsSnRK2.2 in both varieties along fruit ripening (Table S6). As ripening progressed, however, CSSnRK2.2 remained almost unchanged in 'Navelate' and 'Pinalate' fruits whereas CsSnRK2.6 showed a transient increase at Bk stage only in the mutant fruit. Similar expression patterns were found in the climacteric tomato fruit. During ripening of tomato, SnRKs expression levels were high in the most immature stages and transiently increased with the rise in ABA (Sun et al., 2011). In spite of differences found in CsSnRK2.6 transcript levels between 'Navelate' and 'Pinalate' fruits, overall results suggest that the relationship between endogenous $A B A$ content and the transcriptional regulation of these components of the ABA-signalosome during Citrus fruit ripening is less relevant than that occurring for the CSPP2CAs.

In order to get further insights on the role of the ABA-signalosome components and to understand whether the key genes are common or tissuespecific in Citrus, the expression analysis of these elements has been also performed in leaves exposed to dehydration. As indicated above, the deficiency in $A B A$ of 'Pinalate' is fruit-specific and, consequently, we did not find relevant 
differences in ABA content or weight loss between 'Navelate' and 'Pinalate' leaves. Since leaves are very prone to dehydration, special attention was paid to minimize water loss in control leaves. Under the experimental conditions used, water loss was always lower than $5 \%$ and 4 -fold lower than in the water-stressed leaves. Thus, changes observed in ABA levels can be related to changes in weight loss. The attenuated expression profiles of some of the studied genes in control leaves suggest that the response of vegetative tissue to dehydration may depend on the severity of the stress imposed.

Gene expression changes of the three core components of the ABAsignalosome in dehydrated leaves (Fig. 5, 6 and 7) were similar to those found in Arabidopsis (Santiago et al., 2009; Szostkiewicz et al., 2009). Overall, transcriptional profiling of these genes suggested that $A B A$ increases caused by dehydration up-regulate the levels of all CSPP2CA and down-regulate some PYR/PYL/RCAR and SnRK2 family members, such as CSPYL2, CSPYL5, CSPYL9 and CsSnRK2.2, whereas the relative levels of other members of these families, such as CSPYR1 and CsSnRK2.6, remain fairly constant. Nevertheless, it is interesting to note that CSPYL2 and CSPYL9 were the most expressed genes in control and dehydrated leaves, suggesting that $C S P Y L 2$ might play a key role in ABA responses in leaves but not in fruit while CSPYL9 could be relevant in both vegetative and reproductive tissues (Table S6). Therefore, results obtained in leaf are complementary to those found in reproductive tissue. The high transcript accumulation of CSPYL9 was down-regulated as ABA increased during both fruit ripening and leaf dehydration. Likewise, CSPYR1 and CSPYL5 gene expression bottomed down when highest ABA levels were achieved during fruit ripening and leaf dehydration, although transcript accumulation of CSPYL5 in fruit was much higher than in vegetative tissue suggesting a minor role of this gene in leaves (Table S6). Moreover, the expression profile of these genes did not mirror that of 
ABA accumulation during leaves dehydration as occurred during fruit ripening. This differential regulation under physiological or stress conditions may provide a mean for the plant to cope with sustained high levels of $A B A$ or to adjust the sensitivity of $A B A$ perception and signalling. It is interesting to mention that some common responses in the ABA-signalosome were observed between fruit and leaf tissues such as the high sensitivity of the CSPP2CAs components to ABA changes and CSSnRK2.6 as the major subclass III SnRK2 expressed gene. Moreover, in both tissues CSPYR1 transcript accumulation was very low as compared to the other CSPYR/PYL/RCAR genes and CSPYL9 was highly expressed. Comparison between fruit and vegetative tissue has also revealed some tissue specificity: CSPYL2 gene was highly expressed in leaves but no expression was detected in fruit, whereas CSPYL4 and CSPYL8 transcripts were detected during fruit development but not in leaves subjected or not to water stress.

In summary, this work reports for the first time the identification of $A B A$ signalling core components in Citrus comprising 6 PYR/PYL/RCAR ABA receptors, 5 PP2CAs and 2 subclass III SnRK2s. During sweet orange fruit development and ripening the expression pattern of some $A B A$ receptors mirrored $A B A$ content whereas CSPP2CAs paralleled the hormone accumulation, modulating together $A B A$ perception, downstream signalling and, consequently, physiological $A B A$ responses. Additionally, transcriptional analysis performed in water-stressed leaves revealed that some members of the PYR/PYL/RCAR family are tissue specific and that sensitivity to ABA changes in the PP2CAs, negative regulators of the $A B A$ signal transduction pathway, was much higher than in other components of the ABA-signalosome. 


\section{REFERENCES}

Agustí J, Zapater M, Iglesias DJ, Cercós M, Tadeo FR, Talón M. 2007. Differential expression of putative 9-cis-epoxycarotenoid dioxygenases and abscisic acid accumulation in water stressed vegetative and reproductive tissues of citrus. Plant Science 172, 85-94.

Alférez F, Zacarías L. 1999. Interaction between ethylene and abscisic acid in the regulation of citrus fruit maturation. In: Kanellis AK, Chang $C$, Klee $H$, Blecker AB, Pech JC, Grierson D, eds. Biology and biotechnology of the plant hormone ethylene II, Amsterdam: Kluwer Academic Publishers, pp. 183-184.

Antoni R, Rodríguez L, González-Guzman M, Pizzio GA, Rodríguez PL. 2011. News on ABA transport, protein degradation, and ABFs/WRKYs in ABA signaling. Current Opinion in Plant Biology 14, 547-553.

Armstrong F, Leung J, Grabov A, Brearley J, Giraudat J, Blatt MR. 1995. Sensitivity to abscisic acid of guard-cell $\mathrm{K}^{+}$channels is suppressed by abi1-1, a mutant Arabidopsis gene encoding a putative protein phosphatase. Proceedings of the National Academy of Sciences of the United States of America 92, 9520-9524.

Ballester AR, Lafuente MT, González-Candelas L. 2006. Spatial study of antioxidant enzymes, peroxidase and phenylalanine ammonia-lyase in the citrus fruit-Penicillium digitatum interaction. Postharvest Biology and Technology 39, 115-124.

Bartels D, Sunkar R. 2005. Drought and salt tolerance in plants. Critical Reviews in Plant Sciences 24, 23-58.

Bastías A, López-Climent M, Valcárcel M, Rosello S, Gómez-Cadenas A, Casaretto JA. 2011. Modulation of organic acids and sugar content in tomato fruits by an abscisic acidregulated transcription factor. Physiologia Plantarum 141, 215-226.

Chai YM, Jia HF, Li CL, Dong QH, Shen YY. 2011. FaPYR1 is involved in strawberry fruit ripening. Journal of Experimental Botany 62, 5079-5089.

Finkelstein R, Gampala SL, Rock CD. 2002. Abscisic acid signaling in seeds and seedlings. The Plant Cell 14, S15-S45.

Fujii H, Zhu JK. 2009. Arabidopsis mutant deficient in 3 abscisic acid-activated protein kinases reveals critical roles in growth, reproduction, and stress. Proceedings of the National Academy of Sciences 106, 8380-8385. 
Galpaz N, Wang Q, Menda N, Zamir D, Hirschberg J. 2008. Abscisic acid deficiency in the tomato mutant high-pigment 3 leading to increased plastid number and higher fruit lycopene content. The Plant Journal 53, 717-730.

Gambetta G, Martínez-Fuentes A, Bentancur O, Mesejo C, Reig C, Gravina A, Agustí M. 2011. Hormonal and nutritional changes in the flavedo regulating rind color development in sweet orange (Citrus sinensis (L.) Osb.). Journal of Plant Growth Regulation 31, 273-282.

Giribaldi M, Gény L, Delrot S, Schubert A. 2010. Proteomic analysis of the effects of ABA treatments on ripening Vitis vinifera berries. Journal of Experimental Botany 61, 24472458.

Gómez-Cadenas A, Arbona V, Jacas J, Primo-Millo E, Talon M. 2002. Abscisic acid reduces leaf abscission and increases salt tolerance in citrus plants. Journal of Plant Growth Regulation 21, 234-240.

Gosti F, Beaudoin N, Serizet C, Webb AAR, Vartanian N, Giraudat J. 1999. ABI1 protein phosphatase $2 \mathrm{C}$ is a negative regulator of abscisic acid signaling. The Plant Cell Online 11, 1897-1910.

Groot SPC, Karssen CM. 1992. Dormancy and germination of abscisic acid-deficient tomato seeds: Studies with the sitiens mutant. Plant Physiology 99, 952-958.

Hirayama T, Umezawa T. 2010. The PP2C-SnRK2 complex: The central regulator of an abscisic acid signaling pathway. Plant Signaling \& Behavior 5, 160-163.

Huai J, Wang M, He J, et al. 2008. Cloning and characterization of the SnRK2 gene family from Zea mays. Plant Cell Reports 27, 1861-1868.

Jia HF, Chai YM, Li CL, Lu D, Luo JJ, Qin L, Shen YY. 2011. Abscisic acid plays an important role in the regulation of strawberry fruit ripening. Plant Physiology 157, 188-199.

Kang J, Hwang JU, Lee M, Kim YY, Assmann SM, Martinoia E, Lee Y. 2010. PDR-type ABC transporter mediates cellular uptake of the phytohormone abscisic acid. Proceedings of the National Academy of Sciences 107, 2355-2360.

Karssen CM, Brinkhorst-van der Swan DLC, Breekland AE, Koornneef M. 1983. Induction of dormancy during seed development by endogenous abscisic acid: studies on abscisic acid deficient genotypes of Arabidopsis thaliana (L.) Heynh. Planta 157, 158-165. 
Kim H, Hwang $\mathbf{H}$, Hong JW, et al. 2012. A rice orthologue of the ABA receptor, OsPYL/RCAR5, is a positive regulator of the ABA signal transduction pathway in seed germination and early seedling growth. Journal of Experimental Botany 63, 1013-1024.

Klingler JP, Batelli G, Zhu JK. 2010. ABA receptors: the START of a new paradigm in phytohormone signalling. Journal of Experimental Botany 61, 3199-3210.

Koornneef M, Alonso-Blanco C, Vreugdenhil D. 2004. Naturally occurring genetic variation in Arabidopsis thaliana. Annual Review of Plant Biology 55, 141-172.

Kuromori T, Miyaji T, Yabuuchi H, et al. 2010. ABC transporter AtABCG25 is involved in abscisic acid transport and responses. Proceedings of the National Academy of Sciences 107, 2361-2366.

Lafuente MT, Martínez-Téllez MA, Zacarías L. 1997. Abscisic acid in the response of 'Fortune' mandarins to chilling. Effect of maturity and high-temperature conditioning. Journal of the Science of Food Agriculture 73, 494-502.

Li FH, Fu FL, Sha LN, He L, Li WC. 2009. Differential expression of serine/threonine protein phosphatase type-2C under drought stress in maize. Plant Molecular Biology Reporter 27, 29-37.

Li G, Xin H, Zheng XF, Li S, Hu Z. 2012. Identification of the abscisic acid receptor VvPYL1 in Vitis vinifera. Plant Biology 14, 244-248.

Ma Y, Szostkiewicz I, Korte A, Moes D, Yang Y, Alexander C, Grill E. 2009. Regulators of PP2C phosphatase activity function as abscisic acid sensors. Science 324, 1064-1068.

Melcher K, Ng LM, Zhou XE, et al. 2009. A gate-latch-lock mechanism for hormone signalling by abscisic acid receptors. Nature 462, 602-608.

Merlot S, Gosti F, Guerrier D, Vavasseur A, Giraudat J. 2001. The ABI1 and ABI2 protein phosphatases $2 \mathrm{C}$ act in a negative feedback regulatory loop of the abscisic acid signalling pathway. The Plant Journal 25, 295-303.

Nambara E, Marion-Poll A. 2005. Abscisic acid biosynthesis and catabolism. Annual Review of Plant Biology 56, 165-185.

Nishimura N, Sarkeshik A, Nito K, et al. 2010. PYR/PYL/RCAR family members are major in-vivo ABI1 protein phosphatase 2C-interacting proteins in Arabidopsis. The Plant Journal 61, 290-299. 
Norman SM, Poling SM, Maier VP. 1988. An indirect enzyme-linked immunosorbent assay for (+)-abscisic acid in Citrus, Ricinus, and Xanthium leaves. Journal of Agricultural and Food Chemistry 36, 225-231.

Park SY, Fung P, Nishimura N, et al. 2009. Abscisic acid inhibits type 2C protein phosphatases via the PYR/PYL family of START proteins. Science 324, 1068-1071.

Peña-Cortés H, Sánchez-Serrano JJ, Mertens R, Willmitzer L, Prat S. 1989. Abscisic acid is involved in the wound-induced expression of the proteinase inhibitor II gene in potato and tomato. Proceedings of the National Academy of Sciences of the United States of America 86, 9851-9855.

Pfaffl MW. 2001. A new mathematical model for relative quantification in real-time RTPCR. Nucleic Acids Research 29, e45.

Ren J, Sun L, Wang C, Zhao S, Leng P. 2011. Expression analysis of the cDNA for magnesium chelatase $\mathrm{H}$ subunit $(\mathrm{CHLH})$ during sweet cherry fruit ripening and under stress conditions. Plant Growth Regulation 63, 301-307.

Rodrigo MJ, Alquézar B, Zacarías L. 2006. Cloning and characterization of two 9-cisepoxycarotenoid dioxygenase genes, differentially regulated during fruit maturation and under stress conditions, from orange (Citrus sinensis L. Osbeck). Journal of Experimental Botany 57, 633-643.

Rodrigo MJ, Marcos JF, Alférez F, Mallent MD, Zacarías L. 2003. Characterization of 'Pinalate', a novel Citrus sinensis mutant with a fruit-specific alteration that results in yellow pigmentation and decreased ABA content. Journal of Experimental Botany 54, 727 738.

Rodrigo MJ, Marcos JF, Zacarías L. 2004. Biochemical and molecular analysis of carotenoid biosynthesis in flavedo of orange (Citrus sinensis L.) during fruit development and maturation. Journal of Agricultural and Food Chemistry 52, 6724-6731.

Romero P, Rodrigo MJ, Alférez F, Ballester AR, González-Candelas L, Zacarías L, Lafuente MT. 2012. Unravelling molecular responses to moderate dehydration in harvested fruit of sweet orange (Citrus sinensis L. Osbeck) using a fruit-specific ABA-deficient mutant. Journal of Experimental Botany 63, 2753-2767.

Roy A, Kucukural A, Zhang Y. 2010. I-TASSER: a unified platform for automated protein structure and function prediction. Nature Protocols 5, 725-738. 
Saez A, Apostolova N, González-Guzman M, González-García MP, Nicolas C, Lorenzo O, Rodríguez PL. 2004. Gain-of-function and loss-of-function phenotypes of the protein phosphatase 2C HAB1 reveal its role as a negative regulator of abscisic acid signalling. The Plant Journal 37, 354-369.

Santiago J, Dupeux F, Round A, et al. 2009a. The abscisic acid receptor PYR1 in complex with abscisic acid. Nature 462, 665-668.

Santiago J, Rodrigues A, Saez A, et al. 2009b. Modulation of drought resistance by the abscisic acid receptor PYL5 through inhibition of clade A PP2Cs. The Plant Journal 60, 575578.

Schwartz SH, Tan BC, Gage DA, Zeevaart JAD, McCarty DR. 1997. Specific oxidative cleavage of carotenoids by VP14 of maize. Science 276, 1872-1874.

Schweighofer A, Hirt H, Meskiene I. 2004. Plant PP2C phosphatases: emerging functions in stress signaling. Trends in Plant Science 9, 236-243.

Shinozaki K, Yamaguchi-Shinozaki K. 2007. Gene networks involved in drought stress response and tolerance. Journal of Experimental Botany 58, 221-227.

Stewart I, Wheaton TA. 1972. Carotenoids in citrus: their accumulation induced by ethylene. Journal of Agricultural and Food Chemistry 20, 448-449.

Sun L, Sun YF, Zhang M, et al. 2012. Suppression of 9-cis-epoxycarotenoid dioxygenase (NCED), which encodes a key enzyme in abscisic acid biosynthesis, alters fruit texture in transgenic tomatoes. Plant Physiology 158, 283-298.

Sun L, Wang YP, Chen P, et al. 2011. Transcriptional regulation of SIPYL, SIPP2C, and SISnRK2 gene families encoding ABA signal core components during tomato fruit development and drought stress. Journal of Experimental Botany 62, 5659-5669

Sun L, Zhang M, Ren J, Qi J, Zhang G, Leng P. 2010. Reciprocity between abscisic acid and ethylene at the onset of berry ripening and after harvest. BMC Plant Biology 10, 257.

Szostkiewicz I, Richter K, Kepka M, et al. 2010. Closely related receptor complexes differ in their ABA selectivity and sensitivity. The Plant Journal 61, 25-35.

Ton J, Flors V, Mauch-Mani B. 2009. The multifaceted role of ABA in disease resistance. Trends in Plant Science 14, 310-317. 
Udvardi MK, Czechowski T, Scheible WR. 2008. Eleven golden rules of quantitative RTPCR. The Plant Cell 20, 1736-1737.

Umezawa T, Nakashima K, Miyakawa T, Kuromori T, Tanokura M, Shinozaki K, Yamaguchi-Shinozaki K. 2010. Molecular basis of the core regulatory network in ABA responses: Sensing, signaling and transport. Plant and Cell Physiology 51, 1821-1839.

Umezawa T, Sugiyama N, Mizoguchi M, et al. 2009. Type 2C protein phosphatases directly regulate abscisic acid-activated protein kinases in Arabidopsis. Proceedings of the National Academy of Sciences 106, 17588-17593.

Vandesompele J, de Preter K, Pattyn F, Poppe B, Van Roy N, de Paepe A, Speleman F. 2002. Accurate normalization of real-time quantitative RT-PCR data by geometric averaging of multiple internal control genes. Genome Biology 3, research0034research0034.11.

Verslues PE, Zhu JK. 2007. New developments in abscisic acid perception and metabolism. Current Opinion in Plant Biology 10, 447-452.

Vlad F, Rubio S, Rodrigues A, et al. 2009. Protein phosphatases $2 \mathrm{C}$ regulate the activation of the Snf1-Related Kinase OST1 by abscisic acid in Arabidopsis. The Plant Cell 21, 31703184.

Walker-Simmons M. 1987. ABA levels and sensitivity in developing wheat embryos of sprouting resistant and susceptible cultivars. Plant Physiology 84, 61-66.

Weiler EW. 1980. Radioimmunoassays for the differential and direct analysis of free and conjugated abscisic acid in plant extracts. Planta 148, 262-272.

Weiner JJ, Peterson FC, Volkman BF, Cutler SR. 2010. Structural and functional insights into core ABA signaling. Current Opinion in Plant Biology 13, 495-502.

Xue T, Wang D, Zhang S, et al. 2008. Genome-wide and expression analysis of protein phosphatase $2 C$ in rice and Arabidopsis. BMC Genomics 9, 550.

Yoshida R, Hobo T, Ichimura K, et al. 2002. ABA-activated SnRK2 protein kinase is required for dehydration stress signaling in Arabidopsis. Plant and Cell Physiology 43, 1473-1483.

Yoshida R, Umezawa T, Mizoguchi T, Takahashi S, Takahashi F, Shinozaki K. 2006a. The regulatory domain of SRK2E/OST1/SnRK2.6 interacts with ABI1 and integrates abscisic acid 
(ABA) and osmotic stress signals controlling stomatal closure in Arabidopsis. Journal of Biological Chemistry 281, 5310-5318.

Yoshida T, Nishimura N, Kitahata N, et al. 2006b. ABA-Hypersensitive Germination3 encodes a protein phosphatase 2C (AtPP2CA) that strongly regulates abscisic acid signaling during germination among Arabidopsis protein phosphatase 2Cs. Plant Physiology 140, 115-126.

Zhang DP, Chen SW, Peng YB, Shen YY. 2001. Abscisic acid-specific binding sites in the flesh of developing apple fruit. Journal of Experimental Botany 52, 2097-2103.

Zhang M, Leng P, Zhang GL, Li XX. 2009a. Cloning and functional analysis of 9-cisepoxycarotenoid dioxygenase (NCED) genes encoding a key enzyme during abscisic acid biosynthesis from peach and grape fruits. Journal of Plant Physiology 166, 1241-1252.

Zhang M, Yuan B, Leng P. 2009b. The role of ABA in triggering ethylene biosynthesis and ripening of tomato fruit. Journal of Experimental Botany 60, 1579-1588. 


\section{SUPPLEMENTARY MATERIAL}

Table S1. Colour evolution of 'Navelate' and 'Pinalate' fruit during ripening.

\begin{tabular}{lccc}
\hline & & \multicolumn{2}{c}{$a / b$ ratio } \\
\cline { 3 - 4 } & Month & Navelate & Pinalate \\
\hline Immature green (IG) & July & $-0.89 \pm 0.01$ & $-0.89 \pm 0.01$ \\
Mature green I (MI) & September & $-0.72 \pm 0.01$ & $-0.72 \pm 0.01$ \\
Mature green II (MII) & October & $-0.41 \pm 0.01$ & $-0.50 \pm 0.01$ \\
Breaker (Bk) & October & $-0.13 \pm 0.01$ & $-0.31 \pm 0.01$ \\
Coloured (C) & November & $0.49 \pm 0.01$ & $0.10 \pm 0.01$ \\
Full coloured (FC) & February & $0.63 \pm 0.01$ & $0.12 \pm 0.01$ \\
\hline Values are mean of three replicates \pm SD. & & \\
\hline
\end{tabular}

Table S2. Primers designed for the ABA-signalling core components gene expression analysis by quantitative RT-PCR (qRT-PCR).

\begin{tabular}{|c|c|c|c|c|}
\hline $\begin{array}{l}\text { Citrus } \\
\text { gene }\end{array}$ & Homologous in A. thaliana & $\begin{array}{l}\text { Forward / } \\
\text { Reverse }\end{array}$ & Sequence $5^{\prime} \rightarrow 3^{\prime}$ & $\begin{array}{l}\text { Amplicon } \\
\text { size (bp) }\end{array}$ \\
\hline CSPYR1 & $\begin{array}{l}\text { AT4G17870; } \\
\text { Pyrabactin Resistance } 1\end{array}$ & $\begin{array}{l}\mathrm{F} \\
\mathrm{R}\end{array}$ & $\begin{array}{l}\text { CCGGGGTAACTCAGGACGAG } \\
\text { CGGAGACGGAACAGCTCTTG }\end{array}$ & 198 \\
\hline CsPYL2 & $\begin{array}{l}\text { AT2G26040; } \\
\text { PYR1-Like protein } 2\end{array}$ & $\begin{array}{l}F \\
R\end{array}$ & $\begin{array}{l}\text { GGCCTATCATCGAAAGATACC } \\
\text { CGATACAACCGTCACTTCTC }\end{array}$ & 209 \\
\hline CsPYL4 & $\begin{array}{l}\text { AT2G38310; } \\
\text { PYR1-Like protein } 4\end{array}$ & $\begin{array}{l}\mathrm{F} \\
\mathrm{R}\end{array}$ & $\begin{array}{l}\text { CGAACGAAGACACCTGCGTG } \\
\text { CGAGAACAGAACATGACCTG }\end{array}$ & 168 \\
\hline CsPYL5 & $\begin{array}{l}\text { AT5G05440; } \\
\text { PYR1-Like protein } 5\end{array}$ & $\begin{array}{l}\mathrm{F} \\
\mathrm{R}\end{array}$ & $\begin{array}{l}\text { GCCCGGCGGTACATCACAAA } \\
\text { GCCCGCAGCTAACAGCACG }\end{array}$ & 184 \\
\hline CsPYL8 & $\begin{array}{l}\text { AT4G27920; } \\
\text { PYR1-Like protein } 8\end{array}$ & $\begin{array}{l}\mathrm{F} \\
\mathrm{R}\end{array}$ & $\begin{array}{l}\text { GCGGTGCATTTTGGACGCTTC } \\
\text { GGCAAAGCCTTAGCAGAATCG }\end{array}$ & 111 \\
\hline CsPYL9 & $\begin{array}{l}\text { AT1G01360; } \\
\text { PYR1-Like protein } 9 \\
\end{array}$ & $\begin{array}{l}\mathrm{F} \\
\mathrm{R}\end{array}$ & $\begin{array}{l}\text { CGGAGATCATCGACGGGAGA } \\
\text { CGGTCCTGCACCGCCATCC }\end{array}$ & 166 \\
\hline CsABI1 & $\begin{array}{l}\text { AT4G26080; } \\
\text { ABA-insensitive } 1\end{array}$ & $\begin{array}{l}\mathrm{F} \\
\mathrm{R}\end{array}$ & $\begin{array}{l}\text { GGTGACTGCAAAAGCACGAT } \\
\text { GGGGCAACAGGTTCACCTCC }\end{array}$ & 129 \\
\hline CSAHG1 & $\begin{array}{l}\text { AT5G51760; } \\
\text { ABA-hypersensitive germination } 1\end{array}$ & $\begin{array}{l}\mathrm{F} \\
\mathrm{R}\end{array}$ & $\begin{array}{l}\text { CGGGTAATGCGAATGCGGG } \\
\text { CCCAACGCTCCCACACGCGCACG }\end{array}$ & 170 \\
\hline CSAHG3 & $\begin{array}{l}\text { AT3G11410; } \\
\text { ABA-hypersensitive germination } 3\end{array}$ & $\begin{array}{l}\mathrm{F} \\
\mathrm{R}\end{array}$ & $\begin{array}{l}\text { GGGATGACTTCAGTTTGCGGTA } \\
\text { CGGAGCTCTTCACTTTAATGGC }\end{array}$ & 227 \\
\hline CsHAB1 & $\begin{array}{l}\text { AT1G72770; } \\
\text { Hypersensitive to ABA } 1\end{array}$ & $\begin{array}{l}\mathrm{F} \\
\mathrm{R}\end{array}$ & $\begin{array}{l}\text { CCGGAGTGTCTTCGAGGTGG } \\
\text { GGCCATTCAAACAGTGGCTC }\end{array}$ & 173 \\
\hline CsHAl3 & $\begin{array}{l}\text { AT5G59220; } \\
\text { Highly ABA-induced } 3\end{array}$ & $\begin{array}{l}\mathrm{F} \\
\mathrm{R} \\
\end{array}$ & $\begin{array}{l}\text { GCCCCTGGCGGCCACTCC } \\
\text { GGCCCACACATATAGAAACC }\end{array}$ & 245 \\
\hline CsSnRK2.2 & $\begin{array}{l}\text { AT3G50500; } \\
\text { SNF1-related protein kinase } 2.2\end{array}$ & $\begin{array}{l}F \\
R\end{array}$ & $\begin{array}{l}\text { CTGTTCCAGACACTAATCCA } \\
\text { GGCTACTCATAGTCTTTTCATCC }\end{array}$ & 165 \\
\hline CsSnRK2.6 & $\begin{array}{l}\text { AT4G33950; } \\
\text { SNF1-related protein kinase } 2.6\end{array}$ & $\begin{array}{l}\mathrm{F} \\
\mathrm{R}\end{array}$ & $\begin{array}{l}\text { GAGCCAAAGAACTTCCGCAA } \\
\text { GGGTTTCGGATCTCGGGTAT }\end{array}$ & 139 \\
\hline CsALDH3 & $\begin{array}{l}\text { AT1G44170; } \\
\text { Aldehyde Dehydrogenase } 3 \mathrm{H} 1\end{array}$ & $\begin{array}{l}F \\
R\end{array}$ & $\begin{array}{l}\text { GGAGTGAGGAGGAGACGAAGA } \\
\text { ACGAAGAGCGTCGACGATGTC }\end{array}$ & 188 \\
\hline CSHVA22E & $\begin{array}{l}\text { AT5G50720; } \\
\text { Abscisic acid induced-like protein }\end{array}$ & $\begin{array}{l}\mathrm{F} \\
\mathrm{R} \\
\end{array}$ & $\begin{array}{l}\text { GCGGCATGGCTGGTTCTGC } \\
\text { GCCTCGTGCTCCCCTTTCTT }\end{array}$ & 178 \\
\hline CSACT & $\begin{array}{l}\text { AT5G09810; } \\
\text { Actin7. Structural constituent }\end{array}$ & $\begin{array}{l}F \\
R\end{array}$ & $\begin{array}{l}\text { TTAACCCCAAGGCCAACAGA } \\
\text { TCCCTCATAGATTGGTACAGTATGAGA }\end{array}$ & 176 \\
\hline CsGAPDH & $\begin{array}{l}\text { AT1G13440; } \\
\text { Glyceraldehyde-3P dehydrogenase }\end{array}$ & $\begin{array}{l}\mathrm{F} \\
\mathrm{R}\end{array}$ & $\begin{array}{l}\text { CGTCCCTCTGCAAGATGACTCT } \\
\text { GGAAGGTCAAGATCGGAATCAA }\end{array}$ & 204 \\
\hline CSTUB & $\begin{array}{l}\text { AT1G75780; } \\
\text { Tubulin1. Structural constituent }\end{array}$ & $\begin{array}{l}\mathrm{F} \\
\mathrm{R}\end{array}$ & $\begin{array}{l}\text { GCATCTTGAACCCGGTAC } \\
\text { ATCAATTCGGCGCCTTCAG }\end{array}$ & 158 \\
\hline
\end{tabular}




\begin{tabular}{|c|c|c|c|c|c|c|c|c|c|c|c|c|c|c|c|c|c|c|c|}
\hline $\begin{array}{l}\frac{8}{2} \\
\frac{0}{6}\end{array}$ & 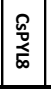 & $\begin{array}{l}0 \\
\frac{\Omega}{9} \\
\xi \\
\vdots\end{array}$ & \begin{tabular}{|l|l} 
\\
$\frac{0}{2}$ \\
$\vdots$ \\
5
\end{tabular} & \begin{tabular}{l}
$\frac{\Omega}{2}$ \\
$\frac{2}{2}$ \\
\multirow{N}{*}{}
\end{tabular} & 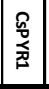 & $\begin{array}{l}\text { 趌 } \\
\text { 章 } \\
\text { W }\end{array}$ & $\begin{array}{l}\text { 蛋 } \\
\text { 紊 } \\
\end{array}$ & 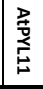 & 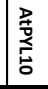 & 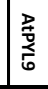 & \begin{tabular}{|l|} 
\\
\\
\multirow{2}{*}{} \\
$\infty$ \\
\end{tabular} & 苞 & 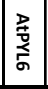 & \begin{tabular}{|l|} 
\\
蛋 \\
ज
\end{tabular} & 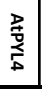 & 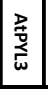 & 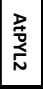 & 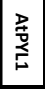 & $\begin{array}{l}\text { 㕝 } \\
\text { 总 } \\
\end{array}$ \\
\hline $\begin{array}{l}\stackrel{\tilde{N}}{\Delta} \\
\dot{\delta}\end{array}$ & \begin{tabular}{|l|}
$\tilde{\circ}$ \\
$\ddot{\circ}$
\end{tabular} & $\begin{array}{l}\mathcal{N} \\
\tilde{b}\end{array}$ & $\mid \begin{array}{l}n \\
0 \\
0 \\
0\end{array}$ & $\stackrel{\vec{\omega}}{\stackrel{\Delta}{o}}$ & $\begin{array}{l}\tilde{u} \\
\dot{\partial}\end{array}$ & 岕 & 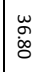 & \begin{tabular}{|l}
$\omega$ \\
$\omega$ \\
$\partial$ \\
$\Delta$
\end{tabular} & $\begin{array}{l}\overrightarrow{0} \\
\dot{0}\end{array}$ & $\mid \begin{array}{l}\omega \\
\stackrel{\delta}{o}\end{array}$ & $\begin{array}{l}\stackrel{R}{\tilde{E}} \\
\text { | }\end{array}$ & 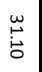 & $\begin{array}{l}\vec{f} \\
\dot{8} \\
\dot{8}\end{array}$ & $\begin{array}{l}\underset{ٌ}{J} \\
\text { d }\end{array}$ & $\begin{array}{l}\vec{r} \\
\vec{\Delta}\end{array}$ & \begin{tabular}{|l|}
$\underset{\omega}{\tilde{\sigma}}$ \\
\end{tabular} & $\begin{array}{l}\stackrel{\omega}{\circ} \\
\stackrel{0}{0}\end{array}$ & $\begin{array}{l}\vec{y} \\
\text { in }\end{array}$ & 호 \\
\hline 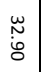 & \begin{tabular}{|l|}
$\tilde{\infty}$ \\
$\infty$ \\
$o$ \\
0
\end{tabular} & $\begin{array}{l}\vec{f} \\
\dot{0} \\
\dot{8}\end{array}$ & $\begin{array}{l}\vec{t} \\
\dot{0} \\
\dot{0}\end{array}$ & $\begin{array}{l}\underset{w}{w} \\
\dot{\infty} \\
i\end{array}$ & \begin{tabular}{|l|}
$\underset{\tilde{O}}{\tilde{O}}$ \\
\end{tabular} & 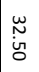 & $\begin{array}{l}\omega \\
\stackrel{+}{0} \\
\stackrel{\delta}{0}\end{array}$ & $\begin{array}{l}w \\
\omega \\
i \\
\text { j }\end{array}$ & \begin{tabular}{|l}
$\omega$ \\
$\omega$ \\
$\delta$
\end{tabular} & $\begin{array}{l}\tilde{o} \\
\ddot{\delta} \\
\ddot{8}\end{array}$ & $\begin{array}{l}\vec{t} \\
\dot{8}\end{array}$ & $\begin{array}{l}\tilde{u} \\
\dot{\sigma}\end{array}$ & $\begin{array}{l}\vec{*} \\
\dot{8}\end{array}$ & $\begin{array}{l}\underset{\tilde{\sim}}{\tilde{\sim}} \\
\end{array}$ & $\begin{array}{l}+5 \\
8 \\
8\end{array}$ & $\begin{array}{l}\omega \\
\stackrel{\omega}{\sigma} \\
\sigma\end{array}$ & \begin{tabular}{|l}
$w$ \\
$w$ \\
$\dot{o}$ \\
$\varnothing$
\end{tabular} & 8 & \\
\hline $\begin{array}{l}\underset{\sim}{w} \\
\tilde{o}\end{array}$ & \begin{tabular}{|c|} 
\\
0 \\
0 \\
0
\end{tabular} & $\underset{\omega}{\vec{w}}$ & 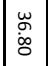 & 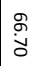 & $\underset{\stackrel{\omega}{\Delta}}{\stackrel{\omega}{\Delta}}$ & $\underset{\tilde{J}}{\tilde{J}}$ & $\underset{\underset{\omega}{w}}{\tilde{w}}$ & \begin{tabular}{|l|l}
$\omega$ \\
$\infty$ \\
$\infty$ \\
$\varnothing$
\end{tabular} & \begin{tabular}{|l}
$\underset{\tilde{g}}{\sigma}$ \\
g.
\end{tabular} & $\mid \stackrel{\underset{\omega}{\omega}}{\underline{\omega}}$ & \begin{tabular}{|l}
$\stackrel{\omega}{\leftrightarrows}$ \\
$\Delta$
\end{tabular} & $\begin{array}{l}\tilde{N} \\
\dot{0}\end{array}$ & \begin{tabular}{|l}
$\omega$ \\
$\ddot{g}$ \\
$g$
\end{tabular} & $\begin{array}{l}\omega \\
\text { ڤે }\end{array}$ & $\begin{array}{l}\underset{\omega}{0} \\
\tilde{O}\end{array}$ & $\begin{array}{ll}\text { un } \\
\text { ind }\end{array}$ & : & & \\
\hline 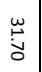 & $\mid$\begin{tabular}{|l}
$\tilde{y}$ \\
$i \tilde{o}$
\end{tabular} & $\begin{array}{l}w \\
\stackrel{+}{ } \\
\stackrel{\Delta}{0}\end{array}$ & $\begin{array}{l}\tilde{0} \\
\dot{b}\end{array}$ & \begin{tabular}{|l}
$\mid \ddot{g}$ \\
$\ddot{g}$
\end{tabular} & \begin{tabular}{|l|}
$w$ \\
$\stackrel{\sim}{\circ}$ \\
$\dot{\delta}$
\end{tabular} & 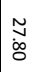 & $\begin{array}{l}\tilde{U} \\
\tilde{O} \\
\end{array}$ & $\begin{array}{l}w \\
\stackrel{\omega}{\delta} \\
\dot{b}\end{array}$ & $\begin{array}{l}\tilde{J} \\
\tilde{J}\end{array}$ & $\begin{array}{l}\tilde{\infty} \\
\tilde{\sigma}\end{array}$ & $\begin{array}{l}w \\
\tilde{O} \\
\tilde{O} \\
\end{array}$ & $\begin{array}{l}\tilde{N} \\
\tilde{N}\end{array}$ & $\begin{array}{l}\tilde{N} \\
\dot{8}\end{array}$ & $\begin{array}{l}\tilde{\infty} \\
\stackrel{\tilde{d}}{ }\end{array}$ & $\stackrel{\stackrel{\omega}{\leftrightarrows}}{\stackrel{\Delta}{\sigma}}$ & 호 & & & \\
\hline $\begin{array}{l}w \\
\infty \\
\dot{b}\end{array}$ & 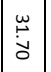 & $\begin{array}{l}0 \\
\text { in } \\
\text { in }\end{array}$ & $\begin{array}{l}\infty \\
\dot{\infty} \\
\dot{\omega}\end{array}$ & $\begin{array}{l}\vec{H} \\
\dot{\omega}\end{array}$ & \begin{tabular}{|l|} 
\\
$\tilde{o}$ \\
$\tilde{\tilde{O}}$
\end{tabular} & $\begin{array}{l}\stackrel{w}{+} \\
\stackrel{\omega}{o}\end{array}$ & $\stackrel{w}{\tilde{J}}^{w}$ & $\begin{array}{l}\omega \\
\omega \\
\text { in }\end{array}$ & $\begin{array}{l} \pm \\
\dot{J}\end{array}$ & $\begin{array}{l}\tilde{N} \\
\dot{\delta}\end{array}$ & $\begin{array}{l}\vec{\infty} \\
\dot{0} \\
\dot{b}\end{array}$ & 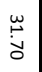 & $\begin{array}{l}\tilde{N} \\
\tilde{O}\end{array}$ & $\begin{array}{l}\vec{t} \\
\dot{f}\end{array}$ & 。ั & & & & \\
\hline $\begin{array}{l}\underset{w}{w} \\
\stackrel{w}{o}\end{array}$ & $\begin{array}{l}\tilde{o} \\
\dot{0}\end{array}$ & 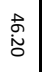 & $\begin{array}{l}\text { tे } \\
\dot{\dot{\delta}}\end{array}$ & $\begin{array}{l}\omega \\
ٌ \\
\stackrel{0}{0}\end{array}$ & \begin{tabular}{|l|}
$w$ \\
$w$ \\
$i$ \\
$i n$
\end{tabular} & $\begin{array}{l}\underset{w}{w} \\
\text { g. }\end{array}$ & $\begin{array}{l}\omega \\
\stackrel{\sim}{0} \\
\text {. }\end{array}$ & $\begin{array}{l}w \\
\infty \\
\text { w } \\
\text { In }\end{array}$ & $\begin{array}{l}\stackrel{w}{\stackrel{\Xi}{0}} \\
\end{array}$ & $\underset{\tilde{J}}{\tilde{\sigma}}$ & $\begin{array}{l}w \\
\stackrel{\omega}{0}\end{array}$ & 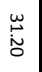 & $\begin{array}{l}\overrightarrow{0} \\
\dot{0} \\
\dot{0}\end{array}$ & tᄒ & & & & & \\
\hline$\underset{\tilde{w}}{\tilde{\omega}}$ & \begin{tabular}{|c|}
$\tilde{\tilde{w}}$ \\
$\tilde{o}$ \\
\end{tabular} & $\begin{array}{l}u \\
\stackrel{u}{0} \\
\tilde{O}\end{array}$ & \begin{tabular}{|l|} 
\\
$\check{J}$ \\
|
\end{tabular} & \begin{tabular}{|l}
$\omega$ \\
$\tilde{\sigma}$ \\
$\dot{\sigma}$
\end{tabular} & $\begin{array}{l}\vec{w} \\
i \\
i n\end{array}$ & $\begin{array}{l}\omega \\
\omega \\
o \\
\Delta\end{array}$ & $\begin{array}{l}w \\
\infty \\
\dot{d}\end{array}$ & $\begin{array}{l}\omega \\
\stackrel{\omega}{0} \\
\dot{\sigma}\end{array}$ & 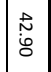 & $\begin{array}{l}\omega \\
\text { ó } \\
\dot{b}\end{array}$ & $\begin{array}{l}\vec{d} \\
d\end{array}$ & $\begin{array}{l}\tilde{0} \\
\dot{0}\end{array}$ & t효 & & & & & & \\
\hline $\begin{array}{l}\stackrel{\vec{w}}{\tilde{o}} \\
\tilde{\sigma}\end{array}$ & \begin{tabular}{|l|}
$\underset{w}{w}$ \\
$\dot{\omega}$
\end{tabular} & $\begin{array}{l}\omega \\
\stackrel{\omega}{\circ} \\
\dot{\delta}\end{array}$ & $\begin{array}{l}\tilde{o} \\
\dot{8}\end{array}$ & $\begin{array}{l}\underset{\sim}{\tilde{g}} \\
\dot{\delta}\end{array}$ & \begin{tabular}{|l|}
\multirow{N}{w}{} \\
$\dot{g}$
\end{tabular} & $\begin{array}{l}\stackrel{\omega}{\oplus} \\
\stackrel{d}{\sigma}\end{array}$ & 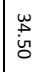 & $\begin{array}{l}\underset{\omega}{\omega} \\
\dot{\omega}\end{array}$ & \begin{tabular}{|l|}
$\omega$ \\
$\stackrel{\circ}{\circ}$ \\
$\dot{o}$
\end{tabular} & $\begin{array}{l}\stackrel{\infty}{\vec{\omega}} \\
\dot{\omega}\end{array}$ & $\begin{array}{l}\vec{P} \\
\dot{o}\end{array}$ & 's & & & & & & & \\
\hline $\begin{array}{l}\text { un } \\
\dot{w} \\
0\end{array}$ & $\mid \begin{array}{l}\tilde{\tilde{J}} \\
\tilde{d}\end{array}$ & $\begin{array}{l}\text { जे } \\
\text { ì }\end{array}$ & $\mid \begin{array}{l}\overrightarrow{1} \\
\dot{o}\end{array}$ & $\mid \underset{\dot{\infty}}{\omega}$ & \begin{tabular}{|l|} 
\\
$\dot{\phi}$ \\
$\dot{0}$
\end{tabular} & 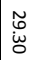 & $\begin{array}{l}\underset{w}{w} \\
\tilde{j}\end{array}$ & \begin{tabular}{|c}
$\underset{\omega}{\omega}$ \\
$\dot{g}$
\end{tabular} & $\begin{array}{l}\dot{u} \\
\dot{w}\end{array}$ & 南 & s̆ & & & & & & & & \\
\hline $\begin{array}{l}\text { N } \\
\tilde{D}\end{array}$ & \begin{tabular}{|l|} 
\\
$\tilde{\tilde{O}}$
\end{tabular} & $\begin{array}{l}\stackrel{\omega}{\sim} \\
\tilde{\sigma}\end{array}$ & \begin{tabular}{|l|}
$\stackrel{\omega}{\vec{\theta}}$ \\
\end{tabular} & \begin{tabular}{|l|}
$\underset{w}{\omega}$ \\
$\stackrel{8}{0}$
\end{tabular} & \begin{tabular}{|l|}
$w$ \\
$w$ \\
$i$
\end{tabular} & 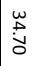 & $\begin{array}{l}w \\
\stackrel{\omega}{i g} \\
\text {. }\end{array}$ & \begin{tabular}{|c}
$\stackrel{\omega}{W}$ \\
$\stackrel{\omega}{\circlearrowleft}$
\end{tabular} & $\begin{array}{l}\stackrel{R}{:} \\
\stackrel{8}{8}\end{array}$ & t. & & & & & & & & & \\
\hline $\begin{array}{l}\vec{N} \\
\stackrel{8}{0}\end{array}$ & \begin{tabular}{|l|} 
\\
$\dot{\infty}$ \\
$i$ \\
$i$
\end{tabular} & $\underset{\substack{f \\
\infty}}{\infty}$ & $\begin{array}{l}\stackrel{\vec{w}}{\dot{w}} \\
\dot{c}\end{array}$ & \begin{tabular}{|l}
$\underset{\leftarrow}{w}$ \\
$\underset{\omega}{\omega}$
\end{tabular} & \begin{tabular}{l|}
$\vec{w}$ \\
$\vec{t}$
\end{tabular} & 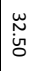 & $\begin{array}{l}\underset{\widetilde{N}}{\tilde{\delta}} \\
\end{array}$ & $\underset{\breve{\omega}}{\omega}$ & $\overrightarrow{8}$ & & & & & & & & & & \\
\hline$\underset{\breve{o}}{\tilde{\iota}}$ & $\mid \begin{array}{l}w \\
\stackrel{d}{\tilde{O}} \\
\end{array}$ & $\begin{array}{l}\vec{\omega} \\
\stackrel{\theta}{0}\end{array}$ & \begin{tabular}{|l}
$\vec{t}$ \\
$\dot{i}$
\end{tabular} & $\mid \begin{array}{l}\omega \\
\dot{\omega} \\
.\end{array}$ & 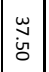 & \begin{tabular}{|l}
$\stackrel{9}{u}$ \\
$\dot{b}$
\end{tabular} & \begin{tabular}{|l|l|}
$\stackrel{\infty}{:}$ \\
$\stackrel{5}{\Delta}$
\end{tabular} & 各 & & & & & & & & & & & \\
\hline $\begin{array}{l}\underset{w}{w} \\
\tilde{w} \\
o\end{array}$ & $\mid \begin{array}{l}w \\
\stackrel{w}{b} \\
\end{array}$ & : & \begin{tabular}{|l}
$\tilde{\omega}$ \\
$\stackrel{\omega}{0}$
\end{tabular} & $\begin{array}{l}\tilde{\omega} \\
\tilde{\sigma} \\
0\end{array}$ & $\mid \begin{array}{l}\tilde{o} \\
\tilde{N} \\
0\end{array}$ & $\begin{array}{l}2 \\
\text { Oे } \\
0\end{array}$ & tః & & & & & & & & & & & & \\
\hline $\begin{array}{l}\omega \\
\stackrel{+}{\Delta} \\
\Delta\end{array}$ & $\begin{array}{l}\underset{\tilde{N}}{\tilde{\sigma}} \\
\end{array}$ & $\begin{array}{l}\omega \\
\ddot{g}\end{array}$ & $\begin{array}{l}\omega \\
\stackrel{\omega}{o} \\
\dot{\delta}\end{array}$ & $\begin{array}{l}\omega \\
\stackrel{\omega}{b} \\
\dot{\sigma}\end{array}$ & $\mid \begin{array}{l}w \\
w \\
o \\
o\end{array}$ & $\overrightarrow{8}$ & & & & & & & & & & & & & \\
\hline $\begin{array}{l}\underset{\sim}{\Delta} \\
\stackrel{\Delta}{0}\end{array}$ & 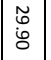 & $\begin{array}{l}\vec{A} \\
\hat{\theta}\end{array}$ & \begin{tabular}{|l|} 
\\
$\dot{8}$ \\
$\dot{8}$
\end{tabular} & \begin{tabular}{|l}
$\vec{w}$ \\
$\tilde{\omega}$
\end{tabular} & 8 & & & & & & & & & & & & & & \\
\hline $\begin{array}{l}\omega \\
\infty \\
o \\
\text { th }\end{array}$ & \begin{tabular}{|l|}
$\stackrel{w}{\tilde{\sigma}}$ \\
$\tilde{\sigma}$
\end{tabular} & $\begin{array}{l}\text { के } \\
\text { tे }\end{array}$ & \begin{tabular}{|l|}
$\stackrel{\omega}{\omega}$ \\
$\dot{\omega}$
\end{tabular} & ') & & & & & & & & & & & & & & & \\
\hline $\mid \begin{array}{l}\underset{N}{w} \\
\dot{o}\end{array}$ & $\mid \begin{array}{l}\tilde{0} \\
\tilde{d}\end{array}$ & $\begin{array}{l}\infty \\
\stackrel{\infty}{0}\end{array}$ & 8 & & & & & & & & & & & & & & & & \\
\hline 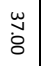 & 岕 & ㅇ & & & & & & & & & & & & & & & & & \\
\hline
\end{tabular}




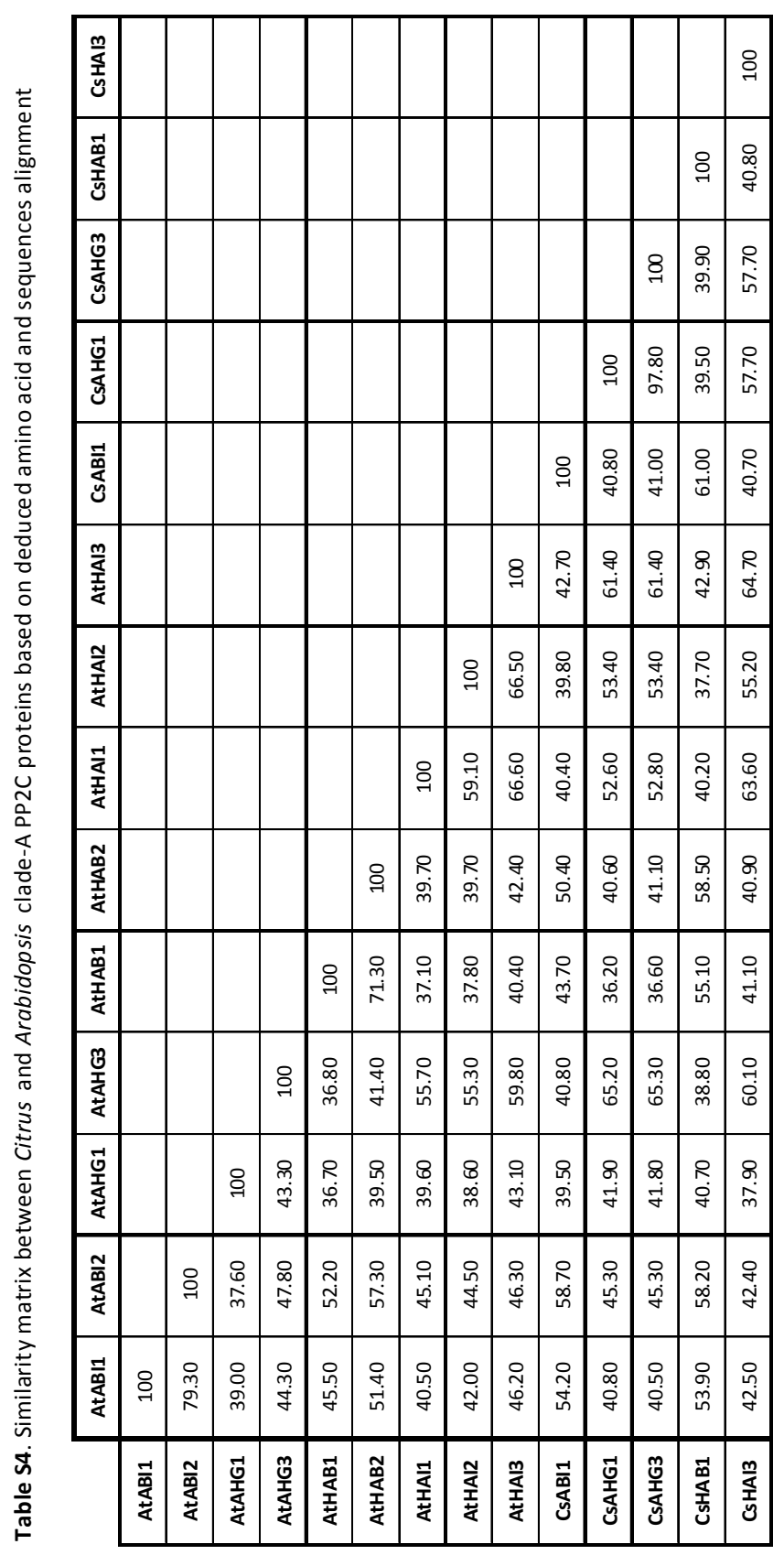


Table S5. Similarity matrix between Citrus and Arabidopsis subclass III SnRK2 proteins based on deduced amino acid and sequences alignment.

\begin{tabular}{|c|c|c|c|c|c|}
\cline { 2 - 6 } \multicolumn{1}{c|}{} & AtSnRK2.2 & AtSnRK2.3 & AtSnRK2.6 & CsSnRK2.2 & CSSnRK2.6 \\
\hline AtSnRK2.2 & 100 & & & & \\
\hline AtSnRK2.3 & 88.40 & 100 & & & \\
\hline AtSnRK2.6 & 74.40 & 75.50 & 100 & & \\
\hline CSSnRK2.2 & 81.50 & 79.40 & 78.10 & 100 & \\
\hline CSSnRK2.6 & 74.70 & 85.30 & 88.90 & 82.00 & 100 \\
\hline
\end{tabular}

Table S6. Absolute gene expression analysis by qRT-PCR of the ABA-signalosome components in 'Navelate' and 'Pinalate' varieties during fruit ripening and leaf dehydration. Values correspond to number of copies of each gene per $\mu \mathrm{g}$ of total RNA. Values are means of three biological replicates for each sampling period and variety.

\begin{tabular}{|c|c|c|c|c|c|c|c|c|c|c|c|c|c|c|c|}
\hline & & \multirow[b]{2}{*}{ Ripening } & \multicolumn{6}{|c|}{ PYR/PYL/RCAR } & \multicolumn{5}{|c|}{ PP2CA } & \multicolumn{2}{|c|}{ SnRK2 } \\
\hline & & & PYR1 & PYL2 & PYL4 & PYL5 & PYL8 & PYL9 & $\mathrm{AB|1}$ & AHG1 & AHG3 & HAB1 & HAl3 & SnRK2.2 & SnRK2.6 \\
\hline \multirow{13}{*}{ Fruit } & \multirow{6}{*}{ Navelate } & IG & 9 & n.d. & 1566 & 1101 & 24 & 12757 & 692 & 267 & 3976 & 8714 & 806 & 16256 & 139325 \\
\hline & & M1 & 11 & n.d. & 710 & 1239 & 16 & 7274 & 410 & 205 & 3897 & 5415 & 1385 & 2172 & 48701 \\
\hline & & M2 & 12 & n.d. & 1548 & 2167 & 20 & 10136 & 452 & 227 & 5780 & 5649 & 386 & 993 & 10790 \\
\hline & & BK & 5 & n.d. & 656 & 772 & 22 & 7393 & 910 & 515 & 5805 & 6409 & 4217 & 1329 & 21883 \\
\hline & & c & 5 & n.d. & 691 & 440 & 17 & 7035 & 1755 & 685 & 14247 & 8034 & 8474 & 975 & 18380 \\
\hline & & FC & 10 & n.d. & 1386 & 1777 & 16 & 4633 & 517 & 455 & 7029 & 4707 & 2473 & 1362 & 17485 \\
\hline & \multirow{7}{*}{ Pinalate } & & & & & & & & & & & & & & \\
\hline & & IG & 16 & n.d. & 1289 & 1313 & 23 & 16294 & 951 & 627 & 3005 & 8842 & 1081 & 9523 & 114626 \\
\hline & & M1 & 10 & n.d. & 827 & 1323 & 17 & 7921 & 448 & 190 & 2590 & 6018 & 1000 & 2338 & 45145 \\
\hline & & M2 & 12 & n.d. & 1271 & 2240 & 18 & 7959 & 293 & 211 & 3756 & 5669 & 570 & 2553 & 25048 \\
\hline & & BK & 7 & n.d. & 228 & 754 & 19 & 5599 & 724 & 153 & 5041 & 5424 & 3150 & 2823 & 73697 \\
\hline & & c & 5 & n.d. & 636 & 236 & 17 & 4575 & 1246 & 1170 & 7237 & 4482 & 6083 & 992 & 27681 \\
\hline & & FC & 15 & n.d. & 1694 & 2461 & 17 & 3890 & 278 & 243 & 2784 & 3253 & 1191 & 878 & 13993 \\
\hline \multirow{24}{*}{ Leaf } & \multirow{7}{*}{$\begin{array}{c}\text { Navelate } \\
\text { Control }\end{array}$} & Time (h) & PYR1 & PYL2 & PYL4 & PYL5 & PYL8 & PYL9 & ABI1 & AHG1 & AHG3 & HAB1 & HAl3 & SnRK2.2 & SnRK2.6 \\
\hline & & 0 & 2 & 14285 & n.d. & 60 & n.d. & 9701 & 941 & 78 & 5792 & 10897 & 1404 & 2081 & 89249 \\
\hline & & 0.5 & 3 & 15739 & n.d. & 19 & n.d. & 5438 & 994 & 74 & 5303 & 5543 & 2617 & 3188 & 80093 \\
\hline & & 1 & 3 & 26296 & n.d. & 34 & n.d. & 23444 & 1265 & 147 & 21048 & 12786 & 1721 & 7058 & 88636 \\
\hline & & 3 & 5 & 6959 & n.d. & 19 & n.d. & 17770 & 12915 & 575 & 17871 & 6708 & 8004 & 7915 & 226187 \\
\hline & & 6 & 7 & 9551 & n.d. & 7 & n.d. & 9128 & 14860 & 993 & 23212 & 32122 & 31092 & 7614 & 280793 \\
\hline & & 24 & 6 & 12976 & n.d. & 12 & n.d. & 7536 & 9828 & 273 & 27177 & 15686 & 7099 & 2477 & 173883 \\
\hline & \multirow{5}{*}{$\begin{array}{c}\text { Navelate } \\
\text { Dehydrated }\end{array}$} & 0.5 & 4 & 9502 & n.d. & 10 & n.d. & 5471 & 1303 & 159 & 7421 & 8349 & 2041 & 10075 & 116749 \\
\hline & & 1 & 3 & 13953 & n.d. & 20 & n.d. & 6409 & 1941 & 333 & 18297 & 6591 & 4435 & 1767 & 123039 \\
\hline & & 3 & 4 & 9016 & n.d. & 13 & n.d. & 10582 & 27461 & 1177 & 45915 & 11233 & 24000 & 3520 & 197336 \\
\hline & & 6 & 6 & 2834 & n.d. & 2 & n.d. & 11275 & 24788 & 1636 & 39621 & 10851 & 30651 & 5186 & 385560 \\
\hline & & 24 & 3 & 4713 & n.d. & 2 & n.d. & 4011 & 20881 & 1257 & 28182 & 13576 & 11416 & 2296 & 98070 \\
\hline & & & & & & & & & & & & & & & \\
\hline & & 0 & 3 & 10088 & n.d. & 47 & n.d. & 7903 & 1225 & 84 & 8043 & 18094 & 1889 & 1658 & 91632 \\
\hline & & 0.5 & 5 & 6931 & n.d. & 19 & n.d. & 4243 & 757 & 60 & 6156 & 6784 & 2008 & 2464 & 106470 \\
\hline & Pinalate & 1 & 5 & 43144 & n.d. & 36 & n.d. & 1548 & 4148 & 477 & 25649 & 35083 & 8803 & 5519 & 178654 \\
\hline & Control & 3 & 10 & 14910 & n.d. & 24 & n.d. & 20635 & 5914 & 329 & 10905 & 6800 & 9468 & 6457 & 361168 \\
\hline & & 6 & 11 & 5060 & n.d. & 8 & n.d. & 17515 & 15664 & 772 & 14101 & 15016 & 21672 & 6257 & 232467 \\
\hline & & 24 & 10 & 8800 & n.d. & 9 & n.d. & 9555 & 13371 & 300 & 21100 & 13213 & 21028 & 5650 & 166202 \\
\hline & \multirow{5}{*}{$\begin{array}{c}\text { Pinalate } \\
\text { Dehydrated }\end{array}$} & 0.5 & 3 & 8659 & n.d. & 18 & n.d. & 5579 & 858 & 87 & 4227 & 12878 & 3402 & 8018 & 153159 \\
\hline & & 1 & 5 & 6180 & n.d. & 32 & n.d. & 7428 & 961 & 104 & 9189 & 6770 & 1709 & 1934 & 106777 \\
\hline & & 3 & 9 & 9079 & n.d. & 14 & n.d. & 9139 & 24848 & 1262 & 26478 & 9791 & 26066 & 2160 & 377740 \\
\hline & & 6 & 10 & 3609 & n.d. & 2 & n.d. & 10084 & 26187 & 1470 & 31848 & 17913 & 24384 & 6420 & 236768 \\
\hline & & 24 & 4 & 5351 & n.d. & 1 & n.d. & 2968 & 23933 & 1359 & 26266 & 7678 & 27236 & 6948 & 302733 \\
\hline
\end{tabular}




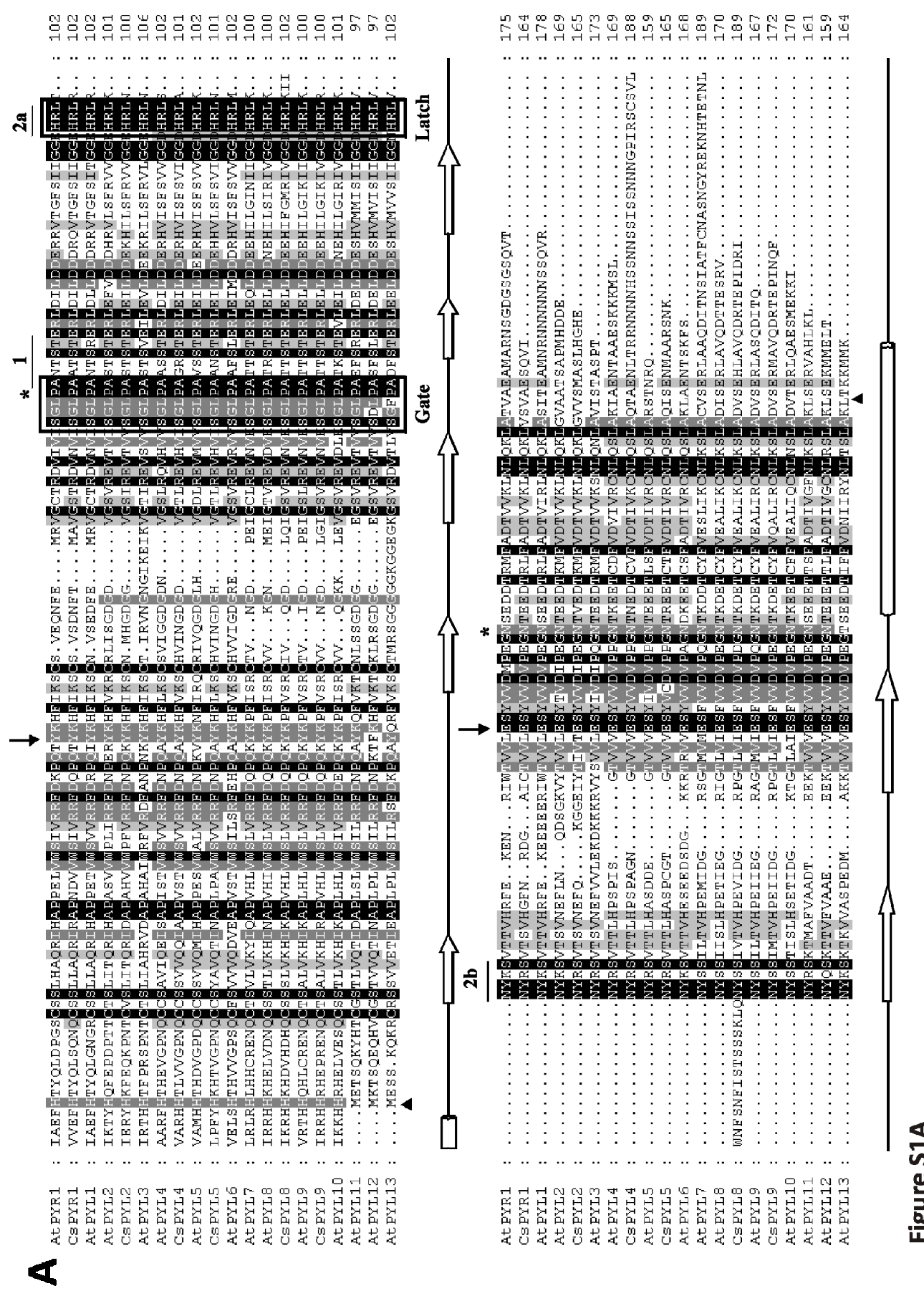

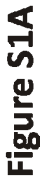




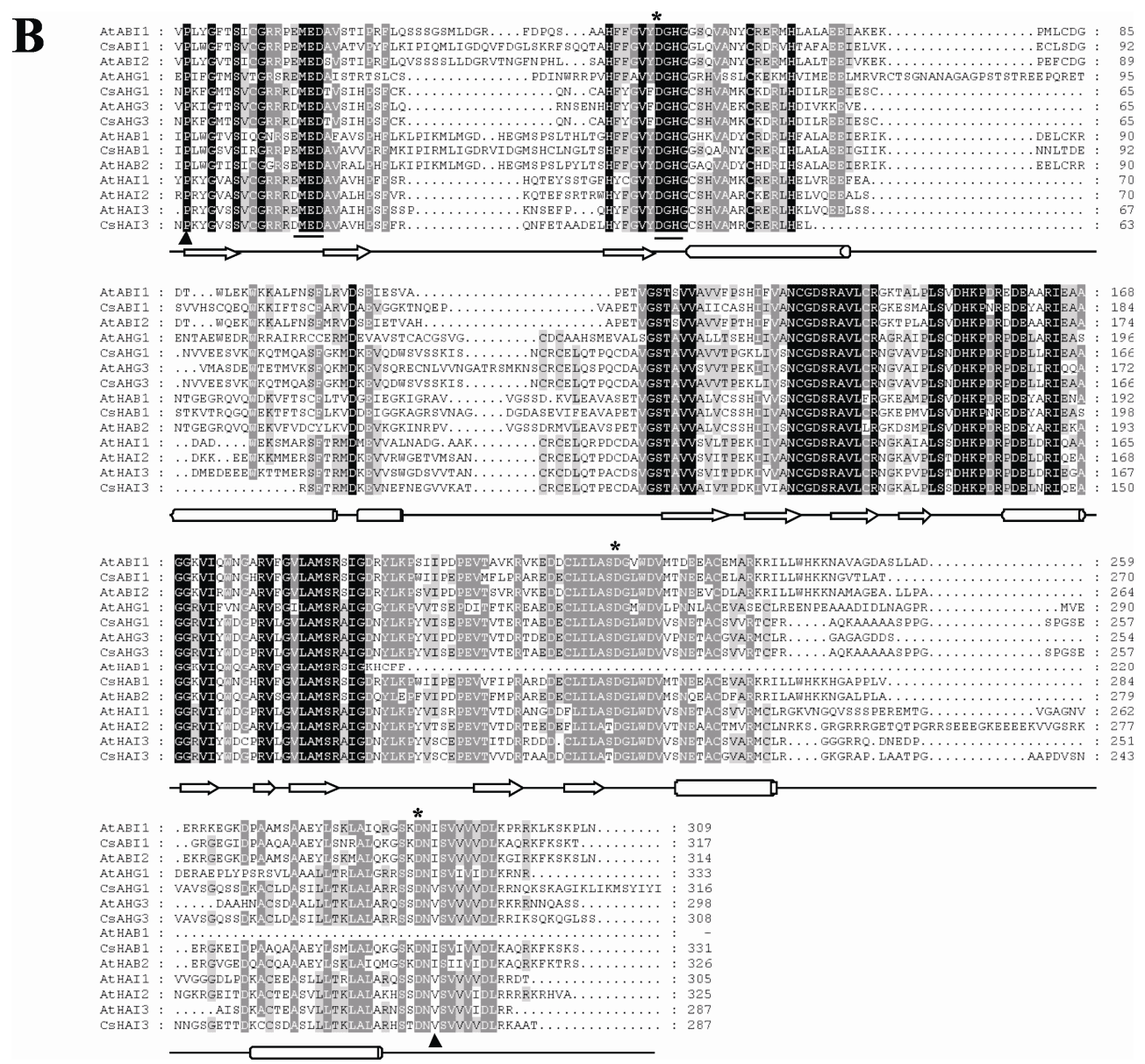

Figure S1B 


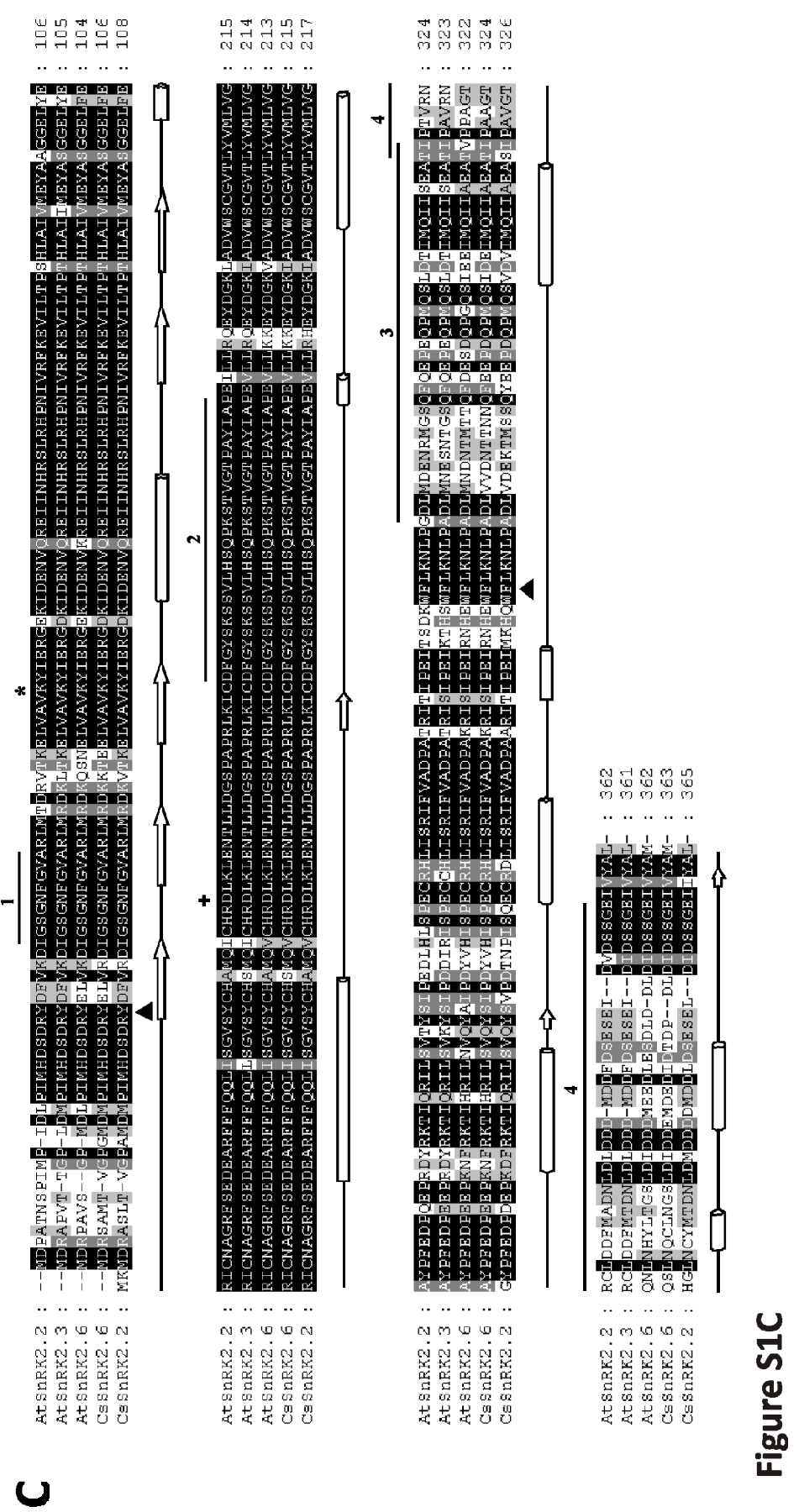


Figure S1. Multiple sequence alignment of the Arabidopsis thaliana and Citrus sinensis ABA signalling core components. (A) START-like domain of the ABA-receptors, delimited by black triangles below the alignment. ABA-binding sites are indicated by arrows and PP2Cs interaction sites by asterisks. Boxes indicate Gate and Latch loops. Horizontal lines ( 1 and 2 ) above the alignment delimit the two ABA-binding regions. Line 2 is divided in $2 a$ and $2 b$ due to the insertion of 17 amino acid residues in CSPYL8 protein. (B) PP2C-like domain of the clade-A PP2Cs proteins, delimited by black triangles below the alignment. Metalbinding sites are pointed out by asterisks and phosphatase activity regulatory sequences are underlined. (C) Subclass III SnRK2s full protein sequences. Black triangles below the alignment delimit protein kinase domain, asterisk indicate ATP binding site and plus symbol highlights the proton acceptor active site. Horizontal lines are numbered as follows: 1 , ATP binding region; 2 , activation loop; 3 , osmotic stress response domain I; and $4, A B A$ response and $A B I 1$ binding domain II. Predicted secondary structures of AtPYR1 (A), AtABI1 (B) and AtSnRK2.6 (C) are reported below the corresponding alignment with alphahelices as tubes, beta-strands as arrows and coiled regions as lines, as estimated by PSIPRED software. Dots indicate gaps in the amino acid sequences when compared with others for obtaining optimal alignments. Amino acids are numbered to the right of each line. Identical residues are in black, highly conservative are in dark grey and less conserved are in light grey. 
A

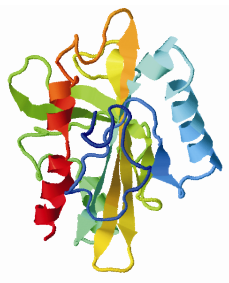

CsPYR1

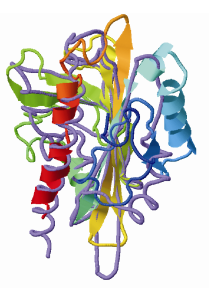

B

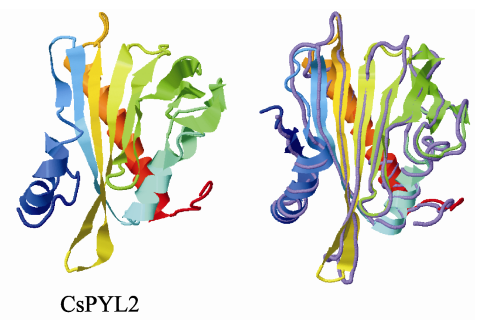

CsPYL2
C

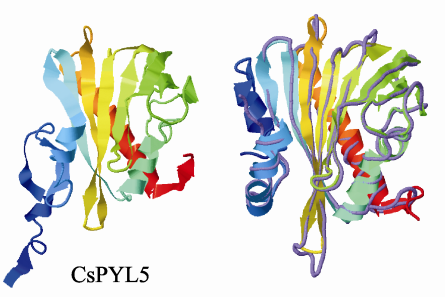

D
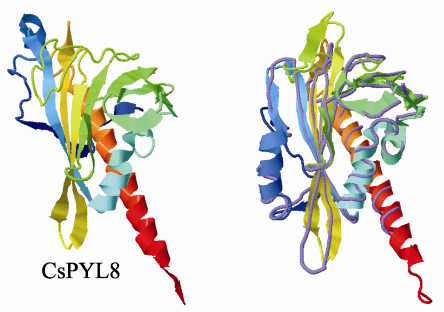

E
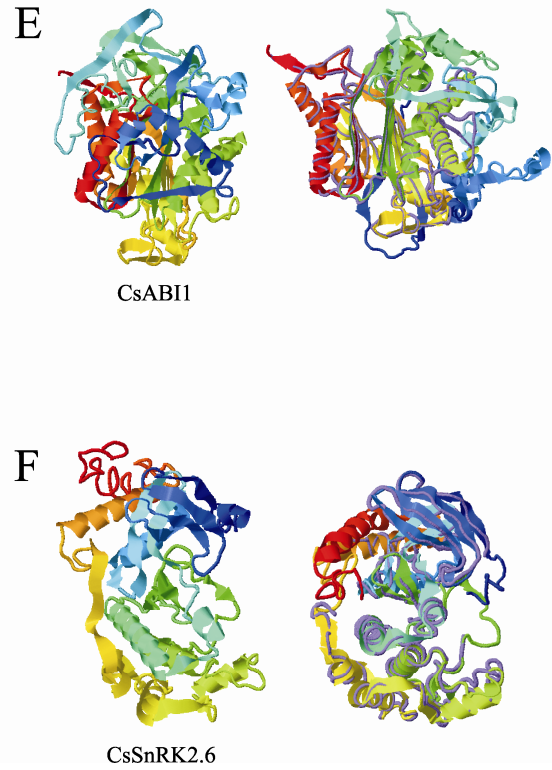

Figure S2. Predicted tertiary structure model of the ABA-signalosome components of Citrus by using the Arabidopsis available crystallographic structure of homologous proteins as templates in I-Tasser program (left). Overlay of the predicted structure with the corresponding Arabidopsis homologous (right). Query structures are shown in cartoon, while templates are displayed using purple trace. (AD) PYR/PYL/RCAR ABA-receptors. (E) PP2CA. (F) SnRK2. 


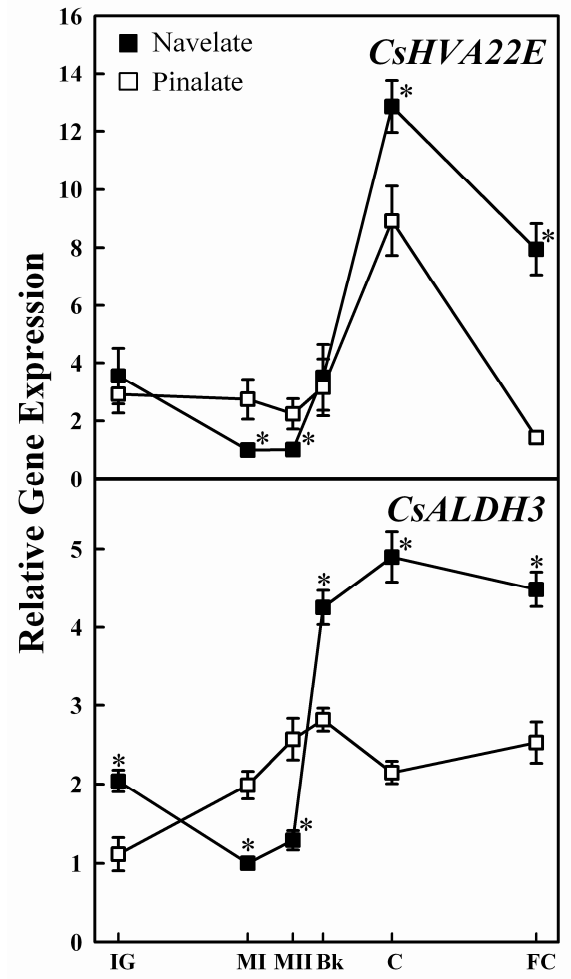

Figure S3. Gene expression analysis by RT-qPCR of Citrus HVA22E (upper panel) and ALDH (lower panel) in 'Navelate' (black) and 'Pinalate' (white) fruits during development and ripening stages (Immature Green, IG; Mature Green I, MI; Mature Green II, MII; Breaker, Bk; Coloured, C; Full Coloured, FC). Expression values are relative to transcript levels obtained in MI 'Navelate' fruits. Values are mean ratios \pm SE from three biological samples for each sampling period and variety, and analyzed in duplicate. Significant differences $(P \leq 0.05)$ in gene expression between 'Navelate' and 'Pinalate' flavedo samples for the same maturity stage are indicated by an asterisk. 


\subsection{CHAPTER 3}

Differential expression of the Citrus sinensis ABA perception system genes in postharvest fruit dehydration

Postharvest Biology and Technology (2012).

DOI: 10.1016/j.postharvbio.2012.09.010

Paco Romero, María J. Rodrigo and María T. Lafuente* 



\section{ABSTRACT}

Water stress occurring during postharvest handling and storage is an important factor affecting external quality of fresh fruit and vegetables. The phytohormone abscisic acid ( $A B A)$ is a key regulator of the dehydration response in citrus fruit, which are prone to develop peel damage in response to water stress. To study the involvement of the ABA perception system in the dehydration response and its relationship with the occurrence of peel damage in citrus fruit, a comparative transcriptional analysis of the ABA signalling core components in water-stressed fruit of the wild-type 'Navelate' orange (Citrus sinensis L. Osbeck) and its spontaneous fruit-specific ABA-deficient mutant 'Pinalate', which is more susceptible to dehydration and to develop non-chilling peel pitting (NCPP), has been performed. Minor differences in ABA receptors (CSPYR/PYL/RCAR) and downstream protein kinases (CsSnRK2) transcripts levels were found in response to dehydration between wild-type and the ABA-deficient mutant fruit. Contrary, the expression of the ABA-mediated PYR/PYL/RCAR-inactivated clade A protein phosphatases 2C (CSPP2CA) was highly regulated by ABA content and showed significant differences between cultivars. Results obtained by $A B A$ application suggest the involvement of these negative regulators in the impaired response of 'Pinalate' fruit to water stress. Overall, the higher responsiveness to ABA changes of the CSPP2CAs during citrus fruit dehydration highlights these components as key regulator control points in the response of citrus fruit to water stress. 


\section{INTRODUCTION}

Water stress during postharvest is one of the most important factors reducing external quality and hence commercial value of fresh fruit. However, the study of the molecular mechanisms underlying fruit dehydration in horticultural crops has been limited to a few set of genes (Alférez et al., 2008; Bonghi et al., 2012; Loyola et al., 2012), and high throughput approaches have been only performed in grape and citrus fruit. Studies in grapes indicate that molecular responses are differently regulated by dehydration occurring before or after harvesting the fruit and also by the stress severity (Deluc et al., 2009; Rizzini et al., 2009; Bonghi et al., 2012). Transcriptomic research in citrus fruit has evidenced the relevance of the early molecular events for coping with water loss and the deleterious effects affecting external fruit quality caused by this stress (Romero et al., 2012b). In this regard, it should be mentioned that many citrus cultivars are prone to develop non-chilling peel pitting (NCPP), a physiological disorder enhanced by dehydration (Alférez et al., 2003; Alférez and Burns, 2004), and manifested as peel depressions affecting both the inner (albedo) and the outer part (flavedo) of the peel that becomes bronze as the disorder progresses (Alférez et al., 2005; Lafuente and Zacarías, 2006; Alférez et al., 2010). The tight relationship between $A B A$ and dehydration is well established as this hormone plays a crucial role regulating stomatal closure and hence water loss (Bartels and Sunkar, 2005; Shinozaki and Yamaguchi-Shinozaki, 2007). Therefore, ABA may have an important effect on fruit such as citrus, which contain abundant stomata in their external tissues. Moreover, it has been demonstrated that ABAindependent pathways may also operate in response to dehydration in model plants (Riera et al., 2005). These observations have been extended recently to citrus fruit (Romero et al., 2012b). 
Natural and induced mutants of ABA-biosynthetic and signalling transduction genes have been characterized in model and crop plants (Groot and Karssen, 1992; Schwartz et al., 1997). Since artificially generated mutants are less affordable in woody plants, the access to spontaneous hormone mutants is of particular scientific interest. Different works have attempted to unravel physiological (Alférez et al., 2005; Holland et al., 2005; Sala et al., 2005) and molecular (Sanchez-Ballesta et al., 2008; Romero et al., 2012b) mechanisms linking $A B A$, fruit dehydration and peel damage development in Citrus taking advantage of a spontaneous fruit-specific ABA deficient mutant from 'Navelate' orange (Citrus sinensis L. Osbeck), named 'Pinalate'. Fruit of this mutant presents a partial blockage of the carotenoid biosynthetic pathway, causing distinctive yellow-coloured fruit and a fruit-specific ABA-deficiency (Rodrigo et al., 2003), and is more prone to dehydration and to develop NCPP than its parental (Alférez et al., 2005). The study performed recently by Romero et al. (2012b) has highlighted the relevance of early molecular responses to dehydration, lacking in the mutant and including both ABA-dependent and independent genes, in the fruit susceptibility to NCPP. Results from this study also suggested that 'Pinalate' mutant could be partially insensitive to $A B A$ but further research is needed to elucidate whether perception of ABA may be related to the higher susceptibility of this mutant to dehydration and NCPP.

As far as we know, the role of hormone perception on postharvest behaviour of citrus fruit is mainly restricted to ethylene (John-Karuppiah and Burns, 2010). Recent works on the ABA-response signalling mechanisms have been particularly relevant to agriculture since they provide a deeper insight into the molecular events involved in stress tolerance. Thus, the discovery of the pyrabactin-resistant (PYR/PYL/RCAR) soluble ABA receptors (Ma et al., 2009; Park et al., 2009; Santiago et al., 2009; Nishimura et al., 2010) and the identification of 
the clade A type $2 \mathrm{C}$ protein phosphatases and SNF1-related protein kinases subclass III complex (PP2CA-SnRK2) as their downstream elements in Arabidopsis thaliana (Umezawa et al., 2009) has encouraged new research aimed to improve drought hardiness in crop plants (Li et al., 2009; Chai et al., 2011; Sun et al., 2011; Boneh et al., 2012a; Boneh et al., 2012b; Kim et al., 2012; Li et al., 2012;). In citrus, ABA signalling core components have been recently identified and their transcriptional regulation has been studied during fruit development and ripening and also in vegetative tissue subjected to water stress (Romero et al., 2012a). Nevertheless, the effect of water stress on the transcriptional regulation of the ABA signalling core components has not been yet studied in any fruit.

Taking into account that $A B A$ accumulation and the expression of its signal transduction components in citrus fruit could be differentially regulated under diverse physiological and stress conditions, and also that plants are less sensitive to exogenous $A B A$ under normal conditions than to the stress-induced rises in endogenous ABA (Imay et al., 1995), the aim of this work was to investigate the transcriptional regulation of the ABA signalling core components in 'Navelate' and its ABA-deficient mutant 'Pinalate' fruit stored under conditions causing moderate water stress and NCPP (70-75\% RH and $12 \stackrel{\circ}{\circ}$ ). Additionally, to test ABA sensitivity of 'Pinalate' fruit, transcriptional analysis of these ABA signalling core components was performed in ABA-treated mutant fruit. 


\section{MATERIALS AND METHODS}

\section{Plant material and ABA treatment}

Mature fruit of 'Navelate' (Citrus sinensis L. Osbeck) orange and its spontaneous ABA-deficient mutant 'Pinalate' were randomly harvested from trees grafted on Citrange carrizo rootstock. The trees were of the same age, grown in the same experimental orchard and subjected to standard cultural practices at 'The Spanish Citrus Germoplasm Bank' at Instituto Valenciano de Investigaciones Agrarias (Moncada, Valencia, Spain). After harvest, fruit without any damage or visual defects were immediately delivered to the laboratory. Fruit of the ABAdeficient mutant were divided into two groups, which were treated with ABA by dipping them for $1 \mathrm{~min}$ in an aqueous solution of $1 \mathrm{mM}$ ABA containing $0.7 \%$ ethanol to dissolve the hormone (group 1 ) or with water containing $0.7 \%$ ethanol (control solution) by following the same procedure (group 2). Likewise, 'Navelate' fruit were dipped in the control solution. Fruit from both cultivars were allowed to dry at room temperature and immediately stored at 12 o $\mathrm{C}$ and $70-75 \% \mathrm{RH}$ for up to 6 weeks. The ABA treatment was repeated every 2 weeks to ensure high ABA levels during fruit storage. Likewise, 'Pinalate' and 'Navelate' control fruit were dipped into $0.7 \%$ ethanol at these times. Periodically, flavedo samples were collected from the total surface of fruit, frozen and homogenized in liquid nitrogen, and kept at $-80 \stackrel{\circ}{\circ}$ for later analysis. The three groups composed of 'Navelate', 'Pinalate' and 'Pinalate' fruit treated with ABA contained the same number of fruit (90 fruit). Three biological replicates, each consisting of 5 fruit, were collected by 1,3 and 6 weeks of storage. In addition, 3 biological replicates of 10 fruit each were used to estimate NCPP incidence and water loss. 


\section{Water loss and peel damage incidence}

The susceptibility to dehydration of 'Navelate' fruit and its ABA-deficient mutant treated or not with $\mathrm{ABA}$ was evaluated by calculating the percentage of fruit weight loss along storage at 12 을 and $70-75 \% \mathrm{RH}$. In addition, the incidence of these fruit to NCPP during storage was estimated by determining the percentage of fruit showing damage. The results are the means of three biological replicate samples of 10 fruit each \pm S.E.M.

\section{ABA analysis}

The ABA was extracted from $1 \mathrm{~g}$ fresh weight (FW) frozen tissue with $80 \%$ acetone containing $0.5 \mathrm{~g} \mathrm{~L}^{-1}$ citric acid and $100 \mathrm{mg} \mathrm{L}^{-1}$ of butylated hydroxytoluene as previously described by Lafuente et al. (1997). After centrifugation, the supernatant was diluted in 3 serial dilutions in ice-cold TBS $\left(6.05 \mathrm{~g}_{\text {Tris L}}^{-1}, 8.8 \mathrm{~g} \mathrm{~L}^{-1}\right.$ $\mathrm{NaCl}$ and $0.2 \mathrm{mg} \mathrm{L}^{-1} \mathrm{Mg} \mathrm{Cl}_{2}$ at $\mathrm{pH}$ 7.8) and 3 samples for each dilution were analyzed by the indirect ELISA reported by Walker-Simmons (1987). The ABA-BSA(4, conjugate) was synthesized as previously reported by Weiler (1980) with some modifications (Norman et al., 1988). The results are the means of three biological replicate samples \pm S.E.M.

\section{RNA isolation and qRT-PCR analysis}

Total RNA was extracted from frozen flavedo samples as reported by Romero et al. (2012b). Total RNA was treated with Ribonuclease-free DNase following the manufacturer's instructions. The amount and integrity of RNA was measured by spectrophotometric analysis and by agarose gel electrophoresis and ethidium-bromide staining, respectively. 
Reverse transcription followed by quantitative polymerase chain reaction (qRT-PCR) was performed in a two-step qRT-PCR assay as previously described Romero et al. (2012b). Gene-specific primers sequences are detailed in Table 1.

Table 1. Primers designed for the gene expression analysis of the ABA-signalling core components by quantitative RT-PCR (qRT-PCR).

\begin{tabular}{|c|c|c|c|c|}
\hline $\begin{array}{l}\text { Citrus } \\
\text { gene }\end{array}$ & Homologous in A. thaliana & $\begin{array}{l}\text { Forward } \\
\text { / Reverse }\end{array}$ & Sequence $5^{\prime} \rightarrow 3^{\prime}$ & $\begin{array}{l}\text { Amplicon } \\
\text { size (bp) }\end{array}$ \\
\hline \multirow[t]{2}{*}{ CsPYR1 } & AT4G17870; & $\mathrm{F}$ & CCGGGGTAACTCAGGACGAG & \multirow{2}{*}{198} \\
\hline & Pyrabactin Resistance 1 & $\mathrm{R}$ & CGGAGACGGAACAGCTCTTG & \\
\hline \multirow[t]{2}{*}{ CsPYL2 } & AT2G26040; & $\mathrm{F}$ & GGCCTATCATCGAAAGATACC & \multirow{2}{*}{209} \\
\hline & PYR1-Like protein 2 & $\mathrm{R}$ & CGATACAACCGTCACTTCTC & \\
\hline \multirow[t]{2}{*}{ CsPYL4 } & AT2G38310; & $\mathrm{F}$ & CGAACGAAGACACCTGCGTG & \multirow{2}{*}{168} \\
\hline & PYR1-Like protein 4 & $\mathrm{R}$ & CGAGAACAGAACATGACCTG & \\
\hline \multirow[t]{2}{*}{ CsPYL5 } & AT5G05440; & $\mathrm{F}$ & GCCCGGCGGTACATCACAAA & \multirow{2}{*}{184} \\
\hline & PYR1-Like protein 5 & $\mathrm{R}$ & GCCCGCAGCTAACAGCACG & \\
\hline \multirow[t]{2}{*}{ CsPYL8 } & AT4G27920; & $\mathrm{F}$ & GCGGTGCATTTTGGGACGCTTC & \multirow{2}{*}{111} \\
\hline & PYR1-Like protein 8 & $\mathrm{R}$ & GGCAAAGCCTTAGCAGAATCG & \\
\hline \multirow[t]{2}{*}{ CSPYL9 } & AT1G01360; & $\mathrm{F}$ & CGGAGATCATCGACGGGAGA & \multirow{2}{*}{166} \\
\hline & PYR1-Like protein 9 & $\mathrm{R}$ & CGGTCCTGCACCGCCATCC & \\
\hline \multirow[t]{2}{*}{ CsABI1 } & AT4G26080; & $\mathrm{F}$ & GGTGACTGCAAAAGCACGAT & \multirow{2}{*}{129} \\
\hline & ABA-insensitive 1 & $\mathrm{R}$ & GGGGCAACAGGTTCACCTCC & \\
\hline \multirow[t]{2}{*}{ CsAHG1 } & AT5G51760; & $\mathrm{F}$ & CGGGTAATGCGAATGCGGG & \multirow{2}{*}{170} \\
\hline & ABA-hypersensitive germination 1 & $\mathrm{R}$ & CCCAACGCTCCCACACGCGCACG & \\
\hline \multirow[t]{2}{*}{ CsAHG3 } & AT3G11410; & $\mathrm{F}$ & GGGATGACTTCAGTTTGCGGTA & \multirow{2}{*}{227} \\
\hline & ABA-hypersensitive germination 3 & $\mathrm{R}$ & CGGAGCTCTTCACTTTAATGGC & \\
\hline \multirow[t]{2}{*}{ CsHAB1 } & AT1G72770; & $\mathrm{F}$ & CCGGAGTGTCTTCGAGGTGG & \multirow{2}{*}{173} \\
\hline & Hypersensitive to ABA 1 & $\mathrm{R}$ & GGCCATTCAAACAGTGGCTC & \\
\hline \multirow[t]{2}{*}{ CsHAI3 } & AT5G59220; & $\mathrm{F}$ & GCCCCTGGCGGCCACTCC & \multirow{2}{*}{245} \\
\hline & Highly ABA-induced 3 & $\mathrm{R}$ & GGCCCACACATATAGAAACC & \\
\hline \multirow[t]{2}{*}{ CsSnRK2.2 } & AT3G50500; & $\mathrm{F}$ & CTGTTCCAGACACTAATCCA & \multirow{2}{*}{165} \\
\hline & SNF1-related protein kinase 2.2 & $\mathrm{R}$ & GGCTACTCATAGTCTTTTCATCC & \\
\hline \multirow[t]{2}{*}{ CsSnRK2.6 } & AT4G33950; & $\mathrm{F}$ & GAGCCAAAGAACTTCCGCAA & \multirow{2}{*}{139} \\
\hline & SNF1-related protein kinase 2.6 & $\mathrm{R}$ & GGGTTTCGGATCTCGGGTAT & \\
\hline
\end{tabular}

The occurrence of non-specific amplified products was ruled out after performing a melting curve analysis and sequencing the reaction products. Statistical analysis (Pair Wise Fixed Reallocation Randomisation Test) was carried out by using the Relative Expression Software Tool (REST, http://rest.genequantification.info) (Pfaffl, 2001). Expression levels were always referred to that obtained in freshly harvested (FH) 'Navelate' fruit. Three biological samples for 
each sampling period and variety were analyzed in duplicate and mean ratios \pm S.E.M. were calculated. In addition, in order to compare absolute gene expression values, amplicons of each gene were cloned in pGEMT vector (Promega) and used to generate standard curves by serial dilutions as described in Romero et al. (2012a). Data were then normalized by using the housekeeping genes CSACT, CSGAPDH and CSTUB (Table 1). Three biological replicates for each sampling period and variety were analyzed in duplicate and mean ratios were calculated.

\section{Statistical design}

Results are the means of three replicates samples \pm S.E.M. A mean comparison using the Tukey's test was performed to determine if means values were significantly different $(P \leq 0.05)$ between varieties at each sampling period. 


\section{RESULTS}

Six CSPYR/PYL/RCAR, five PP2CA and two subclass III SnRK2 genes, homologous to those of Arabidopsis, have been recently identified in Citrus as the core elements of the ABA perception system (Romero et al., 2012a). In the present work, the relationship between changes in endogenous $A B A$ content and in gene expression levels of the ABA-signalosome components occurring in the flavedo of 'Navelate' oranges and of its spontaneous ABA-deficient mutant 'Pinalate' stored under conditions causing moderate water stress and NCPP (12 ㅇ and $70-75 \% \mathrm{RH}$ ) have been examined.

Transcriptional regulation of CSPYR/PYL/RCAR in the flavedo of 'Navelate' and its ABA-deficient mutant 'Pinalate' stored under conditions inducing moderate water stress

No significant differences were found in the relative expression levels of CSPYR/PYL/RCAR genes between the flavedo of FH parental and ABA-deficient mutant fruit (Fig. 1). Two different expression patterns were found among these genes in 'Navelate', 'Pinalate' and ABA-treated 'Pinalate' fruit exposed to moderate dehydration (Fig. 1). The expression levels of CSPYR1, CSPYL8 and CSPYL9 genes increased in both parental and mutant fruit and the most important increases occurred by the first storage week. Thereafter, the rate of increase in the accumulation of CSPYR1 and CSPYL9 transcripts in 'Navelate' and 'Pinalate' fruit non-treated with $A B A$ was slower and no relevant changes were found in CSPYL8 gene expression (Fig. 1). These patterns did not parallel that of weight loss, which continuously increased during the whole storage period (Table 2). In contrast, the most important increases in ABA levels occurred also in both cultivars by the first week (Table 2). 


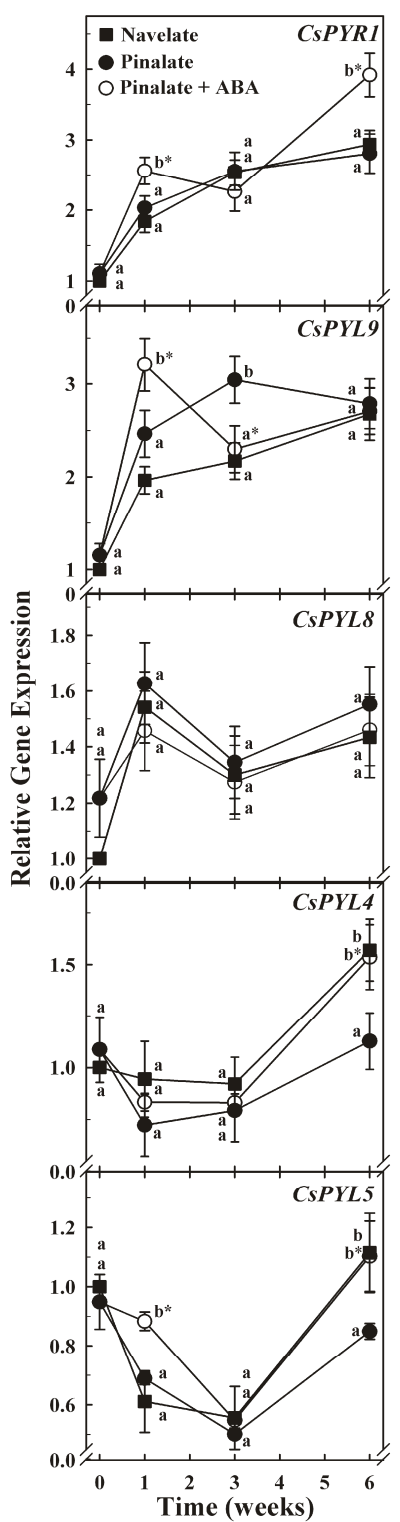

Figure 1. Relative gene expression analysis by qRT-PCR of Citrus PYR/PYL/RCAR ABA receptors in 'Navelate' (squares) and 'Pinalate' (circle) fruit, treated (white) or not (black) with ABA and stored under conditions causing moderate water-stress (70-75\% RH and $12 \circ \mathrm{o})$. Expression values are relative to transcript levels obtained in $\mathrm{FH}$ 'Navelate' fruit. Values are mean ratios \pm S.E.M. from three biological replicates for each sampling period and variety analyzed in duplicate. Significant differences $(P \leq 0.05)$ for the same storage period are indicated by different letters. Asterisks 
indicate significant differences $(P \leq 0.05)$ between 'Pinalate' fruit treated or not with ABA for the same storage period.

In spite of the differences found in the ABA content between parental and the ABA-deficient mutant fruit, and in the higher ability of parental fruit to increase the hormone levels under mild water stress (Table 2), significant differences in the expression levels of this set of genes (CSPYR1, CSPYL8 and CSPYL9) were found only when analyzing the receptor CSPYL9. As shown in Fig. 1, the accumulation of this transcript was significantly higher in the ABA-deficient mutant by 3 weeks although such difference was lost after prolonged storage ( 6 weeks). Exogenous ABA had, in general, little effect on the expression of these genes (Fig. 1) in spite of the efficacy of the treatment increasing ABA content in the flavedo of mutant fruit (Table 2). The most relevant changes were observed in the expression levels of CSPYR1 and CSPYL9, which were transiently increased by ABA application in 'Pinalate' fruit by 1 week. Final CSPYL9 transcript levels in 'Navelate' and 'Pinalate' fruit treated or not with ABA were similar, whereas CSPYR1 gene expression was significantly higher in the ABA-treated mutant fruit by 6 weeks (Fig. 1).

On the other hand, the expression of CSPYL5 gene decreased in all cultivars for up to 3 weeks although it increased thereafter. The accumulation of CSPYL4 transcript also decreased by 1 week in the mutant and this effect was not counteracted by ABA application (Fig. 1). Exogenous ABA delayed the sharp decline in CSPYL5 transcript accumulation occurring by 1 week in 'Pinalate' fruit although expression levels of this gene were similar by this period in the mutant and parental fruit. Transcript levels of both CSPYL4 and CSPYL5 increased after 3 weeks in all conditions. As shown in Fig. 1, expression levels of both genes reached by 6 weeks in mutant fruit were significantly lower than those reached in the parental or in the ABA-treated 'Pinalate' fruit. 


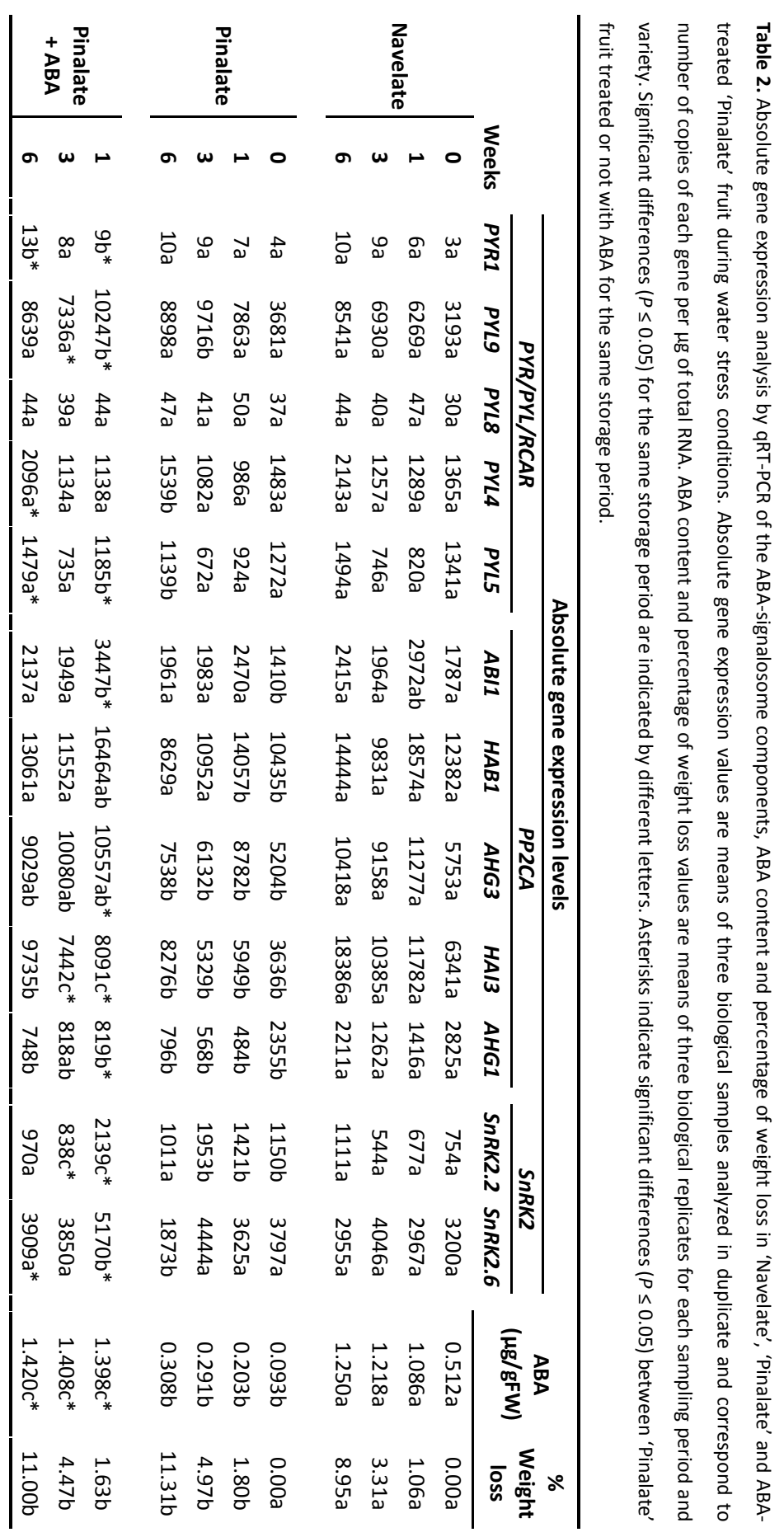


Absolute gene expression analysis further revealed that the least expressed gene was CSPYR1, followed by CSPYL8 (Table 2). CSPYL4 and CSPYL5 transcripts accumulation was at least 15-fold higher than those of CSPYR1 and CSPYL8 genes and similar along whole storage (Table 2). The most expressed gene during fruit dehydration was CSPYL9, whose transcript accumulation was up to 10fold higher than that of the other genes of this family (Table 2). In contrast, the expression of CSPYL2 gene was not detected in the flavedo of fruit of any cultivar under these experimental conditions.

Transcriptional regulation of the CSPP2CAs-SnRK2 complex in the flavedo of 'Navelate' and its ABA-deficient mutant 'Pinalate' stored under conditions inducing moderate water stress

Relative gene expression levels of all CSPP2CAs were significantly higher in $\mathrm{FH}$ parental fruit than in the FH mutant (Fig. 2). Applying ABA to the mutant partially rescued the wild-type phenotype since significantly increased the accumulation of CSPP2CAs transcripts in 'Pinalate' fruit stored for 1 week under conditions causing moderate dehydration (see asterisks in Fig. 2). As result of these increases, some of the differences afforded by applying ABA were lost when gene expression levels were compared simultaneously with those of 'Navelate' fruit (see letters in Fig. 2).

As shown in Fig. 2, transcript levels of CSABI1, CSHAB1 and CSAHG3 sharply and transiently increased in 'Navelate' and 'Pinalate' fruit, treated or not with ABA, during the first storage week and rises in CSHAB1 and CSAHG3 were higher in the parental than in the mutant fruit. ABA application to 'Pinalate' fruit, which was effective increasing the hormone content in the flavedo (Table 2), significantly increased the expression levels of the CSABII and CSAHG3 genes by 1 week in 'Pinalate' fruit but not those of CSHAB1 (Fig. 2). 


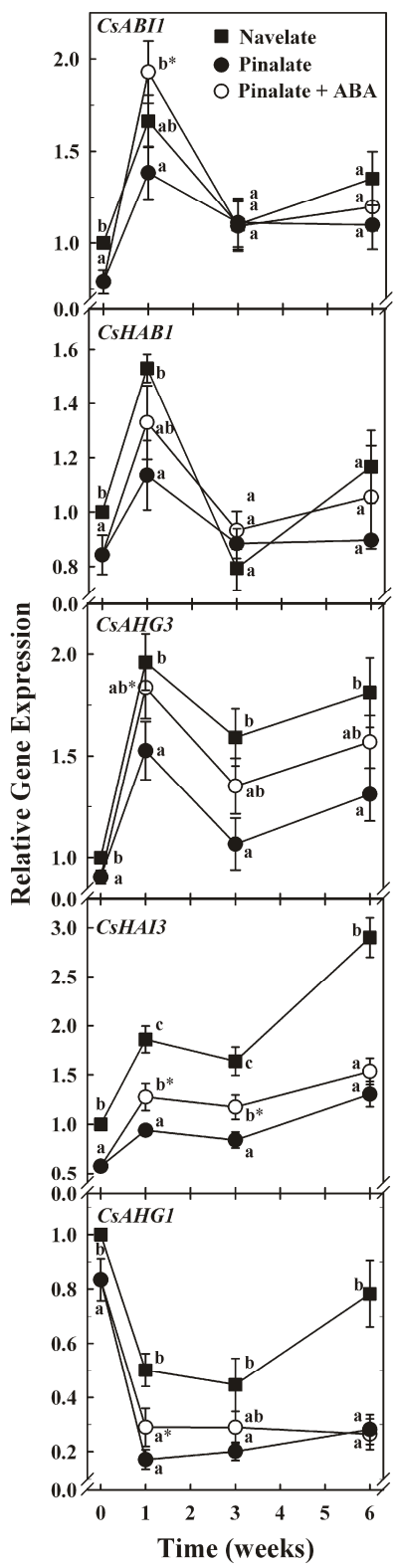

Figure 2. Relative gene expression analysis by qRT-PCR of Citrus PP2CA negative regulators in 'Navelate' (squares) and 'Pinalate' (circle) fruit, treated (white) or not (black) with ABA and stored under conditions causing moderate water-stress (70-75\% RH and $12 \stackrel{\circ}{\circ}$ ). Expression values are relative to transcript levels obtained in $\mathrm{FH}$ 'Navelate' fruit. Values are mean ratios \pm S.E.M. from three biological replicates for each sampling period and variety analyzed in duplicate. Significant differences $(P \leq 0.05)$ for the same storage period are indicated by different letters. Asterisks 
indicate significant differences $(P \leq 0.05)$ between 'Pinalate' fruit treated or not with ABA for the same storage period.

The accumulation of CSABI1 and CSHAB1 transcripts levelled off in the parental by 3 weeks, reached similar levels to those of mutant fruit treated or not with $A B A$, and remained almost steady thereafter in all conditions (Fig. 2). The expression levels of $C S A H G 3$ also decreased by 3 weeks in both varieties, although such decrease was lower in the parental. Therefore, transcript levels of this gene were significantly higher in the parental than in the mutant fruit by 3 and 6 storage weeks (Fig. 2).

The expression levels of CSHAI3 increased during storage in both 'Navelate' and 'Pinalate' fruit (Fig. 2). This effect was much higher in wild-type fruit and hence CSHAI3 expression levels were higher in the parental during the whole storage period and doubled those of the mutant fruit by the end of the experiment (Fig. 2). Treating 'Pinalate' fruit with ABA also favoured the accumulation of this transcript during storage although statistical differences with respect to control mutant fruit were lost by 6 weeks.

The gene CSAHG1 was the unique CSPP2CA whose expression was downregulated during the first storage week. By this period, a 2 and 4-fold decreases in transcript levels were found in parental and mutant fruit, respectively, and this major decrease in 'Pinalate' was slightly counteracted by applying ABA. Thereafter, transcript accumulation remained steady in 'Pinalate' fruit treated or not with ABA. However, CSAHG1 gene expression increased after 3 weeks in 'Navelate' fruit and reached levels 4 -fold higher than in mutant fruit by the end of the experiment (Fig. 2). Absolute transcript levels of this gene were similar to those of CSABI1 and much lower than those of the other CSPP2CAs in both parental and mutant FH fruit (Table 2). Thus, CSAHG3 and CSHAl3 transcripts accumulation was similar and remained at higher levels than those of CSABI1 and 
AHG1, whereas CSHAB1 was the most expressed CSPP2CA in FH fruit of both cultivars.

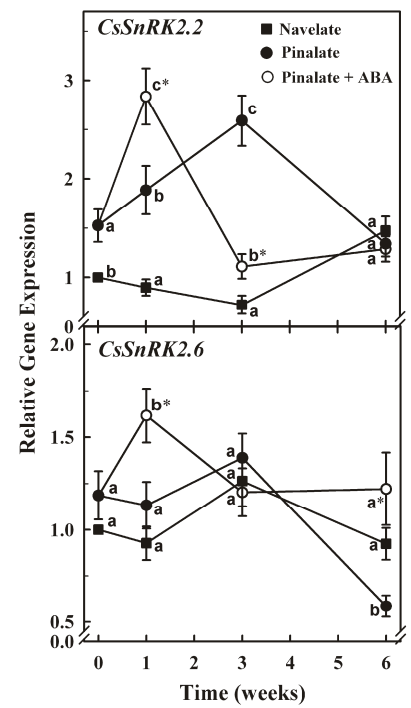

Figure 3. Relative gene expression analysis by qRT-PCR of Citrus SnRK2 downstream protein kinases in 'Navelate' (squares) and 'Pinalate' (circle) fruit, treated (white) or not (black) with ABA and stored under conditions causing moderate water-stress (70-75\% RH and $12 \stackrel{\circ}{\circ}$ ). Expression values are relative to transcript levels obtained in $\mathrm{FH}$ 'Navelate' fruit. Values are mean ratios \pm S.E.M. from three biological replicates for each sampling period and variety analyzed in duplicate. Significant differences $(P \leq 0.05)$ for the same storage period are indicated by different letters. Asterisks indicate significant differences $(P \leq 0.05)$ between 'Pinalate' fruit treated or not with ABA for the same storage period.

The expression levels of CSSnRK2.2 and CsSnRK2.6 genes, belonging to the citrus subclass III SnRK2 family, were higher in the FH ABA-deficient mutant fruit than in the parental, although significant differences were only found in CsSnRK2.2 transcript accumulation (Fig. 3). These genes showed different patterns of changes during fruit storage (Fig. 3). The CSSnRK2.6 gene expression barely increased by 3 weeks in both parental and mutant fruit. Thereafter, it decreased and reached final levels 2-fold lower in 'Pinalate'. Applying the hormone to the ABA-deficient mutant increased the expression level of this gene by 1 week and 
avoided the sharp decrease occurring in 'Pinalate' fruit by 6 weeks (Fig. 3). The CsSnRK.2.2 transcript accumulation reached a maximum by 3 weeks in 'Pinalate' fruit. A sharp decrease in gene expression was observed thereafter in this cultivar while transcript levels increased by 6 weeks in parental fruit (Fig. 3). As in the case of the CSSnRK2.6 gene, exogenous ABA significantly induced the accumulation of the CSSnRK.2.2 transcript by 1 week in 'Pinalate' respect to control mutant fruit. The expression levels of this gene sharply decreased thereafter in ABA-treated 'Pinalate' fruit and similar levels were found in all conditions by the end of the experiment (Fig. 3). In addition, absolute gene expression analyses revealed that the accumulation of the CsSnRK2.6 protein kinase transcript was at least 2-fold higher than that of the CSSnRK2.2 gene in freshly and dehydrated fruit of both cultivars (Table 2).

\section{Incidence of NCPP in 'Navelate' fruit and its ABA-deficient mutant 'Pinalate'}

Peel pitting was evident by 1 week and the percentage of damaged mutant fruit doubled that of the parental cultivar (Fig. 4). By this period, about $60 \%$ of mutant fruit displayed damaged, although NCPP severity was still very low in the mutant and almost undetectable in the parental fruit (data not shown). This difference between mutant and wild-type fruit was maintained as storage progressed. By the end of the experiment ( 6 weeks), all mutant fruit developed NCPP, whereas only a $60 \%$ of parental fruit displayed damage (Fig. 4). NCPP incidence in ABA-treated mutant fruit became significantly lower than that of the control non-treated mutant fruit after 3 weeks, but it was still much higher than that of the parental fruit (Fig. 4). 


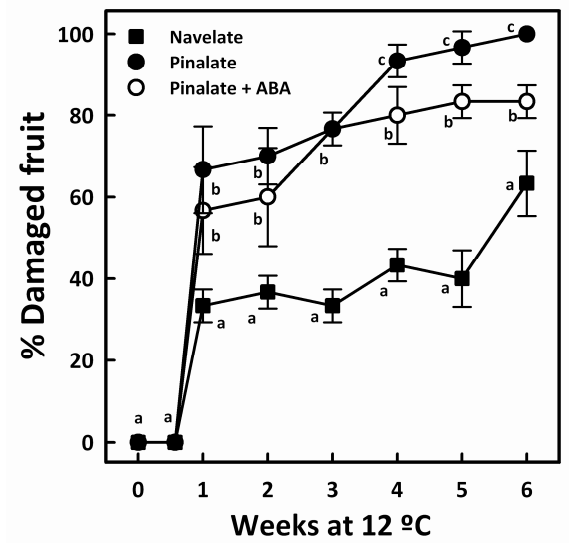

Figure 4. Non-chilling peel pitting incidence in 'Navelate' (squares) and 'Pinalate' (circle) fruit, treated (white) or not (black) with ABA, stored for up to 6 weeks at $12{ }^{\circ} \mathrm{C}$ and $70-75 \% \mathrm{RH}$. Results are means of three biological replicates of 10 fruit each \pm S.E.M. Mean separation was performed by applying Tukey's test. Different letters indicate statistical $(P \leq 0.05)$ differences between varieties for the same storage period. 


\section{DISCUSSION}

The hormone $\mathrm{ABA}$ has been involved in postharvest quality and stress tolerance of fruit (Serrano et al., 2004; Alférez et al., 2005; Cantín et al., 2007). The three core components of the $A B A$ perception and signal transduction pathway have been recently identified in Citrus and the relationship existing between their transcriptional regulation and $A B A$ accumulation during natural fruit ripening and severe leaf dehydration has been described (Romero et al., 2012a). However, the regulation of the ABA-signalosome in response to moderate dehydration occurring in fruit during postharvest handling and storage remains still unknown. In citrus fruit, water stress increases $A B A$ and favours the occurrence of postharvest physiological disorders such as NCPP (Lafuente and Zacarías, 2006). Therefore, this research has focused on comparing the effect of moderate water stress on the transcriptional regulation of the ABA-signalosome in the flavedo of 'Navelate' and its fruit-specific ABA-deficient mutant 'Pinalate', which is more prone to dehydration and to develop NCPP (Alférez et al., 2005).

Results obtained have revealed that the expression of some ABAsignalosome elements are differentially regulated in the flavedo of harvested fruit of both cultivars under water stress conditions, which may fit with the lower ability of the mutant to increase $A B A$ levels when stored at $70-75 \% \mathrm{RH}$ and/or with its higher susceptibility to dehydration (Table 2). Thus, although minor differences were found in the expression levels of the ABA receptors (CSPYR/PYL/RCARs) between 'Navelate' and 'Pinalate' fruit in response to dehydration for the same storage period (Fig. 1 and Table 2) differences in the negative regulators (CSPP2CAs) gene expression were relevant (Fig. 2 and Table 2). This is in agreement with previous findings showing that the different ability of both cultivars to increase $A B A$ during fruit maturation has little effect on gene 
expression of the positive regulators of the $A B A$ signalling pathway (CSPYR/PYL/RCARs and CsSnRK2s) (Romero et al., 2012a). In this context, it is noteworthy that rises in $A B A$ occurring during fruit maturation were similar to those found in the present work in response to moderate dehydration. Furthermore, little changes in the regulation of both $A B A$ receptors and downstream protein kinases were observed between non-stressed citrus leaves and those exposed to severe water stress conditions causing a 15-fold ABA increment and a 20\% weight loss (Romero et al., 2012a). Therefore, results of the present work reinforce the idea that $P Y R / P Y L / R C A R$ genes are barely affected by the endogenous $A B A$ content in Citrus, independently of the tissue and the physiological or stressful conditions examined. Our results in Citrus agree with other found in tomato fruit treated with $\mathrm{ABA}$ and in Vitis and tomato leaves exposed to water stress (Sun et al., 2011; Li et al., 2012), although PYR/PYL/RCAR genes may be regulated by water stress and/or ABA content in Arabidopsis seedlings (Szostkiewicz et al., 2010).

Results presented herein also revealed that transcript levels of CSPYL9, which was the most expressed ABA receptor, continuously increased during fruit dehydration. In contrast, this gene was down-regulated by dehydration in leaves and during fruit ripening. These results, together with the fact that CSPYL2 gene expression was detected in leaves (Romero et al., 2012a) but not in flavedo (Fig. 1), highlights the relevance of the differential regulation and tissue specificity expression of the different genes in this family and brings to question the effect of the stress severity on the modulation of the ABA perception and response. Such effect appears to be independent of the hormone content since rises in ABA levels during fruit ripening were similar to those found in response to moderate dehydration. In this regard, it is noticing that although some CSPYR/PYL/RCAR gene expression patterns were tightly related to $A B A$ and mirrored the hormone 
accumulation in both 'Navelate' and its ABA-deficient mutant 'Pinalate' during fruit ripening (Romero et al., 2012a), this behaviour was not fully conserved either in dehydrated flavedo (Fig. 1) or leaf tissues (Romero et al., 2012a). Therefore, transcriptional regulation of Citrus ABA receptors might be differentially modulated by tissue specificity and by the developmental or stress conditions responsible for the induction of the hormone signal.

Differences in the expression levels of the CSPP2CAs genes between 'Navelate' and 'Pinalate' fruit in response to dehydration were relevant, which is in concordance with the fact that they function as negative regulators of the ABA signalling pathway and their expression is highly induced by $A B A$ in plants (Merlot et al., 2001; Saez et al., 2004; Yoshida et al., 2006; Xue et al., 2008; Li et al., 2009). Thus, we found that moderate water stress is able to induce CSPP2CAs gene expression in 'Navelate' and 'Pinalate' fruit concomitantly with ABA accumulation (Fig. 2 and Table 2), which agrees with previous findings in Arabidopsis and tomato leaves and also with PP2CAs responses occurring in tomato and strawberry during fruit ripening (Szostkiewicz et al., 2010; Chai et al., 2011; Sun et al., 2011). It is noticing that all CSPP2CAs followed similar expression patterns in fruit of both cultivars during moderate water stress (Fig. 2), as it occurred during maturation (Romero et al., 2012a), although absolute transcript levels in the fruitspecific ABA-deficient mutant 'Pinalate' were significantly lower than in the parental fruit (Table 2). Likewise, non-dehydrated leaves displayed similar CSPP2CAs expression patterns than water-stressed leaves although transcript accumulation remained at lower levels in control samples, which might be associated with much lower ABA levels (Romero et al., 2012a). Therefore, it appears that the expression of the CSPP2CAs negative regulators is tightly regulated by the endogenous $A B A$ content under both physiological and stressful conditions, independently of the tissue and the severity of the stress. 


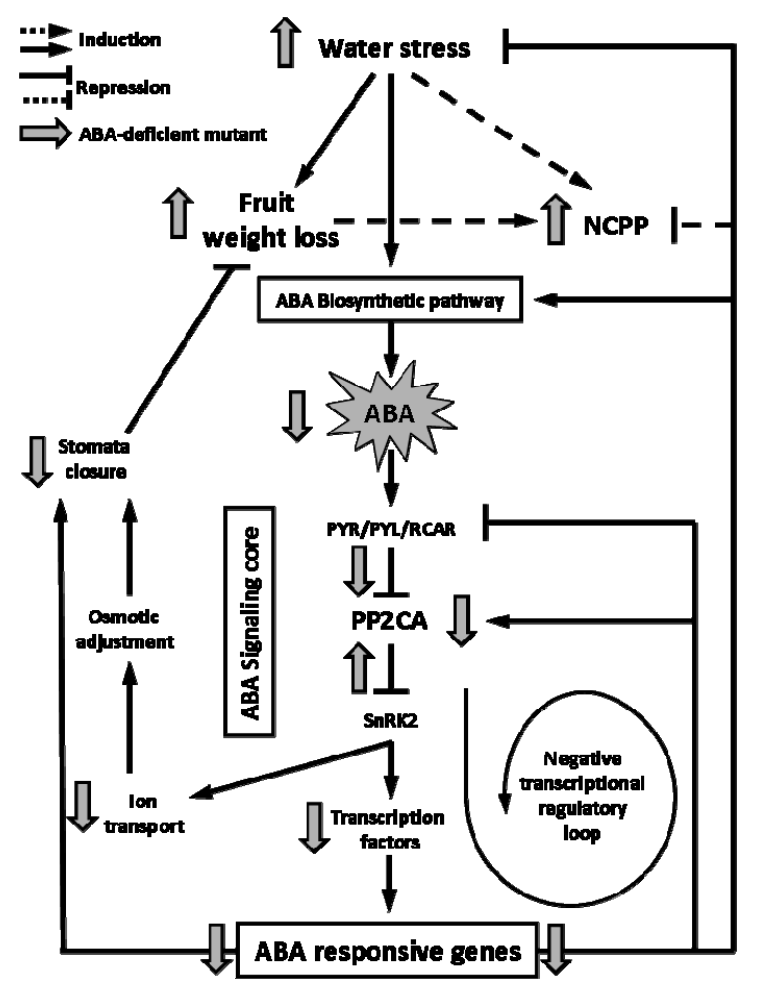

Figure 5. Proposed $A B A$ signalling integration model in dehydrated citrus fruit and influence of $A B A-$ deficiency: Water stress causes fruit weight loss and enhances the development of NCPP in citrus fruit. Stress signal promotes $A B A-b i o s y n t h e t i c$ genes expression and, consequently, $A B A$ accumulation. ABA-mediated PYR/PYL/RCAR-inactivation of the PP2CAs, negative regulators of the ABA signalling pathway, releases SnRK2 downstream protein kinases from their constitutive blockage, allowing its activation by phosphorilation and the transduction of the ABA signal downstream in the pathway. Thus, SnRK2s regulate the phosphorilation degree of transcription factors and ion channels, which modulate the expression of ABA-responsive genes and adjust cell osmotic pressure, respectively. These responses would cope with dehydration and the deleterious effects caused by this stress and would attenuate the ABA signal by a negative transcriptional regulatory loop that involves the repression of the $A B A$ receptors and the induction of the PP2CA negative regulators. Grey arrows indicate the hypothesized molecular response of the ABA-deficient mutant fruit 'Pinalate'. In this mutant, water stress increases weight loss and NCPP incidence, but trigger a deficient accumulation of endogenous ABA. Consequently, the release of the SnRK2s, the subsequent downstream signal transduction including the osmotic adjustment, the water stress and NCPP responses, and the negative transcriptional loop that regulates the PP2CAs levels are attenuated. Therefore, this ABA-deficient mutant would result in an impaired $A B A$ response to dehydration mainly caused by an inefficient $A B A$ signalling. Dotted lines refer to interactions that have not been confirmed in model plants or in Citrus cultivars. 
Among downstream protein kinases forming the CSPP2CAs-SnRK2 complex, it should be highlighted that the CsSnRK2.6 kinase was more expressed in fruit (Table 2) and leaves (Romero et al., 2012a) than the second kinase (CsSnRK2.2) identified in Citrus, and that changes in CsSnRK2.6 gene expression in response to dehydration appears to be tissue-specific. Thus, this gene was downregulated in both cultivars during fruit dehydration concomitantly with ABA rises (Table 2 and Fig. 3) as it occurred during fruit ripening (Romero et al., 2012a), but it was up-regulated by water stress in leaves (Romero et al., 2012a). Contrary, CSSnRK2.2 gene expression continuously decreased during dehydration in both fruit (Table 2 and Fig. 3) and leaves (Romero et al., 2012a) and also during fruit ripening, concomitantly with $A B A$ increases. It should be also mentioned that relevant differences in the expression pattern of this gene were found between 'Navelate' and 'Pinalate' fruit under water stress, which encourage further research to better understand the role of CsSnRK2.2 gene in the differential response of parental and mutant fruit to dehydration.

Results obtained in a previous work by comparing transcriptomic profiling of dehydrated 'Navelate' and 'Pinalate' fruit suggested that the ABA perception system could be impaired in the mutant and that this might affect its water-stress responses and NCPP susceptibility (Romero et al., 2012b). Results from the present work also revealed that ABA application to 'Pinalate' fruit was effective modifying the transcriptional regulation of some ABA-signalling components. Thus, exogenous $A B A$ mainly increased gene expression of the $A B A$ receptors by 1 week and at the end of the storage (Fig. 1), whereas transcript levels of all components of the downstream complex (PP2CA-SnRK2) peaked by 1 week (Fig. 2 and 3). The treatment also increased the ABA content in the flavedo (Table 2 ) but it did not modify significantly $(P \leq 0.5)$ the weight loss of this mutant (Table 2 ). Differences in NCPP incidence between ABA-treated and non-treated mutant fruit 
were significant, however, after 3 storage weeks. Thus, the percentage of damaged fruit was reduced by the ABA treatment but it was still much higher in the ABA-treated 'Pinalate' than in the parental fruit (Fig. 4). These results may indicate that exogenous ABA partially rescues the susceptibility of 'Pinalate' fruit to NCPP, which would be in concordance with previous findings showing that water stress favours the occurrence of NCPP although other factors should be important for its development (Petracek et al., 1998; Ben Yoshua et al., 2001; Porat et al., 2004; Cajuste et al., 2007). Complementary, results found and summarized in the model proposed in Fig. 5 suggest that this mutant is not fully sensitive to the hormone. This behaviour could be explained by the occurrence of a negative transcriptional loop that regulates $A B A$ receptors and PP2CAs expression levels, as suggested by Merlot et al. (2001) in Arabidopsis plants. Accordingly, overall results of the present work might suggest that ABA-reduction and, hence, the decreased expression levels of the CSPP2CA negative regulators in 'Pinalate' fruit could be in part responsible for its inefficient response to ABArelated signals and for its higher susceptibility to develop NCPP under moderate water stress.

In summary, results revealed the first evidence for the transcriptional regulation of the ABA-signalosome components in fruit subjected to water-stress conditions. Low differences in $\mathrm{ABA}$ receptors and downstream protein kinases transcript levels were found between 'Navelate' and its ABA-deficient mutant 'Pinalate' fruit in response to dehydration. Contrary, CSPP2CAs gene expression was substantially regulated by $A B A$ content and showed significant differences between varieties. Moreover, it appears that transcriptional regulation of the ABA receptors and downstream protein kinases might be differentially affected by tissue specificity, the stress severity and the source of the ABA signal from a developmental or stressful stimulus. In contrast, CSPP2CAs negative regulators 
have shown a consistent response among all studied conditions and tissues, which point out these components as potential targets to improve drought hardiness in citrus. 


\section{REFERENCES}

Alférez F, Agustí M, Zacarías L. 2003. Postharvest rind staining in Navel oranges is aggravated by changes in storage relative humidity: effect on respiration, ethylene production and water potential. Postharvest Biology and Technology 28, 143-152.

Alférez F, Alquézar B, Burns JK, Zacarías L. 2010. Variation in water, osmotic and turgor potential in peel of 'Marsh' grapefruit during development of postharvest peel pitting. Postharvest Biology and Technology 56, 44-49.

Alférez F, Burns JK. 2004. Postharvest peel pitting at non-chilling temperatures in grapefruit is promoted by changes from low to high relative humidity during storage. Postharvest Biology and Technology 32, 79-87.

Alférez F, Lluch Y, Burns JK. 2008. Phospholipase A2 and postharvest peel pitting in citrus fruit. Postharvest Biology and Technology 49, 69-76.

Alférez F, Sala JM, Sanchez-Ballesta MT, Mulas M, Lafuente MT, Zacarías L. 2005. A comparative study of the postharvest performance of an ABA-deficient mutant of oranges: I. Physiological and quality aspects. Postharvest Biology and Technology 37, 222-231.

Bartels D, Sunkar R. 2005. Drought and salt tolerance in plants. Critical Reviews in Plant Sciences 24, 23-58.

Ben-Yehoshua, S, Peretz, J, Moran, R, Lavie, B, Kim, JJ. 2001. Reducing the incidente of superficial flavedo necrosis (noxan) of 'Shamouti' oranges (Citrus sinensis, Osbeck). Postharvest Biol. Technol. 22, 19-27.

Boneh U, Biton I, Schwartz A, Ben-Ari G. 2012a. Characterization of the ABA signal transduction pathway in Vitis vinifera. Plant Science 187, 89-96.

Boneh U, Biton I, Zheng C, Schwartz A, Ben-Ari G. 2012b. Characterization of potential ABA receptors in Vitis vinifera. Plant Cell Reports 31, 311-321.

Bonghi C, Rizzini FM, Gambuti A, Moio L, Chkaiban L, Tonutti P. 2012. Phenol compound metabolism and gene expression in the skin of wine grape (Vitis vinifera L.) berries subjected to partial postharvest dehydration. Postharvest Biology and Technology 67, 102109. 
Cajuste, JF, González-Candelas, L, Veyrat, A, García-Breijo, FJ, Reig-Armiñana, J, Lafuente, MT. 2010. Epicuticular wax content and morphology as related to ethylene and storage performance of 'Navelate' orange fruit. Postharvest Biol. Technol. 55, 29-35.

Cantín CM, Fidelibus MW, Crisosto CH. 2007. Application of abscisic acid (ABA) at veraison advanced red color development and maintained postharvest quality of 'Crimson Seedless' grapes. Postharvest Biology and Technology 46, 237-241.

Chai YM, Jia HF, Li CL, Dong QH, Shen YY. 2011. FaPYR1 is involved in strawberry fruit ripening. Journal of Experimental Botany 62, 5079-5089.

Deluc L, Quilici D, Decendit A, et al. 2009. Water deficit alters differentially metabolic pathways affecting important flavor and quality traits in grape berries of Cabernet Sauvignon and Chardonnay. BMC Genomics 10, 212.

Groot SPC, Karssen CM. 1992. Dormancy and germination of abscisic acid-deficient tomato seeds: Studies with the sitiens mutant. Plant Physiology 99, 952-958.

Holland N, Menezes HC, Lafuente MT. 2005. Carbohydrate metabolism as related to hightemperature conditioning and peel disorders occurring during storage of citrus fruit. Journal of Agricultural and Food Chemistry 53, 8790-8796.

Imay R, Moses MS, Bray EA. 1995. Expression of an ABA-induced gene of tomato in transgenic tobacco during periods of water deficit. Journal of Experimental Botany 46, 1077-1084.

John-Karuppiah KJ, Burns JK. 2010. Degreening behavior in 'Fallglo' and 'Lee x Orlando' is correlated with differential expression of ethylene signaling and biosynthesis genes. Postharvest Biology and Technology 58, 185-193.

Kim H, Hwang H, Hong JW, et al. 2012. A rice orthologue of the ABA receptor, OsPYL/RCAR5, is a positive regulator of the ABA signal transduction pathway in seed germination and early seedling growth. Journal of Experimental Botany 63, 1013-1024.

Lafuente MT, Martínez-Téllez MA, Zacarías L. 1997. Abscisic acid in the response of 'Fortune' mandarins to chilling. Effect of maturity and high-temperature conditioning. Journal of the Science of Food Agriculture 73, 494-502.

Lafuente MT, Zacarías L. 2006. Postharvest physiological disorders in citrus fruit. Stewart Postharvest Review 1, 1-9. 
Li FH, Fu FL, Sha LN, He L, Li WC. 2009. Differential expression of serine/threonine protein phosphatase type-2C under drought stress in maize. Plant Molecular Biology Reporter 27, 29-37.

Li G, Xin H, Zheng XF, Li S, Hu Z. 2012. Identification of the abscisic acid receptor VvPYL1 in Vitis vinifera. Plant Biology 14, 244-248.

Loyola J, Verdugo I, González E, Casaretto JA, Ruiz-Lara S. 2012. Plastidic isoprenoid biosynthesis in tomato: Physiological and molecular analysis in genotypes resistant and sensitive to drought stress. Plant Biology 14, 149-156.

Ma Y, Szostkiewicz I, Korte A, Moes D, Yang Y, Alexander C, Grill E. 2009. Regulators of PP2C phosphatase activity function as abscisic acid sensors. Science 324, 1064-1068.

Merlot S, Gosti F, Guerrier D, Vavasseur A, Giraudat J. 2001. The ABI1 and ABI2 protein phosphatases $2 \mathrm{C}$ act in a negative feedback regulatory loop of the abscisic acid signalling pathway. The Plant Journal 25, 295-303.

Nishimura N, Sarkeshik A, Nito K, et al. 2010. PYR/PYL/RCAR family members are major in-vivo ABI1 protein phosphatase $2 \mathrm{C}$-interacting proteins in Arabidopsis. The Plant Journal 61, 290-299.

Norman SM, Poling SM, Maier VP. 1988. An indirect enzyme-linked immunosorbent assay for (+)-abscisic acid in Citrus, Ricinus, and Xanthium leaves. Journal of Agricultural and Food Chemistry 36, 225-231.

Park SY, Fung P, Nishimura N, et al. 2009. Abscisic acid inhibits type 2C protein phosphatases via the PYR/PYL family of START proteins. Science 324, 1068-1071.

Petracek, PD, Dou, H, Pao, S. 1998. The influence of applied waxes on postharvest physiological behaviour and pitting of grapefruit. Postharvest Biol. Technol. 14, 99-106.

Pfaffl MW. 2001. A new mathematical model for relative quantification in real-time RT̃PCR. Nucleic Acids Research 29, e45.

Porat, R, Weiss, B, Cohen, L, Daus, A, Aharoni, N. 2004. Reduction of postharvest rind disorders in citrus fruit by modified atmosphere packaging. Postharvest Biol. Technol. 33, 35-43.

Riera M, Valon C, Fenzi F, Giraudat J, Leung J. 2005. The genetics of adaptive responses to drought stress: abscisic acid-dependent and abscisic acid-independent signalling components. Physiologia Plantarum 123, 111-119. 
Rizzini FM, Bonghi C, Tonutti P. 2009. Postharvest water loss induces marked changes in transcript profiling in skins of wine grape berries. Postharvest Biology and Technology 52, 247-253.

Rodrigo MJ, Marcos JF, Alférez F, Mallent MD, Zacarías L. 2003. Characterization of 'Pinalate', a novel Citrus sinensis mutant with a fruit-specific alteration that results in yellow pigmentation and decreased ABA content. Journal of Experimental Botany 54, 727738.

Romero P, Lafuente MT, Rodrigo MJ. 2012a. The Citrus ABA signalosome: Identification and transcriptional regulation during sweet orang fruit ripening and leaf dehydration. Journal of Experimental Botany 63, 4931-4945.

Romero P, Rodrigo MJ, Alférez F, Ballester AR, González-Candelas L, Zacarías L, Lafuente MT. 2012b. Unravelling molecular responses to moderate dehydration in harvested fruit of sweet orange (Citrus sinensis L. Osbeck) using a fruit-specific ABA-deficient mutant. Journal of Experimental Botany 63, 2753-2767.

Saez A, Apostolova N, González-Guzman M, González-García MP, Nicolas C, Lorenzo O, Rodríguez PL. 2004. Gain-of-function and loss-of-function phenotypes of the protein phosphatase 2C HAB1 reveal its role as a negative regulator of abscisic acid signalling. The Plant Journal 37, 354-369.

Sala JM, Sanchez-Ballesta MT, Alférez F, Mulas M, Zacarías L, Lafuente MT. 2005. A comparative study of the postharvest performance of an ABA-deficient mutant of oranges. II. Antioxidant enzymatic system and phenylalanine ammonia-lyase in non-chilling and chilling peel disorders of citrus fruit. Postharvest Biology and Technology 37, 232-240.

Sanchez-Ballesta MT., Zacarías L, Granell A, Lafuente MT. 2008. $\beta-1,3-G l u c a n a s e ~ g e n e$ expression as a molecular marker for postharvest physiological disorders in citrus fruit and its hormonal regulation. Postharvest Biology and Technology 48, 146-149.

Santiago J, Rodrigues A, Saez A, et al. 2009. Modulation of drought resistance by the abscisic acid receptor PYL5 through inhibition of clade A PP2Cs. The Plant Journal.

Schwartz SH, Tan BC, Gage DA, Zeevaart JAD, McCarty DR. 1997. Specific oxidative cleavage of carotenoids by VP14 of maize. Science 276, 1872-1874.

Serrano M, Martínez-Romero D, Castillo S, Guillén F, Valero D. 2004. Role of calcium and heat treatments in alleviating physiological changes induced by mechanical damage in plum. Postharvest Biology and Technology 34, 155-167. 
Shinozaki K, Yamaguchi-Shinozaki K. 2007. Gene networks involved in drought stress response and tolerance. Journal of Experimental Botany 58, 221-227.

Sun L, Wang YP, Chen P, et al. 2011. Transcriptional regulation of SIPYL, SIPP2C, and SISnRK2 gene families encoding ABA signal core components during tomato fruit development and drought stress. Journal of Experimental Botany 62, 5659-5669.

Szostkiewicz I, Richter K, Kepka M, et al. 2010. Closely related receptor complexes differ in their ABA selectivity and sensitivity. The Plant Journal 61, 25-35.

Umezawa T, Sugiyama N, Mizoguchi M, et al. 2009. Type 2C protein phosphatases directly regulate abscisic acid-activated protein kinases in Arabidopsis. Proceedings of the National Academy of Sciences 106, 17588-17593.

Walker-Simmons M. 1987. ABA levels and sensitivity in developing wheat embryos of sprouting resistant and susceptible cultivars. Plant Physiology 84, 61-66.

Weiler EW. 1980. Radioimmunoassays for the differential and direct analysis of free and conjugated abscisic acid in plant extracts. Planta 148, 262-272.

Xue T, Wang D, Zhang S, et al. 2008. Genome-wide and expression analysis of protein phosphatase $2 \mathrm{C}$ in rice and Arabidopsis. BMC Genomics 9, 550.

Yoshida T, Nishimura N, Kitahata N, et al. 2006. ABA-Hypersensitive Germination3 encodes a protein phosphatase 2C (AtPP2CA) that strongly regulates abscisic acid signaling during germination among Arabidopsis protein phosphatase 2Cs. Plant Physiology 140, 115-126. 
4. GENERAL DISCUSSION 

Drought is one of the major environmental causes of poor plant performance and limited crop yield worldwide (Yamaguchi-Shinozaki and Shinozaki, 2006). Numerous researches have been focused on understanding the molecular mechanisms underlying this stress in model and crop plants (Bray, 1993; Bray et al., 2000; Seki et al., 2002; Bartels and Sunkar, 2005). Among the water stress-induced compounds, the hormone $A B A$ is one of the most relevant because it plays a key role in the modulation and activation of numerous processes, such as the stomata closure, to prevent water loss in the plant (Wilkinson et al., 2012). Under drought conditions, ABA content is regulated by the induction of biosynthetic genes, and its signal transduction is modulated by the induction of signalling genes and ABA-responsive proteins or transcription factors (Bray, 1993; Ingram and Bartels, 1996; Shinozaki et al., 1998; Ramanjulu and Bartels, 2002; Bartels and Sunkar, 2005; Yamaguchi-Shinozaki and Shinozaki, 2006; Seki et al., 2007; Shinozaki and Yamaguchi-Shinozaki, 2007). During postharvest handling of fruits of agronomic interest, water stress is one of the most important factors reducing the external quality and hence the commercial value. However, the study of the molecular responses during dehydration in harvested fruit has been limited to a few set of genes (Alférez et al., 2008; Bonghi et al., 2012; Loyola et al., 2012), and global changes occurring in fruits under water stress conditions was only performed in grapes (Grimplet et al., 2007; Rizzini et al., 2009; Deluc et al., 2009; Zamboni et al., 2010).

In the present work, the availability of the sweet orange fruit-specific ABA-deficient mutant 'Pinalate' has allowed to get a deeper insight into the molecular mechanisms involved in the response of harvested citrus fruits to dehydration and the potential role of $A B A$ in this process. Within this context, it is interesting to note the link existing between water stress and the occurrence of NCPP in citrus fruit (Alférez et al., 2003; Lafuente and Zacarías, 2006). Although 
dehydration is not a limiting step (Lafuente and Sala, 2002; Cajuste and Lafuente, 2007; Cajuste et al., 2010), it enhances the development of this peel disorder (Alférez and Burns, 2004). 'Pinalate' fruit is prone to dehydration and much more susceptible to develop NCPP than its parental 'Navelate' (Alférez et al., 2005). Therefore, the comparative high throughput transcriptional analysis of fruits from both cultivars stored under conditions causing moderate water stress and the development of NCPP (12 으 and 70-75\% RH) allowed investigating the putative relationship existing between $A B A$, dehydration and the occurrence of this peel disorder.

Functional categorization of differentially expressed genes between both cultivars indicated the ability of parental fruit to trigger early molecular responses for coping with dehydration and the deleterious effects caused by this stress (Fig. 2 and Table 2, Results Chapter 1). The biological processes induced in 'Navelate' fruit included $A B A$ biosynthetic and signalling genes, $A B A$-dependent transcription factors, and genes encoding ABA-responsive proteins, but also ABA-independent genes such as cysteine-proteases and ion transporters (Table 2 and 3, Results Chapter 1). The lack of induction of these genes in 'Pinalate' fruits (Fig. 4 and Table 2, Results Chapter 1) suggested that the higher ability of 'Navelate' fruits to synthesize $A B A$ and to modulate $A B A$-related genes was important for reducing water loss and for maintaining cell homeostasis and viability, hence reducing the incidence of peel damage.

The molecular responses displayed by 'Navelate' fruit fit into the classical responses induced in Arabidopsis plants subjected to water stress conditions, which showed the involvement of ion transporters, aquaporins, and chaperone and other protective proteins for maintaining cellular structures and to avoid water loss (Bray, 1993; Ingram and Bartels, 1996; Shinozaki et al., 1998; Ramanjulu and Bartels, 2002). Those results also agreed with previous findings in 
detached grape berries, showing that both ABA-dependent and independent genes were affected by dehydration occurring before or after harvesting the fruit and by the stress severity (Grimplet et al., 2007; Rizzini et al., 2009; Deluc et al., 2009; Zamboni et al., 2010). Likewise, our results were in concordance with those reported by Riera et al. (2005) suggesting the involvement of both ABAdependent and independent signals for regulating the dehydration response in Arabidopsis plants. Wilkinson et al. (2010) suggested the existence of alternative dehydration-responsive pathways operating in plants under ABA-deficiency to minimize water loss. Moreover, it is well known that cuticle plays a key role in fruit dehydration (Islam et al., 2009; Curvers et al., 2010). However, results of the present work indicated that the lower ability of 'Pinalate' fruit to synthesize ABA was crucial for the impaired response of this mutant to water stress, which might be related to the higher susceptibility of this mutant to develop NCPP.

Results from the comparative transcriptomic assay further revealed that mutant fruits down-regulated the biosynthesis of carbohydrates at late stages of the storage, when NCPP incidence was much higher than in the wild-type fruits (Fig. 1 and Table 2, Results Chapter 1). Since sugars play protective roles against osmotic and water stresses in plants (Bartels and Sunkar, 2005; Seki et al., 2007), the repression of this biological process might be relevant for the susceptibility of citrus fruit to such stresses leading to peel damage. This was in agreement with previous findings showing the higher reduction in soluble sugars and starch in 'Pinalate' than in 'Navelate' fruit during the development of NCPP (Holland et al., 2005). Furthermore, the repression of this process was also associated with the enhancement of NCPP in 'Navelate' fruits exposed to a different postharvest stress (Establés-Ortiz et al., 2009), indicating the relevance of carbohydrate metabolism in the convergence of the mechanisms underlying NCPP. 
Results obtained after treating 'Navelate' fruits with ABA suggested that endogenous levels of the hormone might be sufficient to trigger cellular processes coping with dehydration and further consequences related to peel damage, since NCPP index and the percentage of weight loss were not significantly affected by ABA application in the wild-type fruits (Fig. S1, Results Chapter 1). In contrast, ABA treatment on mutant fruit increased the hormone content to levels even higher than those of the parental and repressed the expression of thousands of genes (Fig. 1 and 2, Results Chapter 1). This set of genes was enriched in genes encoding proteins with E3-ubiquitin ligase activity (Table 2 and 3, Results Chapter 1), which is involved in protein recycling (Rechsteiner, 1987). In spite of ubiquitination has been largely associated with the degradation of proteins involved in hormonesignal transduction pathways (Ueguchi-Tanaka et al., 2005; Kepinski and Leyser, 2005), including those of ABA (López-Molina et al., 2003; Zhang et al., 2005; Luo et al., 2006; Ryu et al., 2010), an exhaustive analysis of the genes belonging to this process revealed that they were related to pathogen signals and infection. Accordingly, it was found that rots developed earlier in ABA-treated than in nontreated mutant fruit (Fig. S2, Results Chapter 1), which agreed with the proposed role of $A B A$ in the resistance suppression and the promotion of the susceptibility to pathogen infection (Anderson et al., 2004; Yasuda et al., 2008; Ton et al., 2009).

Results of the present work showed that water loss and NCPP incidence occurring in mutant fruit during storage were barely counteracted by the $A B A$ application, and that there were no statistical differences between ABA-treated and control mutant fruits. Although plants are less sensitive to exogenous ABA than to stress-induced rises in endogenous ABA (Imay et al., 1995), these results suggested that the ABA-deficient mutant 'Pinalate' might be partially insensitive to the hormone, being able to modulate gene expression but showing a fail in the 
regulation of the dehydration response. These results encouraged new research focused on determining whether the genes encoding the proteins responsible for the $A B A$ perception and signal transduction in citrus fruit were differentially regulated in 'Navelate' and 'Pinalate' genotypes.

Therefore, the homologous genes of the $A B A$ perception system components, identified recently in Arabidopsis (Santiago et al., 2009; Park et al., 2009; Ma et al., 2009; Nishimura et al., 2010) so-called ABA-signalosome, were characterized for the first time in the Citrus genome. To unravel the relationship between endogenous $A B A$ and the expression of these components, we performed a comparative transcriptional analysis between 'Navelate' and 'Pinalate' fruits and leaves subjected to conditions increasing ABA content. Thus, to study whether the expression of these genes was affected by the source of the ABA signal from stressful or developmental conditions, fruits from both cultivars were exposed to moderated water stress or harvested at different ripening stages. It is interesting to note herein that rises in $A B A$ occurring during postharvest fruit dehydration were similar to those found during fruit development and ripening, and that $\mathrm{ABA}$ content in the $\mathrm{ABA}$-deficient mutant 'Pinalate' was up to 4-fold lower than in 'Navelate' in both processes (Fig. 1, Results Chapter 1; Fig.2, Results Chapter 2). In addition, in order to identify the occurrence of some tissue specificity and to get further insights on the relevance of the stress severity for the regulation of the ABA-signalosome components, transcriptional analyses were also performed in leaves subjected to severe water stress (50-55\% RH) (Fig. 4, Results Chapter 2). In this regard, it should be mentioned that basal ABA levels in 'Navelate' and 'Pinalate' leaves were similar and much lower than those detected in freshly harvested 'Navelate' fruits, although the hormone content in dehydrated leaves increased about 15-fold and 
reached levels similar to those of the stored parental fruit (Fig. 4, Results Chapter 2 and Fig.1, Results Chapter 1).

The identification of the Citrus ABA-signalosome genes was performed by in silico analysis of the Citrus genome, which revealed that 6 CSPYR/PYL/RCAR, 5 CSPP2CA and 2 subclass III CSSnRK2 genes encoded proteins with high homology degree to the Arabidopsis core elements of the ABA perception. It appeared that these proteins were less represented in Citrus than in Arabidopsis (Park et al., 2009; Ma et al., 2009) and Vitis (Boneh et al., 2012a; Boneh et al., 2012b). Nevertheless, a lower number of PYR/PYL/RCARs and PP2CAs genes has been also found in tomato (Sun et al., 2011) and strawberry (Chai et al., 2011) compared to Arabidopsis. Amino acid alignments revealed that relevant motifs for functional protein folding, such as the gate and latch regions in PYR/PYL/RCARs (Melcher et al., 2009), and for phosphatase activity in PP2CAs (Weiner et al., 2010), were conserved in Citrus proteins (Supplementary Fig. S1A and S1B, Results Chapter 2). D-rich C-terminal domain II, which has been shown to be essential for ABA signal transduction (Yoshida et al., 2006a), was also fully conserved in Citrus SnRK2s proteins (Supplementary Fig. S1C, Results Chapter 2). Results obtained from the phylogenetic analysis showed the distribution of these proteins close to their respective homologous in Arabidopsis (Fig. 1, Results Chapter 2). In addition, protein folding analysis revealed high similarity between the tertiary structure of Arabidopsis and Citrus proteins (Supplementary Fig. S2, Results Chapter 2), which further supported that these proteins might function as the core elements of the ABA perception in Citrus.

Transcriptional studies performed in 'Navelate' and 'Pinalate' fruits and leaves revealed that $C S P Y R / P Y L / R C A R$ genes expression was barely affected by the endogenous $\mathrm{ABA}$ content in both tissues and cultivars. CSPYR/PYL/RCAR transcript levels found during fruit development and ripening were similar in both cultivars 
in spite of $A B A$ content in the ABA-deficient mutant was at least 2-fold lower than in the parental at coloured stages (Fig. 2 and 4, Results Chapter 2), which suggested that $A B A$ accumulation found in the $A B A$-deficient fruit may be sufficient for regulating the expression of these genes.

Different expression patterns were found among genes belonging to this family, which is in agreement with previous findings in tomato fruits (Sun et al., 2011). On one hand, CSPYR1, CSPYL4 and CSPYL5 expression patterns mirrored that of the ABA accumulation in both 'Navelate' and 'Pinalate' fruits during ripening (Fig. 2 and 3A, Results Chapter 2). The concomitant repression of these genes with the induction of $A B A$ content was in concordance with the transcriptional response observed in Arabidopsis seedlings after osmotic and drought stresses (Szostkiewicz et al., 2010). On the other hand, CSPYL8 and CSPYL9 gene expression decreased as ripening progressed, although a sudden increase was observed in both genes when maximum ABA content was achieved in parental and mutant fruits (Fig. 2 and 3 A, Results Chapter 2). It is also interesting that CSPYL2 transcripts were not detected in fruits of both cultivars during ripening, which suggested that the expression of some ABA receptors could be tissue specific in Citrus. In agreement with this, some tomato genes such as SIPYL5, belonging to the same subfamily as CSPYL2 (subfamily III; Fig. 1A, Results Chapter 2), were almost undetectable during fruit ripening (Sun et al., 2011). In spite of the expression of the $A B A$ receptors was differently regulated during fruit ripening, the study of ABA-responsive genes, such as CSHVA22E and CSALDH3, showed expression patterns that mostly paralleled the ABA accumulation (Fig. S3, Results Chapter 2).

The transcriptional analysis of the ABA-signalosome components in water stressed fruits, which has been performed for the first time in this work, confirmed that the expression of most of the CSPYR/PYL/RCAR genes was barely 
affected by the difference in ABA content between cultivars. Thus, little differences were observed between 'Navelate' fruit and its ABA-deficient mutant 'Pinalate' in spite of ABA content in the parental was 4-fold higher from the first week of postharvest storage (Fig. 1 and Table 2, Results Chapter 3). Interestingly, the expression patterns of these genes were not coincident with those found during fruit ripening in spite of the $A B A$ content achieved was similar during both processes. In fact, whereas CSPYR1, CSPYL9 and CSPYL8 genes were repressed along ripening in fruit of both genotypes, they were induced concomitantly with $A B A$ rises from the first week of storage under conditions causing moderate water stress. In contrast, CSPYL4 and CSPYL5 were down-regulated in both cultivars during fruit ripening and dehydration (Fig. 3A, Results Chapter 2; Fig. 1, Results Chapter 3). Therefore, these results suggested that the expression of some members of the CSPYR/PYL/RCAR family might be modulated by the source of the ABA signal from developmental or stressful conditions. In addition, $A B A$ treatment on 'Pinalate' fruits transiently increased the expression of CSPYR1, CSPYL9 and CSPYL5 genes by the first week of postharvest storage although, thereafter, these genes followed similar expression patterns than non-treated mutant fruits. These transient inductions partially agreed with previous data reported by Szostkiewicz et al (2010) in Arabidopsis seedlings treated with ABA and with studies performed in ABA-treated tomato fruit (Sun et al., 2011), and also reinforced the idea that ABA content found in 'Pinalate' fruits during ripening and dehydration might be sufficient to regulate the expression of this gene family in a manner similar to that of the parental.

Little changes in the regulation of ABA receptors were observed between non-stressed Citrus leaves and those exposed to water stress, where a 15-fold $A B A$ increment and a $20 \%$ weight loss was observed (Fig. 5, Results Chapter 2). These results agree with the slight differences found in the expression pattern of 
these receptors between 'Navelate' and 'Pinalate' dehydrated fruits. Differences in the transcripts accumulation of CSPYL2 and CSPYL9, the most expressed CSPYR/PYL/RCAR genes in vegetative tissue, between stressed and non-stressed leaves were detected before the sharp increase in ABA (Fig. 4 and 5, Results Chapter 2), which suggested that these changes may be due to osmotic adjustments but not to ABA content. Contrary, CSPYL5 continuously decreased as dehydration progressed and, in both cultivars, transcript levels in dehydrated leaves became significantly lower than in their controls only when ABA rose dramatically (6 hours; Fig. 4 and 5, Results Chapter 2). Taking together this result and the consistent repression of CSPYL5 during fruit dehydration and ripening, these data suggest that the regulation of this gene might be tightly related to $A B A$ accumulation in Citrus. Nevertheless, overall results indicated that most of the members of the CSPYR/PYL/RCAR family were barely affected by endogenous ABA content, independently of the tissue and the physiological or stressful conditions studied. This agreed with results found in ABA-treated tomato fruit and in Vitis and tomato leaves exposed to water stress (Sun et al., 2011; Li et al., 2012), while it differs with results obtained in Arabidopsis seedlings since PYR/PYL/RCAR genes appeared to be mainly regulated by both ABA and water stress (Szostkiewicz et al., 2010).

Studies performed in Citrus leaves further allowed identifying tissue specificities. Thus, CSPYL2 gene, whose transcripts were not detectable in fruits, was one of the most expressed genes in leaves (Supplemental Table 6, Results Chapter 2). Contrary, CSPYL4 and CSPYL8 genes were expressed in fruits but not in vegetative tissue. It is also noteworthy that CSPYL9 continuously increased during moderate fruit dehydration in both 'Navelate' and 'Pinalate' cultivars (Fig. 1, Results Chapter 3), whereas this gene was down-regulated by dehydration in leaves (Fig. 5, Results Chapter 2). These results highlighted the relevance of the 
tissue specificity and/or the stress severity in the modulation of the ABA perception in Citrus. Overall results suggested that the transcriptional regulation of the Citrus ABA receptors might be differentially modulated by tissue specificity and also by the physiological or stress conditions responsible for the induction of the hormone signal.

Clade A PP2Cs function as negative regulators of the ABA signalling pathway and their transcript levels are highly induced by ABA in plants (Merlot et al., 2001; Saez et al., 2004; Saez et al., 2006; Yoshida et al., 2006b; Xue et al., 2008; Li et al., 2009). Comparative transcriptional analyses between 'Navelate'

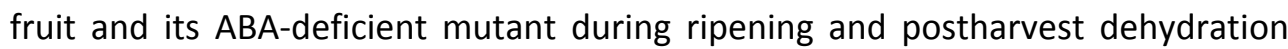
revealed that the expression of the genes belonging to CSPP2CA family mostly paralleled $A B A$ accumulation in both genotypes, independently of the process examined (Fig. 3B, Results Chapter 2; Fig. 2, Results Chapter 3). The relationship between dehydration and $A B A$ is supported by the fact that transcript levels of the ABA biosynthetic gene CSNCED1 increased transiently by the first week of storage promoting ABA synthesis (Fig.1 and 4A, Results Chapter 1), which agreed with results reported in harvested grapes and tomatoes (Sun et al., 2010; Sun et al., 2012a; Sun et al., 2012b) and in vegetative tissues (Tan et al., 2003; Loyola et al., 2012; Frey et al., 2012). Interestingly, CSNCED1 followed an expression pattern highly similar to that displayed by the members of the CSPP2CA family in citrus fruit (Fig.2, Results Chapter 3). Accordingly, ABA-induced genes, such as CsHVA22E and $C S A L D H 3$, showed expression patterns that paralleled $A B A$ accumulation during fruit ripening (Fig. S3, Results Chapter 2). However, transcripts levels of all these genes in the ABA-deficient mutant 'Pinalate' were lower than that of the 'Navelate' fruit, which suggested a strong effect of ABA content on the expression of the CSPP2CAs and the selected ABA-regulated downstream genes. Moreover, $A B A$ application to 'Pinalate' fruit during storage enhanced the induction of 
CSPP2CAs genes, which reached values close to those observed in the parental by the end of the experiment (Fig. 2, Results Chapter 3). Overall, this was in concordance with the studies performed in grapes and tomato fruits, in which PP2CAs transcript levels were highly induced concomitantly with ABA raises during fruit ripening or in response to ABA application (Sun et al., 2011; Boneh et al., 2012a). Results obtained from vegetative tissue studies agreed with those performed in fruits since CSPP2CAs gene expression paralleled ABA accumulation in both control and water-stressed leaves, and transcripts levels were much higher in dehydrated than in the control non-stressed leaves (Fig. 6, Results Chapter 2). Accordingly, dehydrated tomato leaves displayed higher transcript levels than those non-stressed (Sun et al., 2011).

Within this context, CSAHG1 protein phosphatase merits special mention because of its differential responsiveness to endogenous $A B A$ during fruit development and dehydration. Among CSPP2CAs, CSAHG1 was the only downregulated by dehydration in both 'Navelate' and 'Pinalate' fruit (Fig. 2, Results Chapter 3). In addition, this was the only CSPP2CA whose fold induction was higher in the mutant than in the parental during fruit ripening in spite of the $A B A$ content in 'Pinalate' was 2-fold lower than in 'Navelate' (Fig. 2 and 3B, Results Chapter 2). Moreover, CSAHG1 was one of the most induced PP2CAs (about 20fold) in dehydrated Citrus leaves (Fig. 6, Results Chapter 2), which agreed with data reported in Arabidopsis leaves (Szostkiewicz et al., 2010). Therefore, it would be interesting to investigate further the involvement of this gene in the differential response of 'Navelate' and 'Pinalate' fruit to physiological or stress conditions causing an increase in ABA levels.

Overall, these findings indicated that the gene expression of the CSPP2CAs negative regulators was highly regulated by $A B A$ content under both developmental and stressful conditions, independently of the tissue and the 
severity of the stress applied. In agreement with this idea and with the lower differences found between cultivars in the CSPYR/PYL/RCAR gene expression, Szostkiewicz et al. (2010) reported that PP2CA genes are more responsive to ABA as compared with $A B A$ receptors, and suggested a higher sensitivity of these negative regulators to $A B A$ changes in plants.

Regarding to the concomitant induction of the PP2CAs gene expression levels and the $A B A$ accumulation, a transcriptional negative feedback regulatory mechanism has been proposed for modulating the ABA responses in model plants (Merlot et al., 2001; Santiago et al., 2009; Melcher et al., 2009; Vlad et al., 2009; Weiner et al., 2010). Thus, it was suggested that exogenous ABA or stress-induced rises in hormone levels would induce the initial ABA-mediated PYR/PYL/RCAR inactivation of PP2CAs. This allows the release of SnRK2s and hence the phosphorylation of ABA-dependent transcription factors, which finally would modulate the expression of ABA-responsive genes. Hormone signal would be later attenuated by the combination of both the ABA-induced down-regulation of PYR/PYL/RCARs gene expression and the up-regulation of the PP2CAs transcript levels, hence restoring the initial conditions (Merlot et al., 2001; Santiago et al., 2009; Vlad et al., 2009) (Fig. 4, Introduction Section). Thus, the resetting of the ABA signal transduction pathway would provide a dynamic and precise mechanism to adjust the adaptive response of the plant to the strength and duration of the stress.

The expression pattern of most of the CSPP2CA genes analysed in this work paralleled the accumulation of ABA in 'Navelate' and 'Pinalate' fruits and leaves. Interestingly, the up-regulation of these CSPP2CA genes during fruit ripening was also concomitant with the down-regulation of the CSPYR1, CSPYL4 and CSPYL5 genes. Similarly, CSPYL4 and CSPYL5 transcript levels bottomed down concomitantly with the transient induction of several CSPP2CAs by the first week 
of fruit storage, when $A B A$ rose in response to water stress. In vegetative tissue, it was found that CSPYL5 gene expression decreased concomitantly with the highest hormone levels and the induction of most of the CSPP2CAs. Therefore, in spite of further research should be addressed at protein level for elucidating the interactions occurring among these components in Citrus, it can not be ruled out that this negative regulatory loop might be modulating the ABA responses during conditions causing the increase of $A B A$ in Citrus fruits and leaves.

SnRK2s positively regulate $A B A$ responses by the phosphorylation of $A B F / A R E B$ bZIP transcription factors that bind to ABA-responsive elements (Kobayashi et al., 2005; Fujita et al., 2009; Yoshida et al., 2010). It is also well known that SnRK2s are able to phosphorylate ion channels and NADPH oxidases in guard cells, hence taking part in the control of the ABA-induced stomata closure (Geiger et al., 2009; Sirichandra et al., 2009). However, the activity of the subclass III SnRK2s is inhibited by their association with the PP2CAs. The ABA-mediated PYR/PYL/RCAR inactivation of PP2CAs, dissociates the PP2CA-SnRK2 complex and release SnRK2s for transducing the ABA signal downstream in the pathway (Santiago et al., 2009; Vlad et al., 2009). The functionality of the subclass III SnRK2s has been confirmed in Arabidopsis plants (Fujii and Zhu, 2009; Fujita et al., 2009) and in crops such as rice (Kobayashi et al., 2004) and maize (Li et al., 2009) but not in fruits of agronomic interest. Nevertheless, the transcriptional analysis of these genes has been performed in tomato fruit (Sun et al., 2011) and in grape plants (Boneh et al., 2012a). Studies performed in tomato fruit showed that SnRK2s were transiently induced by exogenous ABA, and highly expressed the most immature stages of the fruit ripening concomitantly with the lowest endogenous $A B A$ levels. In contrast, water stress-induced $A B A$ rises in tomato leaves provoked little changes in the transcript levels of these genes (Sun et al., 
2011). Accordingly, water stress slightly affected gene expression of the subclass III SnRK2s in grape (Boneh et al., 2012a).

In concordance with results obtained during tomato fruit ripening, CsSnRK2.2 and CsSnRK2.6 genes reached their highest transcript levels at the most immature stages, when the minimum ABA content was detected in both cultivars (Fig. 2 and Fig. 3C, Results Chapter 2). Moreover, ABA treatment on mutant fruit triggered the transient induction of both genes by the first week of storage, which was also in agreement with tomato fruit results (Sun et al., 2011). Nevertheless, as reported in the CSPYR/PYL/RCAR analyses, little differences were found in CsSnRK2.2 and CSSnRK2.6 genes expression between 'Navelate' and its ABAdeficient mutant 'Pinalate' during fruit ripening, which suggested that the low $A B A$ content in mutant fruit might be sufficient for modulating the expression of these genes in a similar manner than in parental fruit during ripening process. During fruit dehydration, however, CsSnRK2.6 did not show relevant differences between cultivars, whereas CsSnRK2.2 peaked by 3 weeks only in 'Pinalate' fruit. Interestingly, no much difference was found in the transcriptional regulation of the CsSnRK2s between water-stressed and control non-stressed Citrus leaves in spite of the sharp increase in ABA levels occurring in dehydrated leaves (Fig. 4 and 7, Results Chapter 2). These results were also in concordance with that found in tomato leaves (Sun et al., 2011) and grape studies (Boneh et al., 2012a), and suggested that, in general, these positive effectors of the ABA signalling pathway might be differentially affected by the tissue, the stress severity and the source of the ABA signal from a physiological or stressful stimulus.

The elucidation of the ABA signalling core components and the molecular mechanisms by which $A B A$ signal is transduced downstream in the pathway have encouraged new investigations addressed to understand the regulation of $A B A-$ related processes in crops of agronomic interest (Chai et al., 2011; Sun et al., 
2011; Li et al., 2012; Kim et al., 2012; Boneh et al., 2012a; Boneh et al., 2012b). Based on the results presented in this work, the PP2CAs appeared to be key regulator points in the $A B A$ response of Citrus under developmental and stress conditions, independently of the tissue and the stress severity imposed. Therefore, the results encourage future research to attempt biotechnological engineering on these genes in order to improve drought hardiness in Citrus. 

5. CONCLUSIONS 

1. The comparative transcriptional analysis between 'Navelate' and its fruitspecific ABA-deficient mutant 'Pinalate' fruit during postharvest storage under mild water stress conditions (70-75\% RH, 12 o C) highlighted the ability of parental fruit to trigger responses to reduce water loss and other detrimental consequences caused by this stress, which may lead to the NCPP development. These responses involved the 'water deprivation' and the 'di-, tri-valent inorganic cation transport' biological processes, which included both ABA-dependent and -independent genes. The lack of these responses in the mutant fruit indicated their relevance for the prevention of water loss and the development of peel damage in citrus fruit. In addition, the repression of the 'carbohydrate biosynthesis' process occurred specifically in 'Pinalate' fruits.

2. Exogenous $A B A$ did not rescue the impaired response of 'Pinalate' fruit to water stress, but modulated relevant transcriptomic changes. Genes related to different biological processes were identified, although only the 'protein ubiquitination' biological process was over-represented in the ABA-treated mutant fruit. An exhaustive analysis revealed that genes belonging to this process were related to the fruit-pathogen interactions.

3. The Citrus $A B A$ signalling core components were identified for the first time. In silico analysis revealed that Citrus ABA-signalosome was composed of six PYR/PYL/RCAR ABA receptors, five PP2CAs negative regulators, and two subclass III SnRK2s downstream protein kinases. The high homology degree with Arabidopsis proteins and the presence of conserved motifs for functional protein folding and activity indicate that 
these proteins are bona fide core elements of the ABA perception in Citrus.

4. Transcriptional analysis performed on 'Navelate' and 'Pinalate' fruits at different ripening stages and stored under mild water stress conditions, as well as in leaves submitted to severe water stress, revealed that genes encoding the $A B A$ perception system components are differently regulated by the endogenous $A B A$ content.

5. $C S P Y R / P Y L / R C A R$ ABA receptors showed minor differences between cultivars, independently of the source of the ABA signal, the tissue and the stress severity. Nevertheless, some components of this family displayed tissue specificity, such as CSPYL2, CSPYL4 and CSPYL8.

6. CSPP2CA negative regulators showed significant differences between 'Navelate' and the ABA-deficient mutant 'Pinalate' fruit, which revealed the high sensitivity and responsiveness of these components to ABA. Furthermore, these genes followed a consistent expression pattern and ABA-response independently of the physiological process responsible for $A B A$ increases, tissue and severity of the stress imposed. The expression pattern of the CSAHG1 during fruit ripening and dehydration bring to question the relevance of this particular gene in the $A B A$ signalling pathway in citrus fruit and in the impaired response of the 'Pinalate' fruit.

7. Subclass III CsSnRK2s, positive effectors of the ABA signalling pathway, showed minor differences in gene expression between cultivars. The expression of these genes was differentially affected by the tissue, the 
stress severity and the source of the ABA signal from a physiological or stressful stimulus.

8. Overall results indicate that the ABA-deficient mutant 'Pinalate' fruit may sense $A B A$, although the hormone signal could be impaired because of reduced CSPP2CAs levels causing altered water stress response and higher NCPP susceptibility. 

6. REFERENCES 

Acharya BR, Assmann SM. 2009. Hormone interactions in stomatal function. Plant Molecular Biology 69, 451-462.

Addicott FT, Lyon JL. 1969. Physiology of abscisic acid and related substances. Annual Review of Plant Physiology 20, 139-164.

Agustí J, Merelo P, Cercós M, Tadeo FR, Talón M. 2008. Ethylene-induced differential gene expression during abscission of citrus leaves. Journal of Experimental Botany 59, 2717-2733.

Agustí J, Zapater M, Iglesias DJ, Cercós M, Tadeo FR, Talón M. 2007. Differential expression of putative 9-cis-epoxycarotenoid dioxygenases and abscisic acid accumulation in water stressed vegetative and reproductive tissues of citrus. Plant Science 172, 85-94.

Agustí M, Almela V, Juan M, Alférez F, Tadeo FR, Zacarías L. 2001. Histological and physiological characterization of rind breakdown of 'Navelate' sweet orange. Annals of Botany 88, 415-422.

Alférez F, Agustí M, Zacarías L. 2003. Postharvest rind staining in Navel oranges is aggravated by changes in storage relative humidity: effect on respiration, ethylene production and water potential. Postharvest Biology and Technology 28, 143-152.

Alférez F, Alquézar B, Burns JK, Zacarías L. 2010. Variation in water, osmotic and turgor potential in peel of 'Marsh' grapefruit during development of postharvest peel pitting. Postharvest Biology and Technology 56, 44-49.

Alférez F, Burns JK. 2004. Postharvest peel pitting at non-chilling temperatures in grapefruit is promoted by changes from low to high relative humidity during storage. Postharvest Biology and Technology 32, 79-87.

Alférez F, Lluch Y, Burns JK. 2008. Phospholipase A2 and postharvest peel pitting in citrus fruit. Postharvest Biology and Technology 49, 69-76.

Alférez F, Sala JM, Sanchez-Ballesta MT, Mulas M, Lafuente MT, Zacarías L. 2005. A comparative study of the postharvest performance of an ABA-deficient mutant of oranges: I. Physiological and quality aspects. Postharvest Biology and Technology 37, 222-231.

Alférez F, Zacarías L. 1999. Interaction between ethylene and abscisic acid in the regulation of citrus fruit maturation. In: Kanellis AK, Chang $C$, Klee $H$, Blecker AB, Pech JC, Grierson D, eds. Biology and biotechnology of the plant hormone ethylene II, Amsterdam: Kluwer Academic Publishers, pp. 183-184.

Alvarez ME, Pennell RI, Meijer PJ, Ishikawa A, Dixon RA, Lamb C. 1998. Reactive oxygen intermediates mediate a systemic signal network in the establishment of plant immunity. Cell 92, 773-784.

Anderson JP, Badruzsaufari E, Schenk PM, et al. 2004. Antagonistic interaction between abscisic acid and jasmonate-ethylene signaling pathways modulates defense gene expression and disease resistance in Arabidopsis. The Plant Cell 16, 3460-3479. 
Aneja M, Gianfagna T, Ng E. 1999. The roles of abscisic acid and ethylene in the abscission and senescence of cocoa flowers. Plant Growth Regulation 27, 149-155.

Armstrong F, Leung J, Grabov A, Brearley J, Giraudat J, Blatt MR. 1995. Sensitivity to abscisic acid of guard-cell $\mathrm{K}^{+}$channels is suppressed by abi1-1, a mutant Arabidopsis gene encoding a putative protein phosphatase. Proceedings of the National Academy of Sciences of the United States of America 92, 9520-9524.

Asensi-Fabado MA, Munné-Bosch S. 2011. The aba3-1 mutant of Arabidopsis thaliana withstands moderate doses of salt stress by modulating leaf growth and salicylic acid levels. Journal of Plant Growth Regulation 30, 456-466.

Barrero JM, Piqueras P, González-Guzman M, Serrano R, Rodríguez PL, Ponce MR, Micol JL. 2005. A mutational analysis of the $A B A 1$ gene of Arabidopsis thaliana highlights the involvement of $A B A$ in vegetative development. Journal of Experimental Botany 56, 20712083.

Barrero JM, Rodríguez PL, Quesada V, Piqueras P, Ponce MR, Micol JL. 2006. Both abscisic acid ( $A B A$ )-dependent and $A B A$-independent pathways govern the induction of NCED3, $A A O 3$ and $A B A 1$ in response to salt stress. Plant, Cell and Environment 29, 20002008.

Bartels D, Sunkar R. 2005. Drought and salt tolerance in plants. Critical Reviews in Plant Sciences 24, 23-58.

Bastías A, López-Climent M, Valcárcel M, Rosello S, Gómez-Cadenas A, Casaretto JA. 2011. Modulation of organic acids and sugar content in tomato fruits by an abscisic acidregulated transcription factor. Physiologia Plantarum 141, 215-226.

Belin C, De Franco PO, Bourbousse C, et al. 2006. Identification of features regulating OST1 kinase activity and OST1 function in guard cells. Plant Physiology 141, 1316-1327.

Blanusa T, Else MA, Davies WJ, Atkinson CJ. 2006. Regulation of sweet cherry fruit abscission: The role of photo-assimilation, sugars and abscisic acid. Journal of Horticultural Science and Biotechnology 81, 613-620.

Boneh U, Biton I, Schwartz A, Ben-Ari G. 2012a. Characterization of the ABA signal transduction pathway in Vitis vinifera. Plant Science 187, 89-96.

Boneh U, Biton I, Zheng C, Schwartz A, Ben-Ari G. 2012b. Characterization of potential ABA receptors in Vitis vinifera. Plant Cell Reports 31, 311-321.

Bonghi C, Rizzini FM, Gambuti A, Moio L, Chkaiban L, Tonutti P. 2012. Phenol compound metabolism and gene expression in the skin of wine grape (Vitis vinifera L.) berries subjected to partial postharvest dehydration. Postharvest Biology and Technology 67, 102109.

Botton A, Eccher G, Forcato C, Ferrarini A, Begheldo M, Zermiani M, Moscatello S, Battistelli A, Velasco R, Ruperti B, Ramina A. 2011. Signalin pathways mediating the induction of apple fruitlet abscission. Plant Physiology 155, 185-208. 
Boudsocq M, Droillard MJ, Barbier-Brygoo H, Lauriere C. 2007. Different phosphorylation mechanisms are involved in the activation of sucrose non-fermenting 1 related protein kinases 2 by osmotic stresses and abscisic acid. Plant Molecular Biology 63, 491-503.

Bray EA, Bayley-Serres J, Weretilnyk E. 2000. Response to abiotic stresses. In: Gruissem W, Buchannan B, Jones R, eds. Biochemistry and Molecular Biology of Plants, American Society of Plant Physiologists, pp. 1158-1249.

Bray EA. 1993. Molecular responses to water deficit. Plant Physiology 103, 1035-1040.

Burbidge A, Grieve TM, Jackson A, Thompson A, McCarty DR, Taylor IB. 1999. Characterization of the ABA-deficient tomato mutant notabilis and its relationship with maize Vp14. Plant Journal 17, 427-431.

Cajuste JF, González-Candelas L, Veyrat A, García-Breijo FJ, Reig-Armiñana J, Lafuente MT. 2010. Epicuticular wax content and morphology as related to ethylene and storage performance 'Navelate' orange fruit. Postharvest Biology and Technology 55, 29-35.

Cajuste JF, Lafuente MT. 2007. Ethylene-induced tolerance to non-chilling peel pitting as related to phenolic metabolism and lignin content in 'Navelate' fruit. Postharvest Biology and Technology 45, 193-203.

Chai YM, Jia HF, Li CL, Dong QH, Shen YY. 2011. FaPYR1 is involved in strawberry fruit ripening. Journal of Experimental Botany 62, 5079-5089.

Chernys JT, Zeevaart JAD. 2000. Characterization of the 9-cis-epoxycarotenoid dioxygenase gene family and the regulation of abscisic acid biosynthesis in avocado. Plant Physiology 124, 343-354.

Choi H, Hong J, Ha J, Kang J, Kim SY. 2000. ABFs, a family of ABA-responsive element binding factors. Journal of Biological Chemistry 275, 1723-1730.

Cornforth JW, Milborrow BV, Ryback G, Wareing PF. 1965. Chemistry and physiology of 'dormins' in sycamore: Identity of sycamore 'dormin' with abscisin II. Nature 205, 12691270.

Cracker LE, Abeles FB. 1969. Abscission: Role of abscisic acid. Plant Physiology 44, 11441149.

Curvers K, Seifi H, Mouille G, et al. 2010. Abscisic acid deficiency causes changes in cuticle permeability and pectin composition that influence tomato resistance to Botrytis cinerea. Plant Physiology 154, 847-860.

Cutler AJ, Krochko JE. 1999. Formation and breakdown of ABA. Trends in Plant Science 4, 472-477.

de Ollas, C, Hernando, B, Arbona, V, Gómez-Cadenas, A. 2012. Jasmonic acid transient accumulation is needed for abscisic acid increase in citrus roots under drought stress conditions. Physiologia Plantarum. doi: 10.1111/j.1399-3054.2012.01659.x. 
De Smet I, Signora L, Beeckman T, Inzé D, Foyer CH, Zhang H. 2003. An abscisic acidsensitive checkpoint in lateral root development of Arabidopsis. Plant Journal 33, 543-555.

de Torres-Zabala M, Truman W, Bennett MH, et al. 2007. Pseudomonas syringae pv. tomato hijacks the Arabidopsis abscisic acid signalling pathway to cause disease. EMBO Journal 26, 1434-1443.

Debeaujon I, Koornneef M. 2000. Gibberellin requirement for Arabidopsis seed germination is determined both by testa characteristics and embryonic abscisic acid. Plant Physiology 122, 415-424.

Deluc L, Quilici D, Decendit A, et al. 2009. Water deficit alters differentially metabolic pathways affecting important flavor and quality traits in grape berries of Cabernet Sauvignon and Chardonnay. BMC Genomics 10, 212.

Dharmasiri N, Dharmasiri S, Estelle M. 2005. The F-box protein TIR1 is an auxin receptor. Nature 435, 441-445.

Dodd IC. 2003. Hormonal interactions and stomatal responses. Journal of Plant Growth Regulation 22, 32-46.

Dupeux F, Antoni R, Betz K, et al. 2011a. Modulation of abscisic acid signaling in vivo by an engineered receptor-insensitive protein phosphatase type $2 \mathrm{C}$ allele. Plant Physiology 156, 106-116.

Dupeux F, Santiago J, Betz K, et al. 2011b. A thermodynamic switch modulates abscisic acid receptor sensitivity. EMBO Journal 30, 4171-4184.

Endo A, Sawada Y, Takahashi H, et al. 2008. Drought induction of Arabidopsis 9-cisepoxycarotenoid dioxygenase occurs in vascular parenchyma cells. Plant Physiology 147, 1984-1993.

Establés-Ortiz B, Lafuente MT, González-Candelas L, Forment J, Gadea J. 2009. Transcriptomic analysis of ethylene-induced tolerance to non-chilling peel pitting in citrus fruit. Acta Horticulturae 839, 555-560.

Fan J, Hill L, Crooks C, Doerner P, Lamb C. 2009. Abscisic acid has a key role in modulating diverse plant-pathogen interactions. Plant Physiology 150, 1750-1761.

Farré G, Sanahuja G, Naqvi S, Bai C, Capell T, Zhu C, Christou P. 2010. Travel advice on the road to carotenoids in plants. Plant Science 179, 28-48.

Finkelstein R, Gampala SL, Rock CD. 2002. Abscisic acid signaling in seeds and seedlings. The Plant Cell 14, S15-S45.

Frey A, Effroy D, Lefebvre V, et al. 2012. Epoxycarotenoid cleavage by NCED5 fine-tunes $A B A$ accumulation and affects seed dormancy and drought tolerance with other NCED family members. Plant Journal 70, 501-512. 
Frey A, Godin B, Bonnet M, Sotta B, Marion-Poll A. 2004. Maternal synthesis of abscisic acid controls seed development and yield in Nicotiana plumbaginifolia. Planta 218, 958964.

Fujii H, Verslues PE, Zhu JK. 2007. Identification of two protein kinases required for abscisic acid regulation of seed germination, root growth, and gene expression in Arabidopsis. The Plant Cell Online 19, 485-494.

Fujii H, Zhu JK. 2009. Arabidopsis mutant deficient in 3 abscisic acid-activated protein kinases reveals critical roles in growth, reproduction, and stress. Proceedings of the National Academy of Sciences 106, 8380-8385.

Fujita M, Fujita Y, Noutoshi Y, Takahashi F, Narusaka Y, Yamaguchi-Shinozaki K, Shinozaki K. 2006. Crosstalk between abiotic and biotic stress responses: a current view from the points of convergence in the stress signaling networks. Current Opinion in Plant Biology 9, 436-442.

Fujita Y, Nakashima K, Yoshida T, et al. 2009. Three SnRK2 protein kinases are the main positive regulators of abscisic acid signaling in response to water stress in Arabidopsis. Plant and Cell Physiology 50, 2123-2132.

Galpaz N, Wang Q, Menda N, Zamir D, Hirschberg J. 2008. Abscisic acid deficiency in the tomato mutant high-pigment 3 leading to increased plastid number and higher fruit lycopene content. The Plant Journal 53, 717-730.

Gambetta G, Martínez-Fuentes A, Bentancur O, Mesejo C, Reig C, Gravina A, Agustí M. 2011. Hormonal and nutritional changes in the flavedo regulating rind color development in sweet orange (Citrus sinensis L. Osb.). Journal of Plant Growth Regulation 31, 273-282.

Gao Y, Zeng Q, Guo J, Cheng J, Ellis BE, Chen JG. 2007. Genetic characterization reveals no role for the reported ABA receptor, GCR2, in ABA control of seed germination and early seedling development in Arabidopsis. The Plant Journal 52, 1001-1013.

Geiger D, Maierhofer T, Al-Rasheid KAS, et al. 2011. Stomatal closure by fast abscisic acid signaling is mediated by the guard cell anion channel SLAH3 and the receptor RCAR1. Science Signaling 4, ra32.

Geiger D, Scherzer S, Mumm P, et al. 2009. Activity of guard cell anion channel SLAC1 is controlled by drought-stress signaling kinase-phosphatase pair. Proceedings of the National Academy of Sciences of the United States of America 106, 21425-21430.

Gillard DF, Walton DC. 1976. Abscisic acid metabolism by a cell-free preparation from Echinocystis lobata liquid endoserum. Plant Physiology 58, 790-795.

Giribaldi M, Gény L, Delrot S, Schubert A. 2010. Proteomic analysis of the effects of ABA treatments on ripening Vitis vinifera berries. Journal of Experimental Botany 61, 24472458. 
Gómez-Cadenas A, Arbona V, Jacas J, Primo-Millo E, Talon M. 2002. Abscisic acid reduces leaf abscission and increases salt tolerance in citrus plants. Journal of Plant Growth Regulation 21, 234-240.

Gómez-Cadenas A, Mehouachi J, Tadeo FR, Primo-Millo E, Talón M. 2000. Hormonal regulation of fruitlet abscission induced by carbohydrate shortage in citrus. Planta 210, 636-643.

Gómez-Cadenas A, Tadeo FR, Talon M, Primo-Millo E. 1996. Leaf abscission induced by ethylene in water-stressed intact seedlings of Cleopatra mandarin requires previous abscisic acid accumulation in roots. Plant Physiology 112, 401-408.

González-Guzman M, Abia D, Salinas J, Serrano R, Rodríguez PL. 2004. Two new alleles of the abscisic aldehyde oxidase 3 gene reveal its role in abscisic acid biosynthesis in seeds. Plant Physiology 135, 325-333.

Gosti F, Beaudoin N, Serizet C, Webb AAR, Vartanian N, Giraudat J. 1999. ABI1 protein phosphatase $2 \mathrm{C}$ is a negative regulator of abscisic acid signaling. The Plant Cell Online 11, 1897-1910.

Grimplet J, Deluc L, Tillett R, Wheatley M, Schlauch K, Cramer G, Cushman J. 2007. Tissue-specific mRNA expression profiling in grape berry tissues. BMC Genomics 8, 187.

Guo J, Zeng Q, Emami M, Ellis BE, Chen JG. 2008. The GCR2 gene family is not required for ABA control of seed germination and early seedling development in Arabidopsis. PLoS ONE 3, e2982.

Halfter U, Ishitani M, Zhu JK. 2000. The Arabidopsis SOS2 protein kinase physically interacts with and is activated by the calcium-binding protein SOS3. Proceedings of the National Academy of Sciences of the United States of America 97, 3735-3740.

Hirayama T, Umezawa T. 2010. The PP2C-SnRK2 complex: The central regulator of an abscisic acid signaling pathway. Plant Signaling \& Behavior 5, 160-163.

Holland N, Menezes HC, Lafuente MT. 2005. Carbohydrate metabolism as related to hightemperature conditioning and peel disorders occurring during storage of citrus fruit. Journal of Agricultural and Food Chemistry 53, 8790-8796.

Hrabak EM, Chan CWM, Gribskov M, et al. 2003. The Arabidopsis CDPK-SnRK superfamily of protein kinases. Plant Physiology 132, 666-680.

Huang D, Wu W, Abrams SR, Cutler AJ. 2008. The relationship of drought-related gene expression in Arabidopsis thaliana to hormonal and environmental factors. Journal of Experimental Botany 59, 2991-3007.

Hubbard KE, Siegel RS, Valerio G, Brandt B, Schroeder JI. 2012. Abscisic acid and $\mathrm{CO}_{2}$ signalling via calcium sensitivity priming in guard cells, new CDPK mutant phenotypes and a method for improved resolution of stomatal stimulus-response analyses. Annals of Botany 109, 5-17. 
Ikegami K, Okamoto M, Seo M, Koshiba T. 2009. Activation of abscisic acid biosynthesis in the leaves of Arabidopsis thaliana in response to water deficit. Journal of Plant Research 122, 235-243.

Imay R, Moses MS, Bray EA. 1995. Expression of an ABA-induced gene of tomato in transgenic tobacco during periods of water deficit. Journal of Experimental Botany 46, 1077-1084.

Ingram J, Bartels D. 1996. The molecular basis of dehydration tolerance in plants. Annual Review of Plant Physiology and Plant Molecular Biology 47, 377-403.

Islam M, Du H, Ning J, Ye H, Xiong L. 2009. Characterization of Glossy1-homologous genes in rice involved in leaf wax accumulation and drought resistance. Plant Molecular Biology 70, 443-456.

Israelsson M, Siegel RS, Young J, Hashimoto M, Iba K, Schroeder JI. 2006. Guard cell ABA and $\mathrm{CO}_{2}$ signaling network updates and $\mathrm{Ca}^{2+}$ sensor priming hypothesis. Current Opinion in Plant Biology 9, 654-663.

Jammes F, Song C, Shin D, et al. 2009. MAP kinases MPK9 and MPK12 are preferentially expressed in guard cells and positively regulate ROS-mediated ABA signaling. Proceedings of the National Academy of Sciences 106, 20520-20525.

Ji K, Chen P, Sun L, et al. 2012. Non-climacteric ripening in strawberry fruit is linked to ABA, FaNCED2 and FaCYP707A1. Functional Plant Biology 39, 351-357.

Jia HF, Chai YM, Li CL, Lu D, Luo JJ, Qin L, Shen YY. 2011. Abscisic acid plays an important role in the regulation of strawberry fruit ripening. Plant Physiology. 157, 188-199.

Joshi-Saha A, Valon C, Leung J. 2011. Abscisic acid signal off the STARTing block. Molecular Plant 4, 562-580.

Kaliff M, Staal J, Myrenas M, Dixelius C. 2007. ABA is required for Leptosphaeria maculans resistance via $\mathrm{ABI} 1$ and $\mathrm{ABI} 4$-dependent signaling. Molecular Plant-Microbe Interactions 20, 335-345.

Kang J, Hwang JU, Lee M, Kim YY, Assmann SM, Martinoia E, Lee Y. 2010. PDR-type ABC transporter mediates cellular uptake of the phytohormone abscisic acid. Proceedings of the National Academy of Sciences 107, 2355-2360.

Kanno Y, Hanada A, Chiba Y, et al. 2012. Identification of an abscisic acid transporter by functional screening using the receptor complex as a sensor. Proceedings of the National Academy of Sciences 109, 9653-9658.

Karssen CM, Brinkhorst-van der Swan DLC, Breekland AE, Koornneef M. 1983. Induction of dormancy during seed development by endogenous abscisic acid: studies on abscisic acid deficient genotypes of Arabidopsis thaliana (L.) Heynh. Planta 157, 158-165. 
Kato M, Matsumoto H, Ikoma Y, Okuda H, Yano M. 2006. The role of carotenoid cleavage dioxygenases in the regulation of carotenoid profiles during maturation in citrus fruit. Journal of Experimental Botany 57, 2153-2164.

Kepczynski J, Kepczynska E. 1997. Ethylene in seed dormancy and germination. Physiologia Plantarum 101, 720-726.

Kepinski S, Leyser 0. 2005. The Arabidopsis F-box protein TIR1 is an auxin receptor. Nature 435, 446-451.

Kim H, Hwang H, Hong JW, et al. 2012. A rice orthologue of the ABA receptor, OsPYL/RCAR5, is a positive regulator of the ABA signal transduction pathway in seed germination and early seedling growth. Journal of Experimental Botany 63, 1013-1024.

Kim, TH, Böhmer, M, Hu, H, Nishimura, N, Schroeder, Jl. 2010. Guard cell signal transduction network: Advances in understanding abscisic acid, $\mathrm{CO}_{2}$, and $\mathrm{Ca}^{2+}$ signaling. Annual Review in Plant Biology 61, 561-591.

Klingler JP, Batelli G, Zhu JK. 2010. ABA receptors: the START of a new paradigm in phytohormone signalling. Journal of Experimental Botany 61, 3199-3210.

Kobayashi Y, Murata M, Minami H, et al. 2005. Abscisic acid-activated SnRK2 protein kinases function in the gene-regulation pathway of $A B A$ signal transduction by phosphorylating ABA response element-binding factors. Plant Journal 44, 939-949.

Kobayashi Y, Yamamoto S, Minami H, Kagaya Y, Hattori T. 2004. Differential activation of the rice sucrose nonfermenting1-related protein kinase 2 family by hyperosmotic stress and abscisic acid. The Plant Cell Online 16, 1163-1177.

Krochko JE, Abrams GD, Loewen MK, Abrams SR, Cutler AJ. 1998. (+)-abscisic acid 8'hydroxylase is a cytochrome P450 monooxygenase. Plant Physiology 118, 849-860.

Kucera B, Cohn MA, Leubner-Metzger G. 2005. Plant hormone interactions during seed dormancy release and germination. Seed Science Research 15, 281-307.

Kuhn JM, Boisson-Dernier A, Dizon MB, Maktabi MH, Schroeder JI. 2006. The protein phosphatase AtPP2CA negatively regulates abscisic acid signal transduction in Arabidopsis, and effects of abh1 on AtPP2CA mRNA. Plant Physiology 140, 127-139.

Kuromori T, Miyaji T, Yabuuchi H, et al. 2010. ABC transporter AtABCG25 is involved in abscisic acid transport and responses. Proceedings of the National Academy of Sciences 107, 2361-2366.

Lafuente MT, Martínez-Téllez MA, Zacarías L. 1997. Abscisic acid in the response of 'Fortune' mandarins to chilling. Effect of maturity and high-temperature conditioning. Journal of the Science of Food Agriculture 73, 494-502.

Lafuente MT, Sala JM. 2002. Abscisic acid levels and the influence of ethylene, humidity and storage temperature on the incidence of postharvest rindstaning of 'Navelina' orange (Citrus sinensis L. Osbeck) fruit. Postharvest Biology and Technology 25, 49-57. 
Lafuente MT, Zacarías L. 2006. Postharvest physiological disorders in citrus fruit. Stewart Postharvest Review 1, 1-9.

Lebaudy A, Véry A-A, Sentenac H. 2007. $\mathrm{K}^{+}$channel activity in plants: Genes, regulations and functions. FEBS Letters 581, 2357-2366.

Lee KH, Piao HL, Kim HY, et al. 2006. Activation of glucosidase via stress-induced polymerization rapidly increases active pools of abscisic acid. Cell 126, 1109-1120.

Lee SC, Luan S. 2012. ABA signal transduction at the crossroad of biotic and abiotic stress responses. Plant, Cell \& Environment 35, 53-60.

Lefebvre V, North H, Frey A, et al. 2006. Functional analysis of Arabidopsis NCED6 and NCED9 genes indicates that ABA synthesized in the endosperm is involved in the induction of seed dormancy. The Plant Journal 45, 309-319.

Leng P, Zhang GL, Li XX, Wang LH, Zheng ZM. 2009. Cloning of 9-cis-epoxycarotenoid dioxygenase (NCED) gene encoding a key enzyme during abscisic acid (ABA) biosynthesis and ABA-regulated ethylene production in detached young persimmon calyx. Chinese Science Bulletin 54, 2830-2838.

Leonhardt N, Kwak JM, Robert N, Waner D, Leonhardt G, Schroeder Jl. 2004. Microarray expression analyses of Arabidopsis guard cells and isolation of a recessive abscisic acid hypersensitive protein phosphatase $2 \mathrm{C}$ mutant. The Plant Cell 16, 596-615.

Li FH, Fu FL, Sha LN, He L, Li WC. 2009. Differential expression of serine/threonine protein phosphatase type-2C under drought stress in maize. Plant Molecular Biology Reporter 27, 29-37.

Li G, Xin H, Zheng XF, Li S, Hu Z. 2012a. Identification of the abscisic acid receptor VvPYL1 in Vitis vinifera. Plant Biology 14, 244-248.

Li J, Wang XQ, Watson MB, Assmann SM. 2000. Regulation of abscisic acid-induced stomatal closure and anion channels by guard cell AAPK kinase. Science 287, 300-303.

Li Q, Li P, Sun L, et al. 2012b. Expression analysis of $\beta$-glucosidase genes that regulate abscisic acid homeostasis during watermelon (Citrullus lanatus) development and under stress conditions. Journal of Plant Physiology 169, 78-85.

Liu J, Ishitani M, Halfter U, Kim CS, Zhu JK. 2000. The Arabidopsis thaliana SOS2 gene encodes a protein kinase that is required for salt tolerance. Proceedings of the National Academy of Sciences of the United States of America 97, 3730-3734.

Liu X, Yue Y, Li B, Nie Y, Li W, Wu WH, Ma L. 2007. A G protein-coupled receptor is a plasma membrane receptor for the plant hormone abscisic acid. Science 315, 1712-1716.

López-Molina L, Mongrand S, Kinoshita N, Chua NH. 2003. AFP is a novel negative regulator of ABA signaling that promotes ABI5 protein degradation. Genes \& Development $17,410-418$. 
Loyola J, Verdugo I, González E, Casaretto JA, Ruiz-Lara S. 2012. Plastidic isoprenoid biosynthesis in tomato: Physiological and molecular analysis in genotypes resistant and sensitive to drought stress. Plant Biology 14, 149-156.

Luo J, Shen G, Yan J, He C, Zhang H. 2006. AtCHIP functions as an E3 ubiquitin ligase of protein phosphatase $2 \mathrm{~A}$ subunits and alters plant response to abscisic acid treatment. The Plant Journal 46, 649-657.

Ma Y, Szostkiewicz I, Korte A, Moes D, Yang Y, Alexander C, Grill E. 2009. Regulators of PP2C phosphatase activity function as abscisic acid sensors. Science 324, 1064-1068.

Macknight R, Bancroft I, Page T, et al. 1997. FCA, a gene controlling flowering time in Arabidopsis, encodes a protein containing RNA-binding domains. Cell 89, 737-745.

Martínez-Andújar C, Ordiz MI, Huang Z, Nonogaki M, Beachy RN, Nonogaki H. 2011. Induction of 9-cis-epoxycarotenoid dioxygenase in Arabidopsis thaliana seeds enhances seed dormancy. Proceedings of the National Academy of Sciences 108, 17225-17229.

Mauch-Mani B, Mauch F. 2005. The role of abscisic acid in plant-pathogen interactions. Current Opinion in Plant Biology 8, 409-414.

McCudden C, Hains M, Kimple R, Siderovski D, Willard F. 2005. G-protein signaling: back to the future. Cellular and Molecular Life Sciences 62, 551-577.

Melcher K, Ng LM, Zhou XE, et al. 2009. A gate-latch-lock mechanism for hormone signalling by abscisic acid receptors. Nature 462, 602-608.

Melotto M, Underwood W, He SY. 2008. Role of stomata in plant innate immunity and foliar bacterial diseases. Annual Review of Phytopathology 46, 101-122.

Melotto M, Underwood W, Koczan J, Nomura K, He SY. 2006. Plant stomata function in innate immunity against bacterial invasion. Cell 126, 969-980.

Merlot S, Gosti F, Guerrier D, Vavasseur A, Giraudat J. 2001. The ABI1 and ABI2 protein phosphatases $2 \mathrm{C}$ act in a negative feedback regulatory loop of the abscisic acid signalling pathway. The Plant Journal 25, 295-303.

Merlot S, Leonhardt N, Fenzi F, et al. 2007. Constitutive activation of a plasma membrane $\mathrm{H}^{+}$-ATPase prevents abscisic acid-mediated stomatal closure. EMBO Journal 26, 32163226.

Miller G, Suzuki N, Ciftci-Yilmaz S, Mittler R. 2010. Reactive oxygen species homeostasis and signalling during drought and salinity stresses. Plant, Cell and Environment 33, 453467.

Miyazono K, Miyakawa T, Sawano Y, et al. 2009. Structural basis of abscisic acid signalling. Nature 462, 609-614.

Mochizuki N, Brusslan JA, Larkin R, Nagatani A, Chory J. 2001. Arabidopsis genomes uncoupled 5 (GUN5) mutant reveals the involvement of $\mathrm{Mg}$-chelatase $\mathrm{H}$ subunit in plastid- 
to-nucleus signal transduction. Proceedings of the National Academy of Sciences 98, 20532058.

Mori IC, Murata Y, Yang Y, et al. 2006. CDPKs CPK6 and CPK3 function in ABA regulation of guard cell S-type anion- and $\mathrm{Ca}^{2+}$-permeable channels and stomatal closure. PLoS Biology 4, 1749-1762.

Müller AH, Hansson M. 2009. The barley magnesium chelatase 150-kD subunit is not an abscisic acid receptor. Plant Physiology 150, 157-166.

Mustilli AC, Merlot S, Vavasseur A, Fenzi F, Giraudat J. 2002. Arabidopsis OST1 protein kinase mediates the regulation of stomatal aperture by abscisic acid and acts upstream of reactive oxygen species production. The Plant Cell Online 14, 3089-3099.

Nambara E, Marion-Poll A. 2005. Abscisic acid biosynthesis and catabolism. Annual Review of Plant Biology 56, 165-185.

Nambara E, Okamoto M, Tatematsu K, Yano R, Seo M, Kamiya Y. 2010. Abscisic acid and the control of seed dormancy and germination. Seed Science Research 20, 55-67.

Nemhauser JL, Hong F, Chory J. 2006. Different plant hormones regulate similar processes through largely nonoverlapping transcriptional responses. Cell 126, 467-475.

Nishimura N, Sarkeshik A, Nito K, et al. 2010. PYR/PYL/RCAR family members are major in-vivo ABI1 protein phosphatase 2C-interacting proteins in Arabidopsis. The Plant Journal 61, 290-299.

Nishimura N, Yoshida T, Kitahata N, Asami T, Shinozaki K, Hirayama T. 2007. ABAHypersensitive Germination 1 encodes a protein phosphatase $2 \mathrm{C}$, an essential component of abscisic acid signaling in Arabidopsis seed. The Plant Journal 50, 935-949.

Nishimura N, Yoshida T, Murayama M, Asami T, Shinozaki K, Hirayama T. 2004. Isolation and characterization of novel mutants affecting the abscisic acid sensitivity of Arabidopsis germination and seedling growth. Plant and Cell Physiology 45, 1485-1499.

Nitsch JP. 1970. Hormonal factors in growth and development. In: Hulme AC, ed. The biochemistry of fruits and their products, London and New York: Academic Press, pp. $427-$ 472.

Nitsch L, Kohlen W, Oplaat C, et al. 2012. ABA-deficiency results in reduced plant and fruit size in tomato. Journal of Plant Physiology 169, 878-883.

North HM, Almeida AD, Boutin JP, et al. 2007. The Arabidopsis ABA-deficient mutant aba4 demonstrates that the major route for stress-induced ABA accumulation is via neoxanthin isomers. Plant Journal 50, 810-824.

Ohkuma K, Lyon JL, Addicott FT, Smith OE. 1963. Abscisin II, an abscission-accelerating substance from young cotton fruit. Science 142, 1592-1593. 
Osakabe Y, Maruyama K, Seki M, Satou M, Shinozaki K, Yamaguchi-Shinozaki K. 2005. Leucine-rich repeat receptor-like kinase1 is a key membrane-bound regulator of abscisic acid early signaling in Arabidopsis. The Plant Cell 17, 1105-1119.

Pandey S, Nelson DC, Assmann SM. 2009. Two novel GPCR-type G proteins are abscisic acid receptors in Arabidopsis. Cell 136, 136-148.

Park SY, Fung P, Nishimura N, et al. 2009. Abscisic acid inhibits type 2C protein phosphatases via the PYR/PYL family of START proteins. Science 324, 1068-1071.

Pei ZM, Kuchitsu K, Ward JM, Schwarz M, Schroeder JI. 1997. Differential abscisic acid regulation of guard cell slow anion channels in Arabidopsis wild-type and abi1 and abi2 mutants. The Plant Cell 9, 409-423.

Pei ZM, Murata Y, Benning G, et al. 2000. Calcium channels activated by hydrogen peroxide mediate abscisic acid signalling in guard cells. Nature 406, 731-734.

Ramanjulu S, Bartels D. 2002. Drought- and desiccation-induced modulation of gene expression in plants. Plant, Cell and Environment 25, 141-151.

Razem FA, El-Kereamy A, Abrams SR, Hill RD. 2006. The RNA-binding protein FCA is an abscisic acid receptor. Nature 439, 290-294.

Razem FA, El-Kereamy A, Abrams SR, Hill RD. 2008. The RNA-binding protein FCA is an abscisic acid receptor. Nature 456, 824.

Rechsteiner M. 1987. Ubiquitin-mediated pathways for intracellular proteolysis. Annual Review of Cell Biology 3, 1-30.

Ren J, Sun L, Wang C, Zhao S, Leng P. 2011. Expression analysis of the cDNA for magnesium chelatase $\mathrm{H}$ subunit $(\mathrm{CHLH})$ during sweet cherry fruit ripening and under stress conditions. Plant Growth Regulation 63, 301-307.

Ren J, Sun L, Wu J, et al. 2010. Cloning and expression analysis of cDNAs for ABA 8'hydroxylase during sweet cherry fruit maturation and under stress conditions. Journal of Plant Physiology 167, 1486-1493.

Riera M, Valon C, Fenzi F, Giraudat J, Leung J. 2005. The genetics of adaptive responses to drought stress: abscisic acid-dependent and abscisic acid-independent signalling components. Physiologia Plantarum 123, 111-119.

Risk JM, Day CL, Macknight RC. 2009. Reevaluation of abscisic acid-binding assays shows that G-protein-coupled receptor 2 does not bind abscisic acid. Plant Physiology 150, 6-11.

Risk JM, Macknight RC, Day CL. 2008. FCA does not bind abscisic acid. Nature 456, E5-E6.

Rizzini FM, Bonghi C, Tonutti P. 2009. Postharvest water loss induces marked changes in transcript profiling in skins of wine grape berries. Postharvest Biology and Technology 52, 247-253. 
Roberts, JA, Elliott, KA, Gonzalez-Carranza, ZH. 2002. Abscission, dehiscence, and other cell separation process. Annual Review in Plant Biology. 53, 131-158.

Rodrigo MJ, Alquézar B, Zacarías L. 2006. Cloning and characterization of two 9-cisepoxycarotenoid dioxygenase genes, differentially regulated during fruit maturation and under stress conditions, from orange (Citrus sinensis L. Osbeck). Journal of Experimental Botany 57, 633-643.

Rodrigo MJ, Marcos JF, Alférez F, Mallent MD, Zacarías L. 2003. Characterization of 'Pinalate', a novel Citrus sinensis mutant with a fruit-specific alteration that results in yellow pigmentation and decreased ABA content. Journal of Experimental Botany 54, 727738.

Rodríguez PL, Benning G, Grill E. 1998a. ABI2, a second protein phosphatase 2C involved in abscisic acid signal transduction in Arabidopsis. FEBS Letters 421, 185-190.

Rodríguez PL, Leube MP, Grill E. 1998b. Molecular cloning in Arabidopsis thaliana of a new protein phosphatase $2 \mathrm{C}$ (PP2C) with homology to $\mathrm{ABI}$ and $\mathrm{ABI}$. Plant Molecular Biology 38, 879-883.

Rodríguez PL. 1998. Protein phosphatase 2C (PP2C) function in higher plants. Plant Molecular Biology 38, 919-927.

Rodríguez-Concepción M. 2010. Supply of precursors for carotenoid biosynthesis in plants. Archives of Biochemistry and Biophysics 504, 118-122.

Romero P, Lafuente MT, Alférez F, Zacarías L, Rodrigo MJ. 2010. Cambios transcriptómicos asociados a la maduración de un mutante de naranja deficiente en $A B A$. Reunión de Biología Molecular de Plantas X, 140.

Rubio S, Rodrigues A, Saez A, et al. 2009. Triple loss of function of protein phosphatases type 2C leads to partial constitutive response to endogenous abscisic acid. Plant Physiology 150, 1345-1355.

Ruiz-Sola, MA, Rodríguez-Concepción, M. 2012. Carotenoid biosynthesis in Arabidopsis: A colorful pathway. The Arabidopsis Book 10, e0158.

Ryu MY, Cho SK, Kim WT. 2010. The Arabidopsis C3H2C3-type RING E3 ubiquitin ligase AtAIRP1 is a positive regulator of an abscisic acid-dependent response to drought stress. Plant Physiology 154, 1983-1997.

Saez A, Apostolova N, González-Guzman M, González-García MP, Nicolas C, Lorenzo O, Rodríguez PL. 2004. Gain-of-function and loss-of-function phenotypes of the protein phosphatase 2C HAB1 reveal its role as a negative regulator of abscisic acid signalling. The Plant Journal 37, 354-369.

Saez A, Robert N, Maktabi MH, Schroeder JI, Serrano R, Rodríguez PL. 2006. Enhancement of abscisic acid sensitivity and reduction of water consumption in Arabidopsis by combined inactivation of the protein phosphatases type 2C ABI1 and HAB1. Plant Physiology 141, 1389-1399. 
Sala JM, Sanchez-Ballesta MT, Alférez F, Mulas M, Zacarías L, Lafuente MT. 2005. A comparative study of the postharvest performance of an ABA-deficient mutant of oranges: II. Antioxidant enzymatic system and phenylalanine ammonia-lyase in non-chilling and chilling peel disorders of citrus fruit. Postharvest Biology and Technology 37, 232-240.

Sanchez-Ballesta MT, Zacarías L, Granell A, Lafuente MT. 2008. $\beta$-1,3-glucanase gene expression as a molecular marker for postharvest physiological disorders in citrus fruit and its hormonal regulation. Postharvest Biology and Technology 48, 146-149.

Santiago J, Dupeux F, Betz K, et al. 2012. Structural insights into PYR/PYL/RCAR ABA receptors and PP2Cs. Plant Science 182, 3-11.

Santiago J, Dupeux F, Round A, et al. 2009a. The abscisic acid receptor PYR1 in complex with abscisic acid. Nature 462, 665-668.

Santiago J, Rodrigues A, Saez A, et al. 2009. Modulation of drought resistance by the abscisic acid receptor PYL5 through inhibition of clade A PP2Cs. The Plant Journal 60, 575588.

Sato A, Sato Y, Fukao Y, et al. 2009. Threonine at position 306 of the KAT1 potassium channel is essential for channel activity and is a target site for ABA-activated. Biochemical Journal 424, 439-448.

Schwartz SH, Tan BC, Gage DA, Zeevaart JAD, McCarty DR. 1997. Specific oxidative cleavage of carotenoids by VP14 of maize. Science 276, 1872-1874.

Schweighofer A, Hirt H, Meskiene I. 2004. Plant PP2C phosphatases: emerging functions in stress signaling. Trends in Plant Science 9, 236-243.

Seiler C, Harshavardhan VT, Rajesh K, et al. 2011. ABA biosynthesis and degradation contributing to $A B A$ homeostasis during barley seed development under control and terminal drought-stress conditions. Journal of Experimental Botany 62, 2615-2632.

Seki M, Narusaka M, Ishida J, et al. 2002. Monitoring the expression profiles of 7000 Arabidopsis genes under drought, cold and high-salinity stresses using a full-length cDNA microarray. The Plant Journal 31, 279-292.

Seki M, Umezawa T, Urano K, Shinozaki K. 2007. Regulatory metabolic networks in drought stress responses. Current Opinion in Plant Biology 10, 296-302.

Seo M, Aoki H, Koiwai H, Kamiya Y, Nambara E, Koshiba T. 2004. Comparative studies on the Arabidopsis aldehyde oxidase $(A A O)$ gene family revealed a major role of $A A O 3$ in $A B A$ biosynthesis in seeds. Plant and Cell Physiology 45, 1694-1703.

Shang Y, Yan L, Liu ZQ, et al. 2010. The Mg-chelatase H subunit of Arabidopsis antagonizes a group of WRKY transcription repressors to relieve ABA-responsive genes of inhibition. The Plant Cell Online 22, 1909-1935. 
Sharp RE, Poroyko V, Hejlek LG, Spollen WG, Springer GK, Bohnert HJ, Nguyen HT. 2004. Root growth maintenance during water deficits: Physiology to functional genomics. Journal of Experimental Botany 55, 2343-2351.

Sharp RE. 2002. Interaction with ethylene: Changing views on the role of abscisic acid in root and shoot growth responses to water stress. Plant, Cell and Environment 25, 211-222.

Shen YY, Wang XF, Wu FQ, et al. 2006. The Mg-chelatase $\mathrm{H}$ subunit is an abscisic acid receptor. Nature 443, 823-826.

Shinozaki K, Yamaguchi-Shinozaki K, Mizoguchi T, et al. 1998. Molecular responses to water stress in Arabidopsis thaliana. Journal of Plant Research 111, 345-351.

Shinozaki K, Yamaguchi-Shinozaki K. 2000. Molecular responses to dehydration and low temperature: differences and cross-talk between two stress signaling pathways. Current Opinion in Plant Biology 3, 217-223.

Shinozaki K, Yamaguchi-Shinozaki K. 2007. Gene networks involved in drought stress response and tolerance. Journal of Experimental Botany 58, 221-227.

Sirichandra C, Gu D, Hu HC, et al. 2009. Phosphorylation of the Arabidopsis AtrbohF NADPH oxidase by OST1 protein kinase. FEBS Letters 583, 2982-2986.

Sun L, Sun Y, Zhang M, et al. 2012a. Suppression of 9-cis-epoxycarotenoid dioxygenase, which encodes a key enzyme in abscisic acid biosynthesis, alters fruit texture in transgenic tomato. Plant Physiology 158, 283-298.

Sun L, Wang YP, Chen P, et al. 2011. Transcriptional regulation of SIPYL, SIPP2C, and SISnRK2 gene families encoding ABA signal core components during tomato fruit development and drought stress. Journal of Experimental Botany 62, 5659-5669.

Sun L, Yuan B, Zhang M, Wang L, Cui M, Wang Q, Leng P. 2012b. Fruit-specific RNAimediated suppression of SINCED1 increases both lycopene and $\beta$-carotene contents in tomato fruit. Journal of Experimental Botany 63, 3097-3108.

Sun L, Zhang M, Ren J, Qi J, Zhang G, Leng P. 2010. Reciprocity between abscisic acid and ethylene at the onset of berry ripening and after harvest. BMC Plant Biology 10, 257.

Szostkiewicz I, Richter K, Kepka M, et al. 2010. Closely related receptor complexes differ in their ABA selectivity and sensitivity. The Plant Journal 61, 25-35.

Tal M, Nevo Y. 1973. Abnormal stomatal behavior and root resistance, and hormonal imbalance in three wilty mutants of tomato. Biochemical Genetics 8, 291-300.

Tan BC, Joseph LM, Deng WT, Liu L, Li QB, Cline K, McCarty DR. 2003. Molecular characterization of the Arabidopsis 9-cis epoxycarotenoid dioxygenase gene family. The Plant Journal 35, 44-56.

Taylor IB, Tarr AR. 1984. Phenotypic interactions between abscisic acid deficient tomato mutants. Theoretical and Applied Genetics 68, 115-119. 
Ton J, Flors V, Mauch-Mani B. 2009. The multifaceted role of ABA in disease resistance. Trends in Plant Science 14, 310-317.

Trivellini A, Ferrante A, Vernieri P, Serra G. 2011. Effects of abscisic acid on ethylene biosynthesis and perception in Hibiscus rosa-sinensis L. flower development. Journal of Experimental Botany 62, 5437-5452.

Ueguchi-Tanaka M, Ashikari M, Nakajima M, et al. 2005. GIBBERELLIN INSENSITIVE DWARF1 encodes a soluble receptor for gibberellin. Nature 437, 693-698.

Umezawa T, Sugiyama N, Mizoguchi M, et al. 2009. Type 2C protein phosphatases directly regulate abscisic acid-activated protein kinases in Arabidopsis. Proceedings of the National Academy of Sciences 106, 17588-17593.

Verslues PE, Bray EA. 2006. Role of abscisic acid (ABA) and Arabidopsis thaliana ABAinsensitive loci in low water potential-induced $A B A$ and proline accumulation. Journal of Experimental Botany 57, 201-212.

Vlad F, Rubio S, Rodrigues A, et al. 2009. Protein phosphatases $2 \mathrm{C}$ regulate the activation of the Snf1-Related Kinase OST1 by abscisic acid in Arabidopsis. The Plant Cell 21, 31703184.

Wasilewska A, Vlad F, Sirichandra C, et al. 2008. An update on abscisic acid signaling in plants and more... Molecular Plant 1, 198-217.

Weiner JJ, Peterson FC, Volkman BF, Cutler SR. 2010. Structural and functional insights into core ABA signaling. Current Opinion in Plant Biology 13, 495-502.

Wilkinson S, Davies WJ. 2002. ABA-based chemical signalling: the co-ordination of responses to stress in plants. Plant, Cell \& Environment 25, 195-210.

Wilkinson S, Davies WJ. 2010. Drought, ozone, ABA and ethylene: new insights from cell to plant to community. Plant, Cell and Environment 33, 510-525.

Wilkinson S, Kudoyarova GR, Veselov DS, Arkhipova TN, Davies WJ. 2012. Plant hormone interactions: Innovative targets for crop breeding and management. Journal of Experimental Botany 63, 3499-3509.

Xiong L, Ishitani M, Lee H, Zhu JK. 2001. The Arabidopsis LOS5/ABA3 locus encodes a molybdenum cofactor sulfurase and modulates cold stress- and osmotic stress-responsive gene expression. The Plant Cell 13, 2063-2083.

Xiong L, Wang RG, Mao G, Koczan JM. 2006. Identification of drought tolerance determinants by genetic analysis of root response to drought stress and abscisic acid. Plant Physiology 142, 1065-1074.

Xue T, Wang D, Zhang S, et al. 2008. Genome-wide and expression analysis of protein phosphatase $2 \mathrm{C}$ in rice and Arabidopsis. BMC Genomics 9, 550. 
Yamaguchi-Shinozaki K, Shinozaki K. 2006. Transcriptional regulatory networks in cellular responses and tolerance to dehydration and cold stress. Annual Review of Plant Biology 57, 781-803.

Yasuda M, Ishikawa A, Jikumaru Y, et al. 2008. Antagonistic interaction between systemic acquired resistance and the abscisic acid-mediated abiotic stress response in Arabidopsis. The Plant Cell 20, 1678-1692.

Yin P, Fan H, Hao Q, et al. 2009. Structural insights into the mechanism of abscisic acid signaling by PYL proteins. Nature Structural and Molecular Biology 16, 1230-1236.

Yoshida R, Hobo T, Ichimura K, et al. 2002. ABA-activated SnRK2 protein kinase is required for dehydration stress signaling in Arabidopsis. Plant and Cell Physiology 43, 1473-1483.

Yoshida R, Umezawa T, Mizoguchi T, Takahashi S, Takahashi F, Shinozaki K. 2006a. The regulatory domain of SRK2E/OST1/SnRK2.6 interacts with ABI1 and integrates abscisic acid $(\mathrm{ABA})$ and osmotic stress signals controlling stomatal closure in Arabidopsis. Journal of Biological Chemistry 281, 5310-5318.

Yoshida T, Fujita Y, Sayama $H$, et al. 2010. AREB1, AREB2, and ABF3 are master transcription factors that cooperatively regulate $A B R E-d e p e n d e n t A B A$ signaling involved in drought stress tolerance and require ABA for full activation. Plant Journal 61, 672-685.

Yoshida T, Nishimura N, Kitahata N, et al. 2006b. ABA-Hypersensitive Germination3 encodes a protein phosphatase $2 \mathrm{C}$ (AtPP2CA) that strongly regulates abscisic acid signaling during germination among Arabidopsis protein phosphatase 2Cs. Plant Physiology 140, 115-126.

Zamboni A, Di Carli M, Guzzo F, et al. 2010. Identification of putative stage-specific grapevine berry biomarkers and omics data integration into networks. Plant Physiology 154, 1439-1459.

Zeng W, Melotto M, He SY. 2010. Plant stomata: a checkpoint of host immunity and pathogen virulence. Current Opinion in Biotechnology 21, 599-603.

Zhang DP, Chen SW, Peng YB, Shen YY. 2001. Abscisic acid-specific binding sites in the flesh of developing apple fruit. Journal of Experimental Botany 52, 2097-2103.

Zhang DP, Wu Z, Li XY, Zhao ZX. 2002. Purification and identification of a 42-kilodalton abscisic acid-specific-binding protein from epidermis of broad bean leaves. Plant Physiology 128, 714-725.

Zhang M, Leng P, Zhang GL, Li XX. 2009a. Cloning and functional analysis of 9-cisepoxycarotenoid dioxygenase (NCED) genes encoding a key enzyme during abscisic acid biosynthesis from peach and grape fruits. Journal of Plant Physiology 166, 1241-1252.

Zhang M, Yuan B, Leng P. 2009b. The role of ABA in triggering ethylene biosynthesis and ripening of tomato fruit. Journal of Experimental Botany 60, 1579-1588. 
Zhang X, Garreton V, Chua NH. 2005. The AIP2 E3 ligase acts as a novel negative regulator of ABA signaling by promoting ABI3 degradation. Genes \& Development 19, 1532-1543.

Zhu, JK. Salt and drought stress signal transduction in plants. 2002. Annual Review in Plant Biology 53, 247-273.

Ziliotto F, Begheldo M, Rasori A, Bonghi C, Tonutti P. 2008. Transcriptome profiling of ripening nectarine (Prunus persica L. Batsch) fruit treated with 1-MCP. Journal of Experimental Botany 59, 2781-2791.

Zou JJ, Wei FJ, Wang C, Wu JJ, Ratnasekera D, Liu WX, Wu WH. 2010. Arabidopsis

calcium-dependent protein kinase CPK10 functions in abscisic acid- and $\mathrm{Ca}^{2+}$-mediated stomatal regulation in response to drought stress. Plant Physiology 154, 1232-1243. 